\title{
The Situation Analysis Approach to Assessing Family Planning and Reproductive Health Services: A Handbook
}

\author{
Robert A. Miller \\ Population Council \\ Andrew A. Fisher \\ Population Council \\ Kate Miller \\ Population Council \\ Lewis Ndhlovu \\ Population Council \\ Baker Ndugga Maggwa \\ Population Council
}

See next page for additional authors

Follow this and additional works at: https://knowledgecommons.popcouncil.org/departments_sbsr-rh

Part of the Demography, Population, and Ecology Commons, Family, Life Course, and Society

Commons, International Public Health Commons, and the Medicine and Health Commons

How does access to this work benefit you? Let us know!

\section{Recommended Citation}

Miller, Robert A., Andrew A. Fisher, Kate Miller, Lewis Ndhlovu, Baker Ndugga Maggwa, lan Askew, Diouratie Sanogo, and Placide Tapsoba. 1997. "The Situation Analysis Approach to Assessing Family Planning and Reproductive Health Services: A Handbook." New York: Population Council. 


\section{Authors}

Robert A. Miller, Andrew A. Fisher, Kate Miller, Lewis Ndhlovu, Baker Ndugga Maggwa, lan Askew, Diouratie Sanogo, and Placide Tapsoba 


\section{The Situation Analysis Approach to Assessing Family Planning and Reproductive Health Services A Handbook}

Robert Miller - Andrew Fisher - Kate Miller Lewis Ndhlovu • Baker Ndugga Maggwa - Ian Askew Diouratie Sanogo • Placide Tapsoba

\footnotetext{
(2) Population Council 


\section{Library of Congress Cataloging-in-Publication Data}

The situation analysis approach to assessing family planning and reproductive health services : a handbook / Robert Miller ... [et al.].

p. $\mathrm{cm}$.

Includes bibliographical references.

ISBN 0-87834-090-4 (paperback : alk. paper)

1. Birth control--Research. 2. Birth control--Data processing. 3. Maternal health services--Evaluation. 4. Evaluation research (Social action programs) I. Miller, Robert, 1942-

II. Population Council.

HQ763.5.S57 1997

The Population Council seeks to improve the wellbeing and reproductive health of current and future generations around the world and to help achieve a humane, equitable, and sustainable balance between people and resources. The Council, a nonprofit, nongovernmental research organization established in 1952, has a multinational board of trustees; its New York headquarters supports a global network of regional and country offices.

Population Council

One Dag Hammarskjold Plaza

New York, New York 10017 USA

tel: (212) 339-0500

fax: (212) 755-6052

email: pubinfo@popcouncil.org

http://www.popcouncil.org

The authors are staff members of the Population Council. Robert Miller is Senior Program Associate, New York; Andrew Fisher is Program Director, Family Planning, and Senior Program Associate, New York; Kate Miller is Staff Program Associate, New York; Lewis Ndhlovu is Program Associate, Nairobi; Baker Ndugga Maggwa is Program Associate, Nairobi; Ian Askew is Project Director and Senior Program Associate, Nairobi; Diouratie Sanogo is Deputy Director for West Africa and Program Associate, Dakar; Placide Tapsoba is Program Associate, Dakar.

This publication was supported by the Population Council's Africa Operations Research and Technical Assistance Project II, Project No. 936-3030 and the Population Council's Expanding Contraceptive Choice Program. The Africa OR/TA Project II is funded by the U.S. Agency for International Development (USAID), Office of Population, Contract No. CCP-3030-C-00-3008-00, Strategies for Improving Family Planning Service Delivery. The Expanding Contraceptive Choice Program is also funded by USAID, Cooperative Agreement No. CCP-3050-A-00-4013.

(C) 1997 by The Population Council, Inc.

Any part of this document may be reproduced without permission of the authors so long as it is not sold for profit. We would appreciate receiving comments and suggestions from readers, and reports from those who carry out Situation Analysis studies. 


\section{Contents}

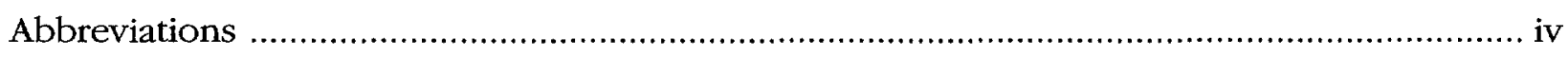

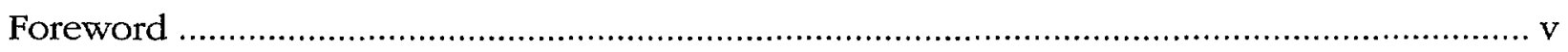

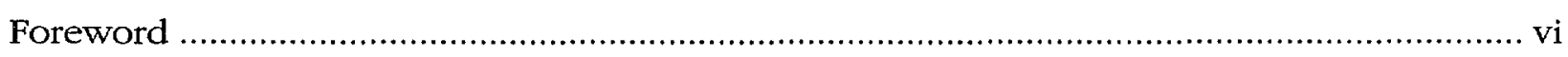

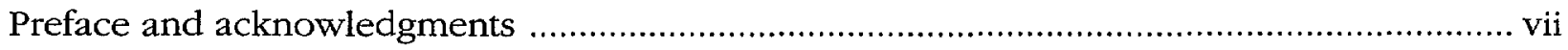

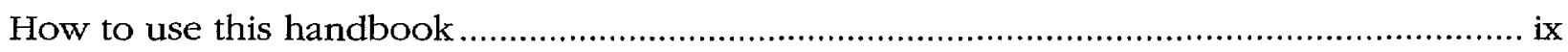

Chapter 1

The Situation Analysis study methodology

Objectives of a Situation Analysis study ...... 3

Basic elements........................................... 4

Study design .............................................. 6

Data collection instruments ......................... 7

Study implementation ................................ 8

Programmatic uses of

Situation Analysis studies ......................... 9

Impact studies and Situation Analysis ...... 10

Operations research and

Situation Analysis . 11

The diffusion of Situation Analysis ........... 12

Methodological issues ............................ 12

Conclusions .......................................... 14

References ........................................... 14

\section{Chapter 2}

\section{Conducting the study}

Ethical issues in the conduct of

Situation Analysis studies 17

Establishing objectives and reviewing questionnaires

The training agenda for the research team

Role of the Team Leader/Supervisor

The research team and a typical day.....

Tips for conducting a good interview

Tips for conducting a good observation ... 24

After data collection.

\section{Chapter 3 \\ Instruments and \\ question-by-question guides}

Inventory

Inventory:

question-by-question guide ..................... 43

Observation guide................................. 50

Observation:

question-by-question guide ..................... 59

Family planning

client exit interview .66

Family planning client exit interview:

question-by-question guide ...................... 98

Staff interview .......................................... 110

Staff interview:

question-by-question guide ................... 125

$\mathrm{MCH}$ client exit interview ....................... 131

$\mathrm{MCH}$ client exit interview:

question-by-question guide .................. 149

\section{Chapter 4}

Data analysis and reporting

Data entry and cleaning ......................... 157

Analysis plan .......................................... 160

Notes to analysis plan ............................. 184

Sample indicator lists .......................... 187

Sample graphs .................................... 192 


\section{Abbreviations}

\begin{tabular}{|c|c|c|c|}
\hline AIBEF & $\begin{array}{l}\text { Association Ivoirienne Pour le } \\
\text { Bien-Être Familial }\end{array}$ & $\begin{array}{l}\text { LAM } \\
\text { LMP }\end{array}$ & $\begin{array}{l}\text { Lactational Amenorrhea Method } \\
\text { Last Menstrual Period }\end{array}$ \\
\hline AIDS & $\begin{array}{l}\text { Acquired Immunodeficiency } \\
\text { Syndrome }\end{array}$ & $\mathrm{MCH}$ & Maternal and Child Health \\
\hline ANC & Antenatal Care & MIS & Management Information System \\
\hline $\mathrm{AV}$ & Audiovisual & $\mathrm{ML} / \mathrm{LA}$ & $\begin{array}{l}\text { Mini-Laparotomy / Local } \\
\text { Anaesthetic }\end{array}$ \\
\hline $\mathrm{BCG}$ & $\begin{array}{l}\text { Calmette-Guérin bacillus } \\
\text { (vaccine) }\end{array}$ & $\mathrm{MOH}$ & Ministry of Health \\
\hline BKKBN & National Family Planning & NFP & Natural Family Planning \\
\hline & Coordinating Board (Indonesia) & NGO & Non-Governmental Organization \\
\hline $\mathrm{BP}$ & Blood Pressure & OR & Operations Research \\
\hline $\mathrm{CBD}$ & Community-Based Distribution & PID & Pelvic Inflammatory Disease \\
\hline CIOMS & Council for International & POP & Progestin-Only Pill \\
\hline & $\begin{array}{l}\text { Organizations of the Medical } \\
\text { Sciences }\end{array}$ & PRICOR & $\begin{array}{l}\text { Primary Health Care Operating } \\
\text { Research }\end{array}$ \\
\hline $\mathrm{COC}$ & Combined Oral Contraceptive & $\mathrm{QA}$ & Quality Assurance \\
\hline DHS & Demographic and Health & $\mathrm{RH}$ & Reproductive Health \\
\hline & & RTI & Reproductive Tract Infection \\
\hline DHT & District Health Teams & $\mathrm{SA}$ & Situation Analysis \\
\hline DPT & $\begin{array}{l}\text { Diphtheria, Pertussis, and } \\
\text { Tetanus Toxoid (vaccine) }\end{array}$ & SAM & Service Availability Module \\
\hline EPI & Expanded Programme of & $\mathrm{SD}$ & Service Delivery Point \\
\hline & Immunizations & SPSS & $\begin{array}{l}\text { Statistical Package for the Social } \\
\text { Sciences }\end{array}$ \\
\hline FP & Family Planning & STD & Sexually Transmitted Disease \\
\hline FPA & Family Planning Association & & Technical Assistance \\
\hline FWE & Family Welfare Educator & TA & \\
\hline HIV & Human Immunodeficiency Virus & TT & Tubal Ligation \\
\hline IEC & $\begin{array}{l}\text { Information, Education, and } \\
\text { Communication }\end{array}$ & USAID & $\begin{array}{l}\text { United States Agency for } \\
\text { International Development }\end{array}$ \\
\hline IUD & Intra-Uterine Device & WFS & World Fertility Surveys \\
\hline KAP & $\begin{array}{l}\text { Knowledge, Attitude, and } \\
\text { Practice }\end{array}$ & ZNFPC & $\begin{array}{l}\text { Zimbabwe National Family } \\
\text { Planning Council }\end{array}$ \\
\hline
\end{tabular}




\section{Foreword}

The mission of family planning managers, indeed of professionals in the family planning field, is to assure that clients receive prompt, safe, and respectful care. Family planning managers who take this mission seriously have the responsibility of orchestrating resources, staff, and service structures to meet the needs of many thousands and, in some cases, many millions of individuals. But in the past, there have been few tools to guide managers concerned about the quality of care clients receive. Whereas in recent years there has been good national-level information about the quality of inputs such as the steadiness of contraceptive supplies, and societal level outcomes such as contraceptive prevalence, managers in general have not had information about what the family planning staff are actually doing, the degree to which they are prepared to respond to clients' actual needs, and most vitally they have lacked a picture of what clients receive in the way of care.

This is where the tool called Situation Analysis comes in. It provides a muchneeded link between the manager and the client he or she is trying to serve. The data marshaled for the Situation Analysis offers a representative picture of how subsystems are working and provides a way to "see" the client's experience. Situation Analyses assist the manager in achieving the broadest management goal-that of efficient administration of a vital health care servicewhile keeping firmly in the viewfinder the ultimate goal-providing good care for those who seek it. 


\section{Foreword}

Good family planning service delivery emphasizing both access and quality is key to the related twin goals of both satisfying individual needs and achieving programmatic success. As a consumer of data and scientific literature on family planning, I have found Situation Analysis a gold mine of useful information. It is the first systematic data collection tool which credibly documents what goes on inside the formidable "black box" of service delivery. In my view, it ranks with the Demographic and Health Surveys as a seminal methodology for our field.

At the same time, it is important to bear in mind some of the limitations of Situation Analysis. It is a snapshot of the reality of service delivery, and findings are undoubtedly influenced by the mere presence of the observers. Likewise, the valuable information Situation Analysis provides has tended to come with a considerable price tag, and results are best interpreted in light of the service delivery context from which they come. We need to continue to improve the Situation Analysis methodology and develop and improve other tools to evaluate and enhance service delivery access and quality.
One of the most valuable attributes of Situation Analysis is the simplicity of the results. For example, consider a Situation Analysis that finds that half of all service delivery sites have had a stock-out of injectable contraceptives in the last six months or that side effects of methods are discussed with new clients only half the time. Such findings are clear and direct for managers and for others. They are also very common. Indeed one of the major lessons from Situation Analysis is the large gap between the ideal and reality. On the one hand such findings can be disappointing, but they also offer hope. They represent situations that can (at least in principle) be easily improved. In my view the most important lesson from the collective findings from Situation Analysis is the huge amount of improvement in access and quality that is potentially within our grasp. Well-executed tools such as Situation Analysis can help make such improvements reality.

James D. Shelton Senior Medical Scientist Office of Population United States Agency for International Development 


\section{Preface and acknowledgments}

Situation Analysis (SA) studies began in Africa. The first was conducted in Kenya, in 1989, with the collaboration of the Division of Family Health, Ministry of Health. Since that time, SA studies have been implemented in three dozen countries around the world with the cooperation and support of national family planning program managers, and the hard work and commitment of many hundreds of researchers, interviewers, and supervisors. We are deeply indebted to all who have been involved with conducting these studies for their enthusiasm, hard work, and willingness to endure the hardships of field research. We are also deeply indebted to the thousands of family planning and reproductive health staff who welcomed our field research teams at their facilities, often found places for them to sleep, opened their cupboards for inspection, allowed their clients to be interviewed and observed, and patiently answered our numerous questions.

Although the development of the methodology was greatly assisted by colleagues working on operations research projects in many different regions, the original instruments evolved in Africa and this particular iteration of them may still carry something of an African perspective. For example, first, African countries have developed integrated programs of maternal-child health and family planning (MCH/FP) that operate within ministries of health. Many Asian and Latin American countries have free-standing family planning sys- tems prevalent. As the Cairo paradigm encouraged attention to much broader issues in reproductive health-especially HIV/AIDS and sexually transmitted diseases-African researchers were particularly well-placed and supported in their efforts to broaden their coverage of reproductive health issues. The current SA instruments reflect the broader, integrated, reproductive health approach, albeit viewed from the family planning perspective. Second, because many African countries lack a functioning Management Information System (MIS), the SA instruments collect considerable information on commodities, stock positions, client utilization, etc., information that in Asian and Latin American countries often comes directly from a functioning MIS.

Despite having been designed to address African programs, the SA methodology has benefitted from innovative contributions from colleagues in other regions. For example, the first linking of Situation Analysis SDPs with the DHS clusters in which they were located was done in Peru under the direction of James Foreit. Other innovations stemming from the Peru SA experience include a scheme for studying logistics chains and the first pharmacy module. Huntington et al. ${ }^{1}$ carried out a study of SA observer re-

\footnotetext{
${ }^{1}$ D. Huntington, K. Miller, and B. Mensch, 1996.

"The reliability of the situation analysis observation guide." Studies in Family Planning 27,5: 277-282.
} 
liability in Turkey and have utilized the methodology to focus on sterilization services and abortion services. It would be difficult to fully represent all of the exciting adjustments to the methodology and creative innovations that are under way as researchers in other regions adapt the material to emphasize their particular national and regional concerns.

This volume represents our attempt to bring out an up-to-date version of procedures and materials as they have evolved over the past eight years. We have no doubt that many additional issues need further debate, testing, and change; and that the instruments as well as some of the procedures may need to be adjusted to new applications and specific settings. Important unsolved questions include: whether the number of variables included in the SA studies should be reduced for manageability, or increased to cover an ever-expanding number of research issues; whether and under what circumstances the SA studies should be integrated with population-based survey studies in order to possibly obtain a more complete picture of both demand and supply considerations; how the reproductive health components of the study (and indeed entire health systems) can be more adequately and independently appraised through the application of a similar but expanded methodology; whether the instruments should be standardized in order to promote cross-national comparisons, or continually adjusted to meet country concerns and changing management concerns; how SA studies can play a role in researching the impact of service quality on the behavior and outcomes of clients; and how the data collected throughout the world can be made easily available to a wider group of researchers and managers.

Throughout the process of SA development and implementation we received considerable support (financial as well as technical) from USAID Washington and many USAID Missions. We are greatly indebted to USAID for this support and for their encouragement. The high level of encouragement, frequent utilization of study findings, technical support, and numerous suggestions for strengthening the methodology are also gratefully acknowledged. We also benefited richly from the comments, suggestions, willingness to debate, and creative research of numerous staff of the Population Council-both in New York and in regional offices around the world. Their numbers are so great that we hesitate to provide a list, and fear that any developed might neglect a deserving colleague. Similarly, our colleagues in USAID's Collaborating Agencies have supported this entire effort through assisting in the implementation of field studies, encouraging the dissemination and utilization of the study findings, and teaching their students and colleagues to use and improve it.

Although the credit for development of the methodology is shared by many, we take full responsibility for errors and shortcomings.

The Authors 


\section{How to use this handbook}

This book is a tool to help implement Situation Analysis (SA) studies. It is not meant to be read cover to cover. Some of the sections of this handbook may be more useful and interesting for policymakers and program planners, other sections for researchers, and still other sections for field interviewers. Each chapter of the handbook is briefly described below.

\section{Chapter 1: The Situation Analysis} study methodology introduces and provides background to the research methodology and a variety of related conceptual issues. This chapter, versions of which have been published elsewhere, gives an overview of SA study objectives, research design, interviewer training, field data collection procedures, data uses, and methodological issues. This information may be useful for researchers, evaluators, program managers, policy decisionmakers, donor agencies, and the many technical assistance personnel working in agencies around the world. The chapter is intended to help decision-makers understand the value and limitations of the type of data collected, and to assist them in making an informed decision about whether to carry out such a study.

\section{Chapter 2: Conducting the study} supplies practical guidance for implement- ing the study in the field. This chapter focuses on the training of field workers, and will be of particular interest to staff concerned with study implementation. This chapter can be photocopied and distributed to the field interviewers and trainees. It may also help program and policy decision-makers to understand the practical steps in study implementation.

\section{Chapter 3: Instruments and ques-} tion-by-question guides provides the core interview schedules, inventory, and observation guide, which can be adjusted by planners to suit particular national or regional interests. This section also supplies instructions and background information on each question, geared toward the data collectors. After the instruments and related questionby-question guides are adjusted to local circumstances, this section should be photocopied and made available to all field staff involved with the study. It will serve as the main aid during training of the field researchers and an important reference document for them.

\section{Chapter 4: Data analysis and report-} ing provides advice on entering and cleaning data, and instructions for producing an initial SA report for discussion by researchers, program managers, clinic personnel, 
donors, and others. It provides a complete list of primary results that can be computed from the SA instruments, with reference to the questions that are needed for each result. It also includes several sample graphs and sample indicator lists from two countries. It is important for program managers and researchers to agree on the analysis plans before the study begins. After agreement is reached, this section will be useful for those charged specifically with the analysis of the data. This chapter assumes at least a minimum proficiency with data processing programs (such as Epi Info or SPSS). 


\section{Chapter 1}

\section{The Situation Analysis study methodology}

Family planning programs have evolved over the last thirty years into complex organizational structures requiring detailed information on the functioning and quality of service delivery subsystems such as training, supervision, logistics, and information, education, and communication (IEC). ${ }^{1}$ The rapid expansion of these programs has often put heavy demands on managers to know how these subsystems are functioning, and what should be done to improve performance and extend services. Unfortunately, national family planning programs often lack viable management information systems (MIS) that might be capable of providing some information for guiding managerial decisions. As has been well-documented by Keller (1991), most MCH/FP programs have extremely weak MIS and in those programs that do have an MIS, "information is too infrequently brought to bear on management decisionmaking" (Keller, 1991:19).

In part because of this, program managers and others for many years have relied on population-based surveys as a source of information to guide program development. The ubiquitous nature of these surveys and their numerous problems have been known for some time (Cleland, 1973). Usually these surveys go under the heading of KAPKnowledge, Attitude, and Practice. Whatever the name, at best they can only provide information about the potential of couples to use or not to use contraception (their knowledge and attitudes) and about their reported current and past use (their practices). KAP surveys do not provide information about the potential of the service delivery environment to provide quality of care to clients, or about the actual provision of services to clients. In short, they focus on the demand for services, not on the supply of services.

As a guide for program planning and service improvement, KAP surveys may not have been very helpful. Indeed, it can be argued that they have tended to highlight the knowledge, attitudes, and practices of clients as the source of problems for programs trying to achieve demographic goals, rather than focus on the availability, accessibility, and quality of programs as the source of problems for clients trying to reach their own reproductive health goals. For example, low levels of knowledge about family planning and unfavorable attitudes are often attributed to traditional client values and low education levels, and less frequently to

\footnotetext{
${ }^{1}$ This chapter is based on A. Fisher, R. Miller, I. Askew, B. Mensch, A. Jain, and D. Huntington, "The Situation Analysis approach to assessing the supply side of family planning programs," Population Council, September 1994. A shorter and modified version will appear in The Joumal of the Center for African Family Studies, forthcoming, 1997.
} 
poorly planned and implemented IEC activities, or weak counseling as a result of poor provider training. Similarly, low levels of contraceptive use are often attributed to a lack of interspousal communication, male resistance to family planning, or religious values, and less frequently to a lack of commodities, formidable barriers to access by males as well as females, or poor quality of services at clinics.

Spearheaded in a large part by operations research, the focus of much family planning research in recent years has shifted somewhat to examining factors that affect the supply of services. A fairly standard operations research methodology (Fisher et al., 1991) has been used to generate a large number of studies (Ross and Frankenberg, 1993; Fisher, 1993) that examine the functioning of programs and the activities or "operations" that are under the control of managers and can be manipulated through administrative action to produce program change. While demand factors are clearly important determinants of contraceptive use, there is now a general recognition that effective family planning programs also depend at least as much on the availability of a range of commodities for client choice, on sound training and supervision for competent providers, on understanding clients' needs for effective provider-client information exchange, on facilitating continuity of contraceptive method use, and on provider attitudes that affect their relationship with clients and the provision of services. These areas are widely viewed as the fundamental elements of quality of care (Bruce, 1990) and are thought to have a major effect on the ability of couples to meet their reproductive intentions.

The development and subsequent evolution of the Situation Analysis methodology for measuring the supply side of family planning programs originated with a request to the Africa Operations Research Project for assistance in determining the equipment needs at service delivery points (SDPs) in Kenya (Miller et al., 1991). Through discussions, the final research approach adopted was broadened to include more complete information on the availability, functioning, and quality of services at the SDPs. An important catalyst for focusing on supply side information was a general feeling that KAPtype surveys simply could not be used to provide guidance for the selection of program options. For example, despite numerous KAP surveys, at the time of the original request for a study in Kenya, there was simply no information on the potential or the actual ability of service delivery points to provide services. It was not known if the SDPs were fully equipped and staffed. It was not known if IEC materials were available and being used. It was not known if contraceptive commodities in sufficient quantities were available. Beyond these areas that relate to the potential of an SDP to provide services, there was only anecdotal information on the quality of care actually being received by clients.

These supply side factors that affect the service delivery environment and quality of care have long been recognized as important (Freedman, 1974). Both the World Fertility Surveys (WFS) and the more recent Demographic and Health Surveys (DHS) have had a community module, called a Service Availability Module (SAM) by the DHS, intended to collect information on the services and facilities available in a geographic area. However, experience with community modules has not always been viewed as satisfactory (Casterline, 1985). In part, one rea- 
son for this has been reliance on knowledgeable informants as a source of information about the facilities and services. Wilkinson (1991) has pointed out that knowledgeable informants are not always completely knowledgeable. They sometimes are unaware of the range of services available at facilities or indeed, even about the existence of particular facilities in a geographic area. As discussed below, the Situation Analysis approach avoids the use of knowledgeable informants and relies instead on interviews with providers and clients coupled with direct observation by trained study investigators of facilities and services. This approach appears to result in more comprehensive and accurate data (ArendsKuenning et al., 1996).

\section{Objectives of a Situation Analysis study}

The Situation Analysis approach to research on the supply side of family planning programs has four essential objectives:

1. To describe the potential of current policies and program standards to promote the delivery of quality services to clients;

2. To describe and compare the current readiness of service delivery staff and facilities to provide quality services to clients against the current policies and program standards;

3. To describe the actual quality of care received by clients;

4. To evaluate the impact the provision of quality services has on client satisfaction, contraceptive use dynamics, fulfillment of reproductive intentions, and ultimately, on fertility (in expanded research designs, most often using a panel of respondents).

The relationship between the four objectives and three levels of measurement-national level, program service delivery point level, and client level-is shown in Figure 1.

As one moves from objective 1 through 4, there is a concomitant increase in the complexity of study design, data collection procedures, and data analysis. Also, there is an increase in the time and cost required for study implementation. For example, the study implied by objective 1 is primarily descriptive in nature and is intended to provide information on the extent to which national-level family planning policies and SDP-level standards tend to facilitate and promote the delivery of quality services to clients or act as barriers to their delivery. The national policies and SDP-level standards are concerned with a variety of issues such as import duties on contraceptives, cost for services, who can receive contraceptive methods, the methods that all SDPs should 
have available, the competencies staff should possess, the information that should be given to clients, etc. (Although not all SA studies have included this objective, an SA interview schedule for managers does exist and has been used in several sites.)

The second objective implies a description of the existing situation at service delivery points. Typically this "basic" Situation Analysis study describes the extent to which the current service delivery system is "ready" to provide quality services. At the SDP level, readiness to deliver quality of care services means that staff are available, trained, and competent to give services; commodities and equipment are available, functioning, and used; and the facility is adequate to handle the client load. In other words, the conditions for the delivery of quality services exist.

The third objective suggests a more analytic study which 1) describes the quality of services received by the client, that is to say, the interaction between the provider and the client, and 2) compares the potential readiness of the program to provide quality services against the actual receipt by clients of quality services. For example, a clinic that does not have contraceptive commodities, trained staff, and basic equipment does not have the potential to provide quality services. Such a clinic is simply not ready to provide family planning services of any kind, let alone quality services. On the other hand, the presence of commodities, trained staff, and basic equipment is not a guarantee that quality services actually will be received by a client. A provider, even highly trained, may not want to give services to unmarried adolescents, offer clients a full range of methods, fully describe each method, discuss side effects of methods, en- courage clients to switch methods if they experience problems, discuss issues related to STDs, or ask questions to understand fully the reproductive goals of a client.

The fourth objective, related to impact, implies a fairly complex study that might use a prospective, longitudinal design to collect data over time in order to test one or more hypotheses concerning the "impact" a particular configuration of services or level of quality has on client satisfaction, contraceptive use, and the ability of couples to meet their own reproductive intentions in a safe and healthful manner. The examination of impact requires either that a Situation Analysis study be linked with a KAP-type population-based study; or that two or more basic Situation Analysis studies be conducted over time, and a panel of respondents be followed from one study to the next (see section below).

\section{Basic elements}

The development of the Situation Analysis methodology was influenced by the systems thinking of PRICOR (Center for Human Services, 1988), by Frerichs's Rapid Survey Methodology (Frerichs, 1989a, and Frerichs and Khin Tar Tar, 1989b), and by the quality of care framework outlined by Bruce and Jain (Bruce 1990). In developing the methodology, several assumptions were made: 1) It would be valuable to have a picture of how all major family planning subsystems were functioning rather than focus on just one or two such as equipment or IEC. 2) The performance of various tasks and subtasks within a particular subsystem was probably highly correlated so that the collection of data on a limited set of subsystem indicators instead of all would probably be sufficient in order to determine whether the 
subsystem was functioning. ${ }^{2} 3$ ) In order to make inferences about the supply side factors influencing the delivery of services, either a representative sample of SDPs or a census of all SDPs would have to be visited.

4) Data collected through actual observations of facilities and staff behavior, as well as interviews with SDP service providers and their clients, would yield richer and more valid information than interview responses from key informants.

The research approach that evolved from the Kenyan study was called a Situation Analysis, defined as:

\section{$A$ description and evaluation of:}

1) current family planning policies and service delivery standards; and the availability and functioning of family planning subsystems at a representative sample or all service delivery points (SDPs) in a geographic area; 2) the readiness of these subsystems to deliver quality of care to clients; 3) the actual quality of care received by clients at these SDPs; and 4) the impact quality of care bas on the fertility bebavior of clients.

Mensch et al. (1994a) noted:

"Although Situation Analysis borrows from other methodologies, it is considered innovative because it integrates a number of approaches to family planning program evaluation. These include: (1) a systems perspective for identifying crucial subsystem components of program operation; (2) visits to a large sample of SDPs rather than visits to only a few SDPs or reliance on expert opinion; (3) a client-oriented focus on quality of care; (4) structured interviews with managers, providers, and clients rather than with community informants as is the case with the DHS availability module; (5) recording of clinic facilities, equipment and commodities available on the day of the team visit; and (6) nonparticipant direct observation of all family planning client-provider interactions on the day of the research team's visit."

All Situation Analysis studies have a basic core set of procedures and approaches to the collection of data. These core procedures and approaches include:

- A representative sample of SDPs, or all SDPs within a geographic area of interest (country, city, district, province), are visited for at least a full day by a team of at least three people, including at least one with clinical training (a physician, nurse, nurse/midwife) and at least one with a social science background and field interview experience.

- A complete inventory is taken of equipment and supplies.

- Service statistics (if available) are recorded for the past 12 months.

- All family planning service providers are interviewed regarding family planning and other reproductive health issues.

- Observations are made of the interaction between service providers and all new and continuing family planning clients on the day of the visit.

- All clients observed are subsequently interviewed as they leave the SDP. A selection of $\mathrm{MCH}$ clients are also interviewed.

Some SA studies also include interviews with program managers, observations of

${ }^{2}$ The complete PRICOR Thesaurus was passed over in favor of a simpler and quicker approach using fewer variables deemed more suited to a large sample study. 
TABLE 1. Sample sizes of selected Situation Analysis studies

\begin{tabular}{|c|c|c|c|c|c|c|}
\hline Country & Year & $\begin{array}{l}\text { Number of } \\
\text { SDPs }\end{array}$ & $\begin{array}{l}\text { Provider-client } \\
\text { observations }\end{array}$ & $\begin{array}{l}\text { Client exit } \\
\text { interviews }\end{array}$ & $\begin{array}{l}\text { Interviews } \\
\text { with staff }\end{array}$ & $\begin{array}{l}\text { Executing } \\
\text { agency }\end{array}$ \\
\hline \multicolumn{7}{|c|}{ Sub-Saharan Africa } \\
\hline Botswana & 1995 & 184 & 406 & 386 & 456 & Ministry of Health \\
\hline Burkina Faso & 1992 & 53 & 66 & 193 & 93 & Ministry of Health \\
\hline Burkina Faso & 1995 & 337 & 509 & 509 & 685 & Ministry of Health \\
\hline Côte d'Ivoire & 1992 & 13 & 163 & 355 & 51 & AlBEF \\
\hline Ghana & 1993 & 399 & 665 & 655 & 783 & Ghana Statistical Office \\
\hline Kenya & 1989 & 99 & 72 & 72 & 99 & Ministry of Health \\
\hline Kenya & 1995 & 254 & 1029 & 997 & 562 & Ministry of Health \\
\hline Nairobi City & 1991 & 46 & 100 & 100 & 46 & Nairobi City Commission \\
\hline Nigeria & 1992 & 181 & 395 & 390 & 289 & Obafemi Awolowo University \\
\hline Senegal & 1994 & 180 & 1123 & 985 & 361 & Ministry of Health \\
\hline Tanzania & 1992 & 348 & 450 & 436 & 537 & Ministry of Health \\
\hline Tanzania (Mbeya) & 1995 & 52 & 111 & 111 & 120 & Family Health Project \\
\hline Zanzibar & 1995 & 100 & 145 & 145 & 191 & Ministry of Health \\
\hline Zimbabwe & 1991-92 & 181 & 463 & 463 & 378 & ZNFPC \\
\hline \multicolumn{7}{|l|}{ Asia } \\
\hline Indonesia & 1994 & 342 & 1625 & 1624 & 651 & BKKBN \\
\hline Pakistan & 1993 & 84 & 103 & 203 & 83 & Ministry of Population Welfare \\
\hline Turkey & 1994 & 115 & 1006 & 975 & 232 & Ministry of Health \\
\hline \multicolumn{7}{|l|}{ Latin America } \\
\hline Ceara, Brazil & 1993 & 40 & 17 & 17 & 47 & $\begin{array}{l}\text { Sociedade Cearense } \\
\text { de Pediatria }\end{array}$ \\
\hline Guatemala & 1993 & 38 & na & 331 & 71 & Ministry of Health/FP Unit \\
\hline Peru & 1992 & 2970 & 599 & 599 & 1951 & $\begin{array}{l}\text { Ministry of Health } \\
\text { and National } \\
\text { Statistical Institute }\end{array}$ \\
\hline
\end{tabular}

non-family planning services, and specialized questionnaires for CBDs and pharmacies.

\section{Study design}

The units of analysis for a Situation Analysis study are service delivery points. Rather than a single clinic or delivery system, multiple SDPs and types of delivery systems (MOH clinics, CBDs, NGO clinics, pharmacies, etc.) representative of the situation in a country or region are examined. The SDPs might include government and parastatal clinics and CBD outlets, NGOs outlets, commercial units such as pharmacists, private hospitals, private physician clinics, and employment (factory, mining, or large farm) based outlets. In short, any and all sources of family planning and health services and supplies potentially could be examined in a Situation Analysis study. The first decision that must be made, therefore, is which type of SDP should be evaluated. Once this decision has been made, a plan can then be formulated to include the entire universe of SDPs in the study or more likely, to develop a sampling strategy. 
If the objective of the Situation Analysis study is to diagnose and describe the availability, functioning, and quality of services in the entire country, sampling of SDPs is almost always necessary. Ideally, the sample should be representative of SDPs in terms of type (hospital, clinic, CBD, etc.) services provided (family planning alone or integrated with reproductive health), geographic location (region, urban/rural), and type of sector (public, NGO, private, etc.). This requires a detailed list of the location of all delivery points as well as some knowledge of the type of SDP in each locality. Assuming a list of all SDPs is available, a simple random sample can then be drawn, or, more likely, some form of stratified random sample, with the units drawn proportionate to the number in a strata. Usually samples are stratified according to the classifications mentioned above: region, type of SDP, sector, etc. Table 1 summarizes the sample sizes used in recent Situation Analysis studies.

\section{Data collection instruments}

A number of data collection instruments are needed in order to obtain information on the three primary areas of interest (availability, functioning, and quality). Some of these instruments must be used in all Situation Analysis studies, otherwise the minimum set of data required to describe subsystem functioning and quality cannot be obtained. Other instruments are optional but may enrich the study findings when used.

In a study of fixed SDPs such as clinics and hospitals, the basic Situation Analysis instruments can be utilized. The administration of these instruments will take approximately four to six hours per SDP depending on the client load at the SDP. Only one SDP should be covered in a single day, otherwise there will not be enough time to examine fully each subsystem. In some cases, it may be advisable to spend more than a single day at each SDP (see discussion of this point below). The data collection team should be present slightly before the SDP is scheduled to open and should stay until it closes.

The basic minimum data collection instruments are:

- Inventory for Facilities Available and Services Provided at the Service Delivery Point

- Observation Guide for Interaction Between Family Planning Clients and Service Providers

- Exit Interview for Family Planning Clients

- Interview for Staff Providing Family Planning/Reproductive Health Services at the Service Delivery Point

- Interview for $\mathrm{MCH}$ Clients Attending the Service Delivery Point

Because generally only a few family planning clients are available on the day of the visit, it is not possible to make an accurate assessment of quality of care at any given individual SDP. However, aggregating all clients across all clinics in the sample can provide a reasonably valid inference about quality of care for the country or region as a whole. If quality at the individual SDP level is desired, information on a larger number of clients must be obtained. This can be done by 1) spending more time (possibly as long as a week or more) at each SDP, or 2) stratifying SDPs by subsystem functioning or client load, selecting a few SDPs per strata, and spending more time collecting data on clients.

Depending on the service delivery system being studied, additional instruments may be administered. For example: 
- Questionnaire for Program Managers and Policymakers

- CBD Interview Schedule

- CBD Client Observation Form

- CBD Client Exit Interview

- Pharmacy Interview Questionnaire

In some SDPs, especially in countries with low contraceptive prevalence, it may not be possible to find many or even any new and continuing clients who can be interviewed. In such instances, the instrument for $\mathrm{MCH}$ clients can help to ascertain the reasons for non-use of services by women living within easy reach of the SDP. If a family planning program includes CBD workers who provide a substantial number of clients with contraceptive supplies, then a CBD instrument also can be developed and used. CBD instruments have been used in a few countries (for example, Zimbabwe and Mali) and are available from the Population Council.

There are many other questionnaire modules that can be added to the standard questionnaires. For example, the Situation Analysis methodology can be used to examine the links (integration) between reproductive health care services (postpartum, antenatal, abortion, STD and HIV) and family planning services. Also, in countries where sterilization is important, a module that examines this service in greater detail can be added. In short, the Situation Analysis approach can be used to obtain a picture not only of family planning services, but also of other related services. For example, recent modifications of the data collection instruments have covered more fully reproductive health issues such as abortion (Senegal SA), sexually transmitted disease services (Botswana SA), and sterilization services (Turkey SA).

\section{Study implementation}

The number of research teams and supervisors used in a study depends on the number and accessibility of SDPs, the objectives selected, and resources available. Usually, each research team consists of three persons-at least one with clinical training (a physician, nurse, nurse/midwife) and at least one with a social science background and field interview experience. It is recommended that a single supervisor coordinate no more than three research teams.

Typically, at the beginning of the day, the person with clinical training will begin observing client and provider interactions. Later, this person will also help one of the other team members to complete the inventory of equipment. The social scientist usually will be responsible for client exit interviews and staff interviews. He/she may also help with collecting information on clinic records, reporting, and service statistics.

The training of the research teams is probably one of the most important aspects of any Situation Analysis study. Unlike KAPtype surveys, Situation Analysis studies use a variety of data collection techniques such as observation and inventory-taking which require substantial training. Ten full days of training is essential as a minimum. The training should include considerable role playing as well as actual field visits to SDPs for practice (see "The training agenda for the research team," page 20).

Before the actual training of interviewers, it is usually very helpful to hold a thorough orientation on the Situation Analysis approach and on managing the study for the principal investigators and study supervisors. The orientation should be for several days to a week. It should cover all aspects of the data collection process including training, 
locating SDPs, organizing and checking questionnaires, call-back procedures, and what to do if emergencies occur.

\section{Programmatic uses of Situation Analysis studies}

The major users of the findings from a Situation Analysis study are policymakers, donor organizations, program administrators, and service providers at all levels (Askew and Fisher, 1995). The standard analysis plan for the data from a Situation Analysis study contains over 100 tables and graphs that typically are generated from each study (see Chapter 4), extensively discussed at a dissemination seminar, and may ultimately go into the first report. The information obtained can be used for a variety of programrelated purposes to:

- Assess the quality of care provided to clients by public and private service clinics and by CBDs;

- Evaluate the extent to which reproductive health services are integrated into family planning programs;

- Refine the estimates of staff training needs (both initial and refresher);

- Examine the availability and use of information, education, and communication (IEC) materials;

- Highlight equipment requirements, particularly for clinical methods such as the IUD and sterilization;

- Guide the plans for facility renovation;

- Quantify the current contraceptive supply levels at service delivery points visited;

- Assess the functioning of the management information and logistics systems;

- Assess barriers to access;

- Provide data for policy formulation or change;

- Identify areas for initiating operations research studies.
Most recent Situation Analysis studies are now used to examine selected aspects of reproductive health such as abortion, STDs, and HIV/AIDS services. Others have used the Situation Analysis approach to examine emergency obstetric care (Center for Population and Family Health, 1995; and Sloan et al., 1995). For example, SDP staff can be asked about access to abortion services, and about questions they receive from clients concerning abortion. They also can be asked about the availability of equipment, supplies, and trained personnel to provide safe abortion or emergency obstetric care services. Similarly, clients can be asked if they ever had an unwanted pregnancy, and if they have, how they handled the pregnancy. This approach has been used in a number of Situation Analysis studies (see Huntington et al., 1993a and Huntington et al., 1996b).

If a Situation Analysis study covers all SDPs in a geographic area such as a city or country (see Mensch et al., 1994b for Nairobi), the weaknesses of any given SDP within the geographic area in terms of lack of staff, equipment, supplies, or other elements can be identified easily and often corrected quickly. Also, of course, the entire system can be described accurately since all SDPs are included in the analysis. On the other hand, if a survey sample approach is taken to the selection of SDPs, it is possible to describe the entire service provision system in terms of probabilities but not in terms of the weaknesses of any given SDP.

A model for implementing Situation Analysis studies has emerged which includes participation by managers in each of the key study implementation phases in order to increase understanding of the research process and use of the study results for program change. First, a planning or orientation meeting is held, attended by the researchers, 
the senior managers responsible for the SDPs to be visited, and the major users of the data (such as policymakers and donors). At this meeting, the Situation Analysis methodology and procedures are explained in detail. In addition, the sampling plan is developed to reflect the needs of all relevant family planning organizations in the country, the core data collection instruments are adapted to the specific service delivery systems being analyzed, and the managers agree on responsibilities for ensuring the research teams' access to the SDPs. Senior program managers continue to be involved throughout the study including in the training and field data collection phases.

Once the data have been collected and processed, a Data Interpretation Workshop is held for the same group of managers, researchers, policymakers and donors to discuss the preliminary study results. Rapid data entry and production of frequency tabulations of the variables, with some basic cross-tabulations where necessary, are essential for this workshop (see Chapter 4). The rapid production of initial data is facilitated by user-friendly computer programs such as Epi Info (Dean et al., 1990). The results are usually presented in the form of bar charts for each variable. Bar charts are fairly easy for all audiences to understand and they appear to stimulate ready discussion and a search for solutions to the problems that emerge. One of the basic purposes of the Data Interpretation Workshop is to allow managers to see the preliminary data before a final report has been written and any analysis or interpretation has been attached to the data. In this way, data interpretation becomes their responsibility, and not that of the researchers. A major objective of the workshop is to obtain agreement on the programmatic implications of the data.

After the Data Interpretation Workshop, a final report is written that includes recommendations for program improvement and change. The final report is presented at one or more Dissemination Workshops and the results are discussed by the participants. Recent Situation Analysis studies in Senegal, Burkina Faso, and Indonesia have focused on disseminating the results not only at the national level but also at the regional level in order to achieve maximum involvement of local-level program managers and increase the probability that the results will be used for positive program change (Diop et al., 1996).

\section{Impact studies and Situation Analysis}

Impact studies build upon the basic Situation Analysis design and meet the fourth objective noted earlier. There are three variations of impact studies that can be undertaken. The first is the simplest and can more accurately be termed an "output" evaluation study rather than an impact study. ${ }^{3}$ The procedure would be to conduct two Situation Analysis studies, each of which would use the same sample of SDPs. The second study would be conducted approximately three years or more after the first. The objective would be to evaluate changes that may have occurred as a result of program improvements. The "impact" of these

\footnotetext{
3 See Bertrand et al., 1994, p. 19. Bertrand and colleagues outline a process of: INPUT $\longrightarrow$ PROCESS $\longrightarrow$ OUTPUT $\longrightarrow$ OUTCOME where the inputs, process, and outputs refer to project or program specific components and outcomes to larger, population-based "ultimate outcomes" that are related to effect and impact.
} 
changes would be measured in terms of improved SDP subsystem potential to provide quality of care, and in the actual receipt of quality of care by clients (Miller and Frerichs, 1992-93; and Miller et al., 1996).

A second type of impact study would be longitudinal and again require conducting two Situation Analysis studies in the same sample of SDPs as well as creating a panel of clients. In the first study, the reproductive intentions of clients would be determined during exit interviews. These clients would form a panel and be reinterviewed approximately two or three years later. During this period, problems at the SDPs identified by the first Situation Analysis might be eliminated or at least reduced through some form of service delivery intervention program. ${ }^{4} \mathrm{~A}$ second, follow-up Situation Analysis study would then be conducted to determine the extent to which SDP subsystem potential readiness and provision of quality of care had been improved. If the potential readiness and quality had been significantly improved, then the impact of this should be noticeable in the behavior of the panel with respect to their ability to meet their own reproductive intentions. Essentially, this type of study examines the extent to which differences in contraceptive behavior can be attributed to differences in the quality and configuration of services provided at SDPs.

The third type of impact study has a similar purpose. It would seek to link a Situation Analysis to a population-based, KAP-type study such as a Demographic and Health Survey. All SDPs in the geographic area covered by the population-based survey would be included in the Situation Analysis. The particular configuration and quality of services offered by the SDPs could then be related to the contraceptive behavior of couples who have been sampled and interviewed in the geographic areas served by the SDPs (see Mensch et al., 1996).

\section{Operations research and Situation Analysis}

Situation Analysis studies are closely linked with operations research (OR) and indeed, are an essential component of the OR process. As defined by Fisher et al. (1991), the OR process has five basic steps: problem identification and diagnosis, strategy selection, strategy experimentation and evaluation, information dissemination, and information utilization. Situation Analysis studies have become one of the single most important tools for gathering data necessary for the first step of the OR process-problem identification and diagnosis.

Situation Analysis studies identify and define in considerable detail supply side constraints to the delivery of services. Once having defined the problem areas, OR studies can then be designed and implemented to test new approaches to overcoming the problem. The results from these studies are then disseminated and utilized for service improvement. After the results have been utilized, a second-round Situation Analysis study can examine changes in the service delivery environment that may have taken place since the first study, and the impact these changes may have had on the fertility behavior of clients. The second-round Situation Analysis study also serves to identify

\footnotetext{
${ }^{4}$ If an intervention is not possible, then it would be necessary to select a geographic setting where there is variation in family planning inputs, including quality of services. In the absence of variation it would not be possible to demonstrate a relationship between quality of care, contraceptive use, and fertility.
} 


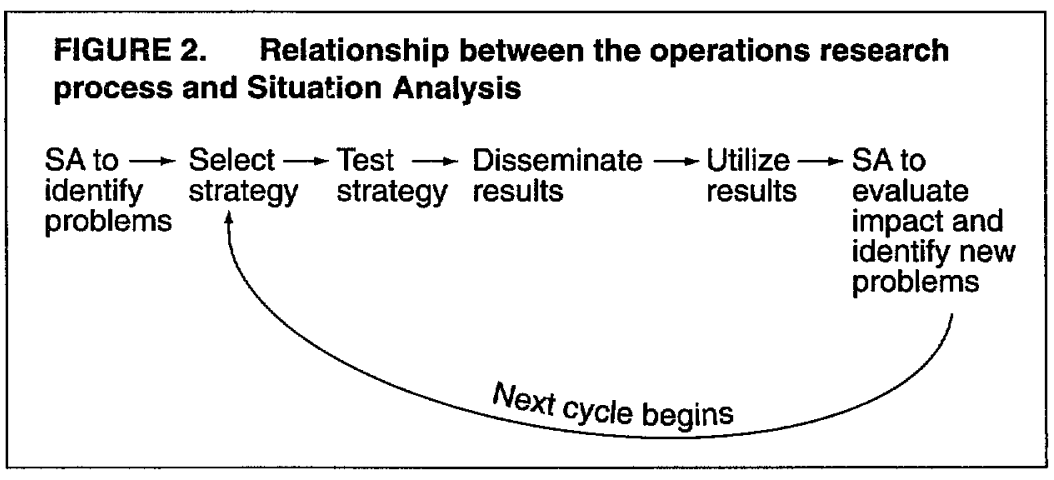

The interest generated by this initial Situation Analysis study and its dissemination effort led to many requests for additional studies, initially in African countries, but later in Asian and Latin American countries. By late 1996, more than 35 studies had been completed or were being com-

and define new problems that may have developed or old problems that were not solved. Thus, Situation Analysis studies not only start the process of operations research with problem identification and diagnosis and end that process by evaluating changes and impact, they also initiate a new cycle of problem identification and diagnosis as shown in Figure 2.

\section{The diffusion of}

\section{Situation Analysis}

The results from the first Kenyan study were provided quickly to program managers in graphic format (Miller et al., 1989) which made the results easily understandable and greatly facilitated the dissemination of both the results and the methodology. The data proved useful to the managers of the Kenyan family planning program who felt that for the first time they had some understanding of the supply side of their program and could represent the program more accurately to their own government and to outside donor agencies. Some specific changes in curriculum design and administration were made in an attempt to solve problems quickly. The data were also used to train selected staff of the $\mathrm{MOH}$ and local universities in OR, and to design and implement several OR studies aimed at solving the problems identified by the Situation Analysis study. pleted around the world and many more were at various planning stages. The utilization of Situation Analysis study findings has been documented in a number of case studies, most recently for Burkina Faso (Population Council, 1996).

\section{Methodological issues}

In the process of planning and conducting Situation Analysis studies, the methodology evolved as a result of three factors: (1) adaptation to local interests and program components; (2) critical analysis by a larger number of researchers involved in the studies; and (3) a desire to explore possible solutions to continuing methodological issues and problems. Several methodological issues, some recognized as early as the first Kenyan study, have become more apparent and need to be addressed in the future.

These include:

\section{- Positive bias of observation and} interview

While the data collected with the "SDP inventory" questionnaire are reasonably unbiased, the observations of the provider-client interaction are quite intrusive and probably bias in a positive direction the results obtained on quality of care. Responses from staff interviews are also probably biased in favor of representing the SDP's operations in 
a more favorable light. These problems have concerned the researchers from the first study. One solution to this problem is to spend more than one day at each SDP so that the presence of the research team becomes more familiar and the behavior of providers becomes more normative (Simmons and Elias, 1993). Another approach to lessening the positive bias might be to use "mystery" clients (Huntington and Schuler, 1993b).

\section{- Reliability of observations}

A key source of data from Situation Analysis studies comes from the observation of the provider-client interaction. An important concern with this data is its reliability. While observers are given extensive training, there obviously is some degree of variability between them. As part of the Situation Analysis study in Turkey, two observers recorded the same provider-client interaction. A comparison of the responses from the two observers revealed, overall, a very high degree of reliability (Huntington et al., 1996a). While this is encouraging, further methodological studies of this type need to be conducted.

\section{- The number and representative-} ness of SDPs and observations

There are a number of important sampling issues associated with Situation Analysis studies. First, there is the issue of how many SDPs to include in the sample. What type of SDP should be included-only MOH SDPs or a mix with private SDPs? Should separate samples be included for each type of SDP? Also, within each SDP, how many provider-client interactions should be observed? This issue becomes important because new clients are often not available at clinics on the day of the research visit, and if clients are less likely to be present at lower quality SDPs, then the resulting observations of provider-client interactions further bias the resulting picture of the entire program in a positive direction. There is also the issue of whether the various types of SDPs (for example, urban hospitals, district health centers, or village health posts) should be weighted in terms of client load or possibly catchment area population.

\section{- Applied research needs versus theory testing}

As noted earlier, the original purpose of the Situation Analysis studies was to describe the strengths and weaknesses of family planning programs. More recently, the purposes of the study have expanded. Researchers in some countries have wanted to answer a number of questions from a Situation Analysis study for which it was not originally designed. There seems to be a fundamental tension between researchers who would like to utilize the data for an analysis of correlates of service use dynamics and family planning managers who are most interested in a description of their program. Most often, Situation Analysis studies have been used for the latter rather than the former purpose.

\section{- Adaptation for routine manage-} ment and program monitoring

To date, Situation Analysis studies have been organized and implemented primarily as discrete research studies. There is, however, a growing interest 
among $\mathrm{MCH}$ and FP managers in utilizing Quality Assurance (QA) procedures for routinely assessing and improving program operations (Katz et al., 1993). Although the Situation Analysis approach in its current form is not suitable for adoption as a $\mathrm{QA}$ procedure (Askew, 1994), it is certainly possible to adapt it for such use. Studies in Kenya and Botswana have been testing ways in which elements of the Situation Analysis approach can be utilized within routine management and MIS procedures. And in several countries (Kenya, Burkina Faso, Senegal, Zimbabwe, and Ghana) two Situation Analysis studies conducted several years apart are being used to monitor program changes over time.

\section{Conclusions}

In a very short period of time since the first Kenyan study in 1989, the Situation Analysis approach to examining the supply side of family planning has diffused rapidly throughout the world. The approach has become one of the key tools in diagnosing the strengths and weaknesses of program functioning, and operationalizing and assessing the concept of quality of care. The approach also holds considerable promise as a methodology to evaluate the impact quality of care has on service utilization and on the fertility behavior of clients. The studies conducted to date have been widely used by program managers as a source of information for improving and expanding programs. As with any new approach, the methodology has evolved, developed, and improved. The sample sizes have increased, new topics including abortion, STDs, and emergency obstetric care are being ad- dressed, and a more standard set of instruments, as well as data analysis plans, are being used. At the same time, several methodological problems not initially foreseen are receiving increasing attention and steps are being taken to improve the way in which data are collected. It is hoped that the strengthened methodology, based on both a theoretically sound framework and fieldtested research methods, will provide a generally acceptable approach for assessing family planning and reproductive health programs.

\section{References}

Arends-Kuenning, M., B. Mensch, and M. R. Garate. 1996. "Comparing the Peru service availability module and situation analysis." Studies in Family Planning 27,1:44-51.

Askew, I. 1994. "Distinguishing between quality assurance mechanisms and quality assessment techniques." Health Policy and Planning 9,3: 274-277.

Askew, I. and A. Fisher. 1995. "Using operations research to guide family planning program development and policy formulation in Sub-Saharan Africa." Population Researcb and Policy Review 14:373-393.

Bertrand, J., R. Magnani, and J. Knowles. 1994. Handbook of Indicators for Family Planning Program Evaluation. The Evaluation Project, Carolina Population Center, University of North Carolina, Chapel Hill, North Carolina.

Bruce, J. 1990. "Fundamental elements of the quality of care: A simple framework." Studies in Family Planning 21,2:61-91.

Casterline, J., ed. 1985. The Collection and Analysis of Community Data: WFS Seminar on Collection and Analysis of Data on Community and Institu tional Factors. 20-23 June 1983, International Statistical Institute, World Fertility Survey.

Center for Human Services. 1988. Primary Healtb Care Tbesaurus: A List of Service and Support Indicators. Chevy Chase, Maryland.

Center for Population and Family Health, Prevention of Maternal Mortality Network. 1995. "Situation Analyses of emergency obstetric care: Examples from eleven operations research 
projects in West Africa." Social Science and Medicine 40,5:657-667.

Cleland, J. 1973. "A Critique of KAP studies and some suggestions for their improvement." Studies in Family Planning 4,2:42-47.

Dean, A., J. Dean, A. Burton, and R. Dicker. 1990. Epi Info, Version 5: A Word Processing, Database and Statistics Program for Epidemiology on Microcomputers. USD Inc., Stone Mountain.

Diop, N., A. Cerulli, and D. Sanogo. 1996. "Regional dissemination of Senegal's Situation Analysis results: A promising way to maximize operations research utilization." Paper presented at Situation Analysis Managers' Utilization Meeting, Nairobi, Kenya.

Fisher, A., J. Laing, J. Stoeckel, and J. Townsend. 1991. Handbook for Family Planning Operations Research Design, Second Edition. Population Council, New York.

Fisher, A., B. Mensch, R. Miller, I. Askew, A. Jain, C. Ndeti, L. Ndhlovu, and P. Tapsoba. 1992. Guidelines and Instruments for a Family Planning Situation Analysis Study. Population Council, New York.

Fisher, A. 1993. "Family planning in Africa: A Summary of recent results from operations research studies." In Conference Proceedings and Papers, Africa OR/TA Project, Africa OR/TA Project, End of Project Conference, Nairobi, Kenya.

Freedman, R. 1974. "Community-level data in fertility surveys." World Fertility Survey Occasional Papers No. 8, London, World Fertility Survey.

Frerichs, R. 1989. "Simple analytic procedures for rapid microcomputer-assisted cluster surveys in developing countries." Public Health Reports 104,1:24-34.

Frerichs, R. and Khin Tar Tar. 1989. "Computer-assisted rapid surveys in developing countries." Public Health Reports 104,1:14-23.

Huntington, D., B. Mensch, and N. Toubia. 1993a. "A new approach to eliciting information about induced abortion." Studies in Family Planning 24,2:120-124.

Huntington, D. and S. Schuler. 1993b. "The simulated client method: Evaluating client-provider interactions in family planning clinics." Studies in Family Planning 24,3:187-193.

Huntington, D., K. Miller, and B. Mensch. 1996a. "The reliability of the situation analysis observation guide." Studies in Family Planning 27,5:277-282.
Huntington, D., B. Mensch, and V. Miller. 1996b. "Survey questions for the measurement of induced abortion." Studies in Family Planning 27,3:155-161.

Katz, K., K. Hardee, and M. Villinski. 1993. Quality of Care in Family Planning: A Catalog of Assessment and Improvement Tools. Family Health International, Durham, North Carolina.

Keller, A. 1991. "Management information systems in maternal and child health/family planning programs: A multi-country analysis." Studies in Family Planning 22,1:19-30.

Kumar, S., A. Jain, and J. Bruce. 1989. "Assessing the quality of family planning services in developing countries." Programs Division Working Paper No. 2, Population Council, New York.

Mensch, B., A. Fisher, I. Askew, and A. Ajayi. 1994a. "Using situation analysis data to assess the functioning of family planning clinics in Nigeria, Tanzania, and Zimbabwe." Studies in Family Planning 25,1:18-31.

Mensch, B., R. Miller, A. Fisher, J. Mwita, N. Keyonzo, F. Mohamed Ali, and C. Ndeti. 1994b. "Family planning services in Nairobi: A Situation Analysis of City Commission clinics." International Family Planning Perspectives 20,2:48-54.

Mensch, B., M. Arends-Kuenning, and A. Jain. 1996. "The impact of the quality of family planning services on contraceptive use in Peru." Studies in Family Planning 27,2;59-75.

Miller, R., L. Ndhlovu, and M. Gachara. 1989. A Situation Analysis of the Family Planning Program of Kenya: The Availability Functioning and Quality of MOH Services. Population Council and Kenya Ministry of Health, Nairobi, Kenya.

Miller, R., L. Ndhlovu, M. Gachara, and A. Fisher. 1991. "The situation analysis study of the family planning program in Kenya." Studies in Family Planning 22,3:131-143.

Miller, R., and R. Frerichs. 1992-93. "An integrated approach to operations research for strengthening family planning programs: A case example in Kenya." International Quarterly of Community Health Education 13,3:183-199.

Miller, R., K. Miller, L. Ndhlovu, J. Solo, and O. Achola. 1996. "A comparison of the 1995 and 1989 Kenya Situation Analysis study findings." Paper presented at the meeting Kenya: Situation Analysis Study of the Family Planning Services. Population Council and Division of Family Health, Ministry of Health, Nairobi. Also pre- 
sented at the APHA Annual Meeting, November 1996, New York.

Population Council, Africa Operations Research and Technical Assistance Project II. 1996. Case Study

Summary Report: A Situation Analysis of the $\mathrm{Na}$ tional Family Planning Program in Burkina Faso. Population Council, Dakar, Senegal.

Ross, J. and E. Frankenberg. 1993. Findings from Two Decades of Family Planning Research. Population Council, New York.

Sloan, N., C. Quimby, B. Winikoff, and N. Schwalbe. 1995. Guidelines and Instruments for a Situation Analysis of Obstetric Services. The
Ebert Program of the Population Council, New York.

Simmons, R. and C. Elias. 1993. "The study of clientprovider interactions: A review of methodological issues." Programs Division Working Paper No. 7, Population Council, New York.

Wilkinson, M. 1991. "The DHS service availability questionnaire." Paper presented at the meeting on Measuring the Influence of Accessibility of Family Planning Services in Developing Countries, National Academy of Sciences Committee on Population, Washington, DC. 


\section{Chapter 2}

\section{Conducting the study}

\section{Ethical issues in the conduct of Situation Analysis studies}

Situation Analysis studies require interviews

of clients and providers, as well as observations of provider-client interactions. These study procedures potentially carry some risks for the study subjects unless mechanisms are established to protect the subjects. Institutions planning to carry out Situation Analysis studies or related technical assistance activities should consider the relevant local laws and regulations that govern the review of research proposals and procedures. In many settings, special committees review research proposals to ensure that issues of confidentiality, privacy, incentives, informed consent, and other general concerns will be handled in a way that is ethical and protects the study subjects from any harm.

The Council for International Organizations of the Medical Sciences (CIOMS), in affiliation with the World Health Organization, addresses ethical issues of concern to the international research community. The four guidelines of the CIOMS for research with human subjects are ${ }^{1}$ :

"(1) Respect for persons, which includes both autonomy, or the respect for the self-determination of those who are capable of deliberating about their personal goals, and protection of per- sons with impaired or diminished autonomy;

(2) beneficence, which is the ethical obligation to maximize benefits and minimize harms or wrongs;

(3) non-maleficence, which means "do no harm"; and

(4) justice, which requires that subjects in studies are treated equally, and studies are designed so that the subjects of study are also the beneficiaries of the study..."

All of these concerns are relevant in a Situation Analysis study, and should be discussed openly and completely with local researchers and managers, and with field research staff during training. The full importance of privacy, informed consent, and protection of subjects needs to be communicated to all involved with the study, and researchers need to practice how they communicate these messages to the study subjects and to others.

Confidentiality and privacy. Information obtained from providers and clients as

\footnotetext{
${ }^{1}$ From T.L. Beauchamp, and J.L. Childress, Principles of Biomedical Etbics, 2nd Edition, Oxford University Press, 1983, as summarized in K. Ringheim, 1995, "Ethical issues in social science research with special reference to sexual behaviour research," Social Science and Medicine, 40,12:1691-1697.
} 
part of a Situation Analysis study must be kept confidential and private, as part of the non-maleficence or "do no harm" guideline. The identity of study subjects must be protected by the researchers, which is usually done by identifying subjects with a code rather than a name and address. Also, the researchers should be careful to control or remove any variables that could be used to identify individual interviewees.

In a few countries, the Situation Analysis study design calls for a panel of clients who will be followed over time and re-interviewed. In panel study designs of this type, clients must be asked at the end of the interview if they are willing to be on the panel, if they are willing to have their names and addresses recorded, and if they are willing to be re-interviewed at a later point in time. At this point, study subjects must be made aware that follow-up contacts may take place in their homes, where a spouse or other family member may learn that the interviewee has been obtaining clinical services such as family planning or possibly treatment for an STD. If the client does not wish to be in the study, then the researchers must honor this decision; only if she agrees can her name and address be recorded. However, because this information so directly identifies clients, the names and addresses must be removed from the rest of the questionnaire and stored separately in a locked cabinet with restricted access. The only identifier on the actual questionnaire should be a code number.

Confidentiality extends not only to the client's identity but also to the exposure a client experiences in the course of the study. Both the observation and the exit interview deal with highly sensitive issues of family life and sexual behavior, which might make the client ill-at-ease, particularly if the client's responses to questions can be heard by others. It is very important to conduct interviews in a private setting where the client can feel at ease (this also increases the validity of the information collected). Also, physical examinations are sometimes uncomfortable and embarrassing for clients. Situation Analysis study observers should always obtain the consent of the client to be present during the examination. The client's desire for privacy in these settings must be respected.

Informed consent. The principle of respect for persons establishes the right of both clients and providers to hear about the nature of the study, about any risks and benefits associated with their participation, and that they can withdraw from the study at any time. Clients must also be informed that they can receive all the services of the health facility whether or not they participate in the study. These issues should be presented in language that is easily understood, and the subject must freely and voluntarily agree to her inclusion in the study. True "informed consent" also requires that the subject is given the opportunity to ask questions about the study before consenting. Field researchers should be given information about how to handle and direct questions from study subjects about family planning and other health related matters. Clear guidance must be provided to field researchers to emphasize the purely voluntary nature of all participation. It is also important to note that consent should only be obtained when the client is not under duress, in pain, medicated with consciousness altering drugs, or in need of acute care. Clients with any of these conditions should not be included in the study since their condition 
precludes their ability to give thoughtful attention to their consent.

The benefits to be derived by both clients and providers from the research are mainly social: the information will be used for developing improved program policies and practices. We believe that the Situation Analysis procedures involve no additional risk for clients beyond the social and psychological risks that may be associated with seeking medical consultation for a sex-related matter. While it is possible that there could be some additional risk to a client from a provider who is nervous about being observed, we believe that the more likely occurrence is for the provider to be especially careful during the observation and to attempt to provide services of as high a quality as she is capable of providing.

\section{Observer's responsibility to the} client's welfare. The Helsinki Declaration of 1964, which addresses ethics in biomedical research, holds that "in research on man, the interest of science and society should never take precedence over considerations related to the well-being of the subject." Occasionally, Situation Analysis observers witness gross violations of acceptable provider behavior that puts the client at risk of morbidity. For example, if a provider drops an IUD on the floor, picks it up, and attempts to insert it in a woman without sterilizing it, she exposes the woman to a risk of infection. In one case, a provider was observed wiping her hands on the drapes before she conducted a physical examination. In such cases of obvious violation of standard acceptable procedures, the Situation Analysis study observer may have a responsibility to intervene to protect the client from potential harm. A list of potential situations that might call for some form of intervention should be developed and discussed during training by MOH officials of the country.

Of course, interventions of this type can influence the research results, but in such instances the safety of the client outweighs the needs of the researchers and managers. When clients' needs and researchers' needs clearly conflict, the research needs should be compromised, as suggested by the Helsinki Declaration. These cases should also be carefully documented. Field observers are trained accordingly in Population Council-assisted Situation Analysis studies.

In less extreme cases observers may face a more difficult and less obvious ethical issue. Most researchers would probably agree that in extreme cases where clients are clearly at some risk, intervention by the observer is necessary. However, these cases are relatively rare. The more common occurrence observed in almost all Situation Analysis studies is to find a vast array of somewhat less serious service quality issues. Indeed, it is usually the case that observers will see a large number of mistakes, lapses, and misinformation transmitted, and interviewers will find that clients may not know crucial information about their selected contraceptive. In fact, it is just this sort of information that the Situation Analysis is designed to uncover so that needed policy and program changes can be made. Should an intervention of some type be attempted with every service delivery situation that is less than optimal? Clearly doing so would prove so intrusive and detrimental to rapport with staff as to ruin the possibility of gathering useful information for program and policy decision-making and thus would greatly lessen the ability to make needed improvements. It is important to discuss 
fully with relevant local authorities the potential ethical issues that may arise during the implementation of a Situation Analysis study, and the type of behaviors by providers that may require some form of intervention by the study observers and interviewers.

\section{Establishing objectives and reviewing questionnaires}

The first step in conducting a Situation Analysis is to hold a planning or orientation meeting for the researchers, the senior managers responsible for the SDPs to be visited, and the major users of the data (such as policymakers and donors). At this meeting, the SA methodology and procedures are explained in detail, and the objectives of the study are discussed. After these points are established, the questionnaires are carefully reviewed for their appropriateness. The objectives of the study should suggest to the group what sort of information will be required, and a set of key indicators can usually be drawn up at this point (see Chapter 4 for suggested indicators). These indicators should guide any revisions to the questionnaires.

In addition, the sampling plan should be developed to reflect the needs of all relevant family planning organizations in the country, and the managers should agree on responsibilities for ensuring the research teams' access to the SDPs. In addition, the program managers should continue to be involved throughout the study including in the training and field data collection phases.

\section{The training agenda for the research team}

The next step is to hold a training for the research team, which usually takes at least ten days. The training consists of a broad introduction to the research objectives, interviewing and observing, ethical issues, and a detailed review of each question in every questionnaire so that all team members fully understand each question's meaning, how to ask the question and how to record the answer. Considerable time is then spent on "role playing" both the interviews and the observations, with the trainees taking turns to act as the interviewer or observer and as the SDP staff person or a client. Role playing gives each team member a chance to practice asking questions and recording answers. Initially, trainees frequently record responses differently. Discussion of these instances provides an opportunity to clarify definitions and understandings. As the training program progresses, trainees develop confidence with the data collection instruments and probably will memorize certain sections. Reliability between observers increases. In addition to role playing, the training session includes at least two days spent at SDPs so that team members can actually practice interviewing, observing, and taking an inventory. See the sample schedule of training activities outlined in Table 1.

The last day of training is spent planning for the fieldwork. Each team meets together and finalizes the following fieldwork issues:

- the list of SDPs to be visited;

- the schedule of visits over the fieldwork period;

- transportation;

- accommodation;

- supervisory visits;

- storage of completed and resupply of fresh data collection instruments.

Fieldwork should begin a week after this final session, giving the study planners 
TABLE 1. Sample training schedule

\begin{tabular}{|c|c|}
\hline Day & Activities \\
\hline One & $\begin{array}{l}\text { Introductions. } \\
\text { Training plans. } \\
\text { Background to SA studies. } \\
\text { Concepts of reliability, validity, and some pitfalls in the data collection process. } \\
\text { Some field experiences from other SA studies. } \\
\text { Overview of the instruments. }\end{array}$ \\
\hline Two & $\begin{array}{l}\text { Review of the Observation Guide. } \\
\text { Review of the FP Client Exit Interview. } \\
\text { Review of the Staff Interview. }\end{array}$ \\
\hline Three & $\begin{array}{l}\text { Review of the Inventory. } \\
\text { Review of the MCH Client Exit Interview. } \\
\text { Plenary meeting to discuss issues arising from instrument reviews. } \\
\text { Guidelines for conducting interviews. }\end{array}$ \\
\hline Four & $\begin{array}{l}\text { Break into specialized groups of researchers and nurse/midwives. } \\
\text { Review administration of specific instruments for each group. } \\
\text { Role playing. }\end{array}$ \\
\hline Five & $\begin{array}{l}\text { Continue role playing. } \\
\text { Plenary meeting to discuss role playing experiences. }\end{array}$ \\
\hline Six & $\begin{array}{l}\text { Fieldwork at selected SDP sites. } \\
\text { Each team to practice administering the data collection instruments. }\end{array}$ \\
\hline Seven & Continue fieldwork at selected SDP sites. \\
\hline Eight & $\begin{array}{l}\text { Review of fieldwork experiences and role playing. } \\
\text { Review of supervisory roles with Team Leaders/Supervisors. }\end{array}$ \\
\hline Nine & Role playing. \\
\hline Ten & $\begin{array}{l}\text { Each team plans its travel logistics. } \\
\text { Plans discussed in group and modified as necessary. } \\
\text { Administrative and financial issues. }\end{array}$ \\
\hline
\end{tabular}

time to revise and print the new questionnaires. After this is completed and the instruments are distributed to the field teams, the schedule of visits to SDPs can begin.

\section{Role of the Team Leader/ Supervisor}

The team leader will be called upon to assume several roles while in the field. $\mathrm{He} / \mathrm{she}$ should be prepared to assist at all times with regards to field operations. High morale among the team members is a very impor- tant factor in the successful execution of the fieldwork. This means that the team members have to be sensitive to each other's needs and points of view. Where difficulties arise, the supervisor may be responsible for facilitating the process of problem-solving. Above all, remember that each team member has different resources and abilities, and these should be tapped to make the field experience successful. Some issues that need attention while in the field are discussed below: 


\section{- Transportation arrangements}

The Team Leader has to make sure that transportation is available and ready every day to take the interviewers to the field. The driver, who becomes part of the field team, has to receive clear instructions on where and when to go. Public transportation may be used as an alternative if appropriate but this is usually not very satisfactory except possibly in urban areas.

- Check on completion of instruments

On a daily basis, the supervisor checks the entries to the data collection instruments to verify consistency and accuracy of the data collected. This will include inaccurate recordings of the interviews. If the reviews are done as a group, it provides a training experience for the team members. This will be particularly important during the first few days of the study.

For all of the instruments, some information on the cover page can be filled in before a visit to the SDP is made. This is encouraged since it saves time and allows for prior planning to make sure that all details are consistent.

To maintain a sufficient supply of instruments, the Team Leader has to keep in contact with the Principal Investigator at the head office. Normally, a date for a field visit by the Principal Investigator will be arranged during the training sessions.

\section{- Safekeeping of the questionnaires}

The Team Leader needs to organize the safe keeping and proper storage of instruments, both used and unused. The instruments need to be kept in a logical order according to type and date of visit to the SDPs.

- Permission from local authorities Permission to visit SDPs should be obtained from local authorities. The Team Leader should organize this. At the SDPs themselves, the team members should be introduced to the SDP staff and the purpose of the study should be explained briefly. The Leader will generally be responsible for this function.

- Disbursing of per diems and other money matters

Each team evolves its own method of organizing for meals and other common needs. Generally, per diem arrangements for the team will be handled through the Leader.

The Team Leader usually keeps some money for fuel and other vehicle expenses. It is important that expenditure receipts are obtained and kept properly in an orderly manner. Another related issue is for the Team Leader to check that the driver keeps a proper daily mileage log book.

- Keeping a daily summary record At the end of every day, the Team Leader reviews with the other team members the activities of the day and then writes a brief report (usually about $1 / 2$ to 1 page). The report may include events at the SDP that made the data collection process unusualperhaps too easy or too difficult. The report is a summary of the experiences of the team and is valuable information for interpreting the research results.

- Keeping contact with the head office If the team experiences unusual difficulties or is in doubt about certain is- 
sues, the head office or supervisor should be contacted immediately.

\section{The research team and a typical day}

As noted in the previous chapter, the number of research teams and supervisors used in a study depends on the number and accessibility of SDPs, the objectives selected, and resources available. Usually between 5 to 10 teams will spend about six weeks visiting a total of 150 to 300 SDPs; each team will visit 25-30 SDPs.

Prior to arriving at the SDP, perhaps during the previous evening, the team members should make sure that the "standard codes" for identifying the type and location of the SDP to be visited have been agreed upon, and possibly entered in advance on the cover and second pages for each instrument to be used. The codes for the type of SDP, type of sector and type of locality should be discussed with the Head of the SDP and should be consistent for every instrument used at that SDP. Moreover, the codes for each staff member and client must be carefully recorded for each interview and observation, and must match across instruments. The Team Leader should assign these codes for staff and clients after arriving at the SDP. These "linking" variables are extremely important in the data analysis, so these codes should always be checked thoroughly by the Team Leader. See Chapter 3 for more information.

The team should always arrive at the SDP before the official opening time. This is necessary in order for them to observe what happens when the SDP opens and, of course, if it opens on time.

As also noted in the previous chapter, the team member with clinical training typically begins observing the interaction between family planning clients and the provider(s) at the start of the day. Later, this person will also help one of the other team members to complete the inventory of equipment. The social scientist is usually responsible for client exit interviews and staff interviews. $\mathrm{He} /$ she may also help with collecting information on clinic records, reporting, and service statistics. Both team members are responsible for interviewing $\mathrm{MCH}$ clients.

At the end of the day, the Team Leader should review with the other team members the visit to the SDP. The Team Leader should then write a brief ( $1 / 2$ to 1 page) report of the visit, noting any unusual circumstances or occurrences that are important but that will not be apparent from the data collection instruments.

In addition, the Team Leader must also review every instrument to ensure that all responses are correctly recorded. This step is sometimes difficult to complete at the end of a long day, but its importance cannot be overemphasized. If the questionnaires are missing information, the quality of the data is highly compromised, and the results will be less informative, and sometimes even unusable. Thus, the cost of missing data is high, and it should be strictly avoided. The check for missing data at the end of a day in the field may be tiring, but it represents the last opportunity to complete any information that is missing.

\section{Tips for conducting a good interview}

The objective of any SA is to collect the most accurate information possible. Collecting information through interviews is not always easy and requires an ability to ask questions clearly and to listen carefully to 
the answers. The objective of an interview is to get the opinions and ideas of the person being interviewed. It is very important to be neutral when interviewing a person. Do not try to indicate that there is one correct answer. The only answers that are correct are those given by the person being interviewed. Here are some tips for conducting a good interview:

- Always introduce yourself in a friendly and pleasant way.

- Be sure to emphasize the voluntary and confidential nature of the interview. If the person refuses to be interviewed, politely end the interview and go to another person.

- Never change the wording of the questions. Ask each question in exactly the way it is written on the questionnaire. Use a neutral voice. Do not try to lead the respondent to one answer or another. Do not suggest answers to the respondent. Let the respondent answer for herself/himself.

- If you do not understand the answer to a question, ask the respondent to repeat the answer. But, do not "lead" the respondent in such a way that you suggest an answer. In a neutral way ask the respondent: "Can you explain a little more? Take your time, there is no burry."

- If the respondent does not understand a question, repeat the question slowly and clearly. If the respondent still does not understand the question, you may have to restate it in different wordsbut be very careful not to change the meaning of the question.

- Do not push the respondent or act as if you are in a hurry. Give the respon- dent as much time as possible to answer your questions.

- Circle the number on the question, tick the box, or write the number that corresponds to the answer given by the respondent. Circle or tick only one answer unless the question clearly indicates that more than one response can be given, in which case circle or tick the relevant categories.

- If there are any difficulties with a particular question or something unusual happens, such as the respondent has to leave suddenly, write what happened in the margin of the questionnaire or on the back. At the end of the day explain to the Team Leader what happened.

- Sometimes you will be required to fill in a response for "Other:___ on the questionnaire. Write clearly and simply. Use the back of the questionnaire if you need more space but be sure that you identify the question number to which your responses apply.

\section{Tips for conducting a good observation}

The observation of client-provider interactions provides most of the information regarding how a client is counseled, examined, and provided with a method. The person doing the observation should always be medically trained and highly experienced in providing family planning services. The most appropriate observers have normally been female nurse-midwives with several years of family planning experience who also train others in family planning; their training experience ensures that they are able to view an interaction 
critically, and will be familiar with all of the provider behaviors listed in the observation instrument.

The observation guide is designed so that the observer ticks boxes or circles numbers that describe what she has seen. Because there is no fixed order for each consultation it is essential that the observer learns the structure of the observation guide so that whenever she sees a particular action or hears a specific issue being discussed she knows exactly where to mark the guide. In some cases it may be necessary to remember what happened and to mark the guide after the consultation is finished.

Before the first consultation, the observer must get the provider's permission to sit in and observe the client-provider interaction. Normally this is not a problem, but it is important to assure the provider that you are not evaluating her competence. There can be problems if the observer is known to the provider, either as a supervisor or a colleague, so every effort should be made to ensure that this does not happen.

The providers should also be told that the research observer cannot participate at all during the consultations. The provider should not ask the research observer for her opinions or advice, except in extremely serious situations; the provider should be requested to behave as if the observer were not present.

The observer will have to be seated fairly close to the client and provider to be able to see and hear exactly what goes on. Moreover, her presence is definitely going to affect the interaction, probably by making both the client and provider more self-conscious and aware of what they are saying and doing. Consequently, the observer should do everything possible to make herself unobtrusive.

Before the consultation begins, the provider should ask the client whether it is acceptable for the observer to be present. If possible, the observer should sit in the background so that she is not directly in eye contact with either the provider or the client. She should wear appropriate clothing (in some cases observers wear their own nursing uniforms) and have a pleasant smile on her face. She should also keep her paper and pen resting in her lap and be discreet when she notes down an observation.

Very occasionally the observer may see a provider doing something that is potentially dangerous to the client. For example, the provider may be using unsterile equipment when doing an examination, inserting an IUD, or administering an injectable. During the training, a list will be drawn up of situations the Ministry of Health feels are in clear violation of safe practice and which, if seen by the observer, should be stopped. (See the earlier section on ethical considerations, page 17.)

At the end of the consultation, the observer should follow the client away from the provider and ask if she would mind being interviewed. If she agrees, then the observer should introduce the client to the social science interviewer and give the observation guide / exit interview instrument to the interviewer. It is very important that the instrument used for the observation of the client-provider interaction be handed to the social science interviewer (see Chapter 3).

\section{After data collection}

Data collection can usually be completed in four to six weeks for a national Situation 
Analysis study. At the end of data collection, it is extremely important to debrief with the supervisors and interviewers. The principal investigator and the key program managers and administrators should meet with the research teams and review the entire data col- lection process. Any unusual circumstances should be noted.

See Chapter 4 for information on how to proceed with the entry, cleaning, analysis, and reporting of the data. 


\section{Instruments and question-by-question guides}

This chapter contains the Situation Analysis instruments:

- Inventory for Facilities Available and Services Provided at the Service Delivery Point (SDP)

- Observation Guide for Interaction Between Family Planning Clients and Service Providers

- Exit Interview for Family Planning Clients

- Interview for Staff Providing Family Planning/Reproductive Health Services at the SDP

- Interview for $\mathrm{MCH}$ Clients Attending the SDP

Each question on the instruments is marked with a suggested variable name in curly brackets: \{ \}. These variables would not appear on the questionnaires used in the field, but they would be used during data entry and analysis. The variable names are based on the question numbers (rather than the content of questions) because this method of naming has proved to be the easiest to use during data analysis. See the section on data entry and cleaning (page 157) for more information on variable names.

Each instrument is followed by a question-by-question guide that explains the purpose and details of each question. These guides are geared toward the data collector, and because they give essential information on how to administer each question, they should be read in conjunction with the instruments during training.

Several questions are common to all the instruments, and are not discussed directly in the question-by-question guides. These questions occur on the cover pages of each instrument, and are particularly important in data analysis. They include:

- Health facility code

- District code

- Village/town code

- Type of health facility

- Type of sector

- Locality

- Study client number

- Study staff number

The codes for health facility, district, and village/town should all be agreed upon before fieldwork begins. If possible, these lists should be copied and sent out with the research teams for reference during data collection. The information on type of facility, sector, and locality can be determined at the SDP, but these responses should match across the inventory and all observations, staff interviews, and exit interviews that are performed at the same SDP.

The study client number and study staff number require some coordination on the part of the Team Leader. These numbers are intended to uniquely identify staff and clients at a particular SDP. For example, the 
first SDP visited might have three service providers working that day. These providers should be numbered 1 to 3 at the start of the day. If the first provider is interviewed, the study staff number " 1 " would be entered on the staff interview cover sheet, and if she is observed with a client, the same number would be entered on the observation cover sheet. Likewise, if that provider is observed with four clients, then those four clients would be numbered 1 to 4 , and this same number would be entered in the cover pages of the observation and client exit interview. If the staff member " 2 " is observed with three clients, they should also be numbered 1 through 3 , etc. In this way, staff and clients can be linked with observations. When the next SDP is visited, the staff identification numbers can again start from 1 . Because this process can become confusing, only the team leader should assign study staff and client numbers, and check carefully at the end of the day that they are coded correctly.

Sometimes clients and providers are concerned about being identified individually on the questionnaires and observation. However, these study numbers are used only to link information between instruments, never to identify individuals. The names of clients and staff are never written down, and no further identification of individuals is required. 


\section{Inventory}

The purpose of this instrument is to assess the readiness of an SDP to provide services. It inventories the services available, makes a complete list of all equipment, supplies, materials, and commodities in working order, and it assesses the functioning of several subsystems, including physical infrastructure, staffing, IEC materials, logistics, management, supervision, and recordkeeping. The question-by-question guide to the inventory has detailed information on how to complete each question.

The codes presented in brackets \{\} in this instrument are suggested variable names for each question or tick mark. These names are referred to in the analysis plan (beginning on page 162). Keep in mind, however, that they would not appear on the actual questionnaires used by researchers in the field. See following pages for instrument. 


\section{Inventory for Facilities Available and Services Provided at the Service Delivery Point}

INSTRUCTIONS TO DATA COLLECTOR: This inventory should be completed by observing the facilities that are available and through discussions with the person in charge of $\mathrm{MCH}$ /family planning on the day of the visit. In all cases you should verify that the items exist by actually observing them yourself - if you are not able to observe them, then code accordingly. Remember that the objective is to identify the equipment and facilities that currently exist and not to evaluate the performance of the staff or clinic. For each item, circle the response or describe, as appropriate.

Health facility visited (name):

\{HFNAME\}

Health facility code:

$\{$ HFCODE $\}$

District (name):

\{DISTNAME\}

District code:

\{DISTCODE\}

Village/town (name):

\{TOWNNAME\}

Village/town code:

\{TOWNCODE\}

Date of visit:

\{DATE\}

Day

Month

Year

Type of health facility: \{TYPE\}

$1=$ Referral Hospital

Type of sector: $\{$ SECT\}

$2=$ District Hospital

$1=$ Government

$2=$ FPA

3 = Primary Hospital

$3=$ Mission

$4=$ Rural Health Center

$5=$ Maternity

$6=$ Health Post

7 = Pharmacy

$8=\mathrm{CBD}$

$9=$ Other

4 = Private

$5=$ Other

Locality: \{LOC\}

$1=$ Rural

2 = Urban

Name of observer:

Signature of team leader: 


\section{Accessibility}

ASK 1. What is the official opening time for this health facility? $\{11\}$

$$
\mathrm{am} / \mathrm{pm}
$$

OBS 2. At what time did the first family planning client arrive today? $\{12\}$

$$
\text { am } / \mathrm{pm} \quad \begin{aligned}
& 98=\text { No family planning clients } \\
& 99=\text { Not observed }
\end{aligned}
$$

OBS 3. At what time was the first family planning client seen today? $\{13\}$

$$
\text { am } / \mathrm{pm} \quad \begin{aligned}
98 & =\text { No family planning clients } \\
99 & =\text { Not observed }
\end{aligned}
$$

OBS 4. At what time was the last family planning client seen today? $\{14\}$

$$
\mathrm{am} / \mathrm{pm}
$$

$98=$ No family planning clients

$99=$ Not observed

ASK 5. What is the official closing time for this health facility? $\{15\}$

$$
\mathrm{am} / \mathrm{pm}
$$

ASK 6. How many days per week are family planning services offered at this health facility? $\{16\}$ days per week

OBS 7. Is there a sign announcing that FP services are available? $\{17\}$

$$
\begin{aligned}
& 1=\text { Outside building } \\
& 2=\text { Inside building } \\
& 3=\text { Both inside and outside building } \\
& 4=\text { No sign visible }
\end{aligned}
$$


ASK 8. Is (read 1-17) usually available to clients at this MCH/FP unit or elsewhere in the health facility?
A. Tick if available at MCH/FP unit

B. Tick if available elsewhere in facility

\begin{tabular}{|c|c|c|}
\hline 1. Family planning & $\{18 \mathrm{~A} 1\}$ & $\{18 \mathrm{~B} 1\}$ \\
\hline 2. Antenatal care & $\{18 \mathrm{~A} 2\}$ & $\{18 \mathrm{~B} 2\}$ \\
\hline 3. Maternity care/delivery services & $\{18 \mathrm{~A} 3\}$ & $\{18 \mathrm{~B} 3\}$ \\
\hline 4. Postnatal care & $\{18 \mathrm{~A} 4\}$ & $\{18 \mathrm{~B} 4\}$ \\
\hline 5. HIV/AIDS counselling/IEC & $\{18 \mathrm{~A} 5\}$ & $\{18 \mathrm{~B} 5\}$ \\
\hline 6. HIV/AIDS testing & $\{18 \mathrm{~A} 6\}$ & $\{18 \mathrm{~B} 6\}$ \\
\hline 7. Other STD counselling/IEC & $\{18 \mathrm{~A} 7\}$ & $\{18 \mathrm{~B} 7\}$ \\
\hline 8. Other STD diagnosis & $\{18 \mathrm{~A} 8\}$ & $\{18 \mathrm{~B} 8\}$ \\
\hline 9. Other STD treatment & $\{18 \mathrm{~A} 9\}$ & $\{18 \mathrm{~B} 9\}$ \\
\hline 10. Child immunization & $\{18 \mathrm{~A} 10\}$ & $\{18 \mathrm{~B} 10\}$ \\
\hline 11. Child growth monitoring & $\{18 \mathrm{~A} 11\}$ & $\{18 \mathrm{~B} 11\}$ \\
\hline 12. Infertility consultation & $\{18 \mathrm{~A} 12\}$ & $\{18 \mathrm{~B} 12\}$ \\
\hline 13. Oral rehydration therapy & $\{18 \mathrm{~A} 13\}$ & $\{18 \mathrm{~B} 13\}$ \\
\hline 14. Treatment of incomplete abortion & $\{18 \mathrm{~A} 14\}$ & $\{18 \mathrm{~B} 14\}$ \\
\hline 15. Nutrition counselling & $\{18 \mathrm{~A} 15\}$ & $\{18 \mathrm{~B} 15\}$ \\
\hline 16. Curative services - client & $\{18 \mathrm{~A} 16\}$ & $\{18 \mathrm{~B} 16\}$ \\
\hline 17. Curative services - child & $\{18 \mathrm{~A} 17\}$ & $\{\mid 8 \mathrm{~B} 17\}$ \\
\hline
\end{tabular}




\section{Infrastructure}

OBS 9. On the day of the visit, does the $\mathrm{MCH} / \mathrm{FP}$ unit have the following:

\begin{tabular}{|l|l|}
\hline 1. Piped running water & $\{19 \times 1\}$ \\
\hline 2. Electricity & $\{19 \times 2\}$ \\
\hline 3. Working toilets / latrines available for clients & $\{19 \times 3\}$ \\
\hline 4. Sufficient seating for clients & $\{19 \times 4\}$ \\
\hline 5. & $\{19 \times 5\}$ \\
\hline 6. & $\{19 \times 6\}$ \\
\hline
\end{tabular}

Staffing

\begin{tabular}{|c|c|c|c|c|}
\hline \multirow[b]{2}{*}{ 1. Medical doctor } & \multicolumn{2}{|c|}{$\begin{array}{ll}\text { ASK } & 10 . \text { How many (read } \\
1-7) \text { are assigned to } \\
\text { work full time at this } \\
\text { MCH/FP section? }\end{array}$} & \multicolumn{2}{|c|}{$\begin{array}{ll}\text { ASK } & 11 . \text { How many } \\
& (\text { read } 1-7) \text { are on duty } \\
\text { today? }\end{array}$} \\
\hline & Number: & $\{110 \times 1\}$ & Number: & $\{111 \times 1\}$ \\
\hline 2. Nurse & Number: & $\{110 \times 2\}$ & Number: & $\{111 \times 2\}$ \\
\hline 3. Nurse-midwife & Number: & $\{110 \times 3\}$ & Number: & $\{111 \times 3\}$ \\
\hline 4. $\mathrm{CBD}$ & Number: & $\{110 \times 4\}$ & Number: & $\{111 \times 4\}$ \\
\hline 5. $\mathrm{MCH}$ assistant & Number: & $\{110 \times 5\}$ & Number: & $\{111 \times 5\}$ \\
\hline 6. & Number: & $\{110 \times 6\}$ & Number: & $\{111 \times 6\}$ \\
\hline 7. & Number: & $\{110 \times 7\}$ & Number: & $\{111 \times 7\}$ \\
\hline
\end{tabular}




\section{IEC materials and activities}

OBS 12. Which IEC materials on the following subjects are available in the MCH/FP unit?

\begin{tabular}{|l|l|l|l|}
\hline 1. Family planning & $\{112 \mathrm{~A} 1\}$ & $\{112 \mathrm{~B} 1\}$ & $\{112 \mathrm{C} 1\}$ \\
\hline 2. Antenatal/postnatal care & $\{112 \mathrm{~A} 2\}$ & $\{112 \mathrm{~B} 2\}$ & $\{112 \mathrm{C} 2\}$ \\
\hline 3. Delivery services & $\{112 \mathrm{~A} 3\}$ & $\{112 \mathrm{~B} 3\}$ & $\{112 \mathrm{C} 3\}$ \\
\hline 4. HIV/AIDS & $\{112 \mathrm{~A} 4\}$ & $\{112 \mathrm{~B} 4\}$ & $\{112 \mathrm{C} 4\}$ \\
\hline 5. Other STDs & $\{112 \mathrm{~A} 5\}$ & $\{112 \mathrm{~B} 5\}$ & $\{112 \mathrm{C} 5\}$ \\
\hline 6. Child welfare & $\{112 \mathrm{~A} 6\}$ & $\{112 \mathrm{~B} 6\}$ & $\{112 \mathrm{C} 6\}$ \\
\hline 7. Nutrition & $\{112 \mathrm{~A} 7\}$ & $\{112 \mathrm{~B} 7\}$ & $\{112 \mathrm{C} 7\}$ \\
\hline
\end{tabular}

OBS/ASK 13. Was a "health talk" (group lecture or discussion with clients) held today? \{113\}

$$
\begin{aligned}
& 1=\text { Yes } \\
& 2=\text { No (to q.15) } \\
& 98=\text { Don't know (to q.15) }
\end{aligned}
$$

OBS/ASK 14. (If yes) Which topics did the health talk include?

\begin{tabular}{|l|l|}
\hline 1. Family planning & $\{114 \times 1\}$ \\
\hline 2. Antenatal care & $\{114 \times 2\}$ \\
\hline 3. Maternity care/ delivery services & $\{114 \times 3\}$ \\
\hline 4. Postnatal care & $\{114 \times 4\}$ \\
\hline 5. HIV/AIDS & $\{114 \times 5\}$ \\
\hline 6. Other STDs & $\{114 \times 6\}$ \\
\hline 7. Child immunization & $\{114 \times 7\}$ \\
\hline 8. Child growth monitoring & $\{114 \times 8\}$ \\
\hline 9. Infertility consultation & $\{114 \times 9\}$ \\
\hline 10. Oral rehydration therapy & $\{114 \times 10\}$ \\
\hline 11. Treatment of incomplete abortion & $\{114 \times 11\}$ \\
\hline 12. Nutrition counselling & $\{114 \times 12\}$ \\
\hline 13. Curative services - client & $\{114 \times 13\}$ \\
\hline 14. Curative services - child & $\{114 \times 14\}$ \\
\hline 15. Breastfeeding & $\{114 \times 15\}$ \\
\hline 16. Other: & $\{114 \times 16\}$ \\
\hline
\end{tabular}




\section{Medical examination facilities}

\begin{tabular}{|c|c|}
\hline $\begin{array}{l}\text { OBS } 15 . \text { Are the following conditions present in } \\
\text { the examination area? }\end{array}$ & Tick if present \\
\hline 1. Auditory privacy & $\{115 \times 1\}$ \\
\hline 2. Visual privacy & $\{115 \times 2\}$ \\
\hline 3. Cleanliness* & $\{115 \times 3\}$ \\
\hline 4. Adequate light $* *$ & $\{115 \times 4\}$ \\
\hline 5. Adequate water*** & $\{115 \times 5\}$ \\
\hline
\end{tabular}

* "Cleanliness" means floors swept and mopped at the start of the day, no dust on window sills or tables.

* * "Adequate light" means functioning electric light or sufficient natural light.

*** "Adequate water" means a sufficient quantity of clean water for washing hands and equipment. 


\section{Equipment and commodities inventory}

OBS 16. Tick if the following types of equipment are available Tick if available and working in the $\mathrm{MCH} / \mathrm{FP}$ unit, and/or in the stockroom for $\mathrm{MCH} / \mathrm{FP}$ services.

\begin{tabular}{|l|l|}
\hline 1. Sterilizing equipment in MCH/FP unit & $\{116 \times 1\}$ \\
\hline 2. Sterilizing equipment outside MCH/FP unit (shared) & $\{116 \times 2\}$ \\
\hline 3. Angle poise/gynecology lamps/torch & $\{116 \times 3\}$ \\
\hline 4. Blood pressure machines & $\{116 \times 4\}$ \\
\hline 5. Adult weighing scale & $\{116 \times 5\}$ \\
\hline 6. Child weighing scales & $\{116 \times 6\}$ \\
\hline 7. Scissors & $\{116 \times 7\}$ \\
\hline 8. Antiseptic lotions & $\{116 \times 8\}$ \\
\hline 9. Stethoscopes & $\{116 \times 9\}$ \\
\hline 10. Refrigerator for EPI (immunization) & $\{116 \times 10\}$ \\
\hline 11. Examination couch & $\{116 \times 11\}$ \\
\hline 12. Thermometer & $\{116 \times 12\}$ \\
\hline 13. Needles & $\{116 \times 13\}$ \\
\hline 14. Syringes & $\{116 \times 14\}$ \\
\hline 15. Microscope & $\{116 \times 15\}$ \\
\hline 16. Cotton wool & $\{116 \times 16\}$ \\
\hline 17. Gauze & $\{116 \times 17\}$ \\
\hline 18. Dettol & $\{116 \times 18\}$ \\
\hline
\end{tabular}

OBS 17. Count the number of the following types of equipment available and working in the $\mathrm{MCH} / \mathrm{FP}$ unit, and/or in the stockroom for MCH/FP services.

\begin{tabular}{|l|lr|}
\hline 1. Sponge holding forceps & Number: & $\{117 \times 1\}$ \\
\hline 2. Uterine sounds & Number: & $\{117 \times 2\}$ \\
\hline 3. Specula & Number: & $\{117 \times 3\}$ \\
\hline 4. Tenacula & Number: & $\{117 \times 4\}$ \\
\hline 5. Non-disposable gloves (number of pairs) & Number: & $\{117 \times 5\}$ \\
\hline 6. Disposable gloves (number of pairs) & Number: & $\{117 \times 6\}$ \\
\hline
\end{tabular}




\begin{tabular}{|c|c|c|c|c|c|c|}
\hline & ASK & $\begin{array}{l}\text { 18. Does the } \\
\text { MCH/FP unit } \\
\text { usually provide } \\
\text { each of the } \\
\text { following } \\
\text { contraceptive } \\
\text { methods? } \\
\text { (Read } 1-9 \text { and } \\
\text { tick if provided) }\end{array}$ & OBS & $\begin{array}{l}\text { 19. (If method is } \\
\text { usually provided) } \\
\text { Physically check } \\
\text { and tick if } \\
\text { commodities } \\
\text { available today. }\end{array}$ & ASK & $\begin{array}{l}\text { 20. (If method is } \\
\text { usually provided) } \\
\text { Has there been } \\
\text { any stock-out in } \\
\text { the last six } \\
\text { months? } \\
\text { (Tick if yes) }\end{array}$ \\
\hline 1. Combined pill & $\{\mid 18 \times 1\}$ & & $\{119 \times 1\}$ & & $\{120 \times 1\}$ & \\
\hline $\begin{array}{l}\text { 2. Progestin-only } \\
\text { pill }\end{array}$ & $\{118 \times 2\}$ & & $\{119 \times 2\}$ & & $\{120 \times 2\}$ & \\
\hline 3. IUD & $\{118 \times 3\}$ & & $\{\mid 19 \times 3\}$ & & $\{120 \times 3\}$ & \\
\hline 4. Injectable & $\{118 \times 4\}$ & & $\{119 \times 4\}$ & & $\{120 \times 4\}$ & \\
\hline 5. NORPLANT ${ }^{\circledR}$ & $\{118 \times 5\}$ & & $\{119 \times 5\}$ & & $\{120 \times 5\}$ & \\
\hline 6. Condom & $\{118 \times 6\}$ & & $\{119 \times 6\}$ & & $\{120 \times 6\}$ & \\
\hline 7. Diaphragm & $\{118 \times 7\}$ & & $\{119 \times 7\}$ & & $\{120 \times 7\}$ & \\
\hline 8. Spermicide & $\{118 \times 8\}$ & & $\{119 \times 8\}$ & & $\{120 \times 8\}$ & \\
\hline 9. Other: $\{118 \times 9 R\}$ & $\{118 \times 9\}$ & & $\{119 \times 9\}$ & & $\{120 \times 9\}$ & \\
\hline
\end{tabular}

ASK 21. Does the health facility (including the $\mathrm{MCH} / \mathrm{FP}$ unit) usually provide the following services or counselling? (Read 1-6)

\begin{tabular}{|l|l|}
\hline 1. Female sterilization (ML/LA) & $\{121 \times 1\}$ \\
\hline 2. Vasectomy & $\{121 \times 2\}$ \\
\hline 3. Natural family planning counselling & $\{121 \times 3\}$ \\
\hline 4. Exclusive breastfeeding counselling (LAM) & $\{121 \times 4\}$ \\
\hline 5. Dual methods counselling & $\{121 \times 5\}$ \\
\hline 6. Emergency contraception & $\{121 \times 6\}$ \\
\hline
\end{tabular}




\section{Screening and diagnostic facilities}

ASK 22. Is any laboratory testing for STDs, HIV, or pregnancy offered at this SDP? \{122\}

$$
\begin{aligned}
& 1=\text { Yes } \\
& 2=\text { No (to q. 24) }
\end{aligned}
$$

ASK 23. Is there a test for (read 1-7) available at this $\mathrm{MCH} / \mathrm{FP}$ unit or at this health facility, or are clients' specimens, or the clients themselves, sent elsewhere?

\begin{tabular}{|l|l|l|}
\hline 1. Syphilis & & \\
\hline 2. Gonorrhea & $\{123 \mathrm{~A} 1\}$ & $\{123 \mathrm{~B} 1\}$ \\
\hline 3. Chlamydia & $\{123 \mathrm{~A} 2\}$ & $\{123 \mathrm{~B} 2\}$ \\
\hline 4. HIV & $\{123 \mathrm{~A} 3\}$ & $\{123 \mathrm{~B} 3\}$ \\
\hline 5. Candida & $\{123 \mathrm{~A} 4\}$ & $\{123 \mathrm{~B} 4\}$ \\
\hline 6. Cervical cancer (pap smear) & $\{123 \mathrm{~A} 5\}$ & $\{123 \mathrm{~B} 5\}$ \\
\hline 7. Pregnancy & $\{123 \mathrm{~A} 6\}$ & $\{123 \mathrm{~B} 6\}$ \\
\hline
\end{tabular}

\begin{tabular}{|c|c|c|c|}
\hline & $\begin{array}{l}\text { ASK } 24 \text {. Does this health facility } \\
\text { usually provide the following } \\
\text { immunization services? (Read 1- } \\
6 \text { and tick if provided) }\end{array}$ & ASK & $\begin{array}{l}\text { 25. (If immunization provided) } \\
\text { Has the drug for the } \\
\text { immunization ever been out of } \\
\text { stock at this health facility in } \\
\text { the last } 6 \text { months? } \\
\text { (Tick if yes) }\end{array}$ \\
\hline 1. $\mathrm{BCG}$ & $\{124 \times 1\}$ & $\{125 \times 1\}$ & \\
\hline 2. Polio & $\{124 \times 2\}$ & $\{125 \times 2\}$ & \\
\hline 3. DPT & $\{124 \times 3\}$ & $\{125 \times 3\}$ & \\
\hline 4. Measles & $\{124 \times 4\}$ & $\{125 \times 4\}$ & \\
\hline 5. Hepatitis B & $\{124 \times 5\}$ & $\{125 \times 5\}$ & \\
\hline $\begin{array}{l}\text { 6. Tetanus for } \\
\text { ANC clients }\end{array}$ & $\{124 \times 6\}$ & $\{125 \times 6\}$ & \\
\hline
\end{tabular}

\section{Immunization services}




\section{Commodity management}

\begin{tabular}{|c|c|c|c|}
\hline & $\begin{array}{ll}\text { ASK } & 26 . \text { Is there a written } \\
\text { inventory for the following } \\
\text { commodities and supplies? } \\
\text { (Read } 1-4 \text { and tick if yes) }\end{array}$ & OBS & $\begin{array}{l}\text { 27. (If there is an inventory) } \\
\text { Is it up-to-date, legible, and } \\
\text { complete? } \\
\text { (Tick if yes) }\end{array}$ \\
\hline 1. FP contraceptives & $\{126 \times 1\}$ & $\{127 \times 1\}$ & \\
\hline $\begin{array}{l}\text { 2. Drugs for STD } \\
\text { treatment }\end{array}$ & $\{126 \times 2\}$ & $\{127 \times 2\}$ & \\
\hline 3. Vaccines & $\{126 \times 3\}$ & $\{127 \times 3\}$ & \\
\hline 4. Other medicines & $\{126 \times 4\}$ & $\{127 \times 4\}$ & \\
\hline
\end{tabular}

\begin{tabular}{|c|c|c|c|c|}
\hline & ASK & $\begin{array}{l}\text { 28. Are the following } \\
\text { commodities stored by } \\
\text { expiry date? In other words, } \\
\text { is there a system of "first } \\
\text { expiry first out?" } \\
\text { (Read } 1-4 \text { and tick if yes) }\end{array}$ & OBS & $\begin{array}{l}\text { 29. For each commodity, } \\
\text { are the storage facilities } \\
\text { protected from rain, sun, } \\
\text { adverse temperatures, rats, } \\
\text { and pests? } \\
\text { (Read } \mathbf{1 - 4} \text { and tick if yes) }\end{array}$ \\
\hline 1. FP contraceptives & $\{128 \times 1$ & & $\{129 \times 1\}$ & \\
\hline $\begin{array}{l}\text { 2. Drugs for STD } \\
\text { treatment }\end{array}$ & $\{128 \times 2$ & & $\{129 \times 2\}$ & \\
\hline 3. Vaccines & $\{128 \times 3$ & & $\{129 \times 3\}$ & \\
\hline 4. Other medicines & $\{128 \times 4$ & & $\{129 \times 4\}$ & \\
\hline
\end{tabular}




\section{Record-keeping and reporting}

ASK 30. How are the clients' record cards maintained at this facility? \{130\}

$$
\begin{aligned}
& 1=\text { Kept in clinic } \\
& 2=\text { Kept by client (to q.32) } \\
& 3=\text { No cards (to q.32) } \\
& 4=\text { Other: }
\end{aligned}
$$

OBS 31 . In what condition is the record-card system? \{131\}

$$
\begin{aligned}
& 1=\text { Well ordered } \\
& 2=\text { Partially ordered, still usable } \\
& 3=\text { Disordered, not usable }
\end{aligned}
$$

ASK 32. Is there a common daily activity register for all the MCH-FP services provided by this health facility? \{132\}

$1=$ Yes for all services

2 = Yes for some of the services

3 = Separate register for each of the services

$4=$ No daily activity register for any of the services

ASK 33. Are service statistics reports for the following services sent to a supervisor or higher unit? (Read 1-3)

Tick if reports sent

\begin{tabular}{|l|l|}
\hline 1. $\mathrm{MCH}$ & \multicolumn{1}{|c|}{ reports sent } \\
\hline 2. FP & $\{133 \times 1\}$ \\
\hline 3. STD/HIV/AIDS & $\{133 \times 2\}$ \\
\hline
\end{tabular}




\section{Management and supervision}

ASK 34. How many times in the last six months has a supervisor come to this MCH/FP unit for supervisory purposes? \{134\}

times

ASK 35. When visiting this facility, what does the supervisor do?

(Do not read, but probe by asking, "Any other actions?")

\begin{tabular}{|l|l|}
\hline 1. Observe delivery of different services & $\{135 \times 1\}$ \\
\hline 2. Observe only service he/she is responsible for & $\{135 \times 2\}$ \\
\hline 3. Inquire about service problems & $\{135 \times 3\}$ \\
\hline 4. Examine the records & $\{135 \times 4\}$ \\
\hline 5. Make suggestions for improvements & $\{135 \times 5\}$ \\
\hline 6. Offer praise for good work & $\{135 \times 6\}$ \\
\hline 7. Other: \{135X7R\} & $\{135 \times 7\}$ \\
\hline
\end{tabular}

\section{Service statistics}

Compile statistics for the number of clients served in a continuous period of 12 months in any of the last 24 months. In those cases where a continuous 12 -month period is not available, use the longest continuous period for which there are statistics, and record the number of months in column $C$.

OBS 36. How many clients received the following services in the past 12 months? (99999 = no data available)

\begin{tabular}{|c|c|c|c|}
\hline (Y999y = no data avallab & & & records \\
\hline 1. Family planning & $\{\mid 36 A 1\}$ & $\{\mid 36 \mathrm{~B} 1\}$ & $\{136 \mathrm{C} 1\}$ \\
\hline 2. Antenatal services & $\{136 \mathrm{~A} 2\}$ & $\{136 \mathrm{~B} 2\}$ & $\{136 \mathrm{C} 2\}$ \\
\hline 3. Delivery services & $\{\mid 36 A 3\}$ & $\{136 \mathrm{~B} 3\}$ & $\{136 \mathrm{C} 3\}$ \\
\hline 4. Postnatal services & $\{136 \mathrm{~A} 4\}$ & $\{136 \mathrm{~B} 4\}$ & $\{136 \mathrm{C} 4\}$ \\
\hline 5. HIV/AIDS services & $\{136 A 5\}$ & $\{136 \mathrm{~B} 5\}$ & $\{136 \mathrm{C} 5\}$ \\
\hline 6. STD services & $\{136 A 6\}$ & $\{136 \mathrm{~B} 6\}$ & $\{136 \mathrm{C} 6\}$ \\
\hline 7. Child welfare & $\{\mid 36 A 7\}$ & $\{13687\}$ & $\{\mid 36 \mathrm{C} 7\}$ \\
\hline
\end{tabular}

OBS 37. Indicate the calendar month and year of the most recent month reported in the table above. month $\{137 \times 1\}$ year $\{137 \times 2\}$ 
ASK 38. What is the client charged for obtaining A. Consultation fee B. Commodity/ each method or service? (Read 1 - 26)

\begin{tabular}{|c|c|c|}
\hline 1. Combined pill & $\{138 \mathrm{~A} 1\}$ & $\{138 \mathrm{~B} 1\}$ \\
\hline 2. Progestin-only pill & $\{138 A 2\}$ & $\{138 \mathrm{~B} 2\}$ \\
\hline 3. IUD & $\{138 \mathrm{~A} 3\}$ & $\{138 \mathrm{~B} 3\}$ \\
\hline 4. Injectable & $\{138 A 4\}$ & $\{138 B 4\}$ \\
\hline 5. NORPLANT ${ }^{\circledR}$ & $\{138 A 5\}$ & $\{138 \mathrm{~B} 5\}$ \\
\hline 6. Condom & $\{138 A 6\}$ & $\{138 \mathrm{~B} 6\}$ \\
\hline 7. Diaphragm & $\{138 A 7\}$ & $\{138 \mathrm{~B} 7\}$ \\
\hline 8. Spermicide & $\{138 A 8\}$ & $\{138 \mathrm{~B} 8\}$ \\
\hline 9. Female sterilization (ML/LA) & $\{138 A 9\}$ & $\{13889\}$ \\
\hline 10. Vasectomy & $\{\mid 38 A 10\}$ & $\{138 \mathrm{~B} 10\}$ \\
\hline 11. NFP counselling & $\{\mid 38 A 11\}$ & $\{138 \mathrm{~B} 11\}$ \\
\hline 12. LAM counselling & $\{\mid 38 A 12\}$ & $\{138 \mathrm{~B} 12\}$ \\
\hline 13. Antenatal care & $\{|38 A| 3\}$ & $\{138 B 13\}$ \\
\hline $\begin{array}{l}\text { 14. Maternity care / } \\
\text { delivery services }\end{array}$ & $\{\mid 38 A 14\}$ & $\{138 B 14\}$ \\
\hline 15. Postnatal care & $\{138 \mathrm{~A} 15\}$ & $\{\mid 38 B 15\}$ \\
\hline 16. HIV/AIDS counselling / IEC & $\{138 A 16\}$ & $\{\mid 38 B 16\}$ \\
\hline 17. HIV/AIDS testing & $\{\mid 38 \mathrm{~A} 17\}$ & $\{\mid 38 \mathrm{~B} 17\}$ \\
\hline 18. Other STD counselling / IEC & $\{\mid 38 \mathrm{~A} 18\}$ & $\{138 \mathrm{~B} 18\}$ \\
\hline 19. Other STD diagnosis & $\{\mid 38 A 19\}$ & $\{138 \mathrm{~B} 19\}$ \\
\hline 20. Other STD treatment & $\{138 \mathrm{~A} 20\}$ & $\{138 B 20\}$ \\
\hline 21. Child immunization & $\{138 \mathrm{~A} 21\}$ & $\{138 \mathrm{~B} 21\}$ \\
\hline 22. Child growth monitoring & $\{138 \mathrm{~A} 22\}$ & $\{138 \mathrm{~B} 22\}$ \\
\hline 23. Infertility consultation & $\{138 \mathrm{~A} 23\}$ & $\{138 \mathrm{~B} 23\}$ \\
\hline 24. Oral rehydration therapy & $\{138 \mathrm{~A} 24\}$ & $\{138 \mathrm{~B} 24\}$ \\
\hline $\begin{array}{l}\text { 25. Treatment of incomplete } \\
\text { abortion }\end{array}$ & $\{138 A 25\}$ & $\{138 \mathrm{~B} 25\}$ \\
\hline 26. Nutrition counselling & $\{138 \mathrm{~A} 26\}$ & $\{138 \mathrm{~B} 26\}$ \\
\hline
\end{tabular}




\section{Inventory: question-by-question guide}

This instrument may take as long as the entire day for one person to fill out. It should be started soon after arrival. If the field researcher is not a nurse, $s /$ he will need the assistance of the nurse to inventory the equipment and supplies. The process of conducting the inventory requires making observations and asking questions of the staff in charge of FP services at the SDP. The abbreviations ASK or OBS on the left side of the item numbers instruct the field researcher whether to ask the question or to observe the situation to obtain the information sought. Note that since the staff in charge of FP services will be interviewed with the Staff Interview Instrument, it will be necessary for the various members of the field research team to coordinate times for each instrument and to be sensitive not to overwhelm the staff.

\section{Cover page}

Before you begin the inventory, complete all the information on the cover page (except the questionnaire number, which will be completed at the end of the data collection by your Team Leader). This page is similar to the cover page on all the other questionnaires. It is extremely important that the codes for health facility, district, and village/ town are correct. Ask your Team Leader if you are not sure. Ask the head of the SDP to identify for you the type of health facility, the type of sector, and the locality. If there is any confusion, ask your Team Leader.

Write (do not sign) your name in the box at the bottom of the page. When you have completed the inventory, your Team Leader will review it and sign below your name.
1. What is the official opening time for this health facility?

2. At what time did the first family planning client arrive today?

3. At what time was the first family planning client seen today?

These questions will determine if the SDP is actually open and providing services at the official opening time. Try to arrive at the SDP before it is officially time for it to open. Record the time that the first family planning client arrived, and at what time she began her consultation with a provider. Receiving a health talk does not count as being "seen" by a provider. When entering times, be sure to circle "am" or "pm."

\section{At what time was the last family planning client seen today?}

This question requires that you stay at the SDP until it stops offering services, to be sure that you have identified the last client of the day. If there was only one FP client, fill in the time that one client was seen in questions 3 and 4 .

\section{What is the official closing time for} this health facility?

Ask the staff in charge of FP services about the official closing time. This question, with question 4 , will show if services are offered during the stated hours.

6. How many days per week are family planning services offered at this health facility?

Ask the staff in charge of FP services the number of days per week FP services are offered. Parts of days count as full days. That is, if services are offered for 
two hours per day, three days a week, enter 3 . If services are offered for eight hours one day a week, enter 1.

\section{Is there a sign announcing that FP services are available?}

Signs help clients understand that they can receive FP services at the SDP. Look for a sign that says FP services are available at this facility. Sometimes the sign is outside near the road, and sometimes it is inside the SDP building. If there are several signs, code appropriately.

\section{Is (several services) usually avail-} able to clients at this MCH/FP unit or elsewhere in the health facility? These questions will help assess the range of services that are offered at the SDP. Ask the staff in charge of FP services whether each of the services is usually available, and at what part of the facility. "Usually available" means offered at least three days per week. If a service is available at both this $\mathrm{MCH} / \mathrm{FP}$ unit and elsewhere in the facility, tick both. If it is available only elsewhere in the facility, tick column $B$, even if there is no standard referral system.

\section{On the day of the visit, does the} MCH/FP unit have the following (basic infrastructure)?

The basic infrastructure of an SDP affects its ability to provide high quality services, as well as clients' satisfaction with services. Tick if the SDP has piped running water, electricity, working toilets, and sufficient seating for clients. Check the water: is it actually running? Sometimes there is a tap and pipes but no water. If there is no running water, do not tick this box. Turn on a light switch. If there is no electricity, do not tick this box, even if the staff tell you that it is a power cut on the day of the visit only. Check the toilets to see that they are actually in working order. If, based on your own judgment, they are dirty and unusable, do not tick this box.

10. How many (various staff types) are assigned to work full time at this MCH/FP section?

The staffing pattern at an SDP can indicate the level of services that could or should be provided there. Ask the staff in charge of FP services how many staff of each type work full time at this $\mathrm{MCH} /$ FP section. Do not include positions that are established but not currently filled. Include staff only if they provide FP services. Staff members provide FP services if they do one or more of the following things:

- counsel clients by giving them information about contraceptive methods or refer them to other SDPs for services;

- perform sterilizations;

- give injections or insert IUDs or NORPLANT ${ }^{\circledR}$;

- prescribe pills;

- give clients condoms, foam, or jelly.

11. How many (various staff types) are on duty today?

As a follow-up to the previous question, ask the number of those staff members identified in the first column who are on duty today. If a staff member is supposed to be on duty, but is out today due to illness or other problem, do not count her as "on duty." This information will assess the SDP's practical, daily ca- 
pacity to deliver services (as compared to the formal capacity measured by the previous question).

\section{Which IEC materials on the follow-} ing subjects are available in the MCH/FP unit?

IEC materials can be valuable aids to communication, and their presence enhances the quality of services. For each item in this question, it is important that you actually verify that a particular IEC material is present. To verify, you must actually see it. Look for posters on the walls or doors of the SDP. Ask the staff in charge of FP services if they have flipcharts, brochures, or pamphlets. Tick the appropriate box only if you actually see the materials. If the SDP only has a few brochures or pamphlets-not enough to distribute to clients-still tick them as available, since they can be used during client counseling.

\section{Was a "health talk" (group lecture or discussion with clients) held today? \\ 14. (If yes) Which topics did the "health talk" include?}

These questions assess whether clients have access to information on FP and RH outside of consultations with providers. Health talks are usually given at the very beginning of the day by a nurse/ midwife. In order to determine if a health talk was given, you must arrive at the SDP before it opens for business. If you did not actually see that a health talk was given because you arrived late, circle 98. If you actually heard the health talk, circle 1 , and tick the topics listed in question 14 that were included in the talk.
15. Are the following conditions present in the examination area?

The conditions of the examination room can dramatically affect the quality of care given as well as clients' satisfaction with the SDP. You will have to. use your judgment regarding auditory and visual privacy, cleanliness, and adequate light and water. Here are some guidelines:

- "auditory privacy" means that a conversation between a client and a nurse or doctor cannot be understood by other clients. The other clients might be able to see that a conversation is taking place but they cannot hear what is being said. If there are no clients on the day of the visit and you cannot judge the level of privacy, enter 98 in the box.

- "visual privacy" means that other clients cannot see the interaction between a client and a doctor or nurse. Usually this means that there is a separate examination room that is private or there is an area that has a curtain or other partition that prevents other clients from seeing what is happening. If there are no clients on the day of the visit and you cannot judge the level of privacy, enter 98 in the box.

- "clean" means that at the start of the day, fresh linen is used on beds and examination tables and fresh towels are provided. It also means that the floors are swept and mopped and there is no visible dust or dirt on the window sills or tables. If you arrived significantly after the start of services, and cannot judge if the linens were clean at the start of the day, enter 98 in the box.

- "adequate light" means a functioning electric light or sufficient natural light 
from a window that a nurse or doctor can do an adequate examination.

- "adequate water" means a sufficient quantity of clean water for washing hands and equipment. The source of the water might be from pipes or a well in the compound.

16. Tick if the following types of equipment are available and working in the MCH/FP unit, and/or in the stockroom for MCH/FP services.

17. Count the number of the following types of equipment available and working in the MCH/FP unit, and/or in the stockroom for MCH/ FP services.

This is one of the most important sections. Each item on the list has been identified as necessary for FP services, $\mathrm{RH}$ service, or infection prevention. The presence or absence of any item will greatly affect services. Verify the presence of each item by actually seeing and counting all the equipment in both the clinic and storeroom. If it is not possible to gain access to the storeroom, enter the number seen in the clinic and note this problem in the margin. It is extremely important to determine whether the equipment actually works. For example, if a flashlight (torch) is available but does not have batteries, then it should not be counted. If a sterilizer is available but is not used because it does not work, it should not be counted. If a piece of equipment is shared with other providers, it should still be counted.

\section{Does the MCH/FP unit usually pro- vide each of the following contra- ceptive methods?}

19. (If method is usually provided) Physically check and tick if commodities available today

20. (If method is usually provided) Has there been any stock-out in the last six months?

The purpose of these questions is to find out if the SDP provides a particular contraceptive method, and if so, how reliable its contraceptive stocks are. The stocks are particularly important because if there are no commodities, an SDP simply cannot offer a method, even if it is otherwise ready to do so.

Ask the staff in charge of FP services which methods are actually provided at the SDP. Tick the appropriate boxes under question 18. Then go to the stock room or cabinet and actually check the contraceptive supplies. Tick the box under question 19 if there is at least one unexpired unit of each type of commodity. Be sure to check the expiration date. If there is no expiration date, do not count the item. (It might seem strange to tick the box if there is only one cycle of pills, for example, but after much experimentation with the methodology, we have found that counting the number of commodities available at an SDP is extremely time consuming and does not actually produce much more informative data.) If it is not possible to gain access to the supplies, then write 98 in these boxes.

The information for question 20 can come from two sources. First, ask the staff in charge of FP services or the person in charge of logistics if any contraceptive methods have ever been out of stock in the last six months. Second, try to verify whether they have been out of stock by checking the records, if avail- 
able. If either the staff member or the records indicate a stock-out, tick the column under question 20. If there is some confusion, enter 98 in these boxes.

21. Does the health facility (including the MCH/FP unit) usually provide the following services or counseling?

Ask the staff in charge of FP services if each service or counseling is usually provided. "Usually provided" means at least three days per week.

\section{Is any laboratory testing for STDs, HIV,} or pregnancy offered at this SDP? Diagnostic services for STDs/HIV and pregnancy should be part of a comprehensive FP/RH service program. Ask the staff in charge of FP services whether the facility offers testing for STDs/HIV or pregnancy. If not, skip to question 24.

\section{Is there a test for (various STDs/} pregnancy) available at this MCH/FP unit or at this health facility, or are clients' specimens, or the clients themselves, sent elsewhere?

The purpose of this question is to discover if this sort of testing is available to clients who visit this SDP, whether or not the testing is performed on-site. Ask the staff in charge of FP services whether the tests are performed at this health facility, or if the clients are referred elsewhere, or if the specimens are sent off-site for testing. If the test is not offered at all, leave both columns blank.

\section{Does this health facility usually provide} the following immunization services? Immunization services are another important component of an integrated FP/
$\mathrm{MCH}$ program. Ask the staff in charge of FP services whether each immunization service is provided. "Usually provided" means at least three days per week.

25. (If immunization provided) Has the drug for the immunization ever been out of stock at this health facility in the last 6 months?

The information for this question can come from two sources. First, ask the staff in charge of FP services or the person in charge of logistics if any of the immunization drugs have ever been out of stock in the last six months. Second, try to verify whether they have been out of stock by checking the records, if available. If either the staff member or the records indicate a stock-out, tick the column under question 25 . If there is some confusion, enter 98 in these boxes.

26. Is there a written inventory for the following commodities and supplies?

27. (If there is an inventory) Is it up-todate, legible, and complete?

Ask the staff in charge of FP services or person in charge of logistics if there is a written inventory for the listed commodities. An "inventory" is a system to keep track of the number of commodities received and the number dispensed. If so, ask to see the inventory and check if it is up-to-date, legible, and complete. If you cannot gain access to the inventory, enter 9 in the column under question 27.

28. Are the following commodities stored by expiry date? In other words, is there a system of "first expiry first out?" A storage system based on expiration date protects clients from receiving ex- 
pired commodities and allows the SDP to avoid wastage. For each commodity, ask the staff in charge of FP services or person in charge of logistics if the commodities are stored by expiration date. Verify the answers by asking to see the system for recording expiration dates and stocking accordingly.

29. For each commodity, are the storage facilities protected from rain, sun, adverse temperatures, rats, and pests?

If commodities are exposed to these various threats, then their effectiveness and safety will be compromised. Ask to see where the commodities are stored and determine whether the storage is adequate, meaning no exposure to rain or sun, protected from rats and pests, and not subject to excessive heat. Note that for some vaccines, protection from adverse temperatures would involve refrigeration. Usually, commodities are stored in a separate room or in a steel or wood cabinet.

\section{How are the clients' record cards} maintained at this facility?

31. In what condition is the record-card system?

These questions address the issue of continuity of care. Well-kept client records allow providers to build on the care previously received and establish at least a partial medical history for each client. Ask the staff in charge of FP services about the client record card system: are the cards maintained at the SDP, or are they kept by clients? If they are kept at the SDP, ask to see the records. Use your judgment as whether the system is well-ordered, partially ordered but still usable, or not usable.

32. Is there a common daily activity register for all the MCH/FP services provided by this health facility?

Daily activity registers are useful for the SDP manager to monitor the client load and plan for services in the future. Ask if there is a daily activity register for all services. Verify the existing registers by asking to see them.

33. Are service statistics reports for the following services sent to a supervisor or higher unit?

It is important that service statistics are sent to a higher unit because this allows central monitoring and coordination of services, which can improve their quality. For each service, ask the staff in charge of FP services if monthly statistical reports of client load are sent to a supervisor or higher unit.

\section{How many times in the last six} months has a supervisor come to this MCH/FP unit for supervisory purposes?

People generally tend to perform better if they know that someone is interested and concerned about their work. Supervisory visits should serve this function and thereby improve the quality of services. Ask the staff in charge of FP services for the number of supervisory visits that were made in the last six months for the purpose of reviewing services. It is important that you deter- 
mine that the visits were made for supervisory purposes, not to provide services or any other function. If there is a supervisor's visit record book, ask to check it.

\section{When visiting this facility, what does the supervisor do?}

If there has been a supervisory visit in the last six months, ask the staff in charge of FP services about the supervisor's actions.

\section{How many clients received the following services in the past 12 months?}

\section{Indicate the calendar month and year of the most recent month re- ported in the table above.}

The purpose of these questions is to assess the client load, by service, at each SDP. This can help illustrate the connection between quality of services and service utilization.

Ask to see the SDP's service statistics records. For each service, check to see if the SDP has 12 consecutive months of service statistics in the last 24 months. You can use any 12 months in the last 24month period, as long as the 12 months are consecutive. If there are gaps and it is impossible to obtain 12 consecutive months, then take the most recent set of months for which statistics are available. In some cases, only two or three consecutive months may be possible.

In columns $\mathrm{A}$ and $\mathrm{B}$, record the total number of new clients and repeat clients for each service. If you have any problems reading the statistics, make a note in the margins. Code " 99999 " if the statistics are not available. Enter the number of months you are using ( 1 to 12) in column $C$.

Once the table is complete, enter in question 37 the calendar month and year of the most recent month used in the table. This gives an idea of the recency of the data.

38. What is the client charged for obtaining each method or service? (Consultation fee, commodity/test/ procedure)

The accessibility of a method or service is affected by its cost. By gathering information on client fees, we can better understand the financial barriers to service. Ask the staff in charge of FP services about the fees new clients pay for each method or service. Remember that these are fees that the client actually pays, not the cost to the SDP of providing a method or service. Ask for the fees charged to an average new client, not one who has complications with the method or service or an unusual medical history. Be sure to divide the fees into those for the consultation (column A) and for the commodity, test, or procedure (column B). If the method/service has fees for both a commodity and a procedure, such as IUD insertion, enter in column $\mathrm{B}$ the complete fee to the client for all commodities, tests, and procedures combined. For some methods/services, such as LAM counseling or nutrition counseling, there will be no fees for commodity/test/procedure. If the method or service is not offered at the SDP, leave both columns blank. 


\section{Observation guide}

This data collection instrument is designed to help you record what happens when a provider, such as a nurse/midwife or doctor, counsels and examines a family planning client. This observation is one of the most important parts of a Situation Analysis study. It is also probably the most difficult to complete and requires good listening and observing skills. Often when observing the interaction between the client and the provider you will have to make notes and then record the answer to some of the items later. You should try to become very familiar with the observation guide and even memorize parts of it so that you know what to look for when the client provider interaction takes place and you know where to record the information. The introductory section of the Observation: question-byquestion guide (page 59) as well as the section on "Tips for conducting a good observation" (page 24) present more information on how to complete this instrument.

The codes presented in brackets \{\} in this instrument are suggested variable names for each question or tick mark. These names are referred to in the analysis plan (beginning on page 162). Keep in mind, however, that they would not appear on the actual questionnaires used by researchers in the field. See following pages for instrument. 
INSTRUCTIONS TO OBSERVER: Obtain the consent of both client and provider before proceeding to observe the interaction between them. Make sure that the provider knows that you are not there to evaluate her/him and that you are not an "expert" who can be consulted during the session. When observing, be as discreet as possible: try to sit so that you are behind the client but not directly in view of the provider, and make notes quickly. For each question, circle the response that most appropriately represents your observation of what happened during the interaction. As discussed in the training, you may witness behavior that poses a serious risk to the client's health. Please keep in mind the guidelines for when to intervene in the consultation on behalf of the client's welfare.

Health facility visited (name):

\{HFNAME\}

Health facility code:

\{HFCODE\}

District (name):

\{DISTNAME\}

District code:

\{DISTCODE\}

Village/town (name):

\{TOWNNAME\}

Village/town code:

\{TOWNCODE\}

Study client number:

\{CLIID\}

Client's location/ward:

\{CLILOC\}

Study staff number:

\{STAFFID\}

Date of visit:

\{DATE\}

Day

Month

Year

Name of observer:

Signature of team leader: 
Type of health facility: \{TYPE\}

1 = Referral Hospital

2 = District Hospital

3 = Primary Hospital

$4=$ Rural Health Center

$5=$ Maternity

$6=$ Health Post

7 = Pharmacy

$8=\mathrm{CBD}$

$9=$ Other

Type of sector: \{SECT\}

$1=$ Government

$2=$ FPA

$3=$ Mission

4 = Private

$5=$ Other

Locality: $\{L O C\}$

$1=$ Rural

$2=$ Urban

Designation of staff member: \{DESIG\}

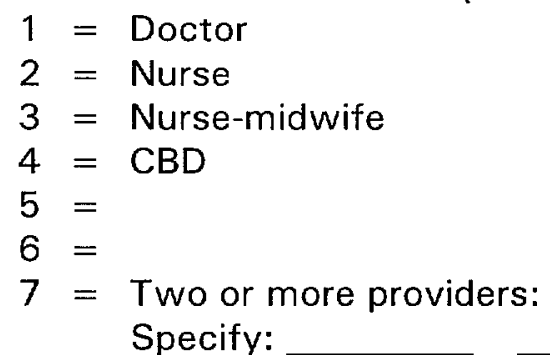
Specify: \{DESIG1\} \{DESIG2\}

\{DESIG3\}

Time observation began:

\{TIMEBEG\}

Main purpose of visit as first indicated by client: [PURPOSE\}
New clients: $\quad 1=$ New FP acceptor
$2=$ "Restart" FP acceptor
Revisit clients: $\quad 3$ = Resupply or repeat visit (without problems)
$4=$ Resupply or repeat visit (problem with method, wanted to change method, or wanted to discontinue FP) 


\begin{tabular}{|c|c|c|c|}
\hline & & & Revisit clients \\
\hline \multicolumn{4}{|c|}{ Greeting and Assessing the Client } \\
\hline 1. & \multicolumn{2}{|c|}{$\begin{array}{l}\text { Did the provider greet the client in a friendly } \\
\text { manner? }\{01\}\end{array}$} & $\begin{array}{l}1=\text { Yes } \\
2=\text { No }\end{array}$ \\
\hline 2. & $\begin{array}{l}\text { Did the provider ask about } \\
\text { or did the client spontaneously } \\
\text { mention any of these subjects? } \\
\text { (Circle all that apply.) }\end{array}$ & $\begin{array}{l}\{02 \times 1\} \\
\{02 \times 2\} \\
\{02 \times 3\} \\
\{02 \times 4\} \\
\{02 \times 5\} \\
\{02 \times 6\} \\
\{02 \times 7\} \\
\{02 \times 8\} \\
\{02 \times 9\} \\
\{02 \times 10\} \\
\{02 \times 11\} \\
\{02 \times 77\}\end{array}$ & $\begin{aligned} 1= & \text { Whether the client wanted more children in the } \\
& \text { future } \\
2= & \text { Age of youngest child } \\
3= & \text { Whether the client is breastfeeding } \\
& \text { (Tick if client breastfeeding during observation: } \\
4= & \text { Client's marital status } \\
5= & \text { If client has had more than one sexual partner in } \\
& \text { past year } \\
6= & \text { If client has any questions } \\
7= & \text { If client has concerns about her own health } \\
8= & \text { If client has concerns about using any method } \\
9= & \text { If client has any concerns about STDs or HIV/AIDS } \\
10= & \text { If client had previous symptoms/signs/treatment } \\
& \text { suggestive of STDs } \\
11= & \text { If client has discussed family planning } \\
& \text { with husband/partner } \\
77= & \text { None of these subjects }\end{aligned}$ \\
\hline 3. & $\begin{array}{l}\text { Did any provider ask about } \\
\text { or did the client spontaneously } \\
\text { mention any of these subjects? } \\
\text { (Circle all that apply.) }\end{array}$ & $\begin{array}{l}\{03 \times 1\} \\
\{03 \times 2\} \\
\{03 \times 3\} \\
\{03 \times 4\} \\
\{03 \times 5\} \\
\{03 \times 6\} \\
\{03 \times 77\}\end{array}$ & $\begin{array}{l}1=\text { Any medical/family history } \\
2=\text { Date of LMP } \\
3=\text { Abnormal vaginal bleeding } \\
4=\text { Abnormal vaginal discharge } \\
5=\text { Genital itching } \\
6=\text { Lower abdominal pain } \\
77=\text { None of these subjects }\end{array}$ \\
\hline 4. & $\begin{array}{l}\text { During the consultation, } \\
\text { did any provider take or perform } \\
\text { any of these actions? } \\
\text { (Circle all that apply.) }\end{array}$ & $\begin{array}{l}\{04 \times 1\} \\
\{04 \times 2\} \\
\{04 \times 3\} \\
\{04 \times 4\} \\
\{04 \times 5\} \\
\{04 \times 6\} \\
\{04 \times 7\} \\
\{04 \times 8\} \\
\{04 \times 77\} \\
\end{array}$ & $\begin{aligned} 1= & \text { Assess weight } \text { (check card) } \\
2= & \text { Take BP (check card) } \\
3= & \text { Perform/refer for pregnancy test } \\
4= & \text { Perform general physical exam } \\
5= & \text { Perform/request/refer for a blood test } \\
6= & \text { Perform a breast exam } \\
7= & \text { Perform/request/refer for a pap smear } \\
& \text { (see Medical Procedures Performed) } \\
8= & \text { Perform a syndromic analysis for STDs } \\
77= & \text { None of these actions }\end{aligned}$ \\
\hline
\end{tabular}




\section{Discussion of Family Planning}

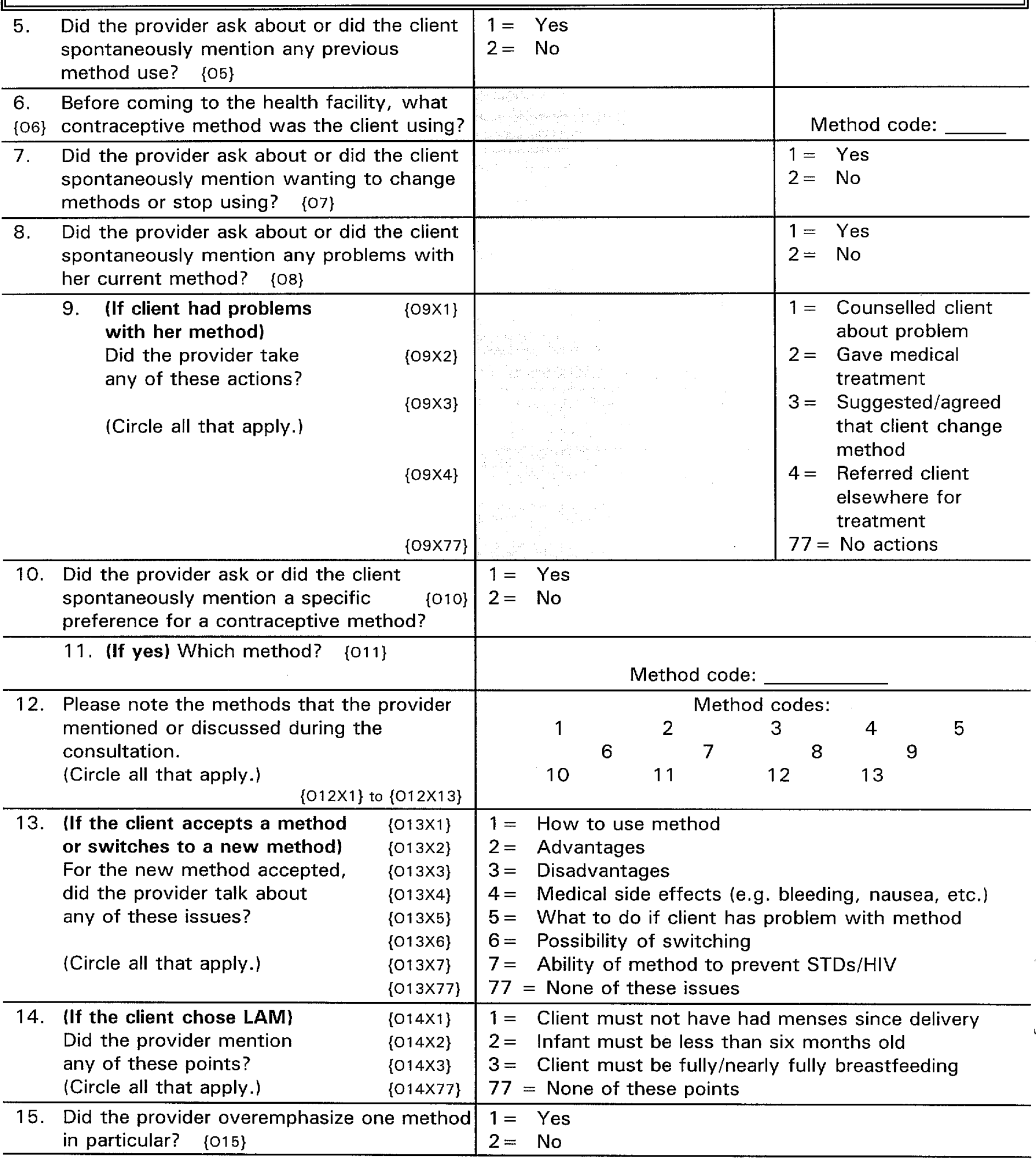




\begin{tabular}{|c|c|c|c|c|}
\hline & & & New clients & Revisit clients \\
\hline 16. & $\begin{array}{l}\text { Which IEC materials, if any, } \\
\text { were used during the } \\
\text { consultation? } \\
\text { (Circle all that apply.) }\end{array}$ & $\begin{array}{l}\{016 \times 1\} \\
\{016 \times 2\} \\
\{016 \times 3\} \\
\{016 \times 4\} \\
\{016 \times 5\} \\
\{016 \times 77\}\end{array}$ & $\begin{array}{l}1=\text { Flipchart } \\
2=\text { Brochure/pamphlets } \\
3=\text { Contraceptive samples } \\
4=\text { Posters } \\
5=\text { Other: } \\
77=\text { None }\end{array}$ & $\{016 \times 5 R\}$ \\
\hline \multicolumn{5}{|c|}{ Discussion of STDs and Other Health Issues } \\
\hline 17. & $\begin{array}{l}\text { During the consultation, did } \\
\text { explicitly mention that the co } \\
\text { against STDs/HIV/AIDS? }\end{array}$ & rovider & $\begin{array}{l}1=\text { Yes } \\
2=\text { No }\end{array}$ & \\
\hline 18. & $\begin{array}{l}\text { Did the provider indicate to th } \\
\text { she might have an STD? }\end{array}$ & ent that & $\begin{array}{l}1=\text { Yes } \\
2=\text { No }\end{array}$ & \\
\hline & $\begin{array}{l}\text { 19. (If yes) What did the } \\
\text { provider do? } \\
\text { (Circle all that apply.) }\end{array}$ & $\begin{array}{l}\{019 \times 1\} \\
\{019 \times 2\} \\
\{019 \times 3\} \\
\{019 \times 4\} \\
\{019 \times 5\} \\
\{019 \times 77\}\end{array}$ & $\begin{array}{l}1=\text { Request laboratory tests } \\
2=\text { Treat } \\
3=\text { Refer elsewhere } \\
4=\text { Provide counselling } \\
5=\text { Other: } \\
77=\text { No actions taken }\end{array}$ & $\{019 \times 5 R\}$ \\
\hline 20. & $\begin{array}{l}\text { What other health issues } \\
\text { were mentioned at any time } \\
\text { during the consultation? } \\
\text { (Circle all that apply.) }\end{array}$ & $\begin{array}{l}\{020 \times 1\} \\
\{020 \times 2\} \\
\{020 \times 3\} \\
\{020 \times 4\} \\
\{020 \times 5\} \\
\{020 \times 6\} \\
\{020 \times 7\} \\
\{020 \times 8\} \\
\{020 \times 9\} \\
\{020 \times 10\} \\
\{020 \times 11\} \\
\{020 \times 12\} \\
\{020 \times 13\} \\
\{020 \times 14\} \\
\{020 \times 15\} \\
\{020 \times 77\}\end{array}$ & $\begin{array}{l}1=\text { HIV/AIDS } \\
2=\text { Other STDs } \\
3=\text { Child immunization } \\
4=\text { Child growth monitoring } \\
5=\text { Infertility } \\
6=\text { Oral rehydration therapy } \\
7=\text { Abortion } \\
8=\text { Nutrition } \\
9=\text { Curative services }- \text { client } \\
10=\text { Curative services }- \text { child } \\
11=\text { Breastfeeding } \\
12=\text { Sexual relations } \\
13=\text { Social/economic factors } \\
14=\text { Pregnancy testing } \\
15=\text { Other: } \\
77=\text { None of these issues }\end{array}$ & . \\
\hline
\end{tabular}




\section{Family Planning Decision, Supply, and Follow-up}

21. Did the client decide to use a contraceptive method? \{021\}

22. (If not) What is the main reason client did not choose a method? \{022\}

(Circle one.)

(No more questions this section.)

\begin{tabular}{|c|c|c|}
\hline $\begin{array}{l}1= \\
2=\end{array}$ & $\begin{array}{l}\text { Yes } \\
\text { No }\end{array}$ & \\
\hline \multirow[t]{3}{*}{$\begin{array}{l}1= \\
2= \\
3= \\
4= \\
5= \\
6= \\
7= \\
8= \\
9=\end{array}$} & $\begin{array}{l}\text { Came for info only } \\
\text { Changed mind } \\
\text { Pregnancy suspected } \\
\text { Medical } \\
\text { Contraindications } \\
\text { Breastfeeding } \\
\text { Other health reasons } \\
\text { Method not available } \\
\text { No obvious reason } \\
\text { Other }\end{array}$ & \\
\hline & & $\begin{aligned} 1= & \text { Continue same } \\
& \text { method } \\
2= & \text { Stop } \\
3= & \text { Switch }\end{aligned}$ \\
\hline & & $\begin{aligned} 1= & \text { Wants pregnancy } \\
2= & \text { Unwanted } \\
& \text { side effects } \\
3= & \text { Inconvenient supply } \\
4= & \text { Husband } / \text { partner } \\
& \text { doesn't like method } \\
5= & \text { Switch spacing to } \\
& \text { permanent method } \\
6= & \text { Other } \\
8= & \text { Reason not clear }\end{aligned}$ \\
\hline
\end{tabular}

25. What new method did the client finally decide to use/switch to? \{025\}

Method code:

26. Was the method that the client decided to $1=$ Yes use the same method she initially preferred? $2=$ No (See q.10 and 11) $\{026\} \quad 3=$ No preference expressed

27. (If not) Why did the client decide not $1=$ Client changed her mind after hearing about methods to use the method she initially preferred? $\{027\}$

$2=$ Provider felt there were medical contraindications

$3=$ Provider felt method inappropriate due to age, marital status, etc.

(Circle one.)

$4=$ Pregnancy suspected

$5=$ Method out of stock

$6=$ Other:

$7=$ No obvious reason $\{027 R\}$

28. Was the method that the client decided to use supplied to the client today? \{028\}

29. (If not) Why was the client not supplied with her method today? \{029\}

$1=$ Yes

$2=$ No

$1=$ Referred to another place for method

$2=$ Client to return with menses

$3=$ Method out of stock

(Circle one.)

$4=$ Client to return for TL/IUD/NORPLANT ${ }^{\circledR}$ procedure

$5=$ Other: \{O29R\} 
30. (If not) Was an alternative method provided to the client to use while waiting to recieve her method of choice? \{030\}

31. (If yes) Which method was given for the interim? \{031\}

$$
1=\text { Yes }
$$

$2=$ No

\begin{tabular}{|c|c|c|}
\hline \multicolumn{2}{|r|}{$\begin{array}{l}\text { 31. (If yes) Which method was given } \\
\text { for the interim? }\{031\}\end{array}$} & Method code: \\
\hline 32. & $\begin{array}{l}\text { (If the client chose pills, condoms, } \\
\text { spermicides) How many units of the } \\
\text { method was the client given? }\{032\} \\
\text { (999 = Not known) }\end{array}$ & $\begin{array}{l}\text { Pill units }=\text { cycles, Condom units }=\text { pieces, } \\
\text { Spermicide units }=\text { tubes (describe if otherwise) }\end{array}$ \\
\hline 33. & $\begin{array}{l}\text { Was the client told when to return for } \\
\text { resupply or follow-up? }\{033\}\end{array}$ & $\begin{array}{l}1=\text { Yes } \\
2=\text { No }\end{array}$ \\
\hline & $\begin{array}{l}\text { 34. (If yes) Did the provider give a written } \\
\text { reminder to the client of when to } \\
\text { return? }\{034\}\end{array}$ & $\begin{array}{l}1=\text { Yes } \\
2=\text { No }\end{array}$ \\
\hline 35. & $\begin{array}{l}\text { Was the client told where to go for resupply } \\
\text { or follow-up? }\{035\}\end{array}$ & $\begin{array}{l}1=\text { Yes } \\
2=\text { No }\end{array}$ \\
\hline & $\begin{array}{l}\text { 36. (If yes) Where? } \\
\text { (Circle all that apply.) }\end{array}$ & $\begin{array}{l}1=\text { This health facility } \\
2=\text { Another health facility } \\
3=\text { Pharmacy / shop / chemist / private doctor } \\
4=\text { CBD/FWE } \\
5=\text { Other }\end{array}$ \\
\hline
\end{tabular}




\section{Medical Procedures Performed}

\begin{tabular}{|c|c|c|c|}
\hline 37. & $\begin{array}{l}\text { If a pelvic exam was performed, } \\
\text { did the provider: } \\
\text { (Circle all that apply.) }\end{array}$ & $\begin{array}{l}\{037 \times 1\} \\
\{037 \times 2\} \\
\{037 \times 3\} \\
\{037 \times 4\} \\
\{037 \times 5\} \\
\{037 \times 6\} \\
\{037 \times 7\} \\
\{037 \times 77\}\end{array}$ & $\begin{array}{l}1=\text { Inform the client what would happen before the } \\
\quad \text { exam? } \\
2=\text { Wash hands before the exam? } \\
3=\text { Visually inspect external genitalia? } \\
4=\text { Take a pap smear/specimen? } \\
5=\text { Perform a digital/bimanual examination? } \\
6=\text { Wash hands after the exam? } \\
7=\text { Inform the client about the result after the exam? } \\
77=\text { None of these actions }\end{array}$ \\
\hline 38. & $\begin{array}{l}\text { If a speculum examination } \\
\text { was performed, did the provider: } \\
\text { (Circle all that apply.) }\end{array}$ & $\begin{array}{l}\{038 \times 1\} \\
\{038 \times 2\} \\
\{038 \times 77\}\end{array}$ & $\begin{array}{l}1=\text { Use a clean speculum? } \\
2=\text { Use gloves? (see gloves question) } \\
77=\text { None of these actions }\end{array}$ \\
\hline 39. & $\begin{array}{l}\text { If an IUD was inserted, } \\
\text { did the provider: } \\
\text { (Circle all that apply.) }\end{array}$ & $\begin{array}{l}\{039 \times 1\} \\
\{039 \times 2\} \\
\{039 \times 3\} \\
\{039 \times 4\} \\
\{039 \times 77\}\end{array}$ & $\begin{array}{l}1=\text { Sound the uterus? } \\
2=\text { Handle the IUD with aseptic procedures? } \\
3=\text { Use gloves? (see gloves question) } \\
4=\text { Offer emotional support? } \\
77=\text { None of these actions }\end{array}$ \\
\hline 40. & $\begin{array}{l}\text { If an injectable was given, } \\
\text { did the provider: } \\
\text { (Circle all that apply.) }\end{array}$ & $\begin{array}{l}\{040 \times 1\} \\
\{040 \times 2\} \\
\{040 \times 3\} \\
\{040 \times 77\}\end{array}$ & $\begin{array}{l}1=\text { Disinfect injection site } \\
2=\text { Use a sterile needle? } \\
3=\text { Massage injection site? } \\
77=\text { None of these actions }\end{array}$ \\
\hline 41. & $\begin{array}{l}\text { If NORPLANT }{ }^{\circledR} \text { was inserted, } \\
\text { did the provider: } \\
\text { (Circle all that apply.) }\end{array}$ & $\begin{array}{l}\{041 \times 1\} \\
\{041 \times 2\} \\
\{041 \times 3\} \\
\{041 \times 4\} \\
\{041 \times 77\}\end{array}$ & $\begin{array}{l}1=\text { Wash client's arm with soap and water? } \\
2=\text { Use gloves? (see gloves question) } \\
3=\text { Apply an antiseptic solution to insertion site? } \\
4=\text { Place client's arm on a sterile cloth? } \\
77=\text { None of these actions }\end{array}$ \\
\hline 42 & $\begin{array}{l}\text { If gloves were used, }\{042\} \\
\text { were the gloves: } \\
\text { (Circle one.) }\end{array}$ & & $\begin{array}{l}1=\text { Sterile } \\
2=\text { Clean but not sterile } \\
3=\text { Not clean } \\
98=\text { Unable to determine level of cleanliness }\end{array}$ \\
\hline
\end{tabular}

Time observation finished: $\{$ TIMEEND $\}$

Duration of interaction: \{DUR

Staple an exit interview to this questionnaire, follow the client out of the consultation, introduce her, and give both questionnaires to the interviewer.

\begin{tabular}{|lll|}
\hline & Method codes: \\
1 & Combined pill (or unspecified) & 8 Spermicide \\
2 & Progestin-only pill & 9 Female sterilization (ML/LA) \\
3 & IUD & 10 Vasectomy \\
4 Injectable & 11 NFP \\
5 NORPLANT & 12 LAM \\
6 Condom & 13 Other \\
7 Diaphragm & \\
\hline
\end{tabular}




\section{Observation: question-by-question guide}

Take note of the instructions to observer on the first page of the instrument. All of the instructions are important. You should be able to fill out most of the material on the first two pages before the observation begins. If you are not sure about any of the identifying codes, ask your Team Leader. Write (do not sign) your name in the box at the bottom of the second page. When you have completed the observation, your Team Leader will review it and sign below your name.

Also near the bottom of the second page, you will find "Main purpose of visit as first indicated by client:" Please keep in mind that we have different expectations of a provider who is giving service to a "new client" and a "revisit client." Both of these types of clients may be classified further as is indicated by the codes. For new clients, stay alert to any questions or mention of whether the client has ever used a contraceptive before or not. If she has never used a FP method ever, she is a "new" FP acceptor. If she has used one or more methods in the past, but is not currently using a method, she is a "restart." If the client is currently using a method (just before this visit) then she is a "revisit client." Note that revisit clients can come for a variety of reasons. There is considerable overlap between "problem with method," "wanted to change method," and "wanted to discontinue FP," because all are generally associated with clients who are having problems. Thus we do not attempt to distinguish between these various clients.

As you proceed through the instrument, keep in mind that an observation is different from an interview in that we do not know the order that items of interest will arise in the interaction. There is no set sequence, as in the ordering of questions in an interview. You need to become familiar with all of the elements that you are expected to observe and their location on the data collection form, so you can quickly find an item and code it as the interaction unfolds.

Several general headings provide some organization of the questions and will help you quickly find the appropriate place to code an item of interest. The headings include: Greeting and Assessing the Client, which covers the medical and social information that the provider may wish to know in order to properly assess the client for family planning; Discussion of Family Planning, which includes specific information about FP methods, the client's history of FP practice, client preferences, etc.; Discussion of STDs and otber Health Issues, and Family Planning Decision, Supply, and Follow-up. During training and practice, you must become familiar with the location of each item of interest in the observation.

Note that this form has two columns on the righthand side-one for new clients and one for revisit clients. Most questions apply to both new and revisit clients, but some apply only to one type of client. When a question is only relevant to a new client, the revisit client column will be shaded out, and visa versa. When a question is relevant to both new and revisit clients, the separation between the columns disappears.

For several questions, instead of writing out individual family planning methods, you will be required to use a code for each method. A list of the codes for methods is on the last page of the observation (page 58). This list of codes is used wherever contraceptive methods are to be recorded in the observation, and with time it will probably 
become easier for you to use the codes than to write out individual methods.

After the observation is over, follow the client out of the room and politely ask if she is willing to be interviewed about her experience. If she agrees, then introduce her to the social science interviewer.

Reviewing the instrument at the conclusion of the observation is an extremely important step. Look over the entire instrument and consider whether each of the items of interest took place. You should be especially alert to code 77 , indicating that none of these subjects were discussed/observed. You will also need to skim down the "new" or "revisit" column on the right side of the page to check that the observation and recording are complete, and that you have always coded the material in the correct column.

The observation form is rather dense; a considerable amount of information is to be recorded on a few pages. The reason this instrument is dense, and uses certain "shortcuts" (method codes, and two columns for new and revisit clients) is to reduce the amount of paper that needs to be shuffled to find a particular item. A previous, and significantly longer, version of the observation led to some errors when observers could not quickly find the items they required.

Although we generally do not want to disturb the provider-client interaction, and doing so may invalidate the research objectives of the visit, remember the guidance provided in training on what to do if you witness provider behavior that poses a serious risk to the client's health. Please keep in mind the guidelines for when to intervene in the consultation on behalf of the client's welfare. (See the "Ethical issues" section for more information, page 17.)

\section{Greeting and Assessing the Client}

1. Did the provider greet the client in a friendly manner?

Refer to your training for a culturally appropriate definition. Remember to pay attention to tone of voice, facial expressions, gestures, eye contact, all of which may be used to decide whether the greeting was friendly or not.

\section{Did the provider ask about or did} the client spontaneously mention any of these subjects?

We are interested in whether the information is available to the provider. We do not distinguish whether the client spontaneously mentioned an item, or answered a question about an item. Note that the client might not mention breastfeeding, and would not normally be asked about whether she is breastfeeding, if she is breastfeeding during the service delivery. There is a special place to tick if the client is breastfeeding during service delivery. Remember these items can only be noted when they bappen or at the conclusion of the observation during your review.

\section{Did any provider ask about or} did the client spontaneously mention any of these subjects?

4. During the consultation, did any provider take or perform any of these actions?

We are interested in whether you observe any of these actions during the interaction. Question 3 deals with health issues discussed with the client, and question 4 addresses physical measure- 
ments taken from the client. Note the use of code 77 in both questions, indicating that none of these items were discussed or performed. This can only be coded in your final review, after the consultation is over.

It is possible that some of these actions - such as taking blood pressuremay have been taken at another place in the facility by another provider, who marked the client record with the information. If possible, check the client record for such actions in addition to making the observations of the specific provider client interaction you are observing.

\section{Discussion of Family Planning}

5. Did the provider ask about or did the client spontaneously mention any previous method use?

This information is sought for new clients only.

\section{Before coming to the health} facility, what contraceptive method was the client using?

Note the client would only be using a contraceptive method before coming to the facility if she is a revisit client. The answer space for "new clients" is shaded out. Use the method codes on page 58.

\section{Did the provider ask about or did} the client spontaneously mention wanting to change methods or stop using?

Note this implies the client was already using a method. Therefore this question should only be answered for revisit clients.
8. Did the provider ask about or did the client spontaneously mention any problems with her current method?

9. (If client had problems with her method) Did the provider take any of these actions?

These questions should only be answered for revisit clients. Note that question 9 is indented, and starts with "(If client had problems with her method)." Proceed to question 9 only if the answer to question 8 is "yes." Note the code 77 on question 9, to be used if the client had problems but the provider took no action.

10. Did the provider ask or did the client spontaneously mention a specific preference for a contraceptive method?

11. (If yes) Which method?

Research indicates that many clients have a contraceptive in mind when they come to the clinic and that clients tend to be happier, and continue using their method longer when they obtain the contraceptive they originally had in mind. Of course, the provider may discover medical contraindications or other reasons why the client may not obtain the method she had in mind, but we are interested in knowing if she had a preference in any case. We are particularly interested in this information prior to the delivery of education/counseling when method-specific information is provided.

Note the skip pattern-answer question 11 only if question 10 is "yes." Use the codes for methods on page 58. 
12. Please note the methods that the provider mentioned or discussed during the consultation.

Note that the methods do not have to be mentioned all at once. Whenever the provider mentions or discusses a method, code accordingly. Any mention of a method whatsoever receives full credit. Use the codes for methods on page 58.

13. (If the client accepts a method or switches to a new method) For the new method accepted, did the provider talk about any of these issues? This question records the content of information given to the client about the method she accepted. Clients who are given more information about their method, particularly concerning side effects, tend to continue contracepting longer. Note the 77 code if none of these issues were discussed.

\section{4. (If the client chose LAM) Did the provider mention any of these points?}

LAM stands for Lactational Amenorrhea Method. It is unlikely that the provider will use this term; be alert to a description of exclusive breastfeeding as a FP method and code accordingly. Use the 77 code only if the client chose LAM but the provider did not mention any of the important dimensions of LAM.

15. Did the provider overemphasize one method in particular?

Overemphasis can be indicated by various provider behaviors-only discussing one FP method, mentioning only the positive aspects of one method and only negative aspects of others, or being very enthusiastic about one method and unenthusiastic about others. We are looking for instances of providers demonstrating biases in favor of a particular method. A specific recommendation from the provider based on a medical condition or particular circumstances that come out in counseling may or may not be "overemphasis."

\section{Which IEC materials, if any, were} used during the consultation? Some providers use visual materials to help demonstrate the points they make. These materials may include posters, brochures, flip charts, or the contraceptive samples themselves. It is common, for example, for providers to hold a package of pills and show the client how to start taking them and in what order. Often, this use of IEC materials communicates information more effectively to clients than language alone.

The inventory instrument takes stock of the IEC materials that are available at each SDP. This information will be used in the data analysis to determine whether IEC materials were available to each provider. If the provider you are observing does not use IEC materials because there are none at the SDP, code this as a 77. The fact that the materials were not available to her will be discerned later.

\section{Discussion of STDs and Otber}

\section{Health Issues}

17. During the consultation, did the provider explicitly mention that the condom protects against STDs/HIV/ AIDS? 
Condoms are used both for FP and for prevention of diseases. We wish to know if the disease protection function of condoms was mentioned explicitly, even if the client is not using condoms currently, or is not accepting condoms as her method today.

18. Did the provider indicate to the client that she might have an STD?

19. (If yes) What did the provider do? The provider may indicate to the client that she might have an STD directly or indirectly. Be aware that she might not specifically mention the term "STD", but might use "vaginal infection" or some other term.

If the provider suspects an STD, question 19 determines what action, if any, the provider took for the client. If no actions were taken, circle 77 .

20. What other health issues were mentioned at any time during the consultation?

The purpose of this question is to measure the integration of services at the SDP.

Family Planning Decision, Supply, and Follow-up

21. Did the client decide to use a contraceptive method?

Note this question for new clients only, since revisit clients are already using a method. Revisit clients who are switching methods are addressed in question 23.

22. (If not) What is the main reason client did not choose a method?

If the new client decides not to use a method, then record her reason here.
Because the rest of this section deals with the supply of methods and followup arrangements, none of the questions apply to clients who stop using FP. If you have answered question 22, you need not answer any more questions in this section.

23. What decision did the client make about family planning?

24. (If stopping or switching) What is the main reason for stop or switch?

These questions are for revisit clients only. If the client is stopping or switching, try to decide on the main reason for that choice and code accordingly.

Because the rest of this section deals with the supply of methods and followup arrangements, none of the questions apply to clients who stop using FP. If you have answered question 24 as "stop," then you need not answer any more questions in this section.

25. What new method did the client finally decide to use/switch to?

This addresses the method that the client finally decided on, not to be confused with the method she preferred initially, the method she may have been using previously, or the method she may have been supplied with today as a temporary method. Use the method codes on page 58 .

26. Was the method that the client decided to use the same method she initially preferred?

27. (If not) Why did the client decide not to use the method she initially preferred? 
If a client has a preference for a method but does not receive it, she may be discouraged from using family planning. Check questions 10 and 11 to see if her final decision matches her preference.

28. Was the method that the client decided to use supplied to the client today?

29. (If not) Why was the client not supplied with her method today? In some cases, the client may decide to use a method, but not actually physically receive that method today. For this question, "supplied" means receiving pills or condoms/spermicides, getting an injection, having and IUD or NORPLANT ${ }^{\circledR}$ inserted, undergoing a tubal ligation, etc. If the client chose LAM or natural family planning, which do not require any supplies or procedures, circle "yes."

30. (If not) Was an alternative method provided to the client to use while waiting to receive her method of choice?

31. (If yes) Which method was given for the interim?

These questions should only be answered if the response to question 28 was "no." Use the method codes on page 58.

32. (If the client chose pills, condoms, or spermicides) How many units of the method was the client given? Note the description of the units used for each of these methods: pills = monthly cycles; condoms = number of individual condom pieces; and spermicides $=$ number of tubes of foam tablets, etc.
33. Was the client told when to return for resupply or follow-up?

34. (If yes) Did the provider give a written reminder to the client of when to return?

35. Was the client told where to go for resupply or follow-up?

36. (If yes) Where?

All of these follow-up and supply questions relate to the ability of the client to continue with her method once she has begun using it. Similar questions are asked of the client in the exit interview, so we can measure whether this information is being absorbed by clients.

\section{Medical Procedures Performed}

Take special note of which procedures were performed on clients, and answer only the relevant questions. If the client did not receive a procedure, do not circle any responses. If the client received a procedure but none of the listed actions were followed, circle 77. Please do not circle 77 to mean "procedure did not take place."

\section{7. (If a pelvic exam was performed)} Did the provider:

This is only for clients who received a pelvic examination. If the provider used a speculum, be sure to answer question 38 as well.

38. (If a speculum examination was performed) Did the provider:

This is only for clients with whom a speculum was used during her pelvic examination. A "clean speculum" is defined as either sterile or "high level clean" (disinfected but not necessarily sterilized). Sometimes it is difficult to tell whether the speculum is clean or not. 
Make your best estimate. If gloves were used, answer question 42.

39. (If an IUD was inserted) Did the provider:

This is only for clients who received an IUD. Recall your training regarding aseptic procedures and the definition of emotional support. If gloves were used, answer question 42 .

40. (If an injectable was given) Did the provider:

This is only for clients who were given an injectable contraceptive.

\section{1. (If NORPLANT ${ }^{\circledR}$ was inserted) Did} the provider:

This is only for clients who were given NORPLANT ${ }^{\circledR}$. If gloves were used, answer question 42 .
42. (If gloves were used) Were the gloves:

This is only for situations in which the provider used gloves during a part or all of the procedures. "Clean" means high level clean or a new pair of disposable gloves. "Sterile" means unwrapped from the autoclave. Make your best estimate, but if it is not clear, circle 98 .

\section{Time observation finished Duration of interaction}

Note the time the observation was finished, and check the time the observation began (on page 52) to find the duration of the interaction. 


\section{Family planning client exit interview}

This instrument gathers information from family planning clients about the services they have just received. This information is used in assessing the quality of care that clients receive from SDPs, which can be compared to the quality of care that is presented to clients. This tells us whether information is communicated effectively, how clients feel about the services, and how much clients understood the process of selecting a family planning method.
The codes presented in brackets \{\} in this instrument are suggested variable names for each question or tick mark. These names are referred to in the analysis plan (beginning on page 162). Keep in mind, however, that they would not appear on the actual questionnaires used by researchers in the field. See instrument on following pages. 


\section{Exit Interview for Family Planning Clients}

INSTRUCTIONS TO INTERVIEWER: Copy the information from the front of the observation guide to this page of the exit interview. Read the greeting on the next page to the client, and continue only if she gives her consent. For each item in the rest of the interview, circle the response or describe as appropriate.

Health facility visited (name):

\{HFNAME\}

Health facility code:

(HFCODE)

District (name):

\{DISTNAME\}

District code:

\{DISTCODE\}

Village/town (name):

\{TOWNNAME\}

Village/town code:

\{TOWNCODE\}

Study client number:

\{CLIID\}

Client's location/ward:

\{CLILOC\}

Study staff number:

\{STAFFID\}

Date of visit:

\{DATE\}

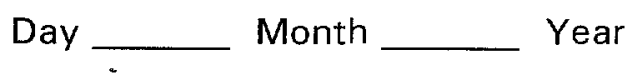

Name of observer:

Signature of team leader: 
Type of health facility: (TYPE)

1 = Referral Hospital

$2=$ District Hospital

3 = Primary Hospital

$4=$ Rural Health Center

$5=$ Maternity

$6=$ Health Post

7 = Pharmacy

$8=\mathrm{CBD}$

$9=$ Other

Type of sector: $\{$ SECT

1 = Government

$2=$ FPA

$3=$ Mission

4 = Private

$5=$ Other

Locality: \{LOC\}

$1=$ Rural

2 = Urban

Main purpose of visit as first indicated by client: (PURPOSE)

New clients:

$1=$ New FP acceptor

$2=$ "Restart" FP acceptor

Revisit clients: $\quad 3$ = Resupply or repeat visit (without problems)

$4=$ Resupply or repeat visit (problem with method, wanted to change method, or wanted to discontinue FP) 


\section{For all clients}

\section{Read greeting:}

Hello. We would like to improve the services provided by the facility and would be interested to find out about your experience today. I would like to ask you some questions about the visit you have just had with the (health facility staff) and would be very grateful if you could spend some time answering these questions. I will not write down your name, and everything you tell me will be kept strictly confidential. Also, you are not obliged to answer any question you don't want to, and you may withdraw from the interview at any time. May I continue?

(If the client agrees to continue, ask if she has any questions. Respond to questions as appropriate, then ask q.1.

If the client does not agree to continue, thank her and go to the next interview.)

1. Overall, would you say you were satisfied with your visit to the facility today, or were you dissatisfied with your visit today? $\{\mathrm{F} 1\}$

$$
\begin{aligned}
& 1=\text { Satisfied (to q.3) } \\
& 2=\text { Dissatisfied } \\
& 3=\text { Other: }
\end{aligned}
$$

2. Why were you dissatisfied with your visit today? $\{F 2\}$

3. In addition to family planning, did you receive any other health services from the service provider? \{F3\}

$$
\begin{aligned}
& 1=\text { Yes } \\
& 2=\text { No (to q.5) }
\end{aligned}
$$


4. Now I would like to ask you about all the other services you received today. Did you receive any of the following

Tick if received services? (Read 1 - 16)

\begin{tabular}{|l|l|}
\hline 1. Antenatal care & $\{\mathrm{F} 4 \times 1\}$ \\
\hline 2. Maternity care/ delivery services & $\{\mathrm{F} 4 \times 2\}$ \\
\hline 3. Postnatal care & $\{\mathrm{F} 4 \times 3\}$ \\
\hline 4. HIV/AIDS counselling & $\{\mathrm{F} 4 \times 4\}$ \\
\hline 5. HIV/AIDS testing & $\{\mathrm{F} 4 \times 5\}$ \\
\hline 6. Other STD counselling & $\{\mathrm{F} 4 \times 6\}$ \\
\hline 7. Other STD diagnosis & $\{\mathrm{F} 4 \times 7\}$ \\
\hline 8. Other STD treatment & $\{\mathrm{F} 4 \times 8\}$ \\
\hline 9. Child immunization & $\{\mathrm{F} 4 \times 9\}$ \\
\hline 10. Child growth monitoring & $\{\mathrm{F} 4 \times 10\}$ \\
\hline 11. Oral rehydration therapy & $\{\mathrm{F} 4 \times 11\}$ \\
\hline 12. Treatment of incomplete abortion & $\{\mathrm{F} 4 \times 12\}$ \\
\hline 13. Nutrition counselling & $\{\mathrm{F} 4 \times 13\}$ \\
\hline 14. Curative services - client & $\{\mathrm{F} 4 \times 14\}$ \\
\hline 15. Curative services - child & $\{\mathrm{F} 4 \times 15\}$ \\
\hline 16. Other: & $\{\mathrm{F} 4 \times 16\}$ \\
\hline
\end{tabular}

5. Do you feel that you received the information and services that you wanted today?

$$
\begin{aligned}
& 1=\text { Yes } \\
& 2=\text { No } \\
& 3=\text { Partially } \\
& 98=\text { Don't know }
\end{aligned}
$$

6. Do you feel that your FP consultation with the clinical staff was too short, too long, or about the right amount of time? $\{\mathrm{FG}\}$

$$
\begin{aligned}
& 1=\text { Too short } \\
& 2=\text { Too long } \\
& 3=\text { About right } \\
& 98=\text { Don't know }
\end{aligned}
$$

7. During this visit, did you have any concerns about family planning or other health issues that you wanted to discuss with the provider?

$$
\begin{aligned}
& 1=\text { Yes } \\
& 2=\text { No (to q.9) }
\end{aligned}
$$


8. (If yes) Did the provider listen to your concerns to your satisfaction?

$$
\begin{aligned}
& 1=\text { Yes } \\
& 2=\text { No }
\end{aligned}
$$

9. During this visit, did you have any questions you wanted to ask? $\quad$ F9\}

$$
\begin{aligned}
& 1=\text { Yes } \\
& 2=\text { No (to q.12) }
\end{aligned}
$$

10. (If yes) Did the provider let you ask the questions? $\{$ F10

$$
\begin{aligned}
& 1=\text { Yes } \\
& 2=\text { No (to q.12) }
\end{aligned}
$$

11. (If yes) Did the provider respond to your questions to your satisfaction? \{F11\}

$$
\begin{aligned}
& 1=\text { Yes } \\
& 2=\text { No }
\end{aligned}
$$

12. During this visit, did the provider conduct any health examinations or procedures?

$$
\begin{aligned}
& 1=\text { Yes } \\
& 2=\text { No (to q.15) }
\end{aligned}
$$

13. (If yes) Did the provider explain the examinations or procedures before they were performed? $\{F 13\}$

$$
\begin{aligned}
& 1=\text { Yes } \\
& 2=\text { No }
\end{aligned}
$$

14. Did the provider explain the results of the health examinations or procedures? \{F14\}

$$
\begin{aligned}
& 1=\text { Yes } \\
& 2=\text { No }
\end{aligned}
$$

15. In your opinion, did you have enough privacy during your consultation with the service provider? $\{\mathrm{F} 15\}$

$$
\begin{aligned}
& 1=\text { Yes } \\
& 2=\text { No }
\end{aligned}
$$

16. During the consultation, did you feel that the provider was easy to understand when explaining things to you, or did you feel that the provider was difficult to understand? $\{F 16\}$

$$
\begin{aligned}
& 1=\text { Easy to understand } \\
& 2=\text { Difficult to understand } \\
& 98=\text { Don't know }
\end{aligned}
$$

17. If you could suggest one improvement to the services provided, what would it be?

$\{\mathrm{F} 17\}$ 
18. During this visit, were you given or did you take any brochure or educational material to bring home? $\{F 18\}$

$$
\begin{aligned}
& 1=\text { Yes } \\
& 2=\text { No (to q.20) } \\
& 98=\text { Don't know (to q.20) }
\end{aligned}
$$

19. (If yes) What was the subject(s) of that material?

\begin{tabular}{|c|c|}
\hline 1. Family planning & $\{F 19 \times 1\}$ \\
\hline 2. Antenatal / Postnatal care & $\{F 19 \times 2\}$ \\
\hline 3. Delivery services & $\{F 19 \times 3\}$ \\
\hline 4. HIV/AIDS & $\{F 19 \times 4\}$ \\
\hline 5. Other STDs & $\{F 19 \times 5\}$ \\
\hline 6. Child welfare & $\{F 19 \times 6\}$ \\
\hline 7. Nutrition & $\{F 19 \times 7\}$ \\
\hline 8. Other: & $\{\mathrm{F} 19 \times 8\}$ \\
\hline 98. Don't know & $\{F 19 \times 98\}$ \\
\hline
\end{tabular}
(Do not read list, but probe by asking, "Any other subjects?")

Tick if mentioned

20. Did you attend a group talk(s) at the facility today? $\{$ F2O $\}$

$$
\begin{aligned}
& 1=\text { Yes } \\
& 2=\text { No (to q.22) } \\
& 98=\text { Don't know (to q.22) }
\end{aligned}
$$


21. (If yes) What topics were covered in the group talk(s)?

(Do not read list, but probe by asking, "Any other topics?" )

Tick if mentioned

\begin{tabular}{|l|l|}
\hline 1. Family planning & $\{\mathrm{F} 21 \times 1\}$ \\
\hline 2. Antenatal care & $\{\mathrm{F} 21 \times 2\}$ \\
\hline 3. Maternity care/ delivery services & $\{\mathrm{F} 21 \times 3\}$ \\
\hline 4. Postnatal care & $\{\mathrm{F} 21 \times 4\}$ \\
\hline 5. HIV/AIDS & $\{\mathrm{F} 21 \times 5\}$ \\
\hline 6. Other STDs & $\{\mathrm{F} 21 \times 6\}$ \\
\hline 7. Child immunization & $\{\mathrm{F} 21 \times 7\}$ \\
\hline 8. Child growth monitoring & $\{\mathrm{F} 21 \times 8\}$ \\
\hline 9. Infertility & $\{\mathrm{F} 21 \times 9\}$ \\
\hline 10. Oral rehydration therapy & $\{\mathrm{F} 21 \times 10\}$ \\
\hline 11. Treatment of incomplete abortion & $\{\mathrm{F} 21 \times 11\}$ \\
\hline 12. Nutrition counselling & $\{\mathrm{F} 21 \times 12\}$ \\
\hline 13. Curative services - clients & $\{\mathrm{F} 21 \times 13\}$ \\
\hline 14. Curative services - children & $\{\mathrm{F} 21 \times 14\}$ \\
\hline 15. Breastfeeding & $\{\mathrm{F} 21 \times 15\}$ \\
\hline 16. Other: & $\{\mathrm{F} 21 \times 16\}$ \\
\hline 98. Don't know & $\{\mathrm{F} 21 \times 98\}$ \\
\hline
\end{tabular}

22. Did any service provider tell you when to come back for another visit?

$\{F 22\}$

$$
\begin{aligned}
& 1=\text { Yes } \\
& 2=\text { No } \\
& 98=\text { Don't know }
\end{aligned}
$$

23. Are the hours this facility is open convenient for you? $\{F 23\}$

$$
\begin{aligned}
& 1=\text { Yes (to q.25) } \\
& 2=\text { No } \\
& 98=\text { Don't know (to q.25) }
\end{aligned}
$$

24. (If no) What time would be most convenient to you? (Circle one.) \{F24\}

$$
\begin{aligned}
& 1=\text { Earlier in morning } \\
& 2=\text { Over lunch hour } \\
& 3=\text { Afternoon } \\
& 4=\text { Evening / night } \\
& 5=\text { Weekends / holidays } \\
& 6=\text { Other: } \\
& 98=\text { Don't know }
\end{aligned}
$$


25. Have you ever been turned away from this facility during official working hours?

$$
\begin{aligned}
& 1=\text { Yes } \\
& 2=\text { No } \\
& 3=\text { No previous experience with facility } \\
& 98=\text { Don't know }
\end{aligned}
$$

26. About how long did you have to wait between the time you first arrived at this facility and the time you began receiving the services that you came for? \{F26\} minutes

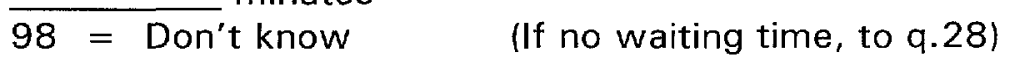

27. Do you feel that the wait between the time you first arrived at this facility and the time you began receiving the services you came for was reasonable or too long? \{F27\}

$$
\begin{aligned}
& 1=\text { Reasonable } \\
& 2=\text { Too long } \\
& 98=\text { Don't know }
\end{aligned}
$$

28. How long did it take you to come here today? \{F28\}

$$
\overline{98=\text { Don't know }}
$$

29. What was the main means of transport that you used to get here? (Circle one.) \{F29\}

$$
\begin{aligned}
& 1=\text { Walked } \\
& 2=\text { Donkey cart } \\
& 3=\text { Bus / combi } \\
& 4=\text { Bicycle } \\
& 5=\text { Private car } \\
& 6=\text { Other: }
\end{aligned}
$$


30. As far as you know, what types of services other than family planning are usually provided at this facility? (Do not read, but probe by asking, "Any other services?"।

\begin{tabular}{|l|l|}
\hline 1. Antenatal care & $\{\mathrm{F} 30 \times 1\}$ \\
\hline 2. Maternity care/delivery services & $\{\mathrm{F} 30 \times 2\}$ \\
\hline 3. Postnatal care & $\{\mathrm{F} 30 \times 3\}$ \\
\hline 4. HIV/AIDS counselling/IEC & $\{\mathrm{F} 30 \times 4\}$ \\
\hline 5. HIV/AIDS testing & $\{\mathrm{F} 30 \times 5\}$ \\
\hline 6. Other STD counselling/IEC & $\{\mathrm{F} 30 \times 6\}$ \\
\hline 7. Other STD diagnosis & $\{\mathrm{F} 30 \times 7\}$ \\
\hline 8. Other STD treatment & $\{\mathrm{F} 30 \times 8\}$ \\
\hline 9. Child immunization & $\{\mathrm{F} 30 \times 9\}$ \\
\hline 10. Child growth monitoring & $\{\mathrm{F} 30 \times 10\}$ \\
\hline 11. Infertility consultation & $\{\mathrm{F} 30 \times 11\}$ \\
\hline 12. Oral rehydration therapy & $\{\mathrm{F} 30 \times 12\}$ \\
\hline 13. Treatment of incomplete abortion & $\{\mathrm{F} 30 \times 13\}$ \\
\hline 14. Nutrition counselling & $\{\mathrm{F} 30 \times 17\}$ \\
\hline 15. Curative services - client & $\{\mathrm{F} 30 \times 98\}$ \\
\hline 16. Curative services - child & $\{\mathrm{F} 30 \times 15\}$ \\
\hline 17. Other: & $\{\mathrm{F} 30 \times 16\}$ \\
\hline 98. Don't know any services & OF 3$\}$ \\
\hline
\end{tabular}

31. Apart from this facility, is there any other place near your home where you can go for family planning? $\{F 31\}$

$$
\begin{aligned}
& 1=\text { Yes } \\
& 2=\text { No (to q.34) } \\
& 98=\text { Don't know (to q. 34) }
\end{aligned}
$$


32. (If yes) What type of facility is it? (Circle one. If more than one facility, choose closest to home.) $\{\mathrm{F} 32\}$

$$
\begin{aligned}
& 1=\text { CBD } \\
& 2=\text { Health post } \\
& 3=\text { Health center } \\
& 4=\text { Hospital } \\
& 5=\text { Other } \\
& 98=\text { Don't know }
\end{aligned}
$$

33. What would you say is the main reason you did not go there for family planning?

(Do not read list. Probe for the main reason and circle one.) \{F33\}

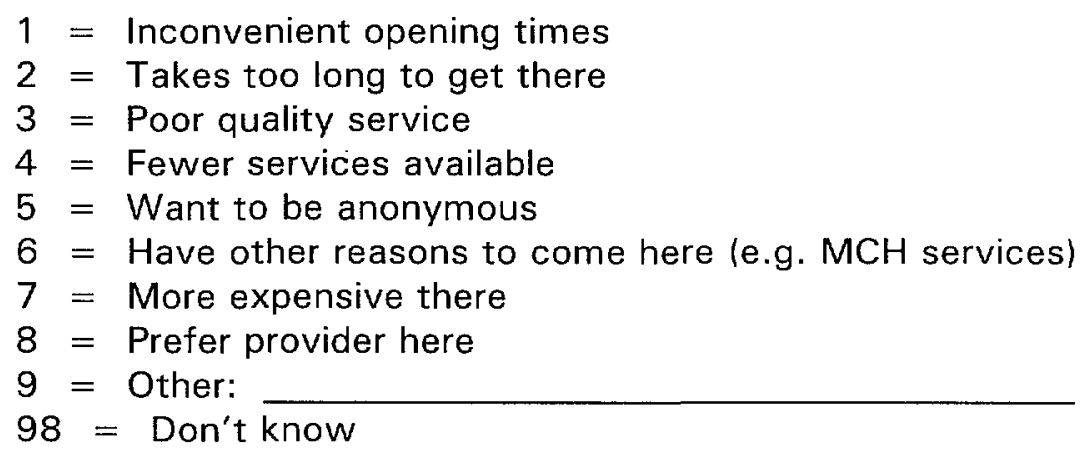

34. Now I would like to ask you about the cost of travel and services that you have recieved from this clinic. How much did you pay for your consultation? \{F34\}

$$
98=\text { Don't know }
$$

(local currency units)

35. How much did you pay for medicines? $\{$ F35 $\}$

$$
\frac{\text { (local currency units) }}{98=\text { Don't know }}
$$

36. How much did you pay for other items such as cotton, gloves, antiseptic, or syringes? \{F36\}

$$
\overline{98=\text { Don't know }}
$$

37. How much did you pay for registration card/membership? \{F37\}

$$
\overline{98}_{=\text {Don't know }} \text { (local currency units) }
$$

38. How much did you pay for travel? $\{F 38\}$

$$
\overline{98=\text { Don't know }} \text { (local currency units) }
$$

39. How much did you pay for any other services or fees? \{F39\}

$$
\overline{98}=\text { Don't know }^{\text {(local currency units) }}
$$


40. Overall, do you feel that the total cost of obtaining services is much too expensive, a little too expensive, or acceptable to you? \{F40\}

$$
\begin{aligned}
& 1=\text { Much too expensive } \\
& 2=\text { A little too expensive } \\
& 3=\text { Acceptable } \\
& 98=\text { Don't know }
\end{aligned}
$$

41. (See client's main purpose of visit on page 2, then read this question.)

I understand that your main purpose for coming to the health facility today was (insert purpose from page 2). Is this correct? \{F41\}

(If correct, circle the same response that appears on page 2, and skip to the question indicated. If not correct, ask for the correct purpose of the client's visit, circle the correct response below, and skip to the question indicated)

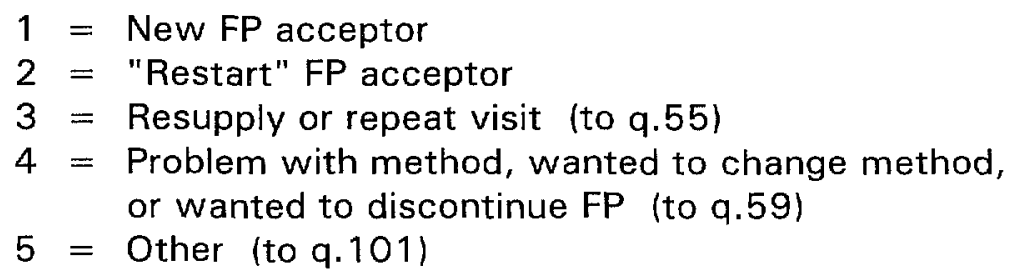




\section{For new acceptors}

42. Just to make sure, 1 understand that you were not using a contraceptive method when you came to the facility today. Is it correct that you were not using a method? \{F42\}

$$
\begin{aligned}
& 1=\text { Was not using } \\
& 2=\text { Was using (return to q.41) }
\end{aligned}
$$

43. Have you ever used any contraceptive method in the past? \{F43\}

$$
\begin{aligned}
& 1=\text { Yes } \\
& 2=\text { No (to q.45) }
\end{aligned}
$$

\begin{tabular}{|c|c|}
\hline 1. Combined pill (or unspecified) & $\{F 44 \times 1\}$ \\
\hline 2. Progestin-only pill & $\{F 44 \times 2\}$ \\
\hline 3. IUD & $\{\mathrm{F} 44 \times 3\}$ \\
\hline 4. Injectable & $\{F 44 X 4\}$ \\
\hline 5. NORPLANT ${ }^{\circledR}$ & $\{F 44 \times 5\}$ \\
\hline 6. Condom & $\{\mathrm{F} 44 \times 6\}$ \\
\hline 7. Diaphragm & $\{F 44 \times 7\}$ \\
\hline 8. Spermicide & $\{F 44 \times 8\}$ \\
\hline 9. Female sterilization (ML/LA) & $\{F 44 \times 9\}$ \\
\hline 10. Vasectomy & $\{F 44 \times 10\}$ \\
\hline 11. NFP & $\{F 44 \times 11\}$ \\
\hline 12. LAM & $\{F 44 \times 12\}$ \\
\hline 13. Other: & $\{F 44 \times 13\}$ \\
\hline 98. Don't know & $\{F 44 \times 98\}$ \\
\hline
\end{tabular}

44. (If yes) Which method(s) have you ever used?

(Do not read methods but probe by asking, "Have you ever used any other methods?")

45. Did you get a contraceptive method during this visit? $\{$ F45

$$
\begin{aligned}
& 1=\text { Yes (to q.47) } \\
& 2=\text { No }
\end{aligned}
$$


46. (If no) What is the main reason you did not obtain a contraceptive method today? (Circle one.) \{F46\}

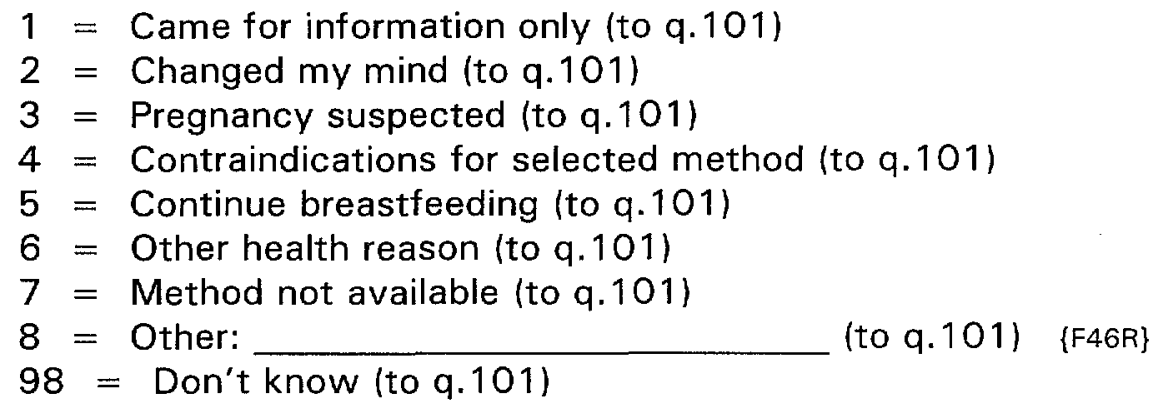

47. Which method(s) did you accept today?

(Do not read methods but probe by asking, "Did you accept any other methods?")

\begin{tabular}{|l|l|}
\hline 1. Combined pill (or unspecified) & $\{\mathrm{F} 47 \times 1\}$ \\
\hline 2. Progestin-only pill & $\{\mathrm{F} 47 \times 2\}$ \\
\hline 3. IUD & $\{\mathrm{F} 47 \times 3\}$ \\
\hline 4. Injectable & $\{\mathrm{F} 47 \times 4\}$ \\
\hline 5. NORPLANT ${ }^{\circledR}$ & $\{\mathrm{F} 47 \times 5\}$ \\
\hline 6. Condom & $\{\mathrm{F} 47 \times 6\}$ \\
\hline 7. Diaphragm & $\{\mathrm{F} 47 \times 7\}$ \\
\hline 8. Spermicide & $\{\mathrm{F} 47 \times 8\}$ \\
\hline 9. Female sterilization (ML/LA) & $\{\mathrm{F} 47 \times 9\}$ \\
\hline 10. Vasectomy & $\{\mathrm{F} 47 \times 10\}$ \\
\hline 11. NFP & $\{\mathrm{F} 47 \times 11\}$ \\
\hline 12. LAM $\{F 47 \times 13 R\}$ & $\{\mathrm{F} 47 \times 13\}$ \\
\hline 13. Other: & $\{\mathrm{F} 47 \times 98\}$ \\
\hline 98. Don't know & $\{\mathrm{F} 47 \times 12\}$ \\
\hline
\end{tabular}


48. Did the provider mention any other methods to you?

$$
\begin{aligned}
& 1=\text { Yes } \\
& 2=\text { No } \\
& 98=\text { Don't know }
\end{aligned}
$$

49. Did the provider tell you that you can switch methods if you are not happy with this method? $\{\mathrm{F} 49\}$

$$
\begin{aligned}
& 1=\text { Yes } \\
& 2=\text { No } \\
& 98=\text { Don't know }
\end{aligned}
$$

50. Did the provider tell you another source of supply or follow-up for your method? \{F50\}

$$
\begin{aligned}
& 1=\text { Yes } \\
& 2=\text { No } \\
& 98=\text { Don't know }
\end{aligned}
$$

51. Is there some method other than the one you accepted today that you would have preferred to use? \{F51\}

$$
\begin{aligned}
& 1=\text { Yes } \\
& 2=\text { No (to q.54) } \\
& 98=\text { Don't know (to q.54) }
\end{aligned}
$$

52. (If yes) Which method would you have preferred to use most? (Circle one.) (F52\}

1. Combined pill (or unspecified)

2. Progestin-only pill

3. IUD

4. Injectable

5. NORPLANT ${ }^{\circledR}$

6. Condom

7. Diaphragm

8. Spermicide

9. Female sterilization (ML/LA)

10. Vasectomy

11. NFP

12. LAM

13. Other:

98. Don't know

$\{F 52 R\}$ 
53. Why are you not going to use this preferred method? (Do not read list, but probe by asking "Any other reasons?")

\begin{tabular}{|l|l|}
\hline 1. Provider said not appropriate & $\{\mathrm{F} 53 \times 1\}$ \\
\hline 2. Method not offered at facility & $\{\mathrm{F} 53 \times 2\}$ \\
\hline 3. Trained provider absent & $\{\mathrm{F} 53 \times 3\}$ \\
\hline 4. Method temporarily out of stock & $\{\mathrm{F} 53 \times 4\}$ \\
\hline 5. Other: $\{\mathrm{F} 53 \times 5 \mathrm{R}\}$ & $\{\mathrm{F} 53 \times 5\}$ \\
\hline 98. Don't know & $\{\mathrm{F} 53 \times 98\}$ \\
\hline
\end{tabular}

54. (Circle the most effective method accepted by the client, from q. 47.)

I would now like to ask you about how to use (read method). (F54\}

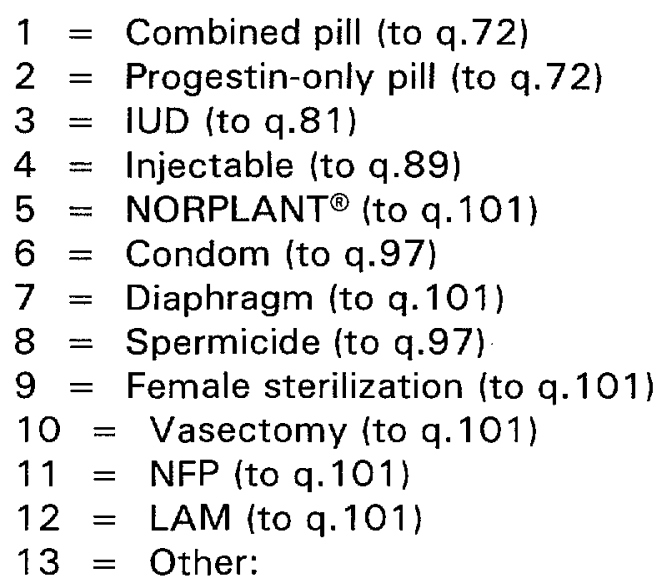
(to q.101) \{F54R\} 


\section{For revisit clients (without problems)}

55. Just to make sure, I understand that you were using a contraceptive method when you came to the facility today. Is it correct that you were using a method? $\quad$ F55 $\}$

$$
\begin{aligned}
& 1=\text { Yes, was using } \\
& 2=\text { No, was not using (return to q.41) }
\end{aligned}
$$

56. Which method(s) were you using?

(Do not read methods but probe by asking, "Any other methods?")

\begin{tabular}{|c|c|}
\hline 1. Combined pill (or unspecified) & $\{F 56 \times 1\}$ \\
\hline 2. Progestin-only pill & $\{F 56 \times 2\}$ \\
\hline 3. IUD & $\{\mathrm{F} 56 \times 3\}$ \\
\hline 4. Injectable & $\{F 56 \times 4\}$ \\
\hline 5. NORPLANT ${ }^{\circledR}$ & $\{F 56 \times 5\}$ \\
\hline 6. Condom & $\{\mathrm{F} 56 \times 6\}$ \\
\hline 7. Diaphragm & $\{F 56 \times 7\}$ \\
\hline 8. Spermicide & $\{F 56 \times 8\}$ \\
\hline 9. Female sterilization (ML/LA) & $\{F 56 \times 9\}$ \\
\hline 10. Vasectomy & $\{\mathrm{F} 56 \times 10\}$ \\
\hline 11. NFP & $\{\mathrm{F} 56 \times 11\}$ \\
\hline 12. LAM & $\{F 56 \times 12\}$ \\
\hline 13. Other: & $\{F 56 \times 13\}$ \\
\hline 98. Don't know & $\{F 563 \times 98\}$ \\
\hline
\end{tabular}

Tick if mentioned

57. Are you planning to continue using this method? $\{\mathrm{F} 57\}$

$$
\begin{aligned}
& 1=\text { Yes } \\
& 2=\text { No (to q.62) } \\
& 98=\text { Don't know (to q.101) }
\end{aligned}
$$

58. (Circle the most effective method used by the client, from q. 56 or 60. ) I would now like to ask you about how to use (read method). $\{F 58\}$

$1=$ Combined pill (to q.72)

2 = Progestin-only pill (to q.72)

$3=$ IUD (to q.81)

$4=$ Injectable (to q.89)

$5=$ NORPLANT $^{\circledR}$ (to q.101)

$6=$ Condom (to q.97)

7 = Diaphragm (to q.101)
$8=$ Spermicide (to q.97)

$9=$ Female sterilization (to q.101)

$10=$ Vasectomy (to q. 101)

$11=$ NFP (to q.101)

$12=$ LAM (to q. 101)

$13=$ Other (to q.101) 
For revisit clients (problem with method, wanted to change or stop)

59. Just to make sure, I understand that you were using a contraceptive method when you came to the facility today. Is it correct that you were using a method? \{F59\}

1 = Yes, was using

2 = No, was not using (return to q.41)

60. Which method(s) were you using?

(Do not read methods but probe by asking, "Any other methods?")

Tick if mentioned

\begin{tabular}{|l|l|}
\hline 1. Combined pill (or unspecified) & $\{\mathrm{F} 60 \times 1\}$ \\
\hline 2. Progestin-only pill & $\{\mathrm{F} 60 \times 2\}$ \\
\hline 3. IUD & $\{\mathrm{F} 60 \times 3\}$ \\
\hline 4. Injectable & $\{\mathrm{F} 60 \times 4\}$ \\
\hline 5. NORPLANT ${ }^{\circledR}$ & $\{\mathrm{F} 60 \times 5\}$ \\
\hline 6. Condom & $\{\mathrm{F} 60 \times 6\}$ \\
\hline 7. Diaphragm & $\{\mathrm{F} 60 \times 7\}$ \\
\hline 8. Spermicide & $\{\mathrm{F} 60 \times 8\}$ \\
\hline 9. Female sterilization (ML/LA) & $\{\mathrm{F} 60 \times 9\}$ \\
\hline 10. Vasectomy & $\{\mathrm{F} 60 \times 10\}$ \\
\hline 11. NFP & $\{\mathrm{F} 60 \times 11\}$ \\
\hline 12. LAM & $\{\mathrm{F} 600 \times 12\}$ \\
\hline 13. Other: & $\{\mathrm{F} 60 \times 13\}$ \\
\hline 98. Don't know & $\{\mathrm{F} 60 \times 98\}$ \\
\hline
\end{tabular}

61. Is it correct that you had a problem, wanted to change methods or wanted to stop family planning? $\{F 61\}$

$$
\begin{aligned}
& 1=\text { Yes } \\
& 2=\text { No (return to q.57) }
\end{aligned}
$$

62. What was the main problem you had, or the main reason you wanted to change or stop? (Circle one.) $\{F 62\}$

$1=$ Medical side effects

2 = Husband/partner did not like method (to q.65)

$3=$ Pressure from others (to q.65)

$4=$ Fear of infertility (to q.65)

$5=$ Wanted pregnancy (to q.65)

$6=$ Didn't like method (to q.65)

7 = Method unavailable / difficult to obtain (to q.65)

8 = Other:

$98=$ Don't know (to q.65) 
63. (If had medical side effects) When you first decided to use this method, were you told that this problem might happen? \{F63\}

$$
\begin{aligned}
& 1=\text { Yes } \\
& 2=\text { No (to q.65) } \\
& 98=\text { Don't know (to q.65) }
\end{aligned}
$$

64. (If yes) Were you told what to do about the problem? $\{$ F64

$$
\begin{aligned}
& 1=\text { Yes } \\
& 2=\text { No } \\
& 98=\text { Don't know }
\end{aligned}
$$

65. After this consultation today, do you feel that you are getting appropriate assistance for your particular needs? \{F65\}

$$
\begin{aligned}
& 1=\text { Yes } \\
& 2=\text { No } \\
& 3=\text { Partially } \\
& 98=\text { Don't know }
\end{aligned}
$$

66. What are you now going to do about family planning? (Circle one.) \{F66\}

$$
\begin{aligned}
& 1=\text { Change to new method } \\
& 2=\text { Continue with same method (to q.71) } \\
& 3=\text { Stop using any method (to q.101) } \\
& 98=\text { Don't know (to q.71) }
\end{aligned}
$$

67. (If changing method) What method(s) will you now be using?

(Do not read methods but probe by asking, "Any other methods?")

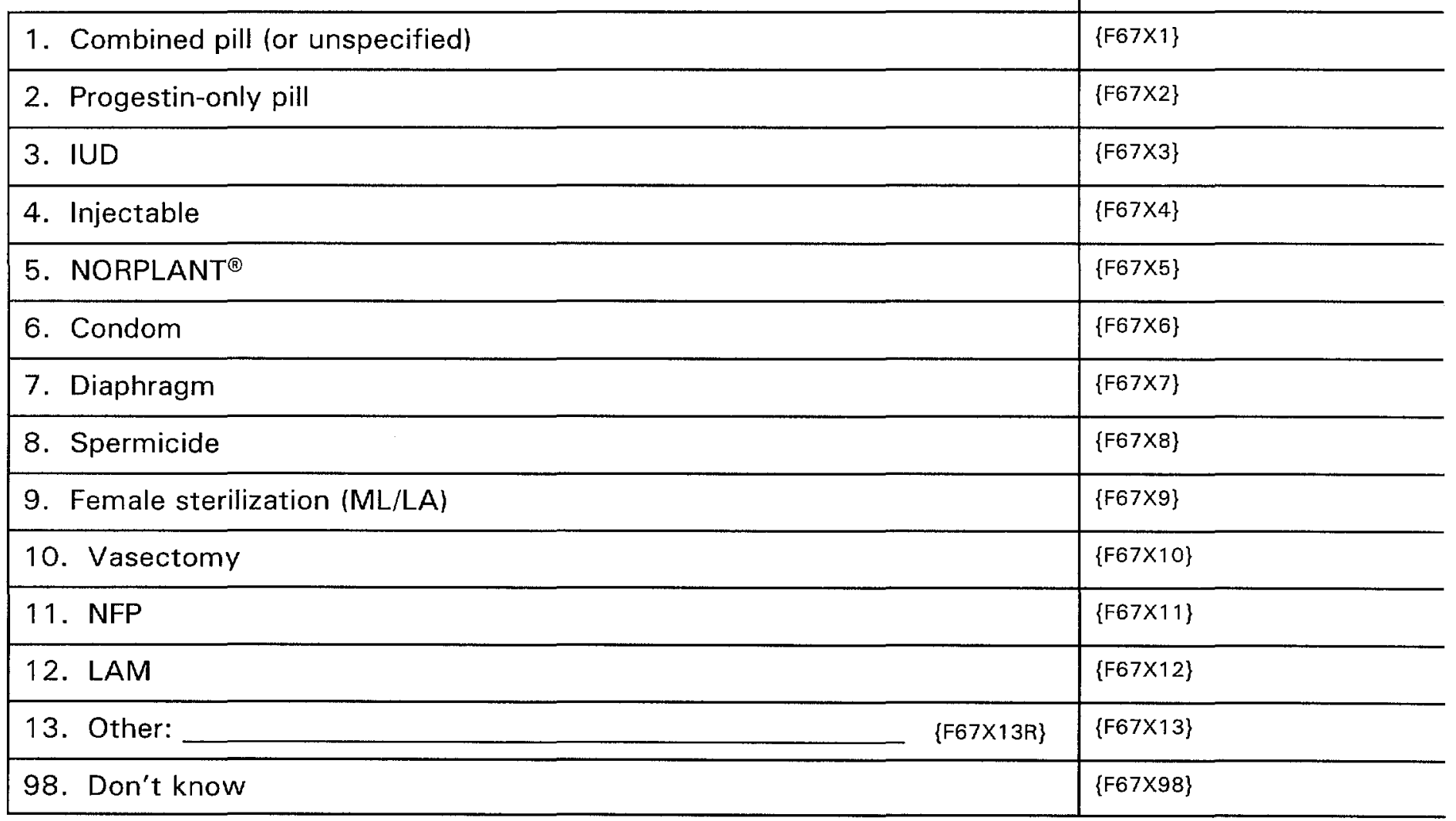


68. Did the provider mention any other methods to you? $\{\mathrm{F} 68\}$

$$
\begin{aligned}
& 1=\text { Yes } \\
& 2=\text { No } \\
& 98=\text { Don't know }
\end{aligned}
$$

69. Did the provider tell you that you can switch methods if you are not happy with this method? \{F69\}

$$
\begin{aligned}
& 1=\text { Yes } \\
& 2=\text { No } \\
& 98=\text { Don't know }
\end{aligned}
$$

70. Did the provider tell you another source of supply or follow-up for your method?

$$
\begin{aligned}
& 1=\text { Yes } \\
& 2=\text { No } \\
& 98=\text { Don't know }
\end{aligned}
$$

71. (Circle the most effective method now used by the client, from q.60 or q.67.)

I would now like to ask you about how to use (read method). \{F71\}

$$
\begin{aligned}
& 1=\text { Combined pill (to q.72) } \\
& 2=\text { Progestin-only pill (to q.72) } \\
& 3=\text { IUD (to q.81) } \\
& 4=\text { Injectable (to q.89) } \\
& 5=\text { NORPLANT }^{\circledR} \text { (to q.101) } \\
& 6=\text { Condom (to q.97) } \\
& 7=\text { Diaphragm (to q.101) } \\
& 8=\text { Spermicide (to q.97) } \\
& 9=\text { Female sterilization (to q.101) } \\
& 10=\text { Vasectomy (to q.101) } \\
& 11=\text { NFP (to q.101) } \\
& 12=\text { LAM (to q.101) } \\
& 13=\text { Other: }
\end{aligned}
$$




\section{For pill users}

72. When a woman first starts using the pill, at what time in the menstrual cycle do you think she should start taking it? $\quad\{$ F72 $\}$

$$
\begin{aligned}
& 1=\text { Within } 1 \text { st }-5 \text { th day of menstrual period } \\
& 2=\text { Any other answer } \\
& 98=\text { Don't know }
\end{aligned}
$$

73. How often do you think a woman should take her contraceptive pills?

$\{F 73\}$

$$
\begin{aligned}
& 1=\text { One every day } \\
& 2=\text { Any other answer } \\
& 98=\text { Don't know }
\end{aligned}
$$

74. If a woman forgets to take the pill for one day, what do you think she should do?

$$
\begin{aligned}
& 1=\text { Take the forgotten one immediately } \\
& 2=\text { Any other answer } \\
& 98=\text { Don't know }
\end{aligned}
$$

\begin{tabular}{|c|c|}
\hline 1. Nausea & $\{F 76 \times 1\}$ \\
\hline 2. Mild headaches & $\{F 76 \times 2\}$ \\
\hline 3. Spotting / bleeding & $\{F 76 \times 3\}$ \\
\hline 4. Weight gain / loss & $\{F 76 \times 4\}$ \\
\hline 5. Cancer & $\{F 76 \times 5\}$ \\
\hline 6. Infertility & $\{F 76 \times 6\}$ \\
\hline 7. Other: & $\{F 76 \times 7\}$ \\
\hline 77. No problems mentioned & $\{F 76 \times 77\}$ \\
\hline 98. Don't know & $\{F 76 \times 98\}$ \\
\hline
\end{tabular}

75. Does the pill protect a woman against STDs/HIV? $\{$ F75\}

$$
\begin{aligned}
& 1=\text { Yes } \\
& 2=\text { Partially } \\
& 3=\text { No } \\
& 98=\text { Don't know }
\end{aligned}
$$

76. As far as you know, what problems, if any, may a woman experience when taking the pill?

(Do not read list, but probe by asking, "Any other problems?")

Tick all mentioned 
77. Apart from the regular return or resupply visit, for what problems, if any, do you think a woman taking pills should come back to the facility?

(Do not read list, but probe by asking, "Any other problems?")

\begin{tabular}{|c|c|}
\hline 1. Severe chest pain, shortage of breath & $\{F 77 \times 1\}$ \\
\hline 2. Severe headache & $\{F 77 \times 2\}$ \\
\hline 3. Vision loss or blurring & $\{F 77 \times 3\}$ \\
\hline 4. Severe abdominal pain & $\{F 77 \times 4\}$ \\
\hline 5. Severe leg pain & $\{F 77 \times 5\}$ \\
\hline 6. Late period & $\{F 77 \times 6\}$ \\
\hline 7. Other: & $\{F 77 \times 7\}$ \\
\hline 77. No problems mentioned & $\{F 77 \times 77\}$ \\
\hline 98. Don't know & $\{F 77 \times 98\}$ \\
\hline
\end{tabular}

78. Did the service provider give you a supply of pills today? \{F78\}

$$
\begin{aligned}
& 1=\text { Yes (to q.80) } \\
& 2=\text { No }
\end{aligned}
$$

79. (If no) Where will you go to get your pills? (Circle one.) \{F79\}

$1=$ Within another section of this health facility today

$2=$ Return to this health facility at another time

$3=$ Another health facility

4 = Pharmacy / shop / chemist / private doctor

$5=$ CBD

$6=$ Other:

$98=$ Don't know

\section{To q.101}




\section{For IUD users}

81. Did your visit to the facility today involve an IUD insertion, removal, or routine check-up?

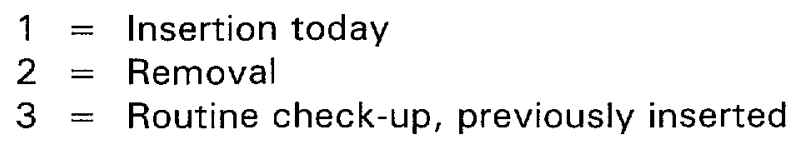

82. As far as you know, how can a woman check to be sure that the IUD is in place? (Circle all that apply.)

$$
\begin{array}{ll}
1=\text { Checking the threads regularly } & \{F 82 \times 1\} \\
2=\text { Go to the health facility } & \{F 82 \times 2\} \\
3=\text { Any other answer } & \{F 82 \times 3\} \\
98=\text { Don't know } & \{F 82 \times 98\}
\end{array}
$$

83. As far as you know, what problems, if any, may a woman experience with an IUD?

(Do not read list, but probe by asking, "Any other problems?")

\begin{tabular}{|l|l|}
\hline 1. Abdominal cramps & $\{\mathrm{F} 83 \times 1\}$ \\
\hline 2. Heavy bleeding & $\{\mathrm{F} 83 \times 2\}$ \\
\hline 3. Spotting between menstrual periods & $\{\mathrm{F} 83 \times 3\}$ \\
\hline 4. Backache / "waist-ache" & $\{\mathrm{F} 83 \times 4\}$ \\
\hline 5. Infection (PID) / lower abdominal pain $\quad\{\mathrm{F} 83 \times 8 \mathrm{R}\}$ & $\{\mathrm{F} 83 \times 5\}$ \\
\hline 6. Infertility & $\{\mathrm{F} 83 \times 6\}$ \\
\hline 7. Increased discharge & $\{\mathrm{F} 83 \times 7\}$ \\
\hline 8. Other: & $\{\mathrm{F} 83 \times 77\}$ \\
\hline 77. No problems mentioned & $\{\mathrm{F} 83 \times 98\}$ \\
\hline 98. Don't know & \\
\hline
\end{tabular}

84. When do you think a woman should come back for the first check-up after an IUD insertion? (Circle one.) \{F84\}

$$
\begin{aligned}
& 1=\text { After one month } \\
& 2=\text { After three months } \\
& 3=\text { After one year } \\
& 4=\text { Any other time } \\
& 5=\text { No need to come back } \\
& 98=\text { Don't know }
\end{aligned}
$$


85. Apart from the regular check-up visits, for what problems, if any, do you think a woman with an IUD should come back to the facility?

(Do not read list, but probe by asking, "Any other problems?")

Tick all mentioned

\begin{tabular}{|l|l|}
\hline 1. Heavy discharge & $\{\mathrm{F} 85 \times 1\}$ \\
\hline 2. Abnormal spotting or bleeding & $\{\mathrm{F} 85 \times 2\}$ \\
\hline 3. Expulsion or cannot feel threads & $\{\mathrm{F} 85 \times 3\}$ \\
\hline 4. Lower abdominal pain & $\{\mathrm{F} 85 \times 4\}$ \\
\hline 5. Severe cramps & $\{\mathrm{F} 85 \times 5\}$ \\
\hline 6. Pain during intercourse & $\{\mathrm{F} 85 \times 6\}$ \\
\hline 7. Back ache & $\{\mathrm{F} 85 \times 7\}$ \\
\hline 8. Late period $\quad\{\mathrm{F} 85 \times 10 \mathrm{R}\}$ & $\{\mathrm{F} 85 \times 10\}$ \\
\hline 9. Not feeling well & $\{\mathrm{F} 85 \times 8\}$ \\
\hline 10. Other: & $\{\mathrm{F} 85 \times 9\}$ \\
\hline 77. No problems mentioned & $\{\mathrm{F} 85 \times 98\}$ \\
\hline 98. Don't know & \\
\hline
\end{tabular}

86. How many years do you think a woman can keep using an IUD once it has been inserted? \{F86\}

$$
\text { years } \quad 98=\text { Don't know }
$$

87. Does the IUD protect a woman against STDs/HIV? \{F87\}

$$
\begin{aligned}
& 1=\text { Yes } \\
& 2=\text { Partially } \\
& 3=\text { No } \\
& 98=\text { Don't know }
\end{aligned}
$$

88. To q.101 
89. Did you receive a contraceptive injection today? $\{\mathrm{F} 89\}$

$$
\begin{aligned}
& 1=\text { Yes (to q.91) } \\
& 2=\text { No }
\end{aligned}
$$

90. (If no) Where will you go to get your injection? (Circle one.) \{F90\}

$$
\begin{aligned}
& 1=\text { Within another section of this health facility today } \\
& 2=\text { Return to this health facility at another time } \\
& 3=\text { Another health facility } \\
& 4=\text { Pharmacy / shop / chemist / private doctor } \\
& 5=\text { CBD } \\
& 6=\text { Other: } \\
& 98=\text { Don't know }
\end{aligned}
$$

91. Which type of injection did (will) you get? (Circle one.) \{F91\}

$$
\begin{aligned}
& 1=\text { Depo Provera } \\
& 2=\text { Noristerat } \\
& 98=\text { Don't know }
\end{aligned}
$$

92. How often do you think you should get this injection? (Circle one.) \{F92\}

$$
\begin{aligned}
& 1=\text { Every month } \\
& 2=\text { Every two months } \\
& 3=\text { Every three months } \\
& 4=\text { Any other interval } \\
& 98=\text { Don't know }
\end{aligned}
$$

93. As far as you know, what problems, if any, do you think a woman may experience after having an injection? (Do not read list, but probe by asking, "Any other problems?")

\begin{tabular}{|l|l|}
\hline 1. Mild headaches & $\{\mathrm{F93} \times 1\}$ \\
\hline 2. Nausea & $\{\mathrm{F93} \times 2\}$ \\
\hline 3. Irregular bleeding / spotting & $\{\mathrm{F93} \times 3\}$ \\
\hline 4. Weight gain $\quad\{\mathrm{F93} \times 7 \mathrm{R}\}$ & $\{\mathrm{F93} \times 4\}$ \\
\hline 5. Infertility & $\{\mathrm{F93} \times 5\}$ \\
\hline 6. Amenorrhea (absence of period) & $\{\mathrm{F93} \times 6\}$ \\
\hline 7. Other: & $\{\mathrm{F93} \times 7\}$ \\
\hline 77. No problems mentioned & $\{\mathrm{F93} \times 77\}$ \\
\hline 98. Don't know & $\{\mathrm{F93} \times 98\}$ \\
\hline
\end{tabular}


94. Apart from the regular return visit, for what problems, if any, do you think a woman receiving injections should come back to the facility? (Do not read list, but probe by asking, "Any other problems?")

\begin{tabular}{|c|c|}
\hline 1. Headaches (severe, persistent) & $\{F 94 \times 1\}$ \\
\hline 2. Heavy bleeding & $\{\mathrm{F} 94 \times 2\}$ \\
\hline 3. Severe chest pain, shortage of breath & $\{\mathrm{F} 94 \times 3\}$ \\
\hline 4. Severe lower abdominal pain & $\{\mathrm{F94X} 4\}$ \\
\hline 5. Severe leg pain & $\{\mathrm{F94} \times 5\}$ \\
\hline 6. Vision loss or blurring & $\{\mathrm{F94X6 \}}$ \\
\hline 7. Frequent urination & $\{\mathrm{F9} 4 \times 7\}$ \\
\hline 8. Late period & $\{\mathrm{F94X8}\}$ \\
\hline 9. Other: & $\{\mathrm{F94X9 \}}$ \\
\hline 77. No problems mentioned & $\{\mathrm{F} 94 \times 77\}$ \\
\hline 98. Don't know & \{F94X98\} \\
\hline
\end{tabular}

95. Does an injection protect a woman against STDs/HIV?

$\{$ F95

$$
\begin{aligned}
& 1=\text { Yes } \\
& 2=\text { Partially } \\
& 3=\text { No } \\
& 98=\text { Don't know }
\end{aligned}
$$

96. To q.101 
97. Do condoms/spermicides protect a woman against STDs/HIV? \{F97\}

$$
\begin{aligned}
& 1=\text { Yes } \\
& 2=\text { Partially } \\
& 3=\text { No } \\
& 98=\text { Don't know }
\end{aligned}
$$

98. Did you receive a supply of condoms and/or spermicides (cream, foam, jelly) today?

$$
\begin{aligned}
& 1=\text { Yes (to q.100) } \\
& 2=\text { No }
\end{aligned}
$$

99. (If no) Where will you go to get your condoms and/or spermicides (cream, foam, jelly)? (Circle one.) $\{\mathrm{F99}\}$

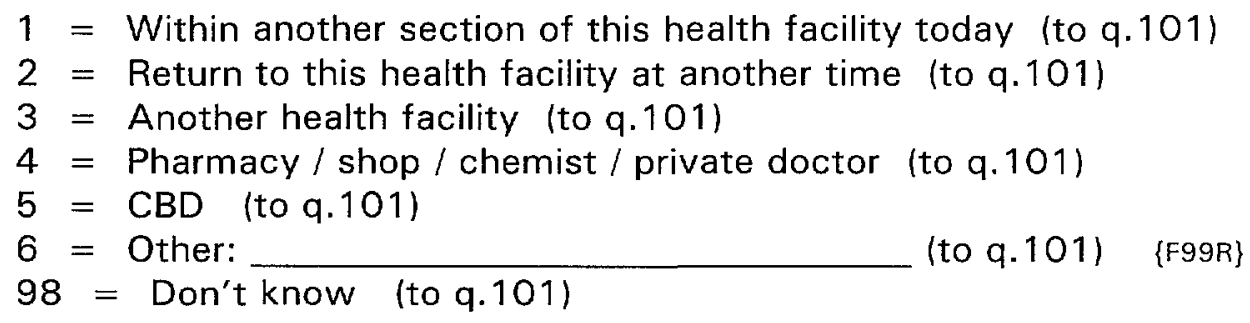

100. After you have finished this supply of condoms and/or spermicides, where will you go to get more supplies? (Circle all that apply.) \{F100\}

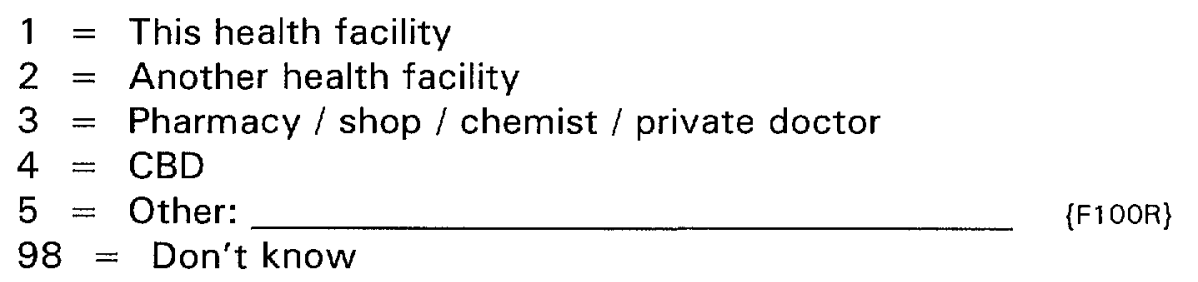




\section{For all clients}

101. Now, I would like to ask you a few questions about yourself. Are you currently breastfeeding? \{F101\}

$$
\begin{aligned}
& 1=\text { Yes } \\
& 2=\text { No (to q.103) }
\end{aligned}
$$

102. (If yes) Are you breastfeeding exclusively, nearly exclusively, or supplemented regularly with food and/or liquids? $\quad\{F 102\}$

$1=$ Breastfeeding exclusively

$2=$ Nearly exclusively

$3=$ Supplemented regularly with food and/or liquids

$98=$ Interviewer unable to determine extent of supplementation

103. How old are you? \{F103\}

$$
98=\text { Don't know }^{\text {years }}
$$

104. What is your current marital status? (Probe for exact status.) \{F104\}

$$
\begin{aligned}
& 1=\text { Married / monogamous (to q.106) } \\
& 2=\text { Married / polygamous (to q.106) } \\
& 3=\text { Cohabiting (to q. 106) } \\
& 4=\text { Single, never married } \\
& 5=\text { Divorced / separated / widowed }
\end{aligned}
$$

105. (If not married) Do you have a regular partner? \{F105\}

$$
\begin{aligned}
& 1=\text { Yes } \\
& 2=\text { No (to q. 108) }
\end{aligned}
$$

106. Have you ever discussed family planning with your husband or regular partner? \{F106\}

$$
\begin{aligned}
& 1=\text { Yes } \\
& 2=\text { No } \\
& 98=\text { Don't know }
\end{aligned}
$$

107. Does your husband or regular partner know that you use or that you are planning to use family planning? $\{\mathrm{F} 107\}$

$$
\begin{aligned}
& 1=\text { Yes } \\
& 2=\text { No } \\
& 98=\text { Don't know }
\end{aligned}
$$

108. How many living children of your own do you have? \{F108\}

$$
\text { children }
$$

$$
\text { (If none, to q.110) }
$$

109. What is the age of your youngest child? \{F109\}

$$
98=\text { Don't know }
$$


110. Would you like to have any (more) children? (Circle one.) \{F110\}

$$
\begin{aligned}
& 1=\text { Yes } \\
& 2=\text { No (to q.112) } \\
& 3=\text { Depends on husband (to q.112) } \\
& 4=\text { Depends on God (to q.112) } \\
& 5=\text { Not sure / undecided (to q.112) }
\end{aligned}
$$

111. (If yes) When would you like (a) (the next) child? (Circle one.) \{F111\}

$$
\begin{aligned}
& 1=\text { Less than one year } \\
& 2=\text { One year } \\
& 3=\text { Between one and two years } \\
& 4=\text { Two years } \\
& 5=\text { More than two years } \\
& 6=\text { Any other response } \\
& 98=\text { Don't know }
\end{aligned}
$$

112. Can you read and understand a letter or a newspaper easily, with difficulty, or not at all?

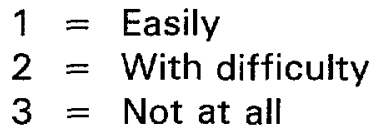

113. Which languages can you read and understand? (Do not read list, but probe by asking, "Any other languages?")

\begin{tabular}{|l|l|}
\hline 1. English/French & $\{\mathrm{F} 113 \times 1\}$ \\
\hline 2. Local dialect $\quad\{\mathrm{F} 113 \times 3 \mathrm{R}\}$ & $\{\mathrm{F} 113 \times 2\}$ \\
\hline 3. Other: $\{\mathrm{F} 113 \times 4 \mathrm{R}\}$ & $\{\mathrm{F} 113 \times 3\}$ \\
\hline 4. Other: $\{\mathrm{F} 113 \times 5 \mathrm{R}\}$ & $\{\mathrm{F} 113 \times 4\}$ \\
\hline 5. Other: & $\{\mathrm{F} 113 \times 5\}$ \\
\hline
\end{tabular}

114. What is the highest level of school you attended? (Circle one.) $\{F 114\}$

$$
\begin{aligned}
& 1=\text { Did not attend formal school } \\
& 2=\text { Lower primary } \\
& 3=\text { Upper primary } \\
& 4=\text { Lower secondary } \\
& 5=\text { Upper secondary } \\
& 6=\text { Post-secondary }
\end{aligned}
$$

115. What is your religion? (Circle one.) $\{\mathrm{F} 115\}$

$$
\begin{aligned}
& 1=\text { Protestant } \\
& 2=\text { Catholic } \\
& 3=\text { Muslim } \\
& 4=\text { African Spiritual } \\
& 5=\text { None } \\
& 6=\text { Other: }
\end{aligned}
$$


116. To end with, I would like to ask you some questions about other reproductive health issues. I would like to remind you that the information you provide will remain strictly confidential, and that you do not have to answer any question you do not want to. Sometimes a woman can become pregnant when she is not ready to be. In the past, have you ever been pregnant at a time when you were not ready for the pregnancy? $\{F 116\}$

$$
\begin{aligned}
& 1=\text { Yes } \\
& 2=\text { No (to q.118) } \\
& 98=\text { Don't know / no response (to q.118) }
\end{aligned}
$$

117. (If yes) What did you do the last time this happened to you? (Circle one.) \{F117\}

$$
\begin{aligned}
& 1=\text { Nothing, continued with the pregnancy } \\
& 2 \text { = Attempted to stop pregnancy but did not succeed, gave birth } \\
& 3=\text { Attempted to stop pregnancy and succeeded } \\
& 4=\text { Other: } \\
& 98=\text { Don't know / no response }
\end{aligned}
$$

118. As far as you know, are there any diseases that can be transmitted through sexual intercourse? $\{\mathrm{F} 118\}$

$$
\begin{aligned}
& 1=\text { Yes } \\
& 2=\text { No (to q.120) } \\
& 98=\text { Don't know (to q.120) }
\end{aligned}
$$

119. From what you've heard or read, what are some common signs and symptoms of sexually transmitted diseases? (Do not read list, but probe by asking, "Any other signs or symptoms?")

\begin{tabular}{|l|l|}
\hline 1. Abnormal vaginal discharge & $\{\mathrm{F} 119 \times 1\}$ \\
\hline 2. Abnormal vaginal bleeding & $\{\mathrm{F} 119 \times 2\}$ \\
\hline 3. Genital itching & $\{\mathrm{F} 119 \times 3\}$ \\
\hline 4. Lesions / sores & $\{\mathrm{F} 119 \times 4\}$ \\
\hline 5. Lower abdominal pain & $\{\mathrm{F} 119 \times 5\}$ \\
\hline 6. Pain during intercourse & $\{\mathrm{F} 119 \times 6\}$ \\
\hline 7. Painful urination & $\{\mathrm{F} 119 \times 7\}$ \\
\hline 8. Abnormal growth in genital area (warts) & $\{\mathrm{F} 119 \times 8\}$ \\
\hline 9. Urethral discharge & $\{\mathrm{F} 119 \times 9\}$ \\
\hline 10. Loss of weight $\{\mathrm{F} 119 \times 12 \mathrm{R}\}$ & $\{\mathrm{F} 119 \times 10\}$ \\
\hline 11. Diarrhea of long duration & $\{\mathrm{F} 119 \times 11\}$ \\
\hline 12. Other: & $\{\mathrm{F} 119 \times 12\}$ \\
\hline 98. Don't know & $\{\mathrm{F} 119 \times 98\}$ \\
\hline
\end{tabular}


120. Have you ever heard of HIV or AIDS, or are you not sure? \{F120\}

$$
\begin{aligned}
& 1=\text { Yes } \\
& 2=\text { No (to q.122) } \\
& 98=\text { Not sure (to q.122) }
\end{aligned}
$$

121. As far as you know, what are the ways to get HIV/AIDS?

(Do not read list but probe by asking, "Any other ways?")

\begin{tabular}{|l|l|}
\hline 1. Sexual intercourse & $\{\mathrm{F} 121 \times 1\}$ \\
\hline 2. Blood transfusion & $\{\mathrm{F} 121 \times 2\}$ \\
\hline 3. Sharing items like razor blades or needles & $\{\mathrm{F} 121 \times 3\}$ \\
\hline 4. Mother to baby $\quad\{F 121 \times 5 \mathrm{R}\}$ & $\{\mathrm{F} 121 \times 5\}$ \\
\hline 5. Other: & $\{\mathrm{F} 121 \times 98\}$ \\
\hline 98. Don't know & $\{\mathrm{F} 121 \times 4\}$ \\
\hline
\end{tabular}

122. Do you know of any ways you can protect yourself from sexually transmitted diseases including HIV/AIDS? $\{$ F122\}

$$
\begin{aligned}
& 1=\text { Yes } \\
& 2=\text { No (to q. 124) }
\end{aligned}
$$

123. (If yes) What are these ways of protecting yourself? (Do not read list. but probe by asking, "Any other ways?")

\begin{tabular}{|l|l|}
\hline 1. Stay faithful to your one spouse/partner & $\{\mathrm{F} 123 \times 1\}$ \\
\hline 2. Encourage spouse/partner to remain faithful & $\{F 123 \times 2\}$ \\
\hline 3. Use condoms & $\{\mathrm{F} 123 \times 3\}$ \\
\hline 4. Avoid sharing needles, razors, etc. & $\{\mathrm{F} 123 \times 4\}$ \\
\hline 5. Other: & $\{\mathrm{F} 123 \times 5\}$ \\
\hline
\end{tabular}

124. How many sexual partners have you had in the past 12 months? $\quad$ F124\}

$$
\text { partners }
$$

(If none, to closing)

125. Did you have sex with any new partner(s) in the past 12 months? $\{$ F125\}

$$
\begin{aligned}
& 1=\text { Yes } \\
& 2=\text { No (to closing) } \\
& 98=\text { Don't know (to closing) }
\end{aligned}
$$


126. (If yes) Did you use a condom the first time you had sex with your most recent new partner? $\{F 126\}$

$$
\begin{aligned}
& 1=\text { Yes } \\
& 2=\text { No } \\
& 98=\text { Don't know/can't recall }
\end{aligned}
$$

\section{Read closing:}

Thank you very much for answering these questions. 


\section{Family planning client exit interview: question-by-question guide}

The client has just finished receiving FP services. Most likely a nurse on the field research team has completed observing the services she received and has now brought the client to you. Be sensitive to the fact that the client may have traveled far, waited a long time for service, and may have been through an ordeal. However, she may agree to an interview with a sensitive and interested person. (See the section "Tips for conducting a good interview" for more information, page 23.)

Lead the client to a preselected private place, away from clinic staff and other clients, and read the greeting. This greeting is extremely important because it ensures that the client has given her "informed consent" to participate in the study. Ask if the client has any questions about the study. If necessary, you may provide some simple encouragement such as, "Your participation will be greatly appreciated," but in all cases respect the client's wishes if she does not want to be interviewed. If she does not agree to participate, thank her and move on to the next client.

You should be able to fill out the information on the first two pages before the interview begins. If you are not sure about any of the codes, ask your Team Leader. Write (do not sign) your name in the box at the bottom of the page. When you have completed the interview, your Team Leader will review it and sign below your name.

For the rest of the interview, follow instructions for recording the client's responses by circling a precoded response, ticking a box, or writing a response as instructed. Some questions are filters, which means that they divide clients who have had a certain experience from those who have not had that ex- perience. Usually, the clients who have had the experience, such as an IUD insertion, will be subject to some questions that other clients will not answer. These filter questions always include a "skip pattern" that skips these questions for those clients who did not have the experience. Pay careful attention to all skip patterns. At the conclusion of the interview, quickly review your coded responses for completeness and correctness and ensure that you followed the correct skips. If possible, correct any problems while the client is still available.

\section{For all clients}

1. Overall, would you say you were satisfied with your visit to the facility today, or were you dissatisfied with your visit today?

Clients are frequently reluctant to express any overall dissatisfaction because they wish to be courteous. However, clients tend to be more expressive of dissatisfaction with more specific questions. Questions 5 through 17 of this interview will give the client more opportunity to specifically critique the services.

2. Why were you dissatisfied with your visit today?

We are very interested in reasons for dissatisfaction. Do not rush. You may encourage the client to talk further about any dissatisfaction she mentions with a simple probe. If appropriate, use probes like "Can you tell me any more about why you feel that way?"

\section{In addition to family planning, did you receive any other health ser- vices from the service provider?}


4. Now I would like to ask you about all the other services you received today. Did you receive any of the following services?

These questions address the integration of other services with family planning. If clients report in question 3 that they received other services, ask question 4 (see the skip pattern). In question 4, read each of the services and carefully place a tick (check mark) in the right column on the appropriate line of each service received. Remember, a blank line in the column (no tick) means the client did not receive that service today.

5. Do you feel that you received the information and services that you wanted today?

Clients come to a facility in order to obtain particular information and services. The purpose of this question is to find out if the client obtained the information and services she desired.

6. Do you feel that your FP consultation with the clinical staff was too short, too long, or about the right amount of time?

Later, this information can be compared to the actual length of the consultation (from the observation) to discover the length of time that clients are most comfortable with.

7. During this visit, did you have any concerns about family planning or other health issues that you wanted to discuss with the provider?

8. (If yes) Did the provider listen to your concerns to your satisfaction?
"Concerns" is a broad term. Concerns include but are not limited to worries or rumors of health risks, side effects, how to maintain privacy, partner reactions, etc. If the client reports that she did have concerns, ask question 8 .

\section{During this visit, did you have any} questions you wanted to ask?

10. (If yes) Did the provider let you ask the questions?

11. (If yes) Did the provider respond to your questions to your satisfaction? Whether clients feel free to ask questions and whether they are responded to satisfactorily is a strong indicator of quality in interpersonal relations, and also probably affect a client's continuity of use. These three questions address the issue of whether the client felt comfortable asking for the information she needed.

"Questions" can be on any subject, such as how a method works or where to buy condoms. Questions can also include "concerns," as defined above.

Many dimensions may be considered by the client in answering question 11: for example, the completeness, correctness, or style the provider used in her responses. Give no assistance in answering this question, because only the client can determine her own satisfaction with the responses to her questions.

12. During this visit, did the provider conduct any health examinations or procedures?

13. (If yes) Did the provider explain the examinations or procedures before they were performed? 
14. Did the provider explain the results of the health examinations or procedures?

"Health examinations" include head-totoe exams, breast exams, pelvic exams, and examinations on any other part of the body. "Procedures" include taking blood pressure or temperature, inserting an IUD, giving an injection, etc.

The idea behind these questions is that if clients are aware of examinations and procedures, they will be more at ease during their visit. An explanation of the examination or procedure involves telling the client what the provider is about to do, why she is doing it, and what the client can expect to feel. Explaining the results of the examination or procedure involves telling the client if the nurse came to any conclusions or diagnosis based on the examination. If a diagnosis is not immediately available, as with a Pap smear, then explaining the results would include telling the client that her smear will be tested and she will be contacted later about the results.

\section{In your opinion, did you have} enough privacy during your consultation with the service provider? This is the client's opinion, however she determines it.

\section{During the consultation, did you} feel that the provider was easy to understand when explaining things to you, or did you feel that the provider was difficult to understand?

This is the client's opinion, however she determines it.
17. If you could suggest one improvement to the services provided, what would it be?

This important question allows the client to mention something that bothered her about the experience, without being critical. Probe with supportive comments such as: "Anything at all you would like to suggest is fine."

18. During this visit, were you given or did you take any brochure or educational material to bring home?

19. (If yes) What was the subject(s) of that material?

No distinction is made between brochures, pamphlets, fliers, or any other educational material. Try to find out the subject matter of the brochure or educational material given to the client. Do not read the list, but probe by asking "Are there any other subjects?"

20. Did you attend a group talk(s) at the facility today?

The "group talk" is sometimes called a "health talk." It is usually conducted by a nurse, and may include many subjects. It is frequently in the lecture format, but when done well, may include questions, display of samples, or other AV aides.

"Attend" and "hear" have similar meanings in this question.

21. (If yes) What topics were covered in the group talk(s)?

Ask this question only if the client attended a group talk. We are interested in the information that the client remembers during the health talk, so do not prompt her by reading the subject list. Also note the appropriate probe, "Any other subjects?" 
22. Did any service provider tell you when to come back for another visit? This information is also collected in the observation, so this question can test whether clients who are given follow-up dates are aware of them.

\section{Are the hours this facility is open convenient for you?}

24. (If no) What time would be most convenient to you?

Opening hours of services can be a large barrier to clients and these questions get at the convenience of the clinic hours. Even in contexts in which clinic hours are set by the Ministry of Health or other central authority, information from these questions can be very useful for getting those policies changed if necessary.

\section{Have you ever been turned away} from this facility during official working hours?

"Turned away" means refused service, or told to come back at another time. Note that this is about the client's history with the facility (ever), rather than about today's visit. Also, this involves being turned away due to overcrowding or other unspecified reason. If the client came once, saw a provider, and was told to return with her menses, this does not count as "turned away" for this question.

\section{About how long did you have to} wait between the time you first arrived at this facility and the time you began receiving the services that you came for?

The purpose of this question is to determine the client waiting time. Encourage the client to estimate the time she waited if she does not have a watch and/or did not keep track of the time. Reserve "don't know" for clients who are unable to estimate, even when requested to do so.

27. Do you feel that the wait between the time you first arrived at this facility and the time you began receiving the services you came for was reasonable or too long?

This is the client's opinion about overall waiting time experienced before she started to receive the services she came for. Do not consider the start of registration procedures as the services she came for.

\section{How long did it take you to come} here today?

We are enquiring about the client's travel time from her home, because travel time can sometimes pose a large barrier to services. If the client was coming from work or relative's house, count the time from there. Encourage the client to estimate the approximate time in minutes.

\section{What was the main means} of transport that you used to get here?

The client may have used two or three or more forms of transportation-walking and minibus would be a common combination. When the client used two or more means of transport, encourage her to decide what she considers her main means. Any criteria she uses for deciding-time, distance, cost, etc.is fine. 
30. As far as you know, what types of services other than family planning are usually provided at this facility? This question addresses clients' awareness of other services, which will later be compared to the actual services available. This gives an idea whether some services are underutilized because people are simply not aware of them.

Remember that the client will not use our exact terms. Interpret her comments into the categories to the best of your ability. If the client says "STD," or "HIV," you may probe with "What kind of STD or HIV services are usually provided?" in order to come closer to the coding categories available.

31. Apart from this facility, is there any other place near your home where you can go for family planning?

32. (If yes) What type of facility is it?

33. What would you say is the main reason you did not go there for family planning?

A client's choice of facilities is important because it may have been motivated by the quality of services she experiences. These three questions address those clients who have decided to come to this facility rather than another.

If the client indicates there is another facility close to her home or workplace, or another place she regularly visits, code question 31 accordingly. Then questions 32 and 33 should be asked, and the client should be encouraged to think about only one other facility, the one closest to her home or workplace. In question 33, the client may mention more than one reason. Encourage her to decide on one main reason.
34. Now I would like to ask you about the cost of travel and services that you have received from this clinic. How much did you pay for your consultation?

35. How much did you pay for medicines?

36. How much did you pay for other items such as cotton, gloves, antiseptic, or syringes?

37. How much did you pay for registration card/membership?

38. How much did you pay for travel?

39. How much did you pay for any other services or fees?

In the inventory, the health facility will report in detail how much it charges FP clients for their services. The information on the amount actually paid by clients will reveal the true cost of services to individuals (including travel, etc.) versus the price charged by the health facility.

Clients may know the total amount paid without knowing how the charges were divided. If this is the case, make a note in the margin with the total amount.

40. Overall, do you feel that the total cost of obtaining services is much too expensive, a little too expensive, or acceptable to you?

Because the burden of expenses can only be judged relative to a client's income, this question gives the client the chance to assess the difficulty she has in paying for services, even if the cost is quite low.

41. I understand that your main purpose for coming to the health facility today was (insert purpose). Is this correct?

This is a filter question to determine where you should go next in the ques- 
tionnaire. Depending on the client's main reason for the visit, we ask different questions. Therefore, it is very important to correctly identify the client's main reason for attending the clinic.

Look at page 68 to see the main reason for the client's visit. Then, read question $\mathbf{4 1}$ to check if the main reason has been correctly recorded. If so, then circle the reason again in question 41 and skip to the appropriate question. If not, then ask the client the correct purpose of her visit, circle her answer, and then skip to the appropriate question number.

\section{For new acceptors}

42. Just to make sure, I understand that you were not using a contraceptive method when you came to the facility today. Is it correct that you were not using a method?

The purpose of this question is to make one last check to see whether we have classified the client correctly before we ask more questions.

43. Have you ever used any contraceptive method in the past?

44. (If yes) Which method(s) have you ever used?

Methods used by husband/partner(s) such as condom, vasectomy, and withdrawal are attributed to the client as well.

45. Did you get a contraceptive method during this visit?

This question gets at the method the client decided to use today. If she decided to use injectables, but did not receive the injection today, count her as "yes." Likewise, if she chose LAM or natural family planning, which do not involve physically receiving anything, count her as "yes."

46. (If no) What is the main reason you did not obtain a contraceptive method today?

If there is more than one reason, probe for the main reason.

47. Which method(s) did you accept today? As with question 45 , this question gets at the method the client decided to use today. If she decided to use injectables, but did not receive the injection today, tick injectable. Likewise, if she chose LAM or natural family planning, which do not involve physically receiving anything, tick those methods.

48. Did the provider mention any other methods to you?

49. Did the provider tell you that you can switch methods if you are not happy with this method?

50. Did the provider tell you another source of supply or follow-up for your method?

The observation will record whether all three of these items took place. These questions are asked again in the exit interview, and the results will be compared with the observation. This will reveal whether information was effectively communicated to the client.

\section{Is there some method other than} the one you accepted today that you would have preferred to use?

52. (If yes) Which method would you have preferred to use most?

Research suggests low continuation/satisfaction if clients do not obtain their pre- 
ferred method, independent of the technical effectiveness of the method. Thus we are very interested in whether they received their preferred method, and what that preferred method might be. Again, this information will also be recorded in the observation, and those results can be compared with these. Remember to ask question 52 only if the client answers "yes" to question 51.

\section{Why are you not going to use this} preferred method?

This will be recorded in the observation as well, which will reveal whether clients who are contraindicated from a method, for example, are aware that that is the reason for not using that method.

\section{I would now like to ask you about} how to use (read method).

In cases where the clients accepted dual or multiple methods-such as condoms and spermicide, or pills and condomsyou are instructed to circle the most effective method accepted and to ask only about the most effective method.

\section{For revisit clients (without problems)}

55. Just to make sure, $I$ understand that you were using a contraceptive method when you came to the facility today. Is it correct that you were using a method?

The purpose of this question is to make one last check to see whether we have classified the client correctly for the following questions.

56. Which method(s) were you using? Methods used by husband/partner(s) such as condoms, vasectomy, and with- drawal are attributed to the client as well.

57. Are you planning to continue using this method?

Note that if the client is not going to continue this method, then she is treated as a revisit who had a problem, and is skipped to that section. She will be asked questions on why she decided to stop or switch methods.

\section{I would now like to ask you about} how to use (read method).

In cases where the clients accepted dual or multiple methods-such as condoms and spermicide, or pills and condomsyou are instructed to circle the most effective method accepted and to ask only about the most effective method.

For revisit clients (problems with metbod or wanting to change or stop)

59. Just to make sure, I understand that you were using a contraceptive method when you came to the facility today. Is it correct that you were using a method?

The purpose of this question is to make one last check to see whether we have classified the client correctly for the following questions.

60. Which method(s) were you using? Methods used by husband/partner(s) such as condoms, vasectomy, and withdrawal are attributed to the client as well.

61. Is it correct that you had a problem, wanted to change methods or wanted to stop family planning? This question checks that the client is 
truly a revisit client who experienced problems. If not, then she is treated as a normal revisit client, and switched to the proper section.

62. What was the main problem you had, or the main reason you wanted to change or stop?

If there is more than one reason, encourage the client to select her main reason.

63. (If had medical side effects) When you first decided to use this method, were you told that this problem might happen?

64. (If yes) Were you told what to do about the problem?

If a client is told about side effects and how to manage them when she accepts a method, then she has a greater chance of continuing to use the method if the side effects occur. This question determines whether clients who experience side effects had been informed about them previously, even if that information did not come from this facility.

65. After this consultation today, do you feel that you are getting appropriate assistance for your particular needs? This is a satisfaction question, aimed specifically at those clients who need special attention for the problems they have been experiencing with their methods.

66. What are you now going to do about family planning?

67. (If changing method) What method(s) will you now be using? These two questions will identify those clients who are switching methods. These clients are important because they should have been given counseling and information as though they were new clients.

68. Did the provider mention any other methods to you?

69. Did the provider tell you that you can switch methods if you are not happy with this method?

70. Did the provider tell you another source of supply or follow-up for your method?

The observation will record whether all three of these items took place. These questions are asked again in the exit interview, and the results will be compared with the observation. This will reveal whether information was effectively communicated to the client.

71. I would now like to ask you about how to use (read method).

In cases where the clients accepted dual or multiple methods-such as condoms and spermicide, or pills and condomsyou are instructed to circle the most effective method accepted and to ask only about the most effective method.

For pill users

72. When a woman first starts using the pill, at what time in the menstrual cycle do you think she should start taking it?

73. How often do you think a woman should take her contraceptive pills?

74. If a woman forgets to take the pill for one day, what do you think she should do?

75. Does the pill protect a woman against STDs/HIV?

These four questions are basic knowledge questions about the pill. The "cor- 
rect" answers for 72,73 , and 74 are " 1 ," and for 75 it is " 3 ."

76. As far as you know, what problems, if any, may a woman experience when taking the pill?

77. Apart from the regular return or resupply visit, for what problems, if any, do you think a woman taking pills should come back to the facility? These are also knowledge questions, but there is no "correct" answer for either, since clients might know of any number of symptoms or problems. If the client does not mention any problems, tick line 98.

Be aware that the client may not use our terms. Classify as well as you can what the client says, using our terms.

78. Did the service provider give you a supply of pills today?

79. (If no) Where will you go to get your pills?

Clients who have supplies and information about resupply will probably achieve more continuity of method use. This information will also be collected in the observation, so the results can be compared.

80. Go to q. 101.

\section{For IUD users}

81. Did your visit to the facility today involve an IUD insertion, removal, or routine check-up?

This question checks whether the client actually received the IUD today.

\section{As far as you know, how can a} woman check to be sure that the IUD is in place?
83. As far as you know, what problems, if any, may a woman experience with an IUD?

84. When do you think a woman should come back for the first check-up after an IUD insertion?

85. Apart from the regular check-up visits, for what problems, if any, do you think a woman with an IUD should come back to the facility?

86. How many years do you think a woman can keep using an IUD once it has been inserted?

87. Does the IUD protect a woman against STDs/HIV?

These are all general knowledge questions about the IUD. The client's responses will be compared with information that was observed to have been given to her during the consultation.

For questions 83 and 85 , be aware that the client will not use our terms. Classify as well as you can what the client says, using our terms. If the client does not mention any problems, tick line 98.

88. Go to q. 91.

For injectable users

89. Did you receive a contraceptive injection today?

This question checks whether the client actually received an injection today.

90. (If no) Where will you go to get your injection?

This question addresses the supply of contraceptives. It was also recorded in the observation, so the responses can be compared. 
91. Which type of injection did (will) you get?

Depo Provera is required every three months and Noristerat is required every two months. If the client mentions the time, rather than the type, code appropriately.

92. How often do you think you should get this injection?

As mentioned above, Depo Provera is required every three months and Noristerat is required every two months.

93. As far as you know, what problems, if any, do you think a woman may experience after having an injection?

94. Apart from the regular return visit, for what problems, if any, do you think a woman receiving injections should come back to the facility?

95. Does an injection protect a woman against STDs/HIV?

These are general knowledge questions for injectable users. Note that there are no strictly "correct" answers for questions 93 and 94, since clients might know any number of symptoms or problems. Be aware that the client will not use our terms. Classify as well as you can what the client says, using our terms. If the client does not mention any problems, tick line 98.

96. Go to q. 91 .

\section{For condom and spermicide users}

97. Do condoms/spermicides protect a woman against STDs/HIV?

This is the only knowledge question for condom/spermicide users. It is par- ticularly important that clients are aware of this protective property of condoms.

98. Did you receive a supply of condoms and/or spermicides (cream, foam, jelly) today?

99. (If no) Where will you go to get your condoms and/or spermicides (cream, foam, jelly)?

100. After you have finished this supply of condoms and/or spermicides, where will you go to get more supplies?

These questions get at contraceptive supply, which is particularly complex with condoms, since they are often available at many more outlets than other methods.

\section{For all clients}

101. Now, I would like to ask you a few questions about yourself. Are you currently breastfeeding?

102. (If yes) Are you breastfeeding exclusively, nearly exclusively, or supplemented regularly with food and/or liquids?

If the client is breastfeeding during the interview, do not ask the question but simply code "yes" on question 101.

Question 102 will be used to assess the appropriateness of progestin-only pills for this client, if that is the method she accepted. For this question, "exclusive breastfeeding" means only breast milk and nothing else; no water, juice, or other foods. "Nearly exclusively" means primarily breast milk but sometimes some water or juice. "Supplemented regularly" means breast milk with other liquids and foods also 
given. Try to determine which of these categories is closest to the current breastfeeding behavior of the client.

\section{How old are you?}

Write the number of years mentioned by the client. If she doesn't know her age exactly, try to help her estimate with some important historical dates as benchmarks as instructed in training. If she has no idea what her age is, write 98.

104. What is your current marital status? This question should be answered using the client's definition of marriage.

105. (If not married) Do you have a regular partner?

A regular partner is someone with whom the client has sexual intercourse on a regular basis, independent of the frequency.

106. Have you ever discussed family planning with your husband or regular partner?

107. Does your husband or regular partner know that you use or that you are planning to use family planning?

Discussion of family planning within couples is a possible factor affecting family planning use and continuation. These questions are also asked of $\mathrm{MCH}$ clients, so the results can be compared between FP and $\mathrm{MCH}$ clients.

108. How many living children of your own do you have?

Emphasize the words "living" and "your own." This question is intended to determine the number of children to whom the woman has given birth. It excludes adopted children and children of other relatives presently living with her.

109. What is the age of your youngest child?

Note that the age of the youngest

child should be recorded in months.

110. Would you like to have any (more) children?

Information from this question can be used to check if the client received an appropriate contraceptive method. Ask "any" with a client who has no children. Ask "any more" with a client who has one or more children.

111. (If yes) When would you like (a) (the next) child?

Information from this question can be used to check if the client received an appropriate contraceptive method. Ask "a" with a client who has no children. Ask "the next" with a client who has one or more children.

112. Can you read and understand a letter or a newspaper easily, with difficulty, or not at all?

113. Which languages can you read and understand?

114. What is the highest level of school you attended?

115. What is your religion?

These four questions address the general socio-economic status of the clients. This can be used in designing programs, producing appropriate IEC materials, and arranging services in socially and culturally acceptable ways. 
In question 114, note that we are enquiring about "attended," not necessarily "completed."

116. To end with, I would like to ask you some questions about other reproductive health issues. I would like to remind you that the information you provide will remain strictly confidential, and that you do not have to answer any question you do not want to. Sometimes a woman can become pregnant when she is not ready to be. In the past, have you ever been pregnant at a time when you were not ready for the pregnancy?

117. (If yes) What did you do the last time this happened to you?

These questions are sensitive, but are usually answered when the interviewer has developed a rapport with the client, and is straightforward and nonjudgmental. For this reason, these questions have been placed at the end of the interview, after the client is used to being asked questions.

118. As far as you know, are there any diseases that can be transmitted through sexual intercourse?

119. From what you've heard or read, what are some common signs and symptoms of sexually transmitted diseases?

Be aware that the client may not use our terms when describing symptoms. Classify as well as you can what the client says, using our terms. If the client does not mention any problems, tick line 98.
120. Have you ever heard of HIV or AIDS, or are you not sure?

121. As far as you know, what are the ways to get HIV/AIDS?

Be aware that the client may not use our terms when describing transmission routes. Classify as well as you can what the client says, using our terms. If the client does not mention any problems, tick line 98.

122. Do you know of any ways you can protect yourself from sexually transmitted diseases including HIV/AIDS?

123. (If yes) What are these ways of protecting yourself?

These knowledge questions are extremely important. Note that although HIV/AIDS is itself a sexually transmitted disease, clients (and providers) may often think of it as a separate and distinct category.

124. How many sexual partners have you had in the past 12 months? Write the number of partners the client mentions. If she says none, end the interview by thanking the client for her time and assistance.

125. Did you have sex with any new partner(s) in the past 12 months?

126. (If yes) Did you use a condom the first time you had sex with your most recent new partner?

These questions address the amount of risk clients are generally exposed to. In question 126 , emphasize that we are asking about the first time you had sex with your most recent new partner. 


\section{Staff interview}

This instrument gathers information on the training, knowledge, and practices of family planning providers. The results of these interviews help program planners to design training programs targeted to the specific needs of staff. This information can also be compared to information from the observations, to see how effectively provider knowledge is translated into provider actions.
The codes presented in brackets \{\} in this instrument are suggested variable names for each question or tick mark. These names are referred to in the analysis plan (beginning on page 162). Keep in mind, however, that they would not appear on the actual questionnaires used by researchers in the field.

See instrument on following pages. 
INSTRUCTIONS TO INTERVIEWER: All health facility staff who are responsible for providing family planning should be interviewed individually and in private at the end of the working day. It should be made clear that you are seeking their assistance in finding ways of improving the functioning and quality of the services offered by facilities in general, and are not evaluating the performance of the facility or of themselves individually. For each item, please circle the response or describe as appropriate.

Health facility visited (name):

\{HFNAME\}

Health facility code:

$\{\mathrm{HFCODE}\}$

District (name):

\{DISTNAME\}

District code:

\{DISTCODE\}

Village/town (name):

\{TOWNNAME\}

Village/town code:

\{TOWNCODE\}

Study staff number:

\{STAFFID\}

Date of visit:

(DATE\}

Day

Month Year

Type of health facility: \{TYPE\}

Type of sector: \{SECT\}

$1=$ Referral Hospital

$2=$ District Hospital

1 = Government

3 = Primary Hospital

$2=$ FPA

$4=$ Rural Health Center

$3=$ Mission

$5=$ Maternity

$6=$ Health Post

$7=$ Pharmacy

$8=\mathrm{CBD}$

$9=$ Other

4 = Private

$5=$ Other

Locality: $\{L O C\}$

$1=$ Rural

2 = Urban

Designation of staff member: \{DESIG\}

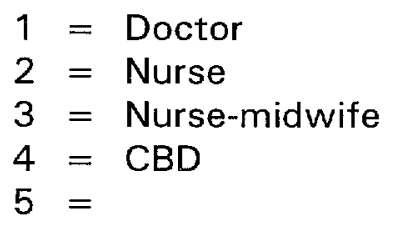

Name of observer:

Signature of team leader: 


\section{Read greeting:}

We are carrying out a survey of health facilities that provide reproductive health services to find ways of improving services. We would be interested to know about your experiences so far with providing family planning services. Could I ask you some questions about this? Please be assured that this discussion is strictly confidential, and your name is not being recorded. Also, you are not obliged to answer any question you don't want to, and you may withdraw from the interview at any time. May I continue?

(If the provider agrees to continue, ask if she has any questions. Respond to questions as appropriate, then ask q. 1

If the provider does not agree to continue, thank her and go to the next interview.)

\section{Experience and training in FP/MCH/STD services}

1. I'd like to ask you about services you provide to clients at this facility. Do you yourself provide (read 1-18) to clients at this health facility?

\begin{tabular}{|l|l|}
\hline 1. Family planning & $\{S 1 \times 1\}$ \\
\hline 2. Antenatal care & $\{S 1 \times 2\}$ \\
\hline 3. Maternity care/delivery services & $\{S 1 \times 3\}$ \\
\hline 4. Postnatal care & $\{S 1 \times 4\}$ \\
\hline 5. HIV/AIDS counselling/IEC & $\{S 1 \times 5\}$ \\
\hline 6. HIV/AIDS testing & $\{S 1 \times 6\}$ \\
\hline 7. Other STD counselling/IEC & $\{S 1 \times 7\}$ \\
\hline 8. Other STD diagnosis & $\{S 1 \times 8\}$ \\
\hline 9. Other STD treatment & $\{S 1 \times 9\}$ \\
\hline 10. Child immunization & $\{S 1 \times 10\}$ \\
\hline 11. Child growth monitoring & $\{S 1 \times 11\}$ \\
\hline 12. Infertility consultation & $\{S 1 \times 12\}$ \\
\hline 13. Oral rehydration therapy & $\{S 1 \times 13\}$ \\
\hline 14. Treatment of incomplete abortion & $\{S 1 \times 14\}$ \\
\hline 15. Nutrition counselling & $\{S 1 \times 15\}$ \\
\hline 16. Curative services - client & $\{S 1 \times 16\}$ \\
\hline 17. Curative services - child & $\{S 1 \times 17\}$ \\
\hline 18. & $\{S 1 \times 18\}$ \\
\hline
\end{tabular}


2. How long have you been working here at this facility? \{S2\}

years

(Round to nearest year)
$00=$ Less than six months

$98=$ Don't know

3. How many years ago did you finish your basic training? $\{53\}$

years ago

(Round to nearest year)
$00=$ Less than six months

97 = No basic training

$98=$ Don't know

\begin{tabular}{|c|c|c|c|}
\hline & $\begin{array}{l}\text { 4. Did your basic } \\
\text { training cover } \\
\text { (read 1-12)? } \\
\text { (Tick if yes) }\end{array}$ & 5. & $\begin{array}{l}\text { Have you ever } \\
\text { had refresher } \\
\text { training in } \\
\text { (read 1-12)? } \\
\text { (Tick if yes) }\end{array}$ \\
\hline 1. Family planning & $\{S 4 \times 1\}$ & $\{S 5 \times 1\}$ & \\
\hline 2. Antenatal care & $\{\mathrm{S} 4 \times 2\}$ & $\{S 5 \times 2\}$ & \\
\hline 3. Maternity care/ delivery services & $\{\mathrm{S} 4 \times 3\}$ & $\{S 5 \times 3\}$ & \\
\hline 4. Postnatal care & $\{\$ 4 \times 4\}$ & $\{55 \times 4\}$ & \\
\hline 5. Child immunization & $\{S 4 \times 5\}$ & $\{55 \times 5\}$ & \\
\hline 6. Child growth monitoring & $\{54 \times 6\}$ & $\{S 5 \times 6\}$ & \\
\hline 7. Infertility consultation & $\{S 4 \times 7\}$ & $\{S 5 \times 7\}$ & \\
\hline 8. Oral rehydration therapy & $\{54 \times 8\}$ & $\{55 \times 8\}$ & \\
\hline 9. Treatment of incomplete abortion & $\{\mathrm{S} 4 \times 9\}$ & $\{\mathrm{S} 5 \times 9\}$ & \\
\hline 10. Nutrition counselling & $\{54 \times 10\}$ & $\{\mathrm{S} 5 \times 10\}$ & \\
\hline 11. & $\{\$ 4 \times 11\}$ & $\{\mathrm{S} 5 \times 11\}$ & \\
\hline 12. & $\{S 4 \times 12\}$ & $\{\mathrm{S} 5 \times 12\}$ & \\
\hline
\end{tabular}


6. Have you attended any refresher or post-basic training courses specifically on family planning clinical skills, family planning program management, or HIV/STD counselling and treatment?

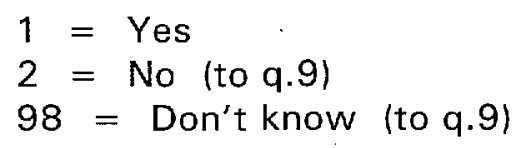

\begin{tabular}{|c|c|c|c|}
\hline & $\begin{array}{l}\text { 7. Did that training } \\
\text { include } \\
\text { (read 1-19)? } \\
\text { (Tick if yes) }\end{array}$ & 8. & $\begin{array}{l}\text { (If topic covered) How } \\
\text { long ago was that } \\
\text { training? } \\
0=\text { Less than one year } \\
98=\text { Don't know }\end{array}$ \\
\hline 1. General clinical skills in FP & $\{S 7 \times 1\}$ & $\{\mathrm{s} 8 \times 1\}$ & years \\
\hline 2. FP counselling & $\{S 7 \times 2\}$ & $\{\mathrm{S} 8 \times 2\}$ & years \\
\hline 3. IUD insertion / removal & $\{s 7 \times 3\}$ & $\{s 8 \times 3\}$ & years \\
\hline 4. NORPLANT ${ }^{\circledR}$ insertion / removal & $\{57 \times 4\}$ & $\{\mathrm{s} 8 \times 4\}$ & years \\
\hline 5. ML/LA (surgical procedure) & $\{S 7 \times 5\}$ & $\{s 8 \times 5\}$ & years \\
\hline 6. Vasectomy (surgical procedure) & $\{57 \times 6\}$ & $\{58 \times 6\}$ & years \\
\hline 7. Exclusive breastfeeding (LAM) & $\{S 7 \times 7\}$ & $\{58 \times 7\}$ & years \\
\hline 8. Natural family planning & $\{57 \times 8\}$ & $\{58 \times 8\}$ & years \\
\hline 9. Management & $\{57 \times 9\}$ & $\{\mathrm{s} 8 \times 9\}$ & years \\
\hline 10. Supervision & $\{S 7 \times 10\}$ & $\{\mathrm{S} 8 \times 10\}$ & years \\
\hline 11. Recordkeeping & $\{S 7 \times 11\}$ & $\{\mathrm{S} 8 \times 11\}$ & years \\
\hline 12. Stockkeeping & $\{S 7 \times 12\}$ & $\{S 8 \times 12\}$ & years \\
\hline 13. STD risk assessment/ screening & $\{57 \times 13\}$ & $\{S 8 \times 13\}$ & years \\
\hline 14. STD counselling & $\{57 \times 14\}$ & $\{\mathrm{S} 8 \times 14\}$ & years \\
\hline 15. STD laboratory diagnosis & $\{S 7 \times 15\}$ & $\{S 8 \times 15\}$ & years \\
\hline $\begin{array}{l}\text { 16. Syndromic approach to diagnosis } \\
\text { and treatment }\end{array}$ & $\{S 7 \times 16\}$ & $\{S 8 \times 16\}$ & years \\
\hline 17. HIV/AIDS counselling & $\{57 \times 17\}$ & $\{S 8 \times 17\}$ & years \\
\hline 18. HIV/AIDS testing & $\{S 7 \times 18\}$ & $\{\mathrm{S} 8 \times 18\}$ & years \\
\hline 19. Other: $\_\{\text {S7X19R }\}$ & $\{57 \times 19\}$ & $\{\mathrm{S} 8 \times 19\}$ & years \\
\hline
\end{tabular}




\section{FP practices}

9. In the last 3 months, have you yourself actually provided family planning to clients?

$$
\begin{aligned}
& 1=\text { Yes } \\
& 2=\text { No (to q.32) } \\
& 98=\text { Don't know (to q.32) }
\end{aligned}
$$

10. (If yes) Which methods have you yourself actually provided in the last 3 months? (Read $1-15)$

\begin{tabular}{|l|l|}
\hline 1. Combined pill & $\{\mathrm{S} 10 \times 1\}$ \\
\hline 2. Progestin-only pill & $\{\mathrm{S} 10 \times 2\}$ \\
\hline 3. IUD & $\{\mathrm{S} 10 \times 3\}$ \\
\hline 4. Injectable & $\{\mathrm{S} 10 \times 4\}$ \\
\hline 5. NORPLANT ${ }^{\circledR}$ & $\{\mathrm{S} 10 \times 5\}$ \\
\hline 6. Condom & $\{\mathrm{S} 10 \times 6\}$ \\
\hline 7. Diaphragm & $\{\mathrm{S} 10 \times 7\}$ \\
\hline 8. Spermicide & $\{\mathrm{S} 10 \times 8\}$ \\
\hline 9. Female sterilization (ML/LA) & $\{\mathrm{S} 10 \times 9\}$ \\
\hline 10. Vasectomy & $\{\mathrm{S} 10 \times 10\}$ \\
\hline 11. Natural family planning & $\{\mathrm{S} 10 \times 11\}$ \\
\hline 12. Exclusive breastfeeding (LAM) & $\{\mathrm{S} 10 \times 12\}$ \\
\hline 13. Emergency FP & $\{\mathrm{S} 10 \times 13\}$ \\
\hline 14. Other: & $\{\mathrm{S} 10 \times 14\}$ \\
\hline 15. & $\{\mathrm{S} 10 \times 15\}$ \\
\hline
\end{tabular}




\begin{tabular}{|c|c|c|c|}
\hline & $\begin{array}{l}\text { 11. Is there a minimum age below } \\
\text { which you yourself will not } \\
\text { prescribe (read 1-5), in the } \\
\text { absence of medical } \\
\text { contraindications? } \\
\text { (Tick if yes) }\end{array}$ & 12. & $\begin{array}{l}\text { (If yes on q.11) } \\
\text { What is that } \\
\text { minimum age? }\end{array}$ \\
\hline 1. Pill (COC) & $\{S 11 \times 1\}$ & Age: & $\{S 12 \times 1\}$ \\
\hline 2. Condom & $\{511 \times 2\}$ & Age: & $\{\$ 12 \times 2\}$ \\
\hline 3. IUD & $\{511 \times 3\}$ & Age: & $\{\$ 12 \times 3\}$ \\
\hline 4. Injectable & $\{S 11 \times 4\}$ & Age: & $\{S 12 \times 4\}$ \\
\hline 5. Sterilization & $\{S 11 \times 5\}$ & Age: & $\{S 12 \times 5\}$ \\
\hline
\end{tabular}

\begin{tabular}{|c|c|c|c|}
\hline & $\begin{array}{l}\text { 13. Is there a maximum age above } \\
\text { which you yourself will not } \\
\text { prescribe (read 1-5), in the } \\
\text { absence of medical } \\
\text { contraindications? } \\
\text { (Tick if yes) }\end{array}$ & 14. & $\begin{array}{l}\text { (If yes on q.13) } \\
\text { What is that } \\
\text { maximum age? }\end{array}$ \\
\hline 1. Pill (COC) & $\{S 13 \times 1\}$ & Age: & $\{S 14 \times 1\}$ \\
\hline 2. Condom & $\{S 13 \times 2\}$ & Age: & $\{\mathrm{S} 14 \times 2\}$ \\
\hline 3. IUD & $\{\$ 13 \times 3\}$ & Age: & $\{\$ 14 \times 3\}$ \\
\hline 4. Injectable & $\{S 13 \times 4\}$ & Age: & $\{S 14 \times 4\}$ \\
\hline 5. Sterilization & $\{\$ 13 \times 5\}$ & Age: & $\{S 14 \times 5\}$ \\
\hline
\end{tabular}




\begin{tabular}{|c|c|c|c|c|}
\hline & 15. & $\begin{array}{l}\text { Is there a minimum number of } \\
\text { children a woman must have } \\
\text { before you yourself will } \\
\text { prescribe (read 1-5), in the } \\
\text { absence of medical } \\
\text { contraindications? } \\
\text { (Tick if yes) }\end{array}$ & $\begin{array}{l}\text { lif } \\
\text { the } \\
\text { nu }\end{array}$ & $\begin{array}{l}\mathrm{t} \text { is } \\
\mathrm{n} \\
\text { ildren? }\end{array}$ \\
\hline 1. Pill (COC) & \multicolumn{2}{|c|}{$\mathrm{S} 15 \times 1$} & Number: & $\{S 16 \times 1\}$ \\
\hline 2. Condom & \multicolumn{2}{|c|}{$S 15 \times 2$} & \multicolumn{2}{|l|}{ Number: } \\
\hline 3. IUD & \multicolumn{2}{|c|}{$S 15 \times 3$} & \multicolumn{2}{|l|}{ Number: } \\
\hline 4. Injectable & \multicolumn{2}{|c|}{$S 15 \times 4$} & \multicolumn{2}{|l|}{ Number: } \\
\hline 5. Sterilization & \multicolumn{2}{|c|}{$S 15 \times 5$} & \multicolumn{2}{|l|}{ Number: } \\
\hline
\end{tabular}

\begin{tabular}{|c|c|c|c|c|}
\hline & 17. & $\begin{array}{l}\text { Would you yourself prescribe } \\
\text { (read } 1-5 \text { ) to an unmarried } \\
\text { woman, in the absence of } \\
\text { medical contraindications? } \\
\text { (Tick if yes) }\end{array}$ & 18. & $\begin{array}{l}\text { Do you require a } \\
\text { husband's consent } \\
\text { before you will } \\
\text { provide (read 1-5)? } \\
\text { (Tick if yes) }\end{array}$ \\
\hline 1. Pill $(\mathrm{COC})$ & \multicolumn{2}{|c|}{$S 17 \times 1$} & \multicolumn{2}{|c|}{$S 18 \times 1$} \\
\hline 2. Condom & \multicolumn{2}{|c|}{$517 \times 2$} & \multicolumn{2}{|c|}{$S 18 \times 2$} \\
\hline 3. IUD & \multicolumn{2}{|c|}{$S 17 \times 3$} & \multicolumn{2}{|c|}{$S 18 \times 3$} \\
\hline 4. Injectable & \multicolumn{2}{|c|}{$S 17 \times 4$} & \multicolumn{2}{|c|}{$s 18 \times 4$} \\
\hline 5. Sterilization & \multicolumn{2}{|c|}{$S 17 \times 5$} & \multicolumn{2}{|c|}{$\$ 18 \times 5$} \\
\hline
\end{tabular}


19. Are there methods of family planning that you recommend for most people who would like to delay or space their next birth, assuming there are no contraindications? $\{\$ 19\}$

$1=$ Yes (to q.19a)

2 = No (to q. 20)

$3=$ Depends on client's health (to q.20)

$4=$ Depends on client's preference (to q. 20)

$99=$ No response (to q.20)

19a. What are those methods?
20. Are there methods of family planning that you recommend for most people who would like to have no more children, assuming there are no contraindications? $\{$ S20 $\}$

$1=$ Yes (to q.20a)

$2=$ No (to q. 21)

3 = Depends on client's health (to q.21)

$4=$ Depends on client's preference (to q.21)

$99=$ No response (to q.21)

20a. What are those methods?

Do not read methods, but probe with "Any other methods?" Tick if mentioned.

\begin{tabular}{|c|c|c|}
\hline 1. Combined pill & $\{$ S19AX1\} & $\{S 20 A \times 1\}$ \\
\hline 2. Progestin-only pill & $\{S 19 A \times 2\}$ & $\{S 20 A \times 2\}$ \\
\hline 3. IUD & $\{S 19 A \times 3\}$ & $\{S 20 A \times 3\}$ \\
\hline 4. Injectable & $\{$ S19AX4\} & $\{S 20 A \times 4\}$ \\
\hline 5. NORPLANT ${ }^{\circledR}$ & $\{S 19 A \times 5\}$ & $\{S 20 A \times 5\}$ \\
\hline 6. Condom & $\{S 19 A \times 6\}$ & $\{S 20 A \times 6\}$ \\
\hline 7. Diaphragm & $\{\mathrm{S} 19 \mathrm{~A} \times 7\}$ & $\{S 20 A \times 7\}$ \\
\hline 8. Spermicide & $\{\mathrm{S} 19 \mathrm{~A} \times 8\}$ & $\{S 20 A \times 8\}$ \\
\hline 9. Female sterilization & $\{\mathrm{S} 19 \mathrm{~A} \times 9\}$ & $\{S 20 A \times 9\}$ \\
\hline 10. Vasectomy & $\{\mathrm{S} 19 \mathrm{~A} \times 10\}$ & $\{\mathrm{S} 20 \mathrm{~A} \times 10\}$ \\
\hline 11. NFP & $\{\mathrm{S} 19 \mathrm{AX} 11\}$ & $\{S 20 A \times 11\}$ \\
\hline 12. LAM & $\{S 19 A \times 12\}$ & $\{\mathrm{S} 20 \mathrm{~A} \times 12\}$ \\
\hline 13. Other: $\begin{array}{l}\{\text { S19AX13R } \\
\{S 20 A \times 13 R\}\end{array}$ & $\{\mathrm{S} 19 \mathrm{AX} 13\}$ & $\{\mathrm{S} 20 \mathrm{~A} \times 13\}$ \\
\hline
\end{tabular}




\begin{tabular}{|c|c|c|}
\hline & $\begin{array}{l}\text { 21. Are there methods of family } \\
\text { planning that you would not } \\
\text { recommend for clients with } \\
\text { an RTI/STD? \{s } 21\} \\
1=\text { Yes (to q. } 21 \mathrm{a} \text { ) } \\
2=\text { No (to q. } 22 \text { ) } \\
3=\text { Depends on client's } \\
\quad \text { health (to q. } 22 \text { ) } \\
4=\text { Depends on client's } \\
\quad \text { preference (to q. } 22 \text { ) } \\
99=\text { No response (to q.22) }\end{array}$ & $\begin{array}{l}\text { 22. Are there methods of family } \\
\text { planning that you would } \\
\text { never recommend under any } \\
\text { circumstances? \{s22\} } \\
1=\text { Yes (to q. } 22 \text { a) } \\
2=\text { No (to q.23) } \\
3=\text { Depends on client's } \\
\quad \text { health (to q. } 23 \text { ) } \\
4=\text { Depends on client's } \\
\quad \text { preference (to q. } 23 \text { ) } \\
99=\text { No response (to q.23) }\end{array}$ \\
\hline & 21a. What are those methods? & 22a. What are those methods? \\
\hline & \multicolumn{2}{|c|}{$\begin{array}{c}\text { Do not read methods, but probe with "Any other methods?" } \\
\text { Tick if mentioned }\end{array}$} \\
\hline 1. Combined pill & $\{\mathrm{S} 21 \mathrm{AX} 1\}$ & $\{S 22 A \times 1\}$ \\
\hline 2. Progestin-only pill & $\{\mathrm{S} 21 \mathrm{~A} \times 2\}$ & $\{S 22 A \times 2\}$ \\
\hline 3. IUD & $\{\mathrm{S} 21 \mathrm{~A} \times 3\}$ & $\{S 22 A \times 3\}$ \\
\hline 4. Injectable & $\{S 21 A \times 4\}$ & $\{S 22 A \times 4\}$ \\
\hline 5. NORPLANT ${ }^{\circledR}$ & $\{\mathrm{S} 21 \mathrm{AX} \times 5\}$ & $\{\mathrm{S} 22 \mathrm{~A} \times 5\}$ \\
\hline 6. Condom & $\{\mathrm{S} 21 \mathrm{AX} 6\}$ & $\{S 22 A \times 6\}$ \\
\hline 7. Diaphragm & $\{S 21 A \times 7\}$ & $\{\mathrm{S} 22 \mathrm{~A} \times 7\}$ \\
\hline 8. Spermicide & $\{\mathrm{S} 21 \mathrm{AX} 8\}$ & $\{S 22 A \times 8\}$ \\
\hline 9. Female sterilization & $\{\mathrm{S} 21 \mathrm{~A} \times 9\}$ & $\{\mathrm{S} 22 \mathrm{AX} \times\}$ \\
\hline 10. Vasectomy & $\{\mathrm{S} 21 \mathrm{~A} \times 10\}$ & $\{\mathrm{S} 22 \mathrm{~A} \times 10\}$ \\
\hline 11. NFP & $\{S 21 \mathrm{~A} \times 11\}$ & $\{\mathrm{S} 22 \mathrm{~A} \times 11\}$ \\
\hline 12. LAM & $\{\mathrm{S} 21 \mathrm{~A} \times 12\}$ & $\{\mathrm{S} 22 \mathrm{~A} \times 12\}$ \\
\hline 13. Other: $\begin{array}{l}\{S 21 \mathrm{~A} \times 13 R\} \\
\{S 22 \mathrm{~A} \times 13 \mathrm{R}\}\end{array}$ & $\{\mathrm{S} 21 \mathrm{AX} 13\}$ & $\{\mathrm{S} 22 \mathrm{~A} \times 13\}$ \\
\hline
\end{tabular}


23. What do you do for a new client who wants the pill or another hormonal method but is not having her menses? (Do not read, but probe with "Anything else?")

\begin{tabular}{|l|l|}
\hline 1. Perform a pregnancy test & $\{\mathrm{S} 23 \times 1\}$ \\
\hline 2. Tell her to come back at next menses & $\{\mathrm{S} 23 \times 2\}$ \\
\hline 3. Try to induce menses & $\{\mathrm{s} 23 \times 3\}$ \\
\hline 4. Supply condoms and ask her to return with menses & $\{\mathrm{s} 23 \times 4\}$ \\
\hline 5. Supply hormonal method & $\{\mathrm{s} 23 \times 5\}$ \\
\hline $\begin{array}{l}\text { 6. Supply hormonal method and condoms and ask her to use } \\
\text { condoms until her menses }\end{array}$ & $\{\mathrm{S} 23 \times 6\}$ \\
\hline 7. Other: \{S23X7R\} & $\{\mathrm{S} 23 \times 7\}$ \\
\hline
\end{tabular}

24. How many packets of combined pills do you routinely supply to a pill client who has successfully used the pill for one year or more? $\{\mathrm{s} 24\}$

packets $\quad 99=$ other response 


\section{Reproductive health practices}

25. If a pill client comes for a check-up/resupply and she appears to be at high risk of infection with an STD or HIVIAIDS, what advice would you give? (Do not read list. Circle all that apply.)

$1=$ Continue to use the pill alone

$\{525 \times 1\}$

$2=$ Continue with the pill but use a condom also

$\{\mathrm{S} 25 \times 2\}$

3 = Switch from the pill to the condom

$4=$ Stop using any type of contraception

$\{525 \times 4\}$

$5=$ Counsel client on STDs/HIV or refer for counseling

$\{\mathrm{S} 25 \times 5\}$

6 = Other:

$98=$ Don't know

\{S25X6R\}

$\{\mathrm{S} 25 \times 6\}$

\{S25×98\}

26. If you think that a client has an STD, what do you do for her? (Do not read list but probe by asking, "Anything else?")

\begin{tabular}{|l|l|}
\hline 1. Request laboratory tests & $\{\mathrm{S} 26 \times 1\}$ \\
\hline 2. Diagnose & $\{\mathrm{S} 26 \times 2\}$ \\
\hline 3. Treat & $\{\mathrm{S} 26 \times 3\}$ \\
\hline 4. Refer for diagnoses & $\{\mathrm{S} 26 \times 4\}$ \\
\hline 5. Refer for treatment & $\{\mathrm{S} 26 \times 5\}$ \\
\hline 6. Provide counselling & $\{\mathrm{S} 26 \times 6\}$ \\
\hline 7. Refer for counselling & $\{\mathrm{S} 26 \times 7\}$ \\
\hline 8. Issue a contact or partner notification slip & $\{\mathrm{S} 26 \times 8\}$ \\
\hline 9. Other: $\{\mathrm{S} 26 \times 9 \mathrm{R}\}$ & $\{\mathrm{S} 26 \times 9\}$ \\
\hline
\end{tabular}


27. If you think that a client has HIV/AIDS, what do you do for her?

Tick if mentioned

(Do not read list but probe by asking, "Anything else?")

\begin{tabular}{|l|l|}
\hline 1. Request HIV test & $\{\mathrm{S} 27 \times 1\}$ \\
\hline 2. Refer for HIV test & $\{\mathrm{S} 27 \times 2\}$ \\
\hline 3. Provide condoms & $\{\mathrm{S} 27 \times 3\}$ \\
\hline 4. Provide or refer for treatment of complications & $\{\mathrm{S} 27 \times 4\}$ \\
\hline 5. Provide counselling & $\{\mathrm{S} 27 \times 5\}$ \\
\hline 6. Refer/request for counselling & $\{\mathrm{S} 27 \times 6\}$ \\
\hline 7. Issue contact or partner slip & $\{\mathrm{S} 27 \times 7\}$ \\
\hline 8. Other: \{S27X8R\} & $\{\mathrm{S} 27 \times 8\}$ \\
\hline
\end{tabular}

28. Do you request a syphilis test for antenatal clients you see at this health facility? \{S28\}

$$
\begin{aligned}
& 1=\text { Yes } \\
& 2=\text { No }
\end{aligned}
$$

29. How comfortable are you discussing sexual behavior related to STD/HIV with clients? Would you say you are very uncomfortable, somewhat uncomfortable, comfortable, or very comfortable? $\{\mathrm{S} 29\}$

$$
\begin{aligned}
& 1=\text { Very uncomfortable } \\
& 2=\text { Somewhat uncomfortable } \\
& 3=\text { Comfortable } \\
& 4=\text { Very comfortable } \\
& 99=\text { No response }
\end{aligned}
$$

30. As far as you know, do women come to this facility for advice on termination of pregnancies? $\{\mathrm{S} 30\}$

$$
\begin{aligned}
& 1=\text { Yes } \\
& 2=\text { No } \\
& 98=\text { Don't know }
\end{aligned}
$$

31. As far as you know, do women come to this facility for medical treatment as a consequence of an incomplete, induced abortion? \{s31\}

$$
\begin{aligned}
& 1=\text { Yes } \\
& 2=\text { No } \\
& 98=\text { Don't know }
\end{aligned}
$$




\section{Socio-demographic characteristics}

32. To end with, I would like to ask you a few questions about yourself. How old are you?

$$
\text { years old } \quad 98=\text { Don't know }
$$

33. What is your current marital status? (Probe for exact status) $\{\mathrm{S} 33\}$

$$
\begin{aligned}
& 1=\text { Married/monogamous } \\
& 2=\text { Married/polygamous } \\
& 3=\text { Cohabiting/living together } \\
& 4=\text { Single, never married } \\
& 5=\text { Divorced/separated } \\
& 6=\text { Widowed }
\end{aligned}
$$

34. How many living children of your own do you have? \{S34\}

$$
\text { children } \quad 99=\text { No response }
$$

35. What is your religion? $\{\mathrm{s} 35\}$

$$
\begin{aligned}
& 1=\text { Protestant } \\
& 2=\text { Catholic } \\
& 3=\text { Moslem } \\
& 4=\text { African Spiritual } \\
& 5=\text { None } \\
& 6=\text { Other: } \\
& 98=\text { Don't know }
\end{aligned}
$$

36. Gender: $\{\mathrm{S} 36\}$

$$
\begin{aligned}
& 1=\text { Female } \\
& 2=\text { Male }
\end{aligned}
$$


37. What method(s) of family planning are you or your partner currently using? (Do not read list, but probe by asking, "Any other methods?")

\begin{tabular}{|l|l|}
\hline 1. Combined pill & $\{\mathrm{S} 37 \times 1\}$ \\
\hline 2. Progestin-only pill & $\{\mathrm{S} 37 \times 2\}$ \\
\hline 3. IUD & $\{\mathrm{S} 37 \times 3\}$ \\
\hline 4. Injectable & $\{\mathrm{S} 37 \times 4\}$ \\
\hline 5. NORPLANT ${ }^{\circledR}$ & $\{\mathrm{S} 37 \times 5\}$ \\
\hline 6. Condom & $\{\mathrm{S} 37 \times 6\}$ \\
\hline 7. Diaphragm & $\{\mathrm{S} 37 \times 7\}$ \\
\hline 8. Spermicide & $\{\mathrm{S} 37 \times 8\}$ \\
\hline 9. Female sterilization & $\{\mathrm{S} 37 \times 9\}$ \\
\hline 10. Vasectomy & $\{\mathrm{S} 37 \times 10\}$ \\
\hline 11. Natural family planning & $\{\mathrm{S} 37 \times 11\}$ \\
\hline 12. Exclusive breastfeeding (LAM) & $\{\mathrm{S} 37 \times 12\}$ \\
\hline 13. Other: & $\{\mathrm{S} 37 \times 13\}$ \\
\hline 77. None & $\{\mathrm{S} 37 \times 77\}$ \\
\hline
\end{tabular}

\section{Read closing:}

Thank you very much for having spent so much time with me. 


\section{Staff interview: question-by- question guide}

The first person to be interviewed is usually the staff person in charge of family planning services. It is necessary to obtain this person's permission to interview other staff, and to make it clear that the interviews are not an evaluation of individual staff or facility performance. Also, staff names will not be recorded on any of the interview schedules. After permission is obtained, all other family planning providers should be interviewed.

The staff member in charge of family planning is the same person who will be asked to assist in conducting the inventory. Because of this, the research team needs to coordinate the taking of the inventory with the interview so as not to take too much of a single staff person's time.

The interviews should be carried out at a time when staff are not actively engaged in the delivery of services to clients, which is usually in the afternoon. In all cases, every effort should be made to minimize the impact of drawing staff away from their other, normal duties. (See the section on "Tips for conducting a good interview," page 23 for more information.)

You should be able to fill out the information on the cover page before the interview begins. If you are not sure about any of the identifying codes, ask your Team Leader. Write (do not sign) your name in the box at the bottom of the page. When you have completed the interview, your Team Leader will review it and sign below your name. Before starting the interview, be sure to read the greeting as printed on the interview schedule and obtain the "informed consent" of each individual provider.
1. I'd like to ask you about services you provide to clients at this facility. Do you yourself provide (various methods/services) to clients at this health facility?

The purpose of this question is to determine all the services the staff person provides to clients. You should make sure that the staff person herself is the one who provides the services. For each service listed, ask the provider "Do you yourself provide (the service listed)," emphasizing the word "yourself."

\section{How long have you been working} here at this facility?

Record the number of years. If less than 6 months, record 00 . If more than six months but less than 12 months, record 1 .

3. How many years ago did you finish your basic training?

4. Did your basic training cover (various topics)?

Emphasize the words "basic training." Basic training refers to the most advanced, long-term training the staff person received for their present position. For example, a nurse/midwife might have been through the same training as a nurse, plus some additional long-term midwifery training. In this case, "basic training" refers to the midwifery training because it is the most advanced she received, and it qualifies her for her position. For a nurse, "basic training" would be the nurse training only.

5. Have you ever had refresher training in (various topics)? Emphasize the words "refresher training." 
Refresher training refers to training received after basic training and usually is of relatively short duration. Sometimes this training is referred to as in-service training.

\section{Have you attended any refresher or} post-basic training courses specifically on family planning clinical skills, family planning program management, or HIV/STD counseling and treatment?

7. Did that training include (various FP topics)?

8. (If topic covered) How long ago was that training?

These questions begin to focus on family planning training in particular. Note that question 7 is only asked if the provider answers "yes" to question 6. Fill in the column for question 8 only for those topics in which the provider was

trained. If the training occurred less than 12 months prior, record 0.

9. In the last 3 months, have you yourself actually provided family planning to clients?

10. (If yes) Which methods have you yourself actually provided in the last 3 months?

These questions serve to identify the providers who are actually providing FP services. In both questions, emphasize the words "you yourself." "Actually provided" means that the staff person physically gave a method to a client or performed a procedure such as a sterilization, an IUD insertion, or an injection. It does not mean merely referring a client to another provider or facility to receive the method. With regard to LAM and NFP, since these two methods do not require contraceptive supplies or invasive procedures, providing information and education to the client constitutes "actually providing" the method.

\section{Is there a minimum age below} which you yourself will not prescribe (various methods), in the absence of medical contraindication.

12. (If yes on q. 11) What is that minimum age?

13. Is there a maximum age above which you yourself will not prescribe (various methods), in the absence of medical contraindications?

14. (If yes on q. 13) What is that maximum age?

These questions determine whether the staff member uses age as a sole criteria for providing a contraceptive method to a client. These questions are some of the most complex in the Situation Analysis, and you may find that they will require some extra explanation to the provider.

First, ask if there is a minimum age below which the provider will not prescribe methods. Emphasize the words "you yourself." Note that this is in the absence of medical contraindicationsthis question is assumed to apply to new family planning clients in good health. If the provider says yes, then ask what that minimum age is and record it.

Remember that the minimum age is the age below which the staff person will not provide the method under any circumstances. For example, suppose a provider says that she will not give pills to a girl of 14 years or below, unless the girl is married. In this case, the provider 
has specified an exception to her rule regarding age and she is not using age as the sole criteria. In this case, you might ask if there is a minimum age for married clients, which would get at the provider's minimum age requirement, regardless of the client's circumstances. If the provider cannot specify an age that she would use as the sole criteria, record that there is no minimum limit.

The same process applies to the maximum age. First ask if the provider has such a maximum limit, emphasizing the words "you yourself," and then ask what the limit is. Again, this applies to new, healthy family planning clients only, and cases in which age is the sole criteria.

Please record the ages that providers give, regardless of how extreme they may appear. For example, a provider may say that her maximum age for condoms is 100 . This may seem to be intuitively equivalent to "no maximum age," but it should be recorded nonetheless. These cases will be dealt with in the data analysis.

Also remember that as you ask these questions, and especially if you engage in a clarifying conversation with the provider, never suggest sample ages. That is, do not explain with, "Do you feel that a client who is 12 is too young for the pill?" If you mention a number, even as an example only, it may bias the response.

Sometimes, specific program policies direct providers not to give methods to clients outside of certain age ranges. For example, sterilization is sometimes barred to women under 35 , as a matter of policy, not as a matter of provider discretion. In those cases, the provider may be hesitant to contradict the policy in this interview, even if she does so quietly with clients. Reassure the provider that the interview is strictly confidential. However, if she would still like to report according to the policy, record her answer.

\section{Is there a minimum number of chil-} dren a woman must have before you yourself will prescribe (various methods), in the absence of medical contraindications?

16. (If yes) What is that minimum number of children?

The purpose of question 15 is to find out if the staff person uses a minimum number of children as a sole criteria for providing a contraceptive method to a client. For example, the provider may say that she requires a client to have two children before giving the injectable, except if she is over 35 . In that case, the provider is using age as another criteria, so the number of children alone is not a rigid barrier. Code this as no barrier. Note also that this involves new family planning clients who are otherwise healthy, so the provider does not have to consider any contraindications. Emphasize the words "you yourself" in question 15.

Sometimes, specific program policies direct providers not to give methods to clients who have no children. For example, IUDs are sometimes barred to women with no children, as a matter of policy, not as a matter of provider discretion. In those cases, the provider may be hesitant to contradict the policy in this interview, even if she does so quietly with clients. Reassure the provider that the interview is strictly confidential. 
However, if she would still like to report according to the policy, record her answer.

17. Would you yourself prescribe (various methods) to an unmarried woman, in the absence of medical contraindications?

18. Do you require a husband's consent before you will provide (various methods)?

These two questions also address provider barriers, but they are much less complex than the age or parity questions (11 through 16). They each result in a simple yes/no answers. However, they still require that the barrier is imposed as a sole criteria. If a provider requires a husband's consent usually, but will waive that requirement if the client has a certain number of living children, then husband's consent is not the sole criteria.

Sometimes, specific program policies direct providers not to give methods to unmarried clients or clients without spousal consent. For example, pills are sometimes barred to single women as a matter of policy, not as a matter of provider discretion. In those cases, the provider may be hesitant to contradict the policy in this interview, even if she does so quietly with clients. Reassure the provider that the interview is strictly confidential. However, if she would still like to report according to the policy, record her answer.

19. Are there methods of family planning that you recommend for most people who would like to delay or space their next birth, assuming there are no contraindications?

19a. What are those methods?
20. Are there methods of family planning that you recommend for most people who would like to have no more children, assuming there are no contraindications?

20a. What are those methods?

21. Are there methods of family planning that you would not recommend for clients with an RTI/STD?

21a. What are those methods?

22. Are there methods of family planning that you would never recommend under any circumstances?

22a. What are those methods?

This sequence of questions addresses the provider's attitudes toward particular methods, and the circumstances under which she would provide them. In each case, ask the introductory question $(19,20,21$, and 22), and if the answer is "yes", ask the subordinate question about the specific methods (19a, 20a, 21a, 22a).

Questions 19 and 20 are concerned with spacing and limiting method recommendations given to new family planning clients who are healthy and have no contraindications. Question 21 is about methods recommended for clients with an RTI/STD, assuming that these clients are otherwise healthy. That is, they have no otber contraindications. Question 22 asks about methods the provider would never recommend under any circumstances. Responses to this question are rare, since most providers recognize that all methods have appropriate applications in at least some circumstances. Nonetheless, some informative provider biases have been identified through this question. 
23. What do you do for a new client who wants the pill or another hormonal method but is not having her menses?

Do not read the responses, but probe by asking "Anything else?" Be aware that the provider may not use exactly the same language listed in the table; try to select the most appropriate response.

\section{How many packets of combined} pills do you routinely supply to a pill client who has successfully used the pill for one year or more? The purpose of this question is to find out how many packets of pills providers intend to give to revisit pill clients. This information will be combined with information from the observation showing how many cycles of pills clients actually receive, and with information from the inventory showing the status of pill stocks at that SDP.

25. If a pill client comes for a check-up/ resupply and she appears to be at high risk of infection with an STD or HIV/AIDS, what advice would you give?

This question enquires about provider behavior that is difficult to observe, i.e. what advice she would give to a client who appeared to be at high risk of infection with an STD or HIV/AIDS.

\section{If you think that a client has an} STD, what do you do for her?

\section{If you think that a client has HIV/} AIDS, what do you do for her? The treatment of clients with STDs or HIV/AIDS is an important subject for integrated family planning programs.
These questions address providers' intentions for treating clients suspected of having these conditions, which can be compared to their actions in the observation. Their actions may be hampered by a lack of tests or materials, discomfort with discussing STDs, or lack of time, but these questions in the interview will determine what they would do in the best circumstances. In this way, any lapses in treatment of clients with STD/HIV/AIDS can be identified as problems of provider training or problems of implementation.

28. Do you request a syphilis test for antenatal clients you see at this health facility?

The purpose of this question is to determine if the provider normally or usually requests a syphilis test for antenatal clients. This is a measure of the integration of FP and RH services.

29. How comfortable are you discussing sexual behavior related to STD/HIV with clients? Would you say you are very uncomfortable, somewhat uncomfortable, comfortable, or very comfortable?

Even if a provider is extremely technically competent, she may feel socially prevented from discussing STDs/HIV with clients. This question attempts to measure how comfortable providers feel in these situations.

30. As far as you know, do women come to this facility for advice on termination of pregnancies?

31. As far as you know, do women come to this facility for medical treatment 
as a consequence of an incomplete, induced abortion?

These questions can be controversial, especially in countries where abortion is illegal. For this reason, they are worded very carefully. Note that question 30 does not ask whether women actually receive advice about abortion or whether women actually receive abortions themselves, but simply if women come seeking such advice. Similarly, question 31 does not ask if women actually receive treatment for incomplete abortions. Moreover, both questions carefully avoid asking the individual provider whether she is directly involved with these clients, but only whether she is aware of their presence.

\section{To end with, I would like to ask you} a few questions about yourself. How old are you?

If the provider does not know her age precisely, try to help her estimate with some important historical dates as benchmarks, as instructed in training. If the provider has no idea what her age is, write 98.

\section{What is your current marital status?}

This question should be answered using the provider's definition of marriage.
34. How many living children of your own do you have?

Emphasize the words "living" and "your own." For female providers, this question is intended to determine the number of children to whom she has given birth. For male providers, this question should determine the number of natural children he has fathered. In both cases, it excludes adopted children and children of other relatives presently living with them.

\section{What is your religion?}

\section{Gender?}

These questions, along with others, will serve to identify any large differences in religion and gender among staff as opposed to clients. Such differences can sometimes be a barrier to services. Note that for question 36 there is no need to actually ask the question; simply mark the correct response.

\section{What method(s) of family planning are you or your partner currently using? \\ Do not read the list. Tick all methods the staff person says she is using now. Among those who are using methods, most will list only one, but some may list two. If the provider is not using a method, tick 77 .}




\section{MCH client exit interview}

This instrument gathers information from $\mathrm{MCH}$ clients about the services they have just received as well as their attitudes toward and use of family planning. Information from $\mathrm{MCH}$ clients is useful in two ways. First, it can be compared with information from the FP client exit interview. This helps identify how FP clients differ from $\mathrm{MCH}$ clients, and whether these differences can explain some of the FP clients' attitudes and practices. Second, $\mathrm{MCH}$ client attitudes toward FP and awareness of FP services can assist managers in designing programs that will attract more FP clients. In this sense, the $\mathrm{MCH}$ client population is used as a proxy to gather information about the general population that is not currently using contraception.

The codes presented in brackets \{\} in this instrument are suggested variable names for each question or tick mark. These names are referred to in the analysis plan (beginning on page 162). Keep in mind, however, that they would not appear on the actual questionnaires used by researchers in the field. See instrument on following pages. 
INSTRUCTIONS TO INTERVIEWER: This questionnaire should be used with female clients aged 15 - 45 years at the health facility who have not come for family planning. If possible, try to interview clients after rather than before the consultation. Ask the woman if she is willing to answer some questions about maternal and child health issues. It is essential that you gain her informed consent by reading the greeting before beginning the interview.

Health facility visited (name):

\{HFNAME\}

Health facility code:

\{HFCODE\}

District (name):

\{DISTNAME\}

District code:

\{DISTCODE\}

Village/town (name):

\{TOWNNAME\}

Village/town code:

\{TOWNCODE\}

Study client number:

\{CLIID\}

Client's location/ward:

\{CLILOC\}

Date of visit:

(DATE)

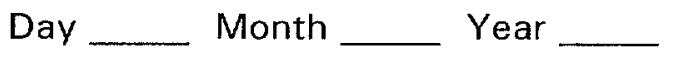

Type of health facility: \{TYPE\}

$1=$ Referral Hospital

$2=$ District Hospital

$3=$ Primary Hospital

$4=$ Rural Health Center

$5=$ Maternity

$6=$ Health Post

7 = Pharmacy

$8=\mathrm{CBD}$

$9=$ Other

Type of sector: $\{$ SECT\}

$1=$ Government

$2=$ FPA

$3=$ Mission

4 = Private

$5=$ Other

Locality: $\{L O C\}$

$1=$ Rural

$2=$ Urban

Timing of interview: \{TIMING

$1=$ Before consultation

$2=$ After consultation

Name of observer:

Signature of team leader: 


\section{Read greeting:}

Hello. We would like to improve the services provided by the facility and would be interested to find out about your experience today. I would like to ask you some questions about your visit today, and would be very grateful if you could spend some time answering these questions. I will not write down your name, and everything you tell me will be kept strictly confidential. Also, you are not obliged to answer any question you don't want to, and you may withdraw from the interview at any time. May I continue?

(If the client agrees to continue, ask if she has any questions and respond to questions as appropriate. If she has had her consultation, ask q.1. If she has not had her consultation yet, skip to q. 26 .

If the client does not agree to continue, thank her and go to the next interview.)

\section{Client satisfaction}

1. What was the main reason you visited the facility today? (Circle one.) \{M1\}

$$
\begin{aligned}
& 1=\text { Antenatal care } \\
& 2=\text { Maternity care/delivery services } \\
& 3=\text { Postnatal care } \\
& 4=\text { HIV/AIDS counselling / IEC } \\
& 5=\text { HIV/AIDS testing } \\
& 6=\text { Other STD counselling / IEC } \\
& 7=\text { Other STD diagnosis } \\
& 8=\text { Other STD treatment } \\
& 9=\text { Child immunization } \\
& 10=\text { Child growth monitoring } \\
& 11=\text { Infertility consultation } \\
& 12=\text { Oral rehydration therapy } \\
& 13=\text { Treatment of incomplete abortion } \\
& 14=\text { Nutrition counselling } \\
& 15=\text { Curative services - client } \\
& 16=\text { Curative services - child } \\
& 17=\text { Other: }
\end{aligned}
$$

2. Overall, would you say you were satisfied with your visit to the facility today, or were you dissatisfied with your visit today? \{M2\}

$$
\begin{aligned}
& 1=\text { Satisfied } \\
& 2=\text { Dissatisfied } \\
& 3=\text { Other: }
\end{aligned}
$$


3. What other health services did you receive today?

Tick if received

(Read 1 - 17, excluding response on q.1)

\begin{tabular}{|l|l|}
\hline 1. Family planning & $\{\mathrm{M} 3 \times 1\}$ \\
\hline 2. Antenatal care & $\{\mathrm{M} 3 \times 2\}$ \\
\hline 3. Maternity care/delivery services & $\{\mathrm{M} 3 \times 3\}$ \\
\hline 4. Postnatal care & $\{\mathrm{M} 3 \times 4\}$ \\
\hline 5. HIV/AIDS counselling & $\{\mathrm{M} 3 \times 5\}$ \\
\hline 6. HIV/AIDS treatment & $\{\mathrm{M} 3 \times 6\}$ \\
\hline 7. Other STD counselling & $\{\mathrm{M} 3 \times 7\}$ \\
\hline 8. Other STD diagnosis & $\{\mathrm{M} 3 \times 8\}$ \\
\hline 9. Other STD treatment & $\{\mathrm{M} 3 \times 9\}$ \\
\hline 10. Child immunization & $\{\mathrm{M} 3 \times 10\}$ \\
\hline 11. Child growth monitoring & $\{\mathrm{M} 3 \times 11\}$ \\
\hline 12. Infertility consultation & $\{\mathrm{M} 3 \times 12\}$ \\
\hline 13. Oral rehydration therapy & $\{\mathrm{M} 3 \times 13\}$ \\
\hline 14. Treatment of incomplete abortion & $\{\mathrm{M} 3 \times 14\}$ \\
\hline 15. Nutrition counselling & $\{\mathrm{M} 3 \times 15\}$ \\
\hline 16. Curative services - client & $\{\mathrm{M} 3 \times 16\}$ \\
\hline 17. Curative services - child & $\{\mathrm{M} 3 \times 17\}$ \\
\hline 77. No other services & $\{\mathrm{M} 3 \times 77\}$ \\
\hline
\end{tabular}

4. Do you feel that you received the information and services that you wanted today? $\{$ M4\}

$$
\begin{aligned}
& 1=\text { Yes } \\
& 2=\text { No } \\
& 3=\text { Partially } \\
& 98=\text { Don't know }
\end{aligned}
$$

5. Do you feel that your consultation with the clinical staff was too short, too long, or about the right amount of time? \{M5\}

$$
\begin{aligned}
& 1=\text { Too short } \\
& 2=\text { Too long } \\
& 3=\text { About right } \\
& 98=\text { Don't know }
\end{aligned}
$$


6. During this visit, did you have any concerns about health issues that you wanted to discuss with the provider? \{M6\}

$$
\begin{aligned}
& 1=\text { Yes } \\
& 2=\text { No (to q.8) } \\
& 98=\text { Don't know (to q.8) }
\end{aligned}
$$

7. (If yes) Did the provider listen to your concerns to your satisfaction? \{M7\}

$$
\begin{aligned}
& 1=\text { Yes } \\
& 2=\text { No } \\
& 98=\text { Don't know }
\end{aligned}
$$

8. During this visit, did you have any questions you wanted to ask? \{M8\}

$$
\begin{aligned}
& 1=\text { Yes } \\
& 2=\text { No (to q.11) } \\
& 98=\text { Don't know (to q.11) }
\end{aligned}
$$

9. (If yes) Did the provider let you ask the questions? \{M9\}

$$
\begin{aligned}
& 1=\text { Yes } \\
& 2=\text { No (to q.11) } \\
& 98=\text { Don't know (to q.11) }
\end{aligned}
$$

10. (If yes) Did the provider respond to your questions to your satisfaction? \{M10\}

$$
\begin{aligned}
& 1=\text { Yes } \\
& 2=\text { No } \\
& 98=\text { Don't know }
\end{aligned}
$$

11. During this visit, did the provider conduct any health examinations or procedures?

$$
\begin{aligned}
& 1=\text { Yes } \\
& 2=\text { No (to q.14) } \\
& 98=\text { Don't know (to q.14) }
\end{aligned}
$$

12. (If yes) Did the provider explain the examinations or procedures before they were performed? (M12\}

$$
\begin{aligned}
& 1=\text { Yes } \\
& 2=\text { No } \\
& 98=\text { Don't know }
\end{aligned}
$$

13. Did the provider explain the results of the health examinations or procedures?

$\{$ M13\}

$$
\begin{aligned}
& 1=\text { Yes } \\
& 2=\text { No } \\
& 98=\text { Don't know }
\end{aligned}
$$

14. In your opinion, did you have enough privacy during your consultation with the service provider? $\{$ M14\}

$$
\begin{aligned}
& 1=\text { Yes } \\
& 2=\text { No } \\
& 98=\text { Don't know }
\end{aligned}
$$


15. During the consultation, did you feel that the provider was easy to understand when explaining things to you, or did you feel that the provider was difficult to understand? \{M15\}

$$
\begin{aligned}
& 1=\text { Easy to understand } \\
& 2=\text { Difficult to understand } \\
& 98=\text { Don't know }
\end{aligned}
$$

16. About how long did you have to wait between the time you first arrived at this facility and the time you began receiving the services that you came for? \{M16\}

$$
\text { minutes } 98=\text { Don't know }
$$

(If no waiting time, to q.18)

17. Do you feel that the wait between the time you first arrived at this facility and the time you began receiving the services you came for was reasonable or too long? \{M17\}

$$
\begin{aligned}
& 1=\text { Reasonable } \\
& 2=\text { Too long } \\
& 98=\text { Don't know }
\end{aligned}
$$

18. If a friend of yours wanted the services that you came here for today, would you encourage her to come to this facility, or would you encourage her to go somewhere else? \{M18\}

$$
\begin{aligned}
& 1=\text { Come to this facility } \\
& 2=\text { Go somewhere else } \\
& 98=\text { Don't know }
\end{aligned}
$$

19. What did you like most about your visit here today? \{M19\}

20. What did you dislike most about your visit here today? \{M2O\}

21. If you could suggest one improvement to the services provided, what would it be? \{M21\} 


\section{IEC activities}

22. During this visit, were you given or did you take any brochure or educational material to bring home? \{M22\}

$$
\begin{aligned}
& 1=\text { Yes } \\
& 2=\text { No (to q.24) } \\
& 98=\text { Don't know (to q.24) }
\end{aligned}
$$

23. (If yes) What was the subject(s) of that material? (Do not read list, but probe by asking, "Any other subjects?"।

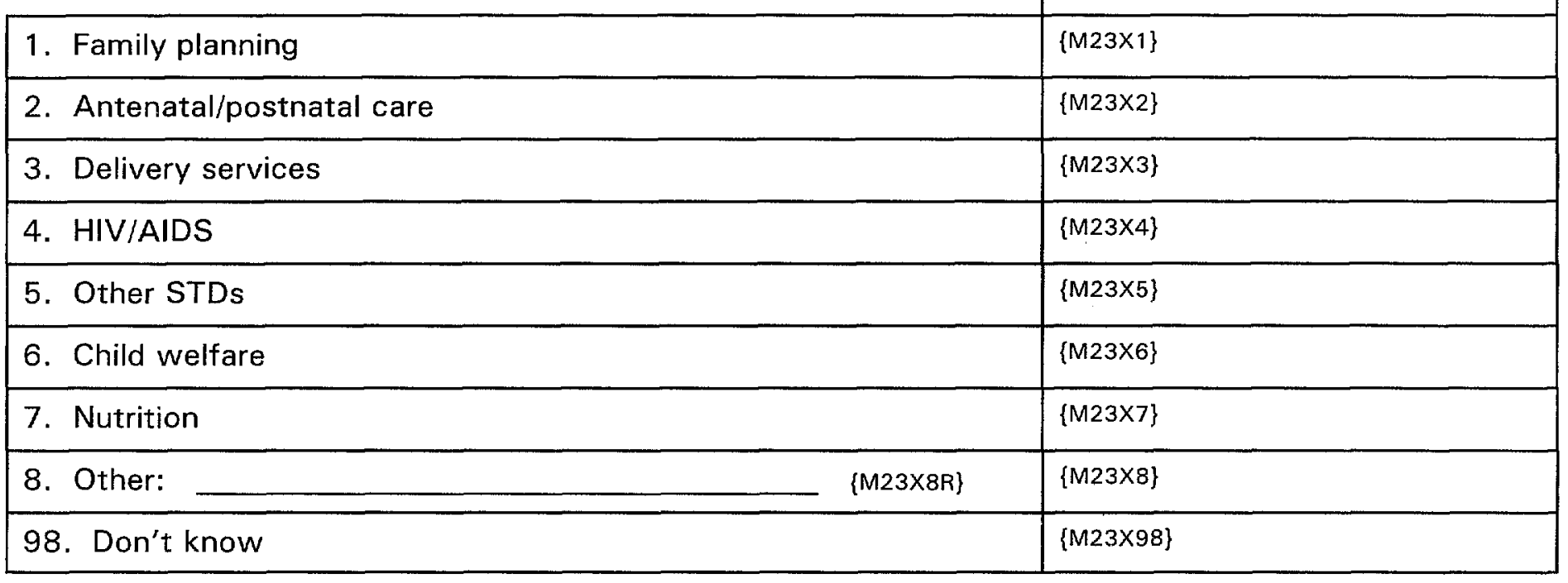

24. Did you attend a group talk(s) at the facility today? \{M24\}

$$
\begin{aligned}
& 1=\text { Yes } \\
& 2=\text { No (to q.26) } \\
& 98=\text { Don't know (to q.26) }
\end{aligned}
$$


25. (If yes) What topics were covered in the group talk(s)?

(Do not read list, but probe by asking, "Any other topics?")

Tick if mentioned

\begin{tabular}{|l|l|}
\hline 1. Family planning & $\{\mathrm{M} 25 \times 1\}$ \\
\hline 2. Antenatal care & $\{\mathrm{M} 25 \times 2\}$ \\
\hline 3. Maternity care/ delivery services & $\{\mathrm{M} 25 \times 3\}$ \\
\hline 4. Postnatal care & $\{\mathrm{M} 25 \times 4\}$ \\
\hline 5. HIV/AIDS & $\{\mathrm{M} 25 \times 5\}$ \\
\hline 6. STD & $\{\mathrm{M} 25 \times 6\}$ \\
\hline 7. Child immunization & $\{\mathrm{M} 25 \times 7\}$ \\
\hline 8. Child growth monitoring & $\{\mathrm{M} 25 \times 8\}$ \\
\hline 9. Infertility & $\{\mathrm{M} 25 \times 9\}$ \\
\hline 10. Oral rehydration therapy & $\{\mathrm{M} 25 \times 10\}$ \\
\hline 11. Treatment of incomplete abortion & $\{\mathrm{M} 25 \times 11\}$ \\
\hline 12. Nutrition counselling & $\{\mathrm{M} 25 \times 12\}$ \\
\hline 13. Curative services - clients & $\{\mathrm{M} 25 \times 13\}$ \\
\hline 14. Curative services - children & $\{\mathrm{M} 25 \times 14\}$ \\
\hline 15. Breastfeeding & $\{\mathrm{M} 25 \times 15\}$ \\
\hline 16. Other: & $\{\mathrm{M} 25 \times 16\}$ \\
\hline 98. Don't know & $\{\mathrm{M} 25 \times 98\}$ \\
\hline
\end{tabular}




\section{Accessibility}

26. Are the hours this facility is open convenient for you? \{M26\}

$$
\begin{aligned}
& 1=\text { Yes (to q.28) } \\
& 2=\text { No } \\
& 98=\text { Don't know (to q.28) }
\end{aligned}
$$

27. (If no) What time would be most convenient to you? (Circle one.) \{M27\}

$$
\begin{aligned}
& 1=\text { Earlier in morning } \\
& 2=\text { Over lunch hour } \\
& 3=\text { Afternoon } \\
& 4=\text { Evening / night } \\
& 5=\text { Weekends / holidays } \\
& 6=\text { Other: } \\
& 98=\text { Don't know }
\end{aligned}
$$

28. Have you ever been turned away from this facility during official working hours?

$$
\begin{aligned}
& 1=\text { Yes } \\
& 2=\text { No } \\
& 3=\text { No previous experience with facility } \\
& 98=\text { Don't know }
\end{aligned}
$$

29. How long did it take you to come here today? $\{M 29\}$

$$
\text { minutes } \quad 98=\text { Don't know }
$$

30. What was the main means of transport that you used to get here? (Circle one.) \{M30\}

$$
\begin{aligned}
& 1=\text { Walked } \\
& 2=\text { Donkey cart } \\
& 3=\text { Bus } / \text { combi } \\
& 4=\text { Bicycle } \\
& 5=\text { Private car } \\
& 6=\text { Other: }
\end{aligned}
$$


31. As far as you know, what types of services are usually provided at this facility?

(Do not read, but probe by asking, "Any other services?")

Tick if mentioned

\begin{tabular}{|c|c|}
\hline 1. Family planning & $\{M 31 \times 1\}$ \\
\hline 2. Antenatal care & $\{M 31 \times 2\}$ \\
\hline 3. Maternity care/delivery services & $\{M 31 \times 3\}$ \\
\hline 4. Postnatal care & $\{M 31 \times 4\}$ \\
\hline 5. HIV/AIDS counselling/IEC & $\{M 31 \times 5\}$ \\
\hline 6. HIV/AIDS testing & $\{M 31 \times 6\}$ \\
\hline 7. Other STD counselling/IEC & $\{M 31 \times 7\}$ \\
\hline 8. Other STD diagnosis & $\{M 31 \times 8\}$ \\
\hline 9. Other STD treatment & $\{M 31 \times 9\}$ \\
\hline 10. Child immunization & $\{\mathrm{M} 31 \times 10\}$ \\
\hline 11. Child growth monitoring & $\{M 31 \times 11\}$ \\
\hline 12. Infertility consultation & $\{M 31 \times 12\}$ \\
\hline 13. Oral rehydration therapy & $\{M 31 \times 13\}$ \\
\hline 14. Treatment of incomplete abortion & $\{M 31 \times 14\}$ \\
\hline 15. Nutrition counselling & $\{M 31 \times 15\}$ \\
\hline 16. Curative services - client & $\{M 31 \times 16\}$ \\
\hline 17. Curative services - child & $\{M 31 \times 17\}$ \\
\hline 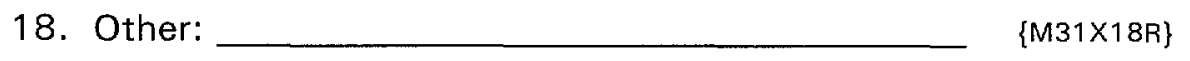 & $\{\mathrm{M} 31 \times 18\}$ \\
\hline 98. Don't know & $\{M 31 \times 98\}$ \\
\hline
\end{tabular}

32. Apart from this facility, is there any other place near your home where you can go for the same services that you came for here today? \{M32\}

$$
\begin{aligned}
& 1=\text { Yes } \\
& 2=\text { No (to q.35) } \\
& 98=\text { Don't know (to q.35) }
\end{aligned}
$$

33. (If yes) What type of facility is it? (Circle one. If more than one facility, choose nearest to home.) \{M33\}

$$
\begin{aligned}
& 1=\text { CBD } \\
& 2=\text { Health post } \\
& 3=\text { Health center } \\
& 4=\text { Hospital } \\
& 5=\text { Other: } \\
& 98=\text { Don't know }
\end{aligned}
$$


34. What would you say is the main reason you did not go there for the services?

(Do not read list. Probe for the main reason and circle one.) $\{\mathrm{M} 34\}$

$1=$ Inconvenient opening times

2 = Takes too long to get there

3 = Poor quality service

$4=$ Fewer services available

$5=$ Want to be anonymous

$6=$ Have other reasons to come here (e.g. immunization services)

7 = More expensive there

$8=$ Prefer provider here

$9=$ Other:

$98=$ Don't know

$\{\mathrm{M} 34 \mathrm{R}\}$

35. In the past 12 months, how many visits have you made to this facility/hospital for (read 1-4)?
36. In the past 12 months, how many visits have you made to any other facility/hospital for (read 1-4)?

\begin{tabular}{|l|llll|}
\hline 1. Family planning & $\{M 35 \times 1\}$ & visits & $\{M 36 \times 1\}$ & visits \\
\hline 2. Child welfare & $\{M 35 \times 2\}$ & visits & $\{M 36 \times 2\}$ & visits \\
\hline 3. Antenatal care & $\{M 35 \times 3\}$ & visits & $\{M 36 \times 3\}$ & visits \\
\hline 4. STD/HIV & $\{M 35 \times 4\}$ & visits & $\{M 36 \times 4\}$ & visits \\
\hline
\end{tabular}

37. Now I would like to ask you about the cost of travel and services that you have received from this clinic. How much did you pay for (read 1-6)?

\begin{tabular}{|l|l|}
\hline 1. Consultation & $\{\mathrm{M} 37 \times 1\}$ \\
\hline 2. Medicines & $\{\mathrm{M} 37 \times 2\}$ \\
\hline 3. Other items such as cotton, gloves, antiseptic, or syringes & $\{\mathrm{M} 37 \times 3\}$ \\
\hline 4. Registration card/membership & $\{\mathrm{M} 37 \times 4\}$ \\
\hline 5. Travel & $\{\mathrm{M} 37 \times 5\}$ \\
\hline 6. Other: $\{$ \{M37X6R $\}$ & $\{\mathrm{M} 37 \times 6\}$ \\
\hline
\end{tabular}

38. Overall, do you feel that the total cost of obtaining services is much too expensive, a little too expensive, or acceptable to you? \{M38\}

$$
\begin{aligned}
& 1=\text { Much too expensive } \\
& 2=\text { A little too expensive } \\
& 3=\text { Acceptable } \\
& 98=\text { Don't know }
\end{aligned}
$$


39. Now I would like to ask you some questions about having children. Do you know of any ways or methods that women and men can use to delay or prevent a pregnancy? \{M39\}

$1=$ Yes

$2=$ No (to q.49)

\begin{tabular}{|c|c|c|}
\hline & $\begin{array}{l}\text { 40. (If yes) Please tell me any } \\
\text { such methods that you know } \\
\text { of. } \\
\text { (Do not read but probe by } \\
\text { asking, "Any other } \\
\text { methods?" Tick if } \\
\text { mentioned.) }\end{array}$ & $\begin{array}{l}\text { 41. (If mentioned) As far as you } \\
\text { know, is it possible to obtain } \\
\text { this method at this health } \\
\text { facility? } \\
\text { (Tick if yes) }\end{array}$ \\
\hline $\begin{array}{l}\text { 1. Combined pill } \\
\text { (or unspecified) }\end{array}$ & $\{M 40 \times 1\}$ & $\{M 41 \times 1\}$ \\
\hline 2. Progestin-only pill & $\{M 40 \times 2\}$ & $\{M 41 \times 2\}$ \\
\hline 3. IUD & $\{M 40 \times 3\}$ & $\{M 41 \times 3\}$ \\
\hline 4. Injectable & $\{M 40 \times 4\}$ & $\{M 41 \times 4\}$ \\
\hline 5. NORPLANT ${ }^{\circledR}$ & $\{M 40 \times 5\}$ & $\{M 41 \times 5\}$ \\
\hline 6. Condom & $\{M 40 \times 6\}$ & $\{M 41 \times 6\}$ \\
\hline 7. Diaphragm & $\{M 40 \times 7\}$ & $\{M 41 \times 7\}$ \\
\hline 8. Spermicide & $\{M 40 \times 8\}$ & $\{M 41 \times 8\}$ \\
\hline 9. Female sterilization & $\{M 40 \times 9\}$ & $\{M 41 \times 9\}$ \\
\hline 10. Vasectomy & $\{M 40 \times 10\}$ & $\{M 41 \times 10\}$ \\
\hline 11. NFP & $\{M 40 \times 11\}$ & $\{M 41 \times 11\}$ \\
\hline 12. LAM & $\{M 40 \times 12\}$ & $\{M 41 \times 12\}$ \\
\hline 13. Other: $\{$ \{M40X13R\} & $\{M 40 \times 13\}$ & $\{M 41 \times 13\}$ \\
\hline
\end{tabular}

42. Did you hear or see anything about family planning in this health facility today? \{M42\}

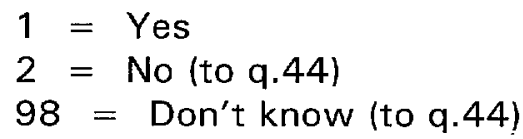


43. (If yes) Did you (read 1-5)?

Tick if yes

1. See a family planning poster?

$\{M 43 \times 1\}$

2. See a family planning pamphlet, flip chart, or information sheet?

$\{M 43 \times 2\}$

3. Hear about family planning during a health talk?

4. Hear about family planning during a consultation?

5. See samples of contraceptives?

$\{M 43 \times 3\}$

\{M43X4\}

\{M43X5\}

44. Do you yourself approve or disapprove of couples using a method of family planning to avoid getting pregnant? \{M44\}

$$
\begin{aligned}
& 1=\text { Approve } \\
& 2=\text { Disapprove } \\
& 98=\text { Don't know / no opinion }
\end{aligned}
$$

45. Are you or your spouse/partner currently using any method to space, avoid or prevent a pregnancy? \{M45\}

$$
\begin{aligned}
& 1=\text { Yes } \\
& 2=\text { No (to q.47) } \\
& 98=\text { Don't know (to q.47) }
\end{aligned}
$$

46. (If yes) Which method? (Circle one.) $\{$ M46\}

1. Combined pill (or unspecified)

2. Progestin-only pill

3. IUD

4. Injectable

5. NORPLANT ${ }^{\oplus}$

6. Condom

7. Diaphragm

8. Spermicide

9. Female sterilization

10. Vasectomy

11. NFP (to q.49)

12. LAM (to q.49)

13. Other: $\{M 46 R\}$

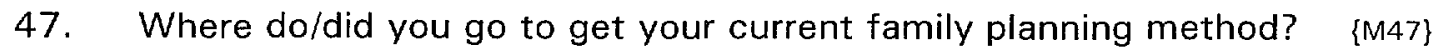

$$
\begin{aligned}
& 1=\text { This health facility } \\
& 2=\text { Another health facility } \\
& 3=\text { Pharmacy/ shop/ chemist/ drugstore } \\
& 4=\text { CBD/FWE } \\
& 5=\text { Private doctor } \\
& 6=\text { Other: }
\end{aligned}
$$


48. What is the main reason you obtain your method from that place and not somewhere else?

(Do not read, but probe for main reason. Circle one.) \{M48\}

$$
\begin{aligned}
& 1=\text { Only knows this source } \\
& 2=\text { Convenient opening times } \\
& 3=\text { Quality of services } \\
& 4=\text { Range of services } \\
& 5=\text { Can be anonymous } \\
& 6=\text { Close to home } \\
& 7=\text { Cost of methods } \\
& 8=\text { Likes/trusts provider } \\
& 9=\text { Other: } \\
& 98=\text { Don't know }
\end{aligned}
$$

\section{Sociodemographic characteristics}

49. Now, I would like to ask you a few questions about yourself. Are you currently breastfeeding? $\{\mathrm{M} 49\}$

$$
\begin{aligned}
& 1=\text { Yes } \\
& 2=\text { No (to q.51) }
\end{aligned}
$$

50. (If yes) Are you breastfeeding exclusively, nearly exclusively, or supplemented regularly with food and/or liquids? \{M50\}

$$
\begin{aligned}
& 1=\text { Breastfeeding exclusively } \\
& 2=\text { Nearly exclusively } \\
& 3=\text { Supplemented regularly with food and/or liquids } \\
& 98=\text { Interviewer unable to determine extent of supplementation }
\end{aligned}
$$

51. How old are you? \{M51\}

$$
\text { years } 98=\text { Don't know }
$$

52. What is your current marital status? (Probe for exact status.) \{M52\}

$$
\begin{aligned}
& 1=\text { Married / monogamous (to q.54) } \\
& 2=\text { Married / polygamous (to q.54) } \\
& 3=\text { Cohabiting (to q.54) } \\
& 4=\text { Single, never married } \\
& 5=\text { Divorced / separated / widowed }
\end{aligned}
$$

53. (If not married) Do you have a regular partner? \{M53\}

$$
\begin{aligned}
& 1=\text { Yes } \\
& 2=\text { No (to q.56) }
\end{aligned}
$$

54. Have you ever discussed family planning with your husband or regular partner? \{M54\}

$$
\begin{aligned}
& 1=\text { Yes } \\
& 2=\text { No } \\
& 98=\text { Don't know }
\end{aligned}
$$


55. Do you think your spouse/partner approves or disapproves of your using a method to space or avoid a pregnancy? $\{$ M55

$$
\begin{aligned}
& 1=\text { Approves } \\
& 2=\text { Disapproves } \\
& 98=\text { Don't know }
\end{aligned}
$$

56. How many living children of your own do you have? \{M56\}

$$
\text { (If none, to q.58) }
$$

$$
\text { children }
$$

57. What is the age of your youngest child? \{M57\}

$$
\text { months } 98=\text { Don't know }
$$

58. Would you like to have any (more) children? (Circle one.) (M58\}

$$
\begin{aligned}
& 1=\text { Yes } \\
& 2=\text { No (to q.60) } \\
& 3=\text { Depends on husband (to q.60) } \\
& 4=\text { Depends on God (to q.60) } \\
& 5=\text { Not sure/ undecided (to q.60) }
\end{aligned}
$$

\begin{tabular}{|c|c|c|}
\hline 1. English/French & & $\{M 61 \times 1\}$ \\
\hline 2. Local dialect & & $\{M 61 \times 2\}$ \\
\hline 3. Other: & $\{M 61 \times 3 R\}$ & $\{M 61 \times 3\}$ \\
\hline 4. Other: & $\{M 61 \times 4 R\}$ & $\{M 61 \times 4\}$ \\
\hline 5. Other: & $\{\mathrm{M} 61 \times 5 \mathrm{R}\}$ & $\{$ M61X5\} \\
\hline
\end{tabular}

59. (If yes) When would you like (a) (the next) child? (Circle one.) \{M59\}

$$
\begin{aligned}
& 1=\text { Less than one year } \\
& 2=\text { One year } \\
& 3=\text { Between one and two years } \\
& 4=\text { Two years } \\
& 5=\text { More than two years } \\
& 6=\text { Any other response } \\
& 98=\text { Don't know }
\end{aligned}
$$

60. Can you read and understand a letter or a newspaper easily, with difficulty, or not at all?

$$
\begin{aligned}
& 1=\text { Easily } \\
& 2=\text { With difficulty } \\
& 3=\text { Not at all }
\end{aligned}
$$

61. Which languages can you read and understand? (Do not read but probe by asking, "Any other languages?") 
62. What is the highest level of school you attended? (Circle one.) \{M62\}

$$
\begin{aligned}
& 1=\text { Did not attend formal school } \\
& 2=\text { Lower primary } \\
& 3=\text { Upper primary } \\
& 4=\text { Lower secondary } \\
& 5=\text { Upper secondary } \\
& 6=\text { Post-secondary }
\end{aligned}
$$

63. What is your religion? (Circle one.) $\{M 63\}$

$$
\begin{aligned}
& 1=\text { Protestant } \\
& 2=\text { Catholic } \\
& 3=\text { Muslim } \\
& 4=\text { African Spiritual } \\
& 5=\text { None } \\
& 6=\text { Other: }
\end{aligned}
$$

\section{Reproductive health issues}

64. To end with, I would like to ask you some questions about other reproductive health issues. I would like to remind you that the information you provide will remain strictly confidential, and that you do not have to answer any question you do not want to. Sometimes a woman can become pregnant when she is not ready to be. In the past, have you ever been pregnant at a time when you were not ready for the pregnancy? \{M64\}

$$
\begin{aligned}
& 1=\text { Yes } \\
& 2=\text { No (to q.66) } \\
& 98=\text { Don't know / no response (to q.66) }
\end{aligned}
$$

65. (If yes) What did you do the last time this happened to you? (Circle one.) \{M65\}

$$
\begin{aligned}
& 1=\text { Nothing, continued with the pregnancy } \\
& 2=\text { Attempted to stop pregnancy but did not succeed, gave birth } \\
& 3=\text { Attempted to stop pregnancy and succeeded } \\
& \begin{array}{l}
\text { S } \\
98=\text { Other : }
\end{array} \text { \{M65R }
\end{aligned}
$$

66. As far as you know, are there any diseases that can be transmitted through sexual intercourse? $\{\mathrm{M} 66\}$

$$
\begin{aligned}
& 1=\text { Yes } \\
& 2=\text { No (to q.69) } \\
& 98=\text { Don't know / no response (to q.69) }
\end{aligned}
$$

67. (If yes) Have you heard or read about some common signs and symptoms of sexually transmitted diseases? $\{M 67\}$

$$
\begin{aligned}
& 1=\text { Yes } \\
& 2=\text { No (to q.69) } \\
& 98=\text { Don't know (to q.69) }
\end{aligned}
$$


68. (If yes) What are some common signs and symptoms of sexually transmitted diseases?

(Do not read list, but probe by asking, "Any other signs or symptoms?"।

\begin{tabular}{|l|l|}
\hline 1. Abnormal vaginal discharge & $\{\mathrm{M} 68 \times 1\}$ \\
\hline 2. Abnormal vaginal bleeding & $\{\mathrm{M} 68 \times 2\}$ \\
\hline 3. Genital itching & $\{\mathrm{M} 68 \times 3\}$ \\
\hline 4. Lesions / sores & $\{\mathrm{M} 68 \times 4\}$ \\
\hline 5. Lower abdominal pain & $\{\mathrm{M} 68 \times 5\}$ \\
\hline 6. Pain during intercourse & $\{\mathrm{M} 68 \times 6\}$ \\
\hline 7. Painful urination & $\{\mathrm{M} 68 \times 7\}$ \\
\hline 8. Abnormal growth in genital area (warts\} & $\{\mathrm{M} 68 \times 8\}$ \\
\hline $\begin{array}{l}\text { 9. Urethral discharge } \\
\text { 10. Los: w } \cdots \text { siaht }\end{array}$ & $\{\mathrm{M} 68 \times 9\}$ \\
\hline 11. Diarrhoea of long duration & $\{\mathrm{M} 68 \times 10\}$ \\
\hline 12. Other: & $\{\mathrm{M} 68 \times 11\}$ \\
\hline
\end{tabular}

69. Have you ever heard of HIV or AIDS, or are you not sure? \{M69\}

$$
\begin{aligned}
& 1=\text { Yes } \\
& 2=\text { No (to q.72) } \\
& 98=\text { Don't know (to q.72) }
\end{aligned}
$$

70. Have you ever heard of ways that people get HIV/AIDS? \{M70\}

$$
\begin{aligned}
& 1=\text { Yes } \\
& 2=\text { No (to q.72) } \\
& 98=\text { Don't know (to q.72) }
\end{aligned}
$$

71. As far as you know, what are the ways people get HIV/AIDS?

(Do not read list but probe by asking, "Any other ways?")

\begin{tabular}{|l|l|}
\hline 1. Sexual intercourse & $\{M 71 \times 1\}$ \\
\hline 2. Blood transfusion & $\{M 71 \times 2\}$ \\
\hline 3. Sharing items like razor blades or needles & $\{M 71 \times 3\}$ \\
\hline 4. Mother to baby & $\{M 71 \times 4\}$ \\
\hline 5. Other: $\{$ M $1 \times 5 R\}$ & $\{M 71 \times 5\}$ \\
\hline
\end{tabular}


72. Do you know of any ways you can protect yourself from sexually transmitted diseases including HIV/AIDS? \{M72\}

$$
\begin{aligned}
& 1=\text { Yes } \\
& 2=\text { No (to q.74) } \\
& 98=\text { Don't know (to q.74) }
\end{aligned}
$$

73. (If yes) What are these ways of protecting yourself? (Do not read, but probe by asking, "Any other ways?")

\begin{tabular}{|l|l|}
\hline 1. Stay faithful to your one spouse/partner & $\{\mathrm{M} 73 \times 1\}$ \\
\hline 2. Encourage spouse/partner to remain faithful & $\{\mathrm{M} 73 \times 2\}$ \\
\hline 3. Use condoms & $\{\mathrm{M} 73 \times 3\}$ \\
\hline 4. Avoid sharing needles, razors, etc. & $\{\mathrm{M} 73 \times 4\}$ \\
\hline 5. Other: \{M73X5R\} & $\{\mathrm{M} 73 \times 5\}$ \\
\hline
\end{tabular}

74. How many sexual partners have you had in the past 12 months? $\{M 74\}$

$$
\text { (If none, to closing) }
$$

75. Did you have sex with any new partner(s) in the past 12 months? \{M75\}

$$
\begin{aligned}
& 1=\text { Yes } \\
& 2=\text { No (to closing) } \\
& 98=\text { Don't know (to closing) }
\end{aligned}
$$

76. (If yes) Did you use a condom the first time you had sex with your most recent new partner? $\{M 76\}$

$$
\begin{aligned}
& 1=\text { Yes } \\
& 2=\text { No } \\
& 98=\text { Don't know }
\end{aligned}
$$

\section{Read closing:}

Thank you very much for answering these questions. 


\section{MCH client exit interview: question-by-question guide}

The client has just finished receiving $\mathrm{MCH}$ services. Be sensitive to the fact that the client may have traveled far, waited a long time for service, and may have been through an ordeal. However, she may agree to an interview with a sensitive and interested person. (See the section "Tips for conducting a good interview" for more information, page 23.)

Lead the client to a preselected private place, away from clinic staff and other clients, and read the greeting. This greeting is extremely important because it ensures that the client has given her "informed consent" to be included in the study. Ask if the client has any questions about the study. If necessary, you may provide some simple encouragement such as, "Your participation will be greatly appreciated," but in all cases respect the client's wishes if she does not want to be interviewed. If she does not agree to participate, thank her and move on to the next client.

You should be able to fill out the information on the first page before the interview begins. If you are not sure about any of the codes, ask your Team Leader. Write (do not sign) your name in the box at the bottom of the page. When you have completed the interview, your Team Leader will review it and sign below your name. For the rest of the interview, follow instructions for recording the client's responses by circling a precoded response, ticking a box, or writing a response as instructed.

Some questions are filters, which means that they divide some clients from others, in order to ask them more questions. For example, question 26 divides clients into those that find the facility hours convenient and those that do not. The clients that do not find the hours convenient will be asked which hours would be more convenient. These filter questions always include a "skip pattern" that skips questions that are not applicable to some clients. Pay careful attention to all skip patterns. At the conclusion of the interview, quickly review your coded responses for completeness and correctness and ensure that you followed the correct skips. If possible, correct any problems while the client is still available.

\section{What was the main reason you vis-} ited the facility today?

Ask the client for the one main reason she came to the facility today. The client will have the opportunity later to list all the services she received (question 3 ).

2. Overall, would you say you were satisfied with your visit to the facility today, or were you dissatisfied with your visit today?

Clients are frequently reluctant to express any overall dissatisfaction because they wish to be courteous. However, clients tend to be more expressive of dissatisfaction with more specific questions. Questions 4 through 21 of this interview will give the client more opportunity to specifically critique the services.

\section{What other health services did you} receive today?

Read each of the services, excluding the client's response on question 1 as the main reason for her visit. Place a tick (check mark) in the right column for each service received. If she received no other services, tick 77 . 
4. Do you feel that you received the information and services that you wanted today?

Clients come to a facility in order to obtain particular information and services. The purpose of this question is to find out if the client obtained the information and services she desired.

\section{Do you feel that your consultation} with the clinical staff was too short, too long, or about the right amount of time?

This information can be compared to the FP clients' satisfaction with the duration of their consultations.

6. During this visit, did you have any concerns about health issues that you wanted to discuss with the provider?

7. (If yes) Did the provider listen to your concerns to your satisfaction? "Concerns" is a broad term. Concerns include but are not limited to worries or rumors of health risks, child health, exposure to STD/HIV/AIDS, how to maintain privacy, etc. If the provider reports that she did have concerns, ask question 7 .

8. During this visit, did you have any questions you wanted to ask?

9. (If yes) Did the provider let you ask the questions?

10. (If yes) Did the provider respond to your questions to your satisfaction? Whether clients feel free to ask questions and whether they are responded to satisfactorily is a strong indicator of quality in interpersonal relations. These three questions address the issue of whether the client felt comfortable asking for the information she needed.
"Questions" can be on any subject, such as how an infection is transmitted, where to get nutrition counseling, etc. Questions can also include "concerns," as defined above.

Many dimensions may be considered by the client in answering question 10 : for example, the completeness, correctness, or style the provider used in her responses. Give no assistance in answering this question, because only the client can determine her own satisfaction with the responses to her questions.

11. During this visit, did the provider conduct any health examinations or procedures?

12. (If yes) Did the provider explain the examinations or procedures before they were performed?

13. Did the provider explain the results of the health examinations or procedures?

"Health examinations" include head-totoe exams, breast exams, pelvic exams, and examinations on any other part of the body. "Procedures" include taking blood pressure or temperature, giving an injection, etc.

The idea behind these questions is that if clients are aware of examinations and procedures, they will be more at ease during their visit. An explanation of the examination or procedure involves telling the client what the provider is about to do, why she is doing it, and what the client can expect to feel. Explaining the results of the examination or procedure involves telling the client if the nurse came to any conclusions or diagnosis based on the examination. If a diagnosis is not immediately available, 
then explaining the results would include telling the client that she will be contacted later about the results.

14. In your opinion, did you have enough privacy during your consultation with the service provider? This is the client's opinion, however she determines it.

15. During the consultation, did you feel that the provider was easy to understand when explaining things to you, or did you feel that the provider was difficult to understand? This is the client's opinion, however she determines it.

16. About how long did you have to wait between the time you first arrived at this facility and the time you began receiving the services that you came for?

The purpose of this question is to determine the client waiting time. Encourage the client to estimate the time she waited if she does not have a watch and/or did not keep track of the time. Reserve "don't know" for clients who are unable to estimate, even when requested to do so.

17. Do you feel that the wait between the time you first arrived at this facility and the time you began receiving the services you came for was reasonable or too long?

This is the client's opinion about overall waiting time experienced before she started to receive the services she came for. Do not consider the start of registration procedures as the services she came for.
18. If a friend of yours wanted the services that you came here for today, would you encourage her to come to this facility, or would you encourage her to go somewhere else? Clients sometimes select a health facility based on recommendations from friends. This question determines whether $\mathrm{MCH}$ clients are recommending this facility to friends, which is a proxy measure of client satisfaction.

19. What did you like most about your visit here today?

Emphasize the word "most." Some clients may not have liked anything, in which case you should skip to question 20 .

20. What did you dislike most about your visit here today?

Emphasize the word "most." Some clients may not have disliked anything, or may not feel comfortable reporting on what they disliked. In these cases, leave the question blank.

21. If you could suggest one improvement to the services provided, what would it be? This important question allows the client to mention something that bothered her about the experience, without being critical. Probe with supportive comments such as: "Anything at all you would like to suggest is fine."

22. During this visit, were you given or did you take any brochure or educational material to bring home?

23. (If yes) What was the subject(s) of that material?

No distinction is made between bro- 
chures, pamphlets, fliers, or any other educational material.

Try to find out the subject matter of the brochure or educational material given to the client. Do not read the list, but probe by asking, "Are there any other subjects?" We are interested in how aware the client is of the material she received. If she would like to refer to her materials and tell you the subjects, mark her answers. However, if she simply shows you the materials, do not look for yourself and mark their subjects, but ask, "What are these about?"

\section{Did you attend a group talk(s) at the} facility today?

The "group talk" is sometimes called a "health talk." It is usually conducted by a nurse, and may include many subjects. It is frequently in the lecture format, but when done well, may include questions, display of samples, or other AV aides.

"Attend" and "hear" have similar meanings in this question.

\section{5. (If yes) What topics were covered in} the group talk(s)?

Ask this question only if the client attended a group talk. We are interested in the information that the client remembers during the health talk, so do not prompt her by reading the subject list. Also note the appropriate probe, "Any other subjects?"

\section{Are the hours this facility is open convenient for you?}

27. (If no) What time would be most convenient to you?

Opening hours of services can be a large barrier to clients and these ques- tions get at the convenience of the clinic hours. Even in contexts in which clinic hours are set by the Ministry of Health or other central authority, information from these questions can be very useful for getting those policies changed if necessary.

28. Have you ever been turned away from this facility during official working hours?

"Turned away" means refused service, or told to come back at another time. Note that this is about the client's history with the facility (ever), rather than about today's visit. Also, this involves being turned away due to overcrowding or other unspecified reason. If the client came once, saw a provider, and was told to return for a procedure at a later date, this does not count as "turned away" for this question.

\section{How long did it take you to come here today?}

We are enquiring about the client's travel time from her home, because travel time can sometimes pose a large barrier to services. If the client was coming from work or a relative's house, count the time from there. Encourage the client to estimate the approximate time in minutes.

30. What was the main means of transport that you used to get here? The client may have used two or three or more forms of transportation-walking and minibus would be a common combination. When the client used two or more means of transport, encourage her to decide what she considers her main means. Any criteria she uses for deciding-time, distance, cost, etc.-is fine. 
31. As far as you know, what types of services other than family planning are usually provided at this facility? This question addresses clients' awareness of other services, which will later be compared to the actual services available. This gives an idea whether some services are underutilized because people are simply not aware of them.

Remember that the client will not use our exact terms. Interpret her comments into the categories to the best of your ability. If the client says "STD," or "HIV," you may probe with "What kind of STD or HIV services are usually provided?" in order to come closer to the coding categories available.

\section{Apart from this facility, is there any} other place near your home where you can go for the services that you came here for today?

33. (If yes) What type of facility is it?

34. What would you say is the main reason you did not go there for the services?

A client's choice of facilities is important because it may have been motivated by the quality of services she experiences. These three questions address those clients who have decided to come to this facility rather than another.

If the client indicates there is another facility close to her home or workplace, or another place she regularly visits, code question 32 accordingly. Then questions 33 and 34 should be asked, and the client should be encouraged to think about only one other facility, the one closest to her home or workplace. In question 34, the client may mention more than one reason. Encourage her to decide on one main reason.
35. In the past 12 months, how many visits have you made to this facility/ hospital for (various services)?

36. In the past 12 months, how many visits have you made to any other facility/hospital for (various services)? These questions assess the level of utilization of services among $\mathrm{MCH}$ clients, both at this facility and elsewhere.

37. Now I would like to ask you about the cost of travel and services that you have received from this clinic. How much did you pay for (various services and travel)?

Clients may know the total amount paid without knowing how the charges were divided. If this is the case, make a note in the margin with the total amount.

38. Overall, do you feel that the total cost of obtaining services is much too expensive, a little too expensive, or acceptable to you?

Because the burden of expenses can only be judged relative to a client's income, this question gives the client the chance to assess the difficulty she has in paying for services, even if the cost is quite low.

39. Now I would like to ask you some questions about having children. Do you know of any ways or methods that women and men can use to delay or prevent a pregnancy?

40. (If yes) Please tell me any such methods that you know of. These questions assess the family planning knowledge of $\mathrm{MCH}$ clients. If the client has heard of some methods, ask question 40 but do not read the list of methods. Let the client tell you all the 
methods she can spontaneously mention. Probe by asking "Any other methods?" Be aware that the client may not use the terms on the list of methods.

Classify as well as you can what the client says, using our terms.

41. (If mentioned) As far as you know, is it possible to obtain this method at this health facility?

For each method that the client mentions, ask her if the method can be obtained at this facility. This information will be checked against the actual availability of the method at this facility, which will give managers an idea of how well-known their services are.

42. Did you hear or see anything about family planning in this health facility today?

43. (If yes) Did you (see poster/see pamphlet/attend health talk/etc.)? Although much of the Situation Analysis is concerned with how RH services are integrated into FP services, these two questions assess whether FP is integrated into $\mathrm{MCH}$ services.

44. Do you yourself approve or disapprove of couples using a method of family planning to avoid getting pregnant?

This attitudinal question is an important proxy for the acceptability of FP in the general population. Presumably, all FP clients approve of FP use, so their attitudes on FP are not representative of the general population. $\mathrm{MCH}$ clients, although also not strictly representative of the general population, can give a better idea of more general attitudes. Also, the results from this question can inform managers about how receptive the $\mathrm{MCH}$ client population is to FP messages.

45. Are you or your spouse/partner currently using any method to space, avoid, or prevent a pregnancy?

46. (If yes) Which method? These results can be compared to the FP results for type of method used. Methods used by husband/partner(s) such as condoms, vasectomy, and withdrawal are attributed to the client as well.

47. Where do/did you go to get your current family planning method?

48. What is the main reason you obtain your method from that place and not somewhere else?

These questions about contraceptive supply give important information about the FP outlets that are used by women who may not come to this facility for FP services. If their responses to question 48 show, for example, that they feel the quality of services is better elsewhere, then the manager will have identified an important problem.

49. Now, I would like to ask you a few questions about yourself. Are you currently breastfeeding?

50. (If yes) Are you breastfeeding exclusively, nearly exclusively, or supplemented regularly with food and/or liquids?

If the client is breastfeeding during the interview, do not ask the question but simply code "yes" on question 49.

For question 50 , "exclusive breastfeeding" means only breast milk and nothing else; no water, juice, or 
other foods. "Nearly exclusively" means primarily breast milk but sometimes some water or juice. "Supplemented regularly" means breast milk with other liquids and foods also given. Try to determine which of these categories is closest to the current breastfeeding behavior of the client.

\section{How old are you?}

Write the number of years mentioned by the client. If she doesn't know her age exactly, try to help her estimate with some important historical dates as benchmarks as instructed in training. If she has no idea what her age is, write 98.

\section{What is your current marital status?} This question should be answered using the client's definition of marriage.

53. (If not married) Do you have a regular partner?

A regular partner is someone with whom the client has sexual intercourse on a regular basis, independent of the frequency.

54. Have you ever discussed family planning with your husband or regular partner?

55. Do you think your spouse/partner approves or disapproves of your using a method to space or avoid a pregnancy?

Discussion of family planning within couples is a possible factor affecting family planning use and continuation. These questions get at the amount of discussion and approval of FP that takes place among couples that may not be using FP at the moment. This can be compared to similar results for the FP clients.
56. How many living children of your own do you have?

Emphasize the words "living" and "your own." This question is intended to determine the number of children to whom the woman has given birth. It excludes adopted children and children of other relatives presently living with her.

57. What is the age of your youngest child? Note that the age of the youngest child should be recorded in months.

58. Would you like to have any (more) children?

Ask "any" with a client who has no children. Ask "any more" with a client who has one or more children.

59. (If yes) When would you like (a) (the next) child?

Ask "a" with a client who has no children. Ask "the next" with a client who has one or more children.

60. Can you read and understand a letter or a newspaper easily, with difficulty, or not at all?

61. Which languages can you read and understand?

62. What is the highest level of school you attended?

63. What is your religion?

These four questions address the general socio-economic status of the clients. This can be used in designing programs, producing appropriate IEC materials, and arranging services in socially and culturally acceptable ways.

In question 62, note that we are enquiring about "attended"-not necessarily "completed." 
64. To end with, I would like to ask you some questions about other reproductive health issues. I would like to remind you that the information you provide will remain strictly confidential, and that you do not have to answer any question you do not want to. Sometimes a woman can become pregnant when she is not ready to be. In the past, have you ever been pregnant at a time when you were not ready for the pregnancy?

65. (If yes) What did you do the last time this happened to you?

These questions are sensitive, but are usually answered when the interviewer has developed a rapport with the client, and is straightforward and nonjudgmental. For this reason, these questions have been placed at the end of the interview, after the client is used to being asked questions.

66. As far as you know, are there any diseases that can be transmitted through sexual intercourse?

67. (If yes) Have you heard or read about some common signs and symptoms of sexually transmitted diseases?

68. (If yes) What are some common signs and symptoms of sexually transmitted diseases?

Be aware that the client may not use our terms when describing symptoms. Classify as well as you can what the client says, using our terms.

69. Have you ever heard of HIV or AIDS, or are you not sure?
70. Have you ever heard of ways that people get HIV/AIDS?

71. As far as you know, what are the ways to get HIV/AIDS?

Be aware that the client may not use our terms when describing transmission routes. Classify as well as you can what the client says, using our terms.

72. Do you know of any ways you can protect yourself from sexually transmitted diseases including HIV/ AIDS?

73. (If yes) What are these ways of protecting yourself?

These knowledge questions are extremely important. Note that although HIV/AIDS is itself a sexually transmitted disease, clients (and providers) may often think of it as a separate and distinct category.

74. How many sexual partners have you had in the past 12 months?

Write the number of partners the client mentions. If she says none, end the interview by thanking the client for her time and assistance.

75. Did you have sex with any new partner(s) in the past 12 months?

76. (If yes) Did you use a condom the first time you had sex with your most recent new partner?

These questions address the amount of risk clients are generally exposed to. In question 76 , emphasize that we are asking about the first time you had sex with your most recent new partner. 


\section{Data analysis and reporting}

\section{Data entry and cleaning}

Once the data collection is complete, then the data must be entered into a computer in preparation for the analysis. The completed questionnaires should be gathered in one central location and ordered by date of visit, district, or any other criteria. After they are ordered, the questionnaire numbers should be filled in for each instrument in the upper righthand corner. These numbers should begin with 1 for each instrument, and will be used to identify individual questionnaires. This process is crucial to the data cleaning and analysis.

Depending on the size of the SA, data entry can take from two to six weeks. Sometimes investigators hire members of the data collection team to stay on and perform the data entry, which requires a certain familiarity with computers. The data entry is usually done using Epi Info, since the data entry process is fairly simple and the software is free. ${ }^{1}$

Once in the computer, the data will contain a variable for each question or tick mark on the questionnaires. Each of these variables will have a different name that can be used in the analysis. For example, the variable corresponding to the first question in the staff interview might be called "S1." The assignment of variable names is entirely up to the researcher-any name will do as long as it is unique, and understandable to the people who will be using the data.
The questionnaires in this book have suggested variable names, presented in brackets \{\}, for each question or tick mark. All five questionnaires share some identifying variables on the opening pages, such as health facility code, district code, type of SDP, sector, etc. These variables are given intuitive names such as [DISTCODE\}, \{DATE $\}$ or \{TYPE\}. Moreover, each questionnaire has an identifying variable, called $\{$ IID $\},\{O I D\},\{F I D\}$, $\{\mathrm{SID}\}$, and $\{\mathrm{MID}\}$, to represent identifying variables from the inventory, observation, FP client exit interview, staff interview, and $\mathrm{MCH}$ client interview, respectively. These variables hold the questionnaire numbers described above.

The rest of the variable names in each instrument follow a simple pattern. They all begin with a letter: " $\mathrm{I}$ " for inventory, "O" for observation, " $F$ " for FP exit interview, "S" for staff interview, or " $\mathrm{M}$ " for $\mathrm{MCH}$ exit interview, to identify the module. Next comes the question number, which ranges from 1 to over 100 in the FP exit interview. If the

${ }^{1}$ Epi Info is a DOS-based epidemiological package that allows for questionnaire design, data entry, and data analysis, developed by the Centers for Disease Control. It is available free from the Division of Surveillance and Epidemiology, Epidemiology Program Office, Centers for Disease Control and Prevention, Atlanta, Georgia, 30033 U.S.A., telephone (404) 728-0545. It can also be downloaded from the CDC's World Wide Web page at www.cdc.gov. 
question has several parts to it, such as several lines in a table that can each be ticked off separately, then each part is considered one "extension" of that question. Extensions are marked with an " $\mathrm{X}$ " and an extension number. For example, question 4 of the FP client interview asks about the other services the client received at the SDP. There are sixteen other services listed, and each can be checked off individually, so they each need a separate variable name. These variables are named: "F4X1," "F4X2," "F4X3," and so on to "F4X16." In this way, the name of each variable gives the researcher information on which questionnaire it is from, which question it addresses, and which part of the question it concerns.

Some of the questions have lists of possible answers, as in the above example, and a space for "Other: ." In these cases, the interviewer writes in the specific category and ticks it. This written information about "other" must also be recorded in the data, and needs a separate string variable. These variables are named with an " $R$ " at the end, to stand for other. ${ }^{3}$ In question 4 of the FP exit interview, for example, the last extension is "Other:__, and the interviewer ticks whether this "other" service was received. The variable name for the tick mark is "F4X16," and the variable name for the information written on the line is "F4X16R."

This suggested variable naming system might seem complex at first, but of the many systems that have been attempted with SA studies, this has proven to be the easiest system to use by far. If variable names are created from shorthand English based on the content of the question, such as "OTHSVC1," the user quickly finds that the variable names become awkward, unintuitive, and not unique. If, however, the variable names are systematically based on the question number, such as " $\mathrm{F} 4 \mathrm{X} 1$," then the user can find the variable name simply by looking at the question, and find the question simply by looking at the variable name. This is extremely valuable and timesaving in analysis.

Once all the data is entered, it must be cleaned. There are two basic kinds of cleaning that should always take place before any analysis:

\section{- Check for wildcodes}

A "wildcode" is a value of a variable that has no meaning. For example, the question might be "Did you accept FP today?" and the responses are " $1=$ no" and "2=yes" for 100 clients. After data entry, the frequency for this variable shows 75 cases as " 1 ," 24 cases as " 2 ," and one case as " 3 ." Since " 3 " is not a possible answer for this question, it must have been a mistake in data entry. This is called a "wildcode." This can be cleaned by looking at the ID variable for that case (IID, OID, FID, SID, or MID), using that to find the original questionnaire, and checking the question of interest. Usually, the correct answer is available this way, and the case can be recoded to a " 1 " or " 2 ."

\footnotetext{
${ }^{2}$ Note that the " $\mathrm{X}$ " is a crucial part of the variable name and should not be deleted. If the " $\mathrm{X}$ " were removed from these variable names, they would become "F41," and "F42," and so on. This is a problem because these names cannot be distinguished from the names for the forty-first and forty-second question of the interview.

${ }^{3}$ It might have been more intuitive to use "O" for Other, but an "O" is very easily confused with a zero, and the variable names become quite difficult with that approach.
} 
This first step, then, is to look at the frequencies of all the variables and check them against the questionnaires for wildcodes. If for some reason the original questionnaires are not available or the data for that question is missing, then the wildcodes should be set to "9" or some other code that means "missing data."

\section{- Check internal consistency}

A "filter question" selects certain people to be asked some follow-up questions. A simple filter question is: "Do you want more children?" with responses "yes" or "no." If the client answers "yes," then she is asked, "When do you want more children?" If 25 of 100 people answer "yes" to the first question, then 25 people should have a response for the second question. If 25 people answer "yes" to the first ques- tion, and 35 answer the second question, then the data are internally inconsistent. The original questionnaires should be checked.

This consistency check is extremely important in the FP exit interview. First, all clients are asked several questions together, and then a filter question divides them into new and revisit clients, who receive specific questions. The clients are then divided further into various method users, and asked another set of specific questions. For this reason, it is important to check all the internal consistencies in this module in particular.

If data is entered in Epi Info, it is possible to create automatic checks that prohibit data entry clerks from entering wildcodes or internal inconsistencies by misktake. For more information, refer to the Epi Info manual on creating .CHK files. 


\section{Analysis plan}

The primary results from most SA studies are presented in a report that gives as much relevant, simple, descriptive information about the program as possible. Later, the data might be used for further secondary analy- sis, but the first step is a simple presentation of results. Over the years, these primary reports have developed a fairly standard structure. Table 1 gives a typical outline for an SA report.

TABLE 1. Typical outline for Situation Analysis primary report

I. Introduction

A. History of FP program in country/region

B. Principal agencies in SA study

C. Justification of the SA study

D. Objectives of SA study

II. Study methodology

A. Sampling method

B. Implementation

i. Revision of questionnaires

ii. Training of data collectors

iii. Data collection process

iv. Cleaning and inputting of data

C. Data analysis and utilization

i. Analysis of data

III. Results

ii. Diffusion of results

A. Description of samples

B. Readiness to provide services

i. Services provided

ii. Infrastructure, facilities, and equipment

iii. Staff experience and training

iv. IEC materials and activities

v. Supplies and logistics

vi. Recordkeeping, reporting, and supervision

C. Quality of services

i. Interpersonal relations

ii. Choice of methods

iii. Information exchange

iv. Technical competence

v. Mechanisms to encourage continuity

vi. Appropriateness and acceptability of services

IV. Recommendations for action

Appendix 1: List of all participants/data collectors

Appendix 2: Instruments 
The following analysis plan deals with the "Results" portion of the outline in Table 1. It arranges the information collected by the SA instruments into three areas: description of samples, readiness to provide services, and quality of care. The latter two parts are further divided into sub-elements. The information under "Readiness to provide services" is arranged by: services provided, infrastructure, staff, IEC materials, supplies, recordkeeping, and supervision. The information under "Quality of care" is arranged according to the Bruce/ Jain framework described in Chapter 1: interpersonal relations, choice of methods, information exchange, technical competence, mechanisms to encourage continuity, and the appropriateness and acceptability of services.

The information under each of these headings is presented as a list of indicators. Each indicator specifies a distribution, percentage, or mean of some result, which can be used as an indication of the quality of services. Some of these indicators are quite simple and straightforward, but others require substantial calculation involving many variables.
The amount of information collected in one SA can be overwhelming. This analysis plan includes information from virtually every variable in all five SA instruments, resulting in over 130 indicators. However, no written analysis has ever used all the indicators listed. Instead, researchers and program managers select the set of indicators they feel to be most important for their program, and report on only those. The indicators that are most frequently used and that seem to be the most informative about program functioning are marked with a check $(\Omega)$ next to the indicator name.

The analysis plan also includes information on how to calculate the indicators. The three central columns in the table direct the user to the instrument, question, and variables that supply the information for each indicator. The rightmost column gives comments on how the indicator is normally calculated and presented. Note that for particularly difficult or complex calculations, more detailed comments are given at the end of the table. 


\section{Analysis Plan: Description of samples}

\begin{tabular}{|c|c|c|c|c|c|}
\hline \multicolumn{2}{|l|}{$\begin{array}{l}\text { Result } \\
\checkmark=\text { frequently used indicator }\end{array}$} & \multirow{2}{*}{\begin{tabular}{|c|} 
Instr. \\
All
\end{tabular}} & \multirow{2}{*}{$\begin{array}{l}\text { Question } \\
\text { numbers }\end{array}$} & \multirow{2}{*}{ Variables } & \multirow{2}{*}{$\begin{array}{l}\text { Comments } \\
\text { This is the total } n \text { from each dataset. } \\
\text { Often presented by district as well. }\end{array}$} \\
\hline $\begin{array}{l}\text { 1. Number of SDPs visited and } \mathrm{n} \text { for } \\
\text { each instrument }\end{array}$ & $\checkmark$ & & & & \\
\hline 2. Distribution of SDPs by type & $\checkmark$ & 1 & Cover page & TYPE & \multirow{3}{*}{$\begin{array}{l}\text { Do not use TYPE, SECT, or LOC } \\
\text { variables from any instrument other } \\
\text { than the inventory. }\end{array}$} \\
\hline 3. Distribution of SDPs by sector & $\checkmark$ & 1 & Cover page & SECT & \\
\hline 4. Distribution of SDPs by locality & $\checkmark$ & 1 & Cover page & LOC & \\
\hline 5. Distribution of FP clients, by type & $\checkmark$ & 0 & Page 2 & PURPOSE & Present as a pie chart. \\
\hline \multirow[t]{2}{*}{$\begin{array}{l}\text { 6. Sociodemographic characteristics of } \\
\text { FP and MCH clients }\end{array}$} & \multirow[t]{2}{*}{$\checkmark$} & $\bar{F}$ & $\begin{array}{l}103,104 \\
105,112 \\
113,114 \\
115\end{array}$ & $\begin{array}{l}F 103, F 104, \\
F 105, F 112, \\
F 113 \times 1 \text { to } F 113 \times 5, \\
F 114, F 115\end{array}$ & \multirow{2}{*}{$\begin{array}{l}\text { These include: age, marital status, } \\
\text { literacy, languages spoken, educational } \\
\text { level, and religion. } \\
\text { Usually, results for FP and MCH clients } \\
\text { are presented as two columns in a } \\
\text { table. }\end{array}$} \\
\hline & & $M$ & $\begin{array}{l}51,52,53 \\
60,61,62 \\
63\end{array}$ & $\begin{array}{l}\text { M51, M52, } \\
\text { M53, M60, } \\
\text { M61X1 to M61X5, } \\
\text { M62, M63 }\end{array}$ & \\
\hline
\end{tabular}

$I=$ Inventory $O=$ Observation guide $F=F P$ exit interview $S=$ Staff interview $M=M C H$ exit interview 


\begin{tabular}{|c|c|c|c|c|c|}
\hline $\begin{array}{l}\text { Result } \\
\checkmark=\text { frequently used indicator }\end{array}$ & & Instr. & $\begin{array}{l}\text { Question } \\
\text { numbers }\end{array}$ & Variables & Comments \\
\hline \multirow[t]{2}{*}{$\begin{array}{l}\text { 7. Reproductive status and sexual } \\
\text { history of FP and } \mathrm{MCH} \text { clients }\end{array}$} & \multirow[t]{2}{*}{$\checkmark$} & $\mathrm{F}$ & $\begin{array}{l}101,102, \\
108,110 \\
110,111 \\
116,117 \\
124,125 \\
126\end{array}$ & $\begin{array}{l}F 101, F 102, F 108, \\
F 109, F 110, F 111, \\
F 116, F 117 F 124, \\
F 125, F 126\end{array}$ & \multirow[t]{2}{*}{$\begin{array}{l}\text { These include: number of children, age } \\
\text { of youngest child, breastfeeding status, } \\
\text { reproductive intentions, number of } \\
\text { partners in last year, any new partners } \\
\text { in last year, whether used condom with } \\
\text { new partner, and abortion history. }\end{array}$} \\
\hline & & M & $\begin{array}{l}49,50,56, \\
57,58,59, \\
64,65,74, \\
75,76\end{array}$ & $\begin{array}{l}\text { M49,M50,M56, } \\
\text { M57,M58,M59, } \\
\text { M64,M65,M74, } \\
\text { M75,M76 }\end{array}$ & \\
\hline \multirow[t]{2}{*}{$\begin{array}{l}\text { 8. Contraceptive background of FP and } \\
\mathrm{MCH} \text { clients }\end{array}$} & \multirow[t]{2}{*}{$\checkmark$} & $\mathrm{F}$ & $\begin{array}{l}43,44,62 \\
106,107\end{array}$ & $\begin{array}{l}F 43, \\
F 44 \times 1 \text { to } F 44 \times 98, \\
F 62, F 106, F 107\end{array}$ & \multirow{2}{*}{$\begin{array}{l}\text { These include: } \\
\text { For all clients: ever discuss FP with } \\
\text { partner, whether partner knows of } \\
\text { FP use. } \\
\text { For MCH clients: knowledge of and } \\
\text { attitude toward FP, current use. } \\
\text { For new FP clients: ever use of FP. } \\
\text { For revisit FP clients: reason for } \\
\text { wanting to stop or switch. }\end{array}$} \\
\hline & & $M$ & $\begin{array}{l}39,40,44, \\
45,46,54, \\
55\end{array}$ & $\begin{array}{l}\text { M39, } \\
\text { M40X1 to M40X13, } \\
\text { M44,M45,M46, } \\
\text { M54,M55 }\end{array}$ & \\
\hline $\begin{array}{l}\text { 9. Sociodemographic characteristics of } \\
\text { providers }\end{array}$ & $\checkmark$ & $S$ & $\begin{array}{l}32,33,34 \\
35,36\end{array}$ & $\begin{array}{l}\mathrm{S} 32, \mathrm{~S} 33, \mathrm{~S} 34 \\
\mathrm{~S} 35, \mathrm{~S} 36\end{array}$ & $\begin{array}{l}\text { These include: age, marital status, } \\
\text { number of children, gender, and religion }\end{array}$ \\
\hline 10. Current use of FP by providers & & $S$ & 37 & $537 \times 1$ to $537 \times 77$ & $\begin{array}{l}\text { Present as pie chart. Include "none" as } \\
\text { part of chart. }\end{array}$ \\
\hline
\end{tabular}

$I=$ Inventory $O=$ Observation guide $F=F P$ exit interview $S=$ Staff interview $M=M C H$ exit interview 


\section{Analysis plan: Readiness to provide services}

\begin{tabular}{|c|c|c|c|c|c|}
\hline $\begin{array}{l}\text { Readiness indicator } \\
\checkmark=\text { frequently used indicator }\end{array}$ & & Instr. & $\begin{array}{l}\text { Question } \\
\text { numbers }\end{array}$ & Variables & Comments \\
\hline \multicolumn{6}{|l|}{ Services provided } \\
\hline $\begin{array}{l}\text { 11. Percent of SDPs that usually offer } \\
\text { FP methods }\end{array}$ & $\checkmark$ & 1 & 18,21 & $\begin{array}{l}118 \times 1 \text { to } 118 \times 9 \\
121 \times 1 \text { to } 121 \times 6\end{array}$ & Present as a bar chart by method. \\
\hline $\begin{array}{l}\text { 12. Percent of SDPs that usually offer } \\
\text { other services, either in FP unit or } \\
\text { elsewhere in facility }\end{array}$ & $\checkmark$ & 1 & 8 & $\begin{array}{l}\text { I8A2 to } 18 \mathrm{~A} 17 \\
\text { I8B2 to } 18 \mathrm{~B} 17\end{array}$ & Present as a bar chart by service. \\
\hline $\begin{array}{l}\text { 13. Mean and median number of new } \\
\text { and revisit clients in a year, by } \\
\text { type of service }\end{array}$ & $\checkmark$ & 1 & 36,37 & $\begin{array}{l}\text { I36A1 to } 136 \mathrm{~A} 7 \\
136 \mathrm{~B} 1 \text { to } 136 \mathrm{~B} 7 \\
136 \mathrm{C} 1 \text { to } 136 \mathrm{C} 7 \\
137 \times 1,137 \times 2\end{array}$ & $\begin{array}{l}\text { If data are supplied for less than a year, } \\
\text { create an annual estimate by taking a monthly } \\
\text { average (based on column C), and multiplying } \\
\text { by } 12 \text {. Use } \mathrm{q} .37 \text { to check the recency of the } \\
\text { information. }\end{array}$ \\
\hline $\begin{array}{l}\text { 14. Distribution of SDPs by FP client } \\
\text { load }\end{array}$ & $\checkmark$ & 1 & 36 & $\begin{array}{l}\text { I36A1 } \\
\text { I36B1 } \\
\text { I36C1 }\end{array}$ & $\begin{array}{l}\text { Divide the SDPs into quartiles by client load } \\
\text { and report the percentage of the total client } \\
\text { load per quartile. }{ }^{1}\end{array}$ \\
\hline $\begin{array}{l}\text { 15. Number of days per week FP } \\
\text { services are offered }\end{array}$ & $\checkmark$ & 1 & 6 & 16 & Present as a mean and/or a pie chart. \\
\hline $\begin{array}{l}\text { 16. Distribution of } \mathrm{MCH} \text { clients among } \\
\text { other services }\end{array}$ & & $M$ & 1 & M1 & $\begin{array}{l}\text { This gives an idea of the relative importance } \\
\text { of other services to the program. }\end{array}$ \\
\hline $\begin{array}{l}\text { 17. } \mathrm{MCH} \text { client service utilization, at } \\
\text { this clinic and others }\end{array}$ & & M & 35,36 & $\begin{array}{l}M 35 \times 1 \text { to } M 35 \times 4 \\
M 36 \times 1 \text { to } M 36 \times 4\end{array}$ & $\begin{array}{l}\text { Present as a bar chart with two series: one } \\
\text { for this clinic, and one for other SDPs. }\end{array}$ \\
\hline
\end{tabular}

$I=$ Inventory $\mathrm{O}=$ Observation guide $\mathrm{F}=\mathrm{FP}$ exit interview $\mathrm{S}=$ Staff interview $\mathrm{M}=\mathrm{MCH}$ exit interview 


\begin{tabular}{|c|c|c|c|c|c|}
\hline \multicolumn{2}{|l|}{$\begin{array}{l}\text { Readiness indicator } \\
\checkmark=\text { frequently used indicator }\end{array}$} & \multirow{2}{*}{ Instr. } & \multirow{2}{*}{$\begin{array}{l}\begin{array}{l}\text { Question } \\
\text { numbers }\end{array} \\
22,23\end{array}$} & \multirow{2}{*}{\begin{tabular}{|l} 
Variables \\
I22 \\
I23A1 to $123 \mathrm{~A} 7$ \\
123B1 to $123 \mathrm{~B} 7$
\end{tabular}} & \multirow{2}{*}{$\begin{array}{l}\text { Comments } \\
\text { Note that "providing" a test means at the } \\
\text { SDP itself or through referral. Present as a bal } \\
\text { chart by test. Use q. } 22 \text { as a filter. }\end{array}$} \\
\hline $\begin{array}{l}\text { 18. Percent of SDPs that offer tests } \\
\text { for pregnancy and specific } \\
\text { diseases }\end{array}$ & & & & & \\
\hline $\begin{array}{l}\text { 19. Percent of SDPs that usually offer } \\
\text { specific immunizations }\end{array}$ & & 1 & 24 & $124 \times 1$ to $124 \times 6$ & Present as a bar chart. \\
\hline $\begin{array}{l}\text { 20. Percent of providers reporting that } \\
\text { clients seek abortion advice at } \\
\text { their SDP }\end{array}$ & & $S$ & 30 & $\$ 30$ & $\begin{array}{l}\text { These questions give a general idea of } \\
\text { abortion demand in the area. They are } \\
\text { suggestive only, since the providers may not }\end{array}$ \\
\hline $\begin{array}{l}\text { 21. Percent of providers reporting that } \\
\text { clients seek post-abortion care at } \\
\text { their SDP }\end{array}$ & & $S$ & 31 & S31 & $\begin{array}{l}\text { patients. Also, heavy reporting biases affect } \\
\text { these questions, particularly in countries } \\
\text { where abortion is illegal. }\end{array}$ \\
\hline \multicolumn{6}{|l|}{ Infrastructure, facilities, and equipment } \\
\hline $\begin{array}{l}\text { 22. Percent of SDPs with working } \\
\text { necessary infrastructure }\end{array}$ & $\boldsymbol{V}$ & 1 & 9 & $19 \times 1$ to $19 \times 6$ & $\begin{array}{l}\text { This includes water, electricity, toilets, and } \\
\text { seating. Present as a bar chart. }\end{array}$ \\
\hline $\begin{array}{l}\text { 23. Percent of SDPs with appropriate } \\
\text { examination areas }\end{array}$ & $\checkmark$ & 1 & 15 & $115 \times 1$ to $115 \times 5$ & $\begin{array}{l}\text { This includes: auditory privacy, visual privacy, } \\
\text { cleanliness, adequate light, and adequate } \\
\text { water. Present as a bar chart. }\end{array}$ \\
\hline $\begin{array}{l}\text { 24. Percent of SDPs missing selected } \\
\text { FP equipment }\end{array}$ & $\checkmark$ & I & 16,17 & $\begin{array}{l}116 \times 1 \text { to } 116 \times 18 \\
117 \times 1 \text { to } 117 \times 6\end{array}$ & $\begin{array}{l}\text { Of the many pieces of equipment listed, } \\
\text { select the ones program managers find most } \\
\text { important. Note that this indicator calls for } \\
\text { the reverse of the data: if } 85 \% \text { of SDPs have } \\
\text { a sterilizer, then report here that } 15 \% \text { are } \\
\text { missing a sterilizer. On the items that are } \\
\text { counted, set an appropriate threshold for the } \\
\text { number of items an SDP should have in order } \\
\text { to be properly equipped. Then report on the } \\
\text { SDPs that have fewer than the threshold. }\end{array}$ \\
\hline
\end{tabular}

$\mathrm{I}=$ Inventory $\mathrm{O}=$ Observation guide $\mathrm{F}=\mathrm{FP}$ exit interview $\mathrm{S}=$ Staff interview $\mathrm{M}=\mathrm{MCH}$ exit interview 


\begin{tabular}{|c|c|c|c|c|c|}
\hline $\begin{array}{l}\text { Readiness indicator } \\
\checkmark=\text { frequently used indicator }\end{array}$ & & Instr. & $\begin{array}{l}\text { Question } \\
\text { numbers }\end{array}$ & Variables & Comments \\
\hline \multicolumn{6}{|l|}{ Staff experience and training } \\
\hline 25. Distribution of providers by type & & 1 & 10 & $110 \times 1$ to $110 \times 7$ & $\begin{array}{l}\text { Present as a pie chart. Do not use the staff } \\
\text { types from the staff interview module, but } \\
\text { only from the inventory. }\end{array}$ \\
\hline $\begin{array}{l}\text { 26. Distribution of providers on duty } \\
\text { today by type }\end{array}$ & & 1 & 11 & $111 \times 1$ to $111 \times 7$ & Compare to total staff in indicator 25. \\
\hline $\begin{array}{l}\text { 27. Percent of staff whose basic } \\
\text { training included various issues }\end{array}$ & $\checkmark$ & $S$ & 4 & $S 4 \times 1$ to $S 4 \times 12$ & $\begin{array}{l}\text { Present as bar chart by subject. Can present } \\
\text { by type of provider as well. }\end{array}$ \\
\hline $\begin{array}{l}\text { 28. Mean and median years since } \\
\text { basic training }\end{array}$ & $\checkmark$ & $S$ & 3 & s3 & $\begin{array}{l}\text { Can present by type of provider if there is a } \\
\text { large difference. }\end{array}$ \\
\hline $\begin{array}{l}\text { 29. Percent of providers whose post- } \\
\text { basic/refresher training included } \\
\text { specific FP/STD issues }\end{array}$ & $\boldsymbol{V}$ & $S$ & 6,7 & $\begin{array}{l}S 6, \\
S 7 \times 1 \text { to } S 7 \times 19\end{array}$ & $\begin{array}{l}\text { Present as a bar chart by subject. Can report } \\
\text { among all staff, or use q. } 6 \text { as a filter and } \\
\text { report only among staff that have had this } \\
\text { training. }\end{array}$ \\
\hline $\begin{array}{l}\text { 30. Mean and median years since } \\
\text { post-basic/refresher training in } \\
\text { FP/STD issues }\end{array}$ & & $S$ & 8 & $S 8 \times 1$ to $S 8 \times 19$ & $\begin{array}{l}\text { Compute this by topic, among those staff } \\
\text { reporting on } q .8 \text {. Note that the } n \text { will change } \\
\text { for each topic. }\end{array}$ \\
\hline $\begin{array}{l}\text { 31. Percent of providers who have had } \\
\text { refresher training in other health } \\
\text { issues }\end{array}$ & $\checkmark$ & $S$ & 5 & $S 5 \times 2$ to $S 5 \times 12$ & Present as a bar chart. \\
\hline $\begin{array}{l}\text { 32. Mean and median years providers } \\
\text { have been working at their facility }\end{array}$ & & S & 2 & S2 & $\begin{array}{l}\text { Can present by type of staff if there is a large } \\
\text { difference. }\end{array}$ \\
\hline $\begin{array}{l}\text { 33. Percent of providers actively } \\
\text { providing various services at this } \\
\text { SDP }\end{array}$ & & $S$ & 1 & $\mathrm{~S} 1 \times 1$ to $\mathrm{S} 1 \times 18$ & Present as a bar chart. \\
\hline
\end{tabular}

$I=$ Inventory $O=$ Observation guide $F=F P$ exit interview $S=$ Staff interview $M=M C H$ exit interview 


\begin{tabular}{|c|c|c|c|c|c|}
\hline \multicolumn{2}{|l|}{$\begin{array}{l}\text { Readiness indicator } \\
\checkmark=\text { frequently used indicator }\end{array}$} & \multirow{2}{*}{ Instr. } & \multirow{2}{*}{$\begin{array}{l}\begin{array}{l}\text { Question } \\
\text { numbers }\end{array} \\
9,10\end{array}$} & \multirow{2}{*}{$\begin{array}{l}\text { Variables } \\
\text { S9 } 10 \times 1 \text { to } S 10 \times 15\end{array}$} & \multirow{2}{*}{$\begin{array}{l}\text { Comments } \\
\text { Present as a bar chart. Usually calculated } \\
\text { among all staff; do not use q. } 9 \text { as a filter. }\end{array}$} \\
\hline $\begin{array}{l}\text { 34. Percent of providers providing } \\
\text { various FP methods in last } 3 \\
\text { months }\end{array}$ & $\checkmark$ & & & & \\
\hline \multicolumn{6}{|l|}{ IEC materials and activities } \\
\hline $\begin{array}{l}\text { 35. Percent of SDPs with a sign } \\
\text { announcing FP services }\end{array}$ & & 1 & 7 & 17 & Present as a pie chart. \\
\hline $\begin{array}{l}\text { 36. Percent of SDPs with various IEC } \\
\text { materials available }\end{array}$ & $\checkmark$ & 1 & 12 & $\begin{array}{l}\mathrm{I} 2 \mathrm{~A} 1 \text { to } 112 \mathrm{~A} 7 \\
\mathrm{I12B} 1 \text { to } 112 \mathrm{~B} 7 \\
\mathrm{I} 2 \mathrm{C} 1 \text { to } 112 \mathrm{C} 7\end{array}$ & $\begin{array}{l}\text { Present as a table or bar chart with the IEC } \\
\text { items on the } x \text {-axis and a different bar for } \\
\text { each subject. }\end{array}$ \\
\hline $\begin{array}{l}\text { 37. Percent of SDPs that offer health } \\
\text { talks }\end{array}$ & $\checkmark$ & 1 & 13 & 113 & \\
\hline $\begin{array}{l}\text { 38. Percent of health talks that include } \\
\text { various subjects }\end{array}$ & $\checkmark$ & 1 & 14 & $114 \times 1$ to $114 \times 15$ & Present as bar chart. Use q.13 as a filter. \\
\hline \multicolumn{6}{|l|}{ Supplies and logistics } \\
\hline $\begin{array}{l}\text { 39. Percent of SDPs experiencing } \\
\text { stockouts of contraceptive } \\
\text { supplies in the previous six } \\
\text { months }\end{array}$ & $\checkmark$ & I & $\begin{array}{l}18,19 \\
20\end{array}$ & $\begin{array}{l}118 \times 1 \text { to } 118 \times 9 \\
119 \times 1 \text { to } 119 \times 9 \\
120 \times 1 \text { to } 120 \times 9\end{array}$ & $\begin{array}{l}\text { If the SDP has had a stockout in the last six } \\
\text { months (q. } 20 \text { ) or has no supplies today } \\
\text { (q.19), count it as having had a stockout. } \\
\text { Use q.18 as a filter - do not include in the } \\
\text { denominator SDPs that do not offer the } \\
\text { particular method. The } n \text { will change for each } \\
\text { method. }\end{array}$ \\
\hline $\begin{array}{l}\text { 40. Percent of SDPs with appropriate } \\
\text { stocking conditions for } \\
\text { commodities }\end{array}$ & $\checkmark$ & 1 & 29 & $129 \times 1$ to $129 \times 4$ & Present as a bar chart by commodity. \\
\hline $\begin{array}{l}\text { 41. Percent of SDPs that store stocks } \\
\text { by expiration date }\end{array}$ & $\checkmark$ & 1 & 28 & $128 \times 1$ to $128 \times 4$ & Present as a bar chart by commodity. \\
\hline
\end{tabular}

$I=$ Inventory $O=$ Observation guide $F=F P$ exit interview $S=$ Staff interview $M=M C H$ exit interview 


\begin{tabular}{|c|c|c|c|c|c|}
\hline \multicolumn{2}{|l|}{$\begin{array}{l}\text { Readiness indicator } \\
\checkmark=\text { frequently used indicator }\end{array}$} & \multirow{2}{*}{ Instr. } & \multirow{2}{*}{$\begin{array}{l}\text { Question } \\
\text { numbers }\end{array}$} & \multirow{2}{*}{$\begin{array}{l}\text { Variables } \\
126 \times 1 \text { to } 126 \times 4 \\
127 \times 1 \text { to } 127 \times 4\end{array}$} & \multirow{2}{*}{$\begin{array}{l}\text { Comments } \\
\text { Present as a pie chart with three slices: SDPs } \\
\text { with no inventory, those with an inventory in } \\
\text { good condition, and those with an inventory } \\
\text { not in good condition. }\end{array}$} \\
\hline $\begin{array}{l}\text { 42. Percent of SDPs with supply } \\
\text { inventories }\end{array}$ & & & & & \\
\hline $\begin{array}{l}\text { 43. Percent of SDPs that have } \\
\text { experienced a stockout of } \\
\text { immunization supplies in last } 6 \\
\text { months }\end{array}$ & & 1 & 24,25 & $\begin{array}{l}124 \times 1 \text { to } 124 \times 6 \\
125 \times 1 \text { to } 125 \times 6\end{array}$ & $\begin{array}{l}\text { Present as bar chart by commodity. Use } q .24 \\
\text { as a filter - do not include in the denominator } \\
\text { SDPs that do not offer the particular } \\
\text { immunization. The } n \text { will change for each } \\
\text { immunization. }\end{array}$ \\
\hline \multicolumn{6}{|l|}{ Recordkeeping, reporting, and supervision } \\
\hline $\begin{array}{l}\text { 44. Percent of SDPs with client record } \\
\text { card systems }\end{array}$ & $\checkmark$ & 1 & 30 & 130 & Present as a pie chart. \\
\hline $\begin{array}{l}\text { 45. Of those SDPs with client record } \\
\text { card systems, percent with cards } \\
\text { in good condition }\end{array}$ & $\checkmark$ & 1 & 30,31 & 130,131 & Present as a pie chart. Use q. 30 as a filter. \\
\hline $\begin{array}{l}\text { 46. Percent of SDPs with daily activity } \\
\text { registers }\end{array}$ & & 1 & 32 & 132 & Present as a pie chart. \\
\hline $\begin{array}{l}\text { 47. Percent of SDPs that send } \\
\text { statistical reports to higher units }\end{array}$ & & 1 & 33 & $133 \times 1$ to $133 \times 3$ & Present as a bar chart by type of service. \\
\hline $\begin{array}{l}\text { 48. Percent of SDPs that have } \\
\text { received at least one supervisory } \\
\text { visit in the previous six months }\end{array}$ & $\checkmark$ & $\mathbf{I}$ & 34 & 134 & $\begin{array}{l}\text { Programs often establish norms for the } \\
\text { frequency of supervisory visits. The wording } \\
\text { of this indicator can be changed to test if } \\
\text { those program norms are being met. Instead } \\
\text { of "at least one," this could read "two or } \\
\text { more," etc. }\end{array}$ \\
\hline
\end{tabular}

$1=$ Inventory $O=$ Observation guide $F=F P$ exit interview $S=$ Staff interview $M=M C H$ exit interview 


\begin{tabular}{|c|c|c|c|c|c|}
\hline $\begin{array}{l}\text { Readiness indicator } \\
\checkmark=\text { frequently used indicator }\end{array}$ & & Instr. & $\begin{array}{l}\text { Question } \\
\text { numbers }\end{array}$ & Variables & Comments \\
\hline $\begin{array}{l}\text { 49. Among SDPs that have received a } \\
\text { supervisory visit in the previous } \\
\text { six months, mean number of visits } \\
\text { per SDP }\end{array}$ & $\checkmark$ & 1 & 34 & 134 & $\begin{array}{l}\text { Average only among those that list } 1 \text { or more } \\
\text { on q.34. }\end{array}$ \\
\hline $\begin{array}{l}\text { 50. Percent of supervisors performing } \\
\text { various activities }\end{array}$ & $v$ & 1 & 34,35 & $\begin{array}{l}134 \\
135 \times 1 \text { to } 135 \times 7\end{array}$ & $\begin{array}{l}\text { Note the reduced } n \text { - use only those SDPs } \\
\text { that have had at least one supervisory visit. } \\
\text { Present as a bar chart. }\end{array}$ \\
\hline
\end{tabular}

$I=$ Inventory $O=$ Observation guide $F=F P$ exit interview $S=$ Staff interview $M=M C H$ exit interview 
Analysis plan: Quality of care

\begin{tabular}{|c|c|c|c|c|c|}
\hline $\begin{array}{l}\text { Quality indicator } \\
\checkmark=\text { frequently used indicator }\end{array}$ & & Instr. & $\begin{array}{l}\text { Question } \\
\text { numbers }\end{array}$ & Variables & Comments \\
\hline \multicolumn{6}{|l|}{ Interpersonal relations } \\
\hline $\begin{array}{l}\text { 51. Percent of FP clients who received } \\
\text { a friendly greeting }\end{array}$ & $\checkmark$ & 0 & 1 & 01 & \\
\hline $\begin{array}{l}\text { 52. Percent of FP clients who feel that } \\
\text { the provider listened to her } \\
\text { concerns }\end{array}$ & $\checkmark$ & $F$ & 7,8 & F7,F8 & $\begin{array}{l}\text { Report either among all clients or among } \\
\text { those who had concerns. }\end{array}$ \\
\hline $\begin{array}{l}\text { 53. Percent of FP clients who a) had } \\
\text { questions, b) provider let ask the } \\
\text { question, and c) were satisfied } \\
\text { with answer }\end{array}$ & $\checkmark$ & $\mathrm{F}$ & $9,10,11$ & F9,F10,F11 & $\begin{array}{l}\text { Note reduced } \mathrm{n} \text { for each part of this indicator. } \\
\text { This is sometimes reported for new clients } \\
\text { only. } \\
\text { These results can also be compared to } \mathrm{MCH} \\
\text { clients (MCH interview } q .8,9,10 \text { ). }\end{array}$ \\
\hline $\begin{array}{l}\text { 54. Percent of providers who are } \\
\text { comfortable discussing HIV/STDs }\end{array}$ & & $\mathrm{S}$ & 29 & $\$ 29$ & Present as a pie chart. \\
\hline $\begin{array}{l}\text { 55. Percent of FP clients reporting that } \\
\text { physical examinations were } \\
\text { explained beforehand and } \\
\text { afterward }\end{array}$ & $\checkmark$ & $\mathrm{F}$ & $\begin{array}{l}12,13 \\
14\end{array}$ & $F 12, F 13, F 14$ & $\begin{array}{l}\text { Use q } 12 \text { as a filter to reduce to only those } \\
\text { clients who had a physical examination. } \\
\text { These results can also be compared to } \mathrm{MCH} \\
\text { clients (MCH interview q. } 11,12,13 \text { ). }\end{array}$ \\
\hline \multicolumn{6}{|l|}{ Choice of methods } \\
\hline $\begin{array}{l}\text { 56. Percent of new FP clients who } \\
\text { were told about various methods }\end{array}$ & $\checkmark$ & $\mathrm{O}$ & 12 & $012 \times 1$ to $012 \times 13$ & Present as a bar chart by method. \\
\hline $\begin{array}{l}\text { 57. Mean number of methods } \\
\text { mentioned to new FP clients }\end{array}$ & $\checkmark$ & O & 12 & $012 \times 1$ to $012 \times 13$ & \\
\hline
\end{tabular}

$I=$ Inventory $O=$ Observation guide $F=F P$ exit interview $S=$ Staff interview $M=M C H$ exit interview 


\begin{tabular}{|c|c|c|c|c|c|}
\hline $\begin{array}{l}\text { Quality indicator } \\
\checkmark=\text { frequently used indicator }\end{array}$ & & Instr. & $\begin{array}{l}\text { Question } \\
\text { numbers }\end{array}$ & Variables & Comments \\
\hline $\begin{array}{l}\text { 58. Percent of new FP clients and } \\
\text { switching revisit clients who } \\
\text { report that they heard about more } \\
\text { than one method from the provider }\end{array}$ & & $\mathrm{F}$ & 48,68 & $\mathrm{~F} 48, \mathrm{~F} 68$ & $\begin{array}{l}\text { Combine new clients and revisit clients who } \\
\text { are switching methods. }\end{array}$ \\
\hline $\begin{array}{l}\text { 59. Percent of new FP clients asked if } \\
\text { they have a preference for a } \\
\text { method }\end{array}$ & $\checkmark$ & 0 & 10 & 010 & \\
\hline $\begin{array}{l}\text { 60. Percent of providers who } \\
\text { encourage one method over others } \\
\text { during the consultation }\end{array}$ & & $\mathrm{O}$ & 15 & 015 & \\
\hline $\begin{array}{l}\text { 61. Percent of providers who report } \\
\text { that they impose barriers on } \\
\text { methods }\end{array}$ & $\checkmark$ & $S$ & $\begin{array}{l}11,12 \\
13,14 \\
15,16 \\
17,18\end{array}$ & $\begin{array}{l}S 11 \times 1 \text { to } S 11 \times 5 \\
S 12 \times 1 \text { to } S 12 \times 5 \\
S 13 \times 1 \text { to } S 13 \times 5 \\
S 14 \times 1 \text { to } S 14 \times 5 \\
S 15 \times 1 \text { to } S 15 \times 5 \\
S 16 \times 1 \text { to } S 16 \times 5 \\
S 17 \times 1 \text { to } S 17 \times 5 \\
S 18 \times 1 \text { to } S 18 \times 5\end{array}$ & $\begin{array}{l}\text { These barriers are: age, marital status, parity, } \\
\text { spousal consent. These indicators take } \\
\text { substantial calculation. }{ }^{2} \text { Present as a table, } \\
\text { by method. }\end{array}$ \\
\hline $\begin{array}{l}\text { 62. Of providers imposing barriers, } \\
\text { mean minimum age, maximum } \\
\text { age, and parity required, by } \\
\text { method }\end{array}$ & $\checkmark$ & $S$ & $\begin{array}{l}11,12 \\
13,14 \\
15,16\end{array}$ & $\begin{array}{l}S 11 \times 1 \text { to } S 11 \times 5 \\
S 12 \times 1 \text { to } S 12 \times 5 \\
S 13 \times 1 \text { to } S 13 \times 5 \\
S 14 \times 1 \text { to } S 14 \times 5 \\
S 15 \times 1 \text { to } S 15 \times 5 \\
S 16 \times 1 \text { to } S 16 \times 5\end{array}$ & $\begin{array}{l}\text { These indicators take substantial calculation. }{ }^{2} \\
\text { Present as a table, by method. }\end{array}$ \\
\hline $\begin{array}{l}\text { 63. Percent of providers who would } \\
\text { recommend various methods for } \\
\text { spacing/limiting clients }\end{array}$ & & $S$ & $\begin{array}{l}19,19 a \\
20,20 a\end{array}$ & $\begin{array}{l}\mathrm{S} 19, \mathrm{~S} 20 \\
\mathrm{~S} 19 \mathrm{~A} \times 1 \text { to } \mathrm{S} 19 \mathrm{~A} \times 13 \\
\mathrm{~S} 2 \mathrm{OA} 1 \text { to } \mathrm{S} 2 \mathrm{OAX} 13\end{array}$ & $\begin{array}{l}\text { Present as a bar chart by method. Use two } \\
\text { bars per method: one for recommendations } \\
\text { for spacing clients, the other for } \\
\text { recommendations for limiting clients. }\end{array}$ \\
\hline
\end{tabular}

$I=$ Inventory $O=$ Observation guide $F=F P$ exit interview $S=$ Staff interview $M=M C H$ exit interview 


\begin{tabular}{|c|c|c|c|c|c|}
\hline \multicolumn{2}{|l|}{$\begin{array}{l}\text { Quality indicator } \\
\checkmark=\text { frequently used indicator }\end{array}$} & \multirow{2}{*}{ Instr. } & \multirow{2}{*}{$\begin{array}{l}\begin{array}{l}\text { Question } \\
\text { numbers }\end{array} \\
22,22 \mathrm{a}\end{array}$} & \multirow{2}{*}{$\begin{array}{l}\text { Variables } \\
\text { S22 } \\
\text { S22AX1 to } S 22 A \times 13\end{array}$} & \multirow[t]{2}{*}{ Comments } \\
\hline $\begin{array}{l}\text { 64. Percent of providers who report } \\
\text { that they would never recommend } \\
\text { certain methods }\end{array}$ & $\checkmark$ & & & & \\
\hline $\begin{array}{l}\text { 65. Percent of FP clients whose } \\
\text { chosen method was the same } \\
\text { they expressed a preference for }\end{array}$ & & 0 & 26 & 026 & \multirow{2}{*}{$\begin{array}{l}\text { Note that these two indicators measure very } \\
\text { similar outcomes, but one is from the } \\
\text { observation and the other is from the client } \\
\text { exit interview. }\end{array}$} \\
\hline $\begin{array}{l}\text { 66. Percent of new FP clients who } \\
\text { report that they received their } \\
\text { method of choice }\end{array}$ & $\checkmark$ & $\mathrm{F}$ & 48 & F48 & \\
\hline $\begin{array}{l}\text { 67. Of those new FP clients that did } \\
\text { not receive their method of } \\
\text { choice, preferred method }\end{array}$ & & $\mathrm{F}$ & 51,52 & $F 51, F 52$ & Present as a pie chart. Use q.51 as a filter. \\
\hline $\begin{array}{l}\text { 68. Of those FP clients whose chosen } \\
\text { method was not their preferred } \\
\text { method, observed reason }\end{array}$ & & 0 & 26,27 & 026,027 & \multirow{2}{*}{$\begin{array}{l}\text { Note that these two indicators measure very } \\
\text { similar outcomes, but one is from the } \\
\text { observation and the other is from the client } \\
\text { exit interview. } \\
\text { Use q. } 26 \text { and q. } 51 \text { as filters. }\end{array}$} \\
\hline $\begin{array}{l}\text { 69. Of those new FP clients that did } \\
\text { not receive their method of } \\
\text { choice, reported reason }\end{array}$ & & $\mathrm{F}$ & 51,53 & $\begin{array}{l}\text { F51, } \\
\text { F53X1 to F53X98 }\end{array}$ & \\
\hline \multirow[t]{2}{*}{$\begin{array}{l}\text { 70. Of new FP clients who decide not } \\
\text { to use FP, reasons }\end{array}$} & & 0 & 21,22 & 021,022 & \multirow{2}{*}{$\begin{array}{l}\text { Present as pie charts. Use q. } 21 \text { and } q .45 \text { as } \\
\text { filters. The comparison between the } \\
\text { observation and exit interview information } \\
\text { gives an idea of how these decisions are } \\
\text { percieved by clients vs. providers. }\end{array}$} \\
\hline & & $\mathrm{F}$ & 45,46 & $F 45, F 46$ & \\
\hline $\begin{array}{l}\text { 71. Of revisit FP clients who want to } \\
\text { stop or switch, reasons for stop or } \\
\text { switch }\end{array}$ & & 0 & 23,24 & 023,024 & Present as a pie chart. Use q.23 as a filter. \\
\hline
\end{tabular}

$I=$ Inventory $O=$ Observation guide $F=F P$ exit interview $S=$ Staff interview $M=M C H$ exit interview 


\begin{tabular}{|c|c|c|c|c|c|}
\hline $\begin{array}{l}\text { Quality indicator } \\
\checkmark=\text { frequently used indicator }\end{array}$ & & Instr. & $\begin{array}{l}\text { Question } \\
\text { numbers }\end{array}$ & Variables & Comments \\
\hline \multicolumn{6}{|l|}{ Information exchange } \\
\hline $\begin{array}{l}\text { 72. Percent of FP clients with whom } \\
\text { various FP issues were discussed }\end{array}$ & $\checkmark$ & 0 & $2,5,7$ & $\begin{array}{l}02 \times 1 \text { to } 02 \times 77 \\
05,07\end{array}$ & $\begin{array}{l}\text { Separate new and revisit clients, since a more } \\
\text { complete discussion is usually required for } \\
\text { new clients. Note that q. } 5 \text { is only for new } \\
\text { clients, q. } 7 \text { is only for revisits. }\end{array}$ \\
\hline $\begin{array}{l}\text { 73. Percent of FP clients who received } \\
\text { information on the method } \\
\text { accepted }\end{array}$ & $\checkmark$ & 0 & 13 & $013 \times 1$ to $013 \times 77$ & $\begin{array}{l}\text { This can be calculated among new users and } \\
\text { revisit clients who are switching to a new } \\
\text { method. Present as a bar chart by type of } \\
\text { information. }\end{array}$ \\
\hline $\begin{array}{l}\text { 74. Percent of new FP clients and } \\
\text { switching revisit clients who } \\
\text { report that they were told they } \\
\text { could change methods if they are } \\
\text { not happy with their new method }\end{array}$ & & $\mathrm{F}$ & 49,69 & F49,F69 & $\begin{array}{l}\text { Combine new clients and revisit clients who } \\
\text { are switching methods. }\end{array}$ \\
\hline $\begin{array}{l}\text { 75. Percent of FP clients with whom } \\
\text { other health services are } \\
\text { discussed }\end{array}$ & $\checkmark$ & 0 & 20 & $020 \times 1$ to $020 \times 77$ & $\begin{array}{l}\text { Present as a bar chart by subject. This is } \\
\text { sometimes reported among new and revisit } \\
\text { clients separately. }\end{array}$ \\
\hline \multirow[t]{2}{*}{$\begin{array}{l}\text { 76. Percent of FP clients with whom } \\
\text { IEC materials were used (at SDPs } \\
\text { with IEC materials available) }\end{array}$} & $\checkmark$ & 0 & 16 & $016 \times 1$ to $016 \times 77$ & \multirow{2}{*}{$\begin{array}{l}\text { Calculate this only among SDPs with IEC } \\
\text { materials, so that the indicator measures the } \\
\text { use of IEC materials rather than their } \\
\text { presence, which is measured in indicator } 36 \text {. } \\
\text { This requires linking the observation data with } \\
\text { the inventory. }\end{array}$} \\
\hline & & I & 12 & $\begin{array}{l}\mathrm{I} 12 \mathrm{~A} 1 \text { to } 112 \mathrm{~A} 7 \\
\mathrm{I12B} 1 \text { to } 112 \mathrm{~B} 7 \\
\mathrm{I} 12 \mathrm{C} 1 \text { to } 112 \mathrm{C} 7\end{array}$ & \\
\hline
\end{tabular}

$I=$ Inventory $O=$ Observation guide $F=F P$ exit interview $S=$ Staff interview $M=M C H$ exit interview 


\begin{tabular}{|c|c|c|c|c|c|}
\hline $\begin{array}{l}\text { Quality indicator } \\
\checkmark=\text { frequently used indicator }\end{array}$ & & Instr. & $\begin{array}{l}\text { Question } \\
\text { numbers }\end{array}$ & Variables & Comments \\
\hline \multirow[t]{2}{*}{$\begin{array}{l}\text { 77. Percent of FP clients given } \\
\text { brochures on various issues (at } \\
\text { SDPs with brochures available) }\end{array}$} & & $F$ & 18,19 & $\begin{array}{l}\text { F18, } \\
\text { F19X1 to F19X98 }\end{array}$ & \multirow{2}{*}{$\begin{array}{l}\text { Calculate this only among SDPs with } \\
\text { brochures available, so that the indicator } \\
\text { measures the distribution of IEC materials } \\
\text { rather than their presence, which is measured } \\
\text { in indicator } 36 \text {. This requires linking the } \\
\text { observation data with the inventory. } \\
\text { These results can also be compared to } \mathrm{MCH} \\
\text { clients (MCH interview q.22,23). }\end{array}$} \\
\hline & & 1 & 12 & I12B1 to $112 \mathrm{~B} 7$ & \\
\hline $\begin{array}{l}\text { 78. Percent of FP clients who were } \\
\text { told that condoms prevent STDs }\end{array}$ & $\checkmark$ & 0 & 17 & 017 & \\
\hline $\begin{array}{l}\text { 79. Percent of LAM clients given } \\
\text { proper information on the method }\end{array}$ & & $\mathrm{O}$ & 14,25 & $\begin{array}{l}025 \\
014 \times 1 \text { to } 014 \times 77\end{array}$ & $\begin{array}{l}\text { Calculate only among LAM clients. Use q. } 25 \\
\text { as a filter. }\end{array}$ \\
\hline $\begin{array}{l}\text { 80. Percent of FP clients that attended } \\
\text { a group talk }\end{array}$ & & $\mathrm{F}$ & 20 & $\mathrm{~F} 20$ & $\begin{array}{l}\text { These results can also be compared to } \mathrm{MCH} \\
\text { clients (MCH interview q.24). }\end{array}$ \\
\hline $\begin{array}{l}\text { 81. Percent of FP clients who report } \\
\text { hearing about various subjects in } \\
\text { group talks }\end{array}$ & & $\mathrm{F}$ & 21 & $\mathrm{~F} 21 \times 1$ to $\mathrm{F} 21 \times 98$ & $\begin{array}{l}\text { Present as a bar chart. If the FP exit } \\
\text { interview is linked to the inventory, }{ }^{3} \text { then you } \\
\text { can compare what was told to clients in these } \\
\text { health talks with what they retain. See } \\
\text { indicator } 37 \text {. } \\
\text { These results can also be compared to } \mathrm{MCH} \\
\text { clients (MCH interview q. } 25 \text { ). }\end{array}$ \\
\hline
\end{tabular}

$I=$ Inventory $O=$ Observation guide $F=F P$ exit interview $S=$ Staff interview $M=M C H$ exit interview 


\begin{tabular}{|c|c|c|c|c|c|}
\hline $\begin{array}{l}\text { Quality indicator } \\
\checkmark=\text { frequently used indicator }\end{array}$ & & Instr. & $\begin{array}{l}\text { Question } \\
\text { numbers }\end{array}$ & Variables & Comments \\
\hline \multirow[t]{3}{*}{$\begin{array}{l}\text { 82. Percent of FP clients who are } \\
\text { knowledgeable about their method }\end{array}$} & \multirow[t]{3}{*}{$\checkmark$} & \multirow[t]{3}{*}{$F$} & $\begin{array}{l}\text { pill: } \\
72-77\end{array}$ & $\begin{array}{l}F 72, F 73, F 74, F 75 \\
F 76 \times 1 \text { to } F 76 \times 98 \\
F 77 \times 1 \text { to } F 77 \times 98\end{array}$ & \multirow{3}{*}{$\begin{array}{l}\text { These indicators can be reported as a group } \\
\text { of individual items that clients are aware of, } \\
\text { or they can be combined into knowledge } \\
\text { scores. }{ }^{4} \text { The results are usually reported by } \\
\text { method, but they can be reported overall as } \\
\text { well. }\end{array}$} \\
\hline & & & $\begin{array}{l}\text { IUD: } \\
82-87\end{array}$ & $\begin{array}{l}\text { F82 } \\
F 83 \times 1 \text { to } F 83 \times 98, \\
F 84 \\
F 85 \times 1 \text { to } F 85 \times 98, \\
F 86, F 87\end{array}$ & \\
\hline & & & $\begin{array}{l}\text { inj: } \\
92-95\end{array}$ & $\begin{array}{l}F 92 \\
F 93 \times 1 \text { to } F 93 \times 98 \\
F 94 \times 1 \text { to } F 94 \times 98 \\
F 95\end{array}$ & \\
\hline $\begin{array}{l}\text { 83. Percent of FP clients who are } \\
\text { knowledgeable about STDs/HIV } \\
\text { symptoms }\end{array}$ & & $F$ & 118,119 & $\begin{array}{l}F 118 \\
F 119 \times 1 \text { to } F 119 \times 98\end{array}$ & \multirow{3}{*}{$\begin{array}{l}\text { These indicators can be reported as a group } \\
\text { of individual items that clients are aware of, } \\
\text { or they can be combined into knowledge } \\
\text { scores }{ }^{4} \text {. } \\
\text { These results can also be compared to } \mathrm{MCH} \\
\text { clients (MCH interview q.66-73). }\end{array}$} \\
\hline $\begin{array}{l}\text { 84. Percent of FP clients who are } \\
\text { knowledgeable about routes of } \\
\text { HIV transmission }\end{array}$ & & $F$ & 120,121 & $\begin{array}{l}F 120 \\
F 121 \times 1 \text { to } F 121 \times 98\end{array}$ & \\
\hline $\begin{array}{l}\text { 85. Percent of FP clients who are } \\
\text { knowledgeable about protection } \\
\text { against STDs/HIV }\end{array}$ & $\checkmark$ & $F$ & 122,123 & $\begin{array}{l}F 122 \\
F 123 \times 1 \text { to } F 123 \times 98\end{array}$ & \\
\hline
\end{tabular}

$\mathrm{I}=$ Inventory $\mathrm{O}=$ Observation guide $\mathrm{F}=\mathrm{FP}$ exit interview $\mathrm{S}=$ Staff interview $\mathrm{M}=\mathrm{MCH}$ exit interview 


\begin{tabular}{|c|c|c|c|c|}
\hline $\begin{array}{l}\text { Quality indicator } \\
\checkmark=\text { frequently used indicator }\end{array}$ & Instr. & $\begin{array}{l}\text { Question } \\
\text { numbers }\end{array}$ & Variables & Comments \\
\hline \multirow[t]{2}{*}{$\begin{array}{l}\text { 86. Percent of FP clients who know of } \\
\text { other services at this facility }\end{array}$} & $\mathrm{F}$ & 30 & $\mathrm{~F} 30 \times 1$ to $\mathrm{F} 30 \times 98$ & \multirow{2}{*}{$\begin{array}{l}\text { If the FP exit interview is linked to the } \\
\text { inventory, }{ }^{3} \text { then you can compare what } \\
\text { services are actually available with the } \\
\text { services clients are aware of (see indicator } \\
12 \text { ). You may find that clients are not aware } \\
\text { of services that are available, or they may be } \\
\text { under the impression that services are } \\
\text { available that actually are not. } \\
\text { These results can also be compared to } \mathrm{MCH} \\
\text { clients (MCH interview q.31). }\end{array}$} \\
\hline & 1 & 8 & $\begin{array}{l}18 \mathrm{~A} 1 \text { to } 18 \mathrm{~A} 17 \\
18 \mathrm{~B} 1 \text { to } 18 \mathrm{~B} 17\end{array}$ & \\
\hline $\begin{array}{l}\text { 87. Among revisit FP clients who } \\
\text { experienced side effects with their } \\
\text { methods, percent who had been } \\
\text { told about side effects when they } \\
\text { first received method }\end{array}$ & $F$ & 62,63 & $\mathrm{~F} 62, \mathrm{~F} 63$ & $\begin{array}{l}\text { This indicator addresses the relationship } \\
\text { between continuity of use and receiving } \\
\text { information on side effects. The results may } \\
\text { show that those who want to switch or stop } \\
\text { due to side effects may not have been } \\
\text { properly informed of them at the outset. } \\
\text { However, the results are suggestive only, } \\
\text { since clients who stop often do not come } \\
\text { back to the SDP, so they are not included in } \\
\text { the indicator. }\end{array}$ \\
\hline $\begin{array}{l}\text { 88. Percent of } \mathrm{MCH} \text { clients aware of } \\
\text { methods available at this SDP }\end{array}$ & $M$ & 41 & $M 41 \times 1$ to $M 41 \times 13$ & $\begin{array}{l}\text { If the FP exit interview is linked to the } \\
\text { inventory, }{ }^{3} \text { then you can compare the } \\
\text { methods that are actually available with those } \\
\mathrm{MCH} \text { clients are aware of (see indicator } 11 \text { ). }\end{array}$ \\
\hline $\begin{array}{l}\text { 89. Percent of } \mathrm{MCH} \text { clients who saw } \\
\text { information on FP during visit }\end{array}$ & $M$ & 42,43 & $\begin{array}{l}\text { M42, } \\
M 43 \times 1 \text { to } M 43 \times 5\end{array}$ & \\
\hline
\end{tabular}

$I=$ Inventory $O=$ Observation guide $F=F P$ exit interview $S=$ Staff interview $M=M C H$ exit interview 


\begin{tabular}{|c|c|c|c|c|c|}
\hline $\begin{array}{l}\text { Quality indicator } \\
\checkmark=\text { frequently used indicator }\end{array}$ & & Instr. & $\begin{array}{l}\text { Question } \\
\text { numbers }\end{array}$ & Variables & Comments \\
\hline \multicolumn{6}{|l|}{ Technical competence } \\
\hline $\begin{array}{l}\text { 90. Percent of FP clients clinically } \\
\text { assessed for FP }\end{array}$ & $\checkmark$ & $\mathrm{O}$ & 3,4 & $\begin{array}{l}03 \times 1,03 \times 2 \\
04 \times 1 \text { to } 04 \times 7\end{array}$ & $\begin{array}{l}\text { FP program policies often specify which } \\
\text { assessments should be carried out on clients. } \\
\text { Refer to these standards when selecting items } \\
\text { to include in this indicator. } \\
\text { Present as a bar chart. This is usually } \\
\text { reported separately among new and revisit } \\
\text { clients. }\end{array}$ \\
\hline $\begin{array}{l}\text { 91. Percent of pelvic exams during } \\
\text { which providers performed various } \\
\text { actions }\end{array}$ & $\checkmark$ & $\mathrm{O}$ & 37,38 & $\begin{array}{l}037 \times 1 \text { to } 037 \times 77 \\
038 \times 1 \text { to } 038 \times 77\end{array}$ & $\begin{array}{l}\text { Present as a bar chart for the } 9 \text { actions listed. } \\
\text { Note that the unit of analysis is the pelvic } \\
\text { exam, not the provider or client. }\end{array}$ \\
\hline $\begin{array}{l}\text { 92. Percent of IUD insertions during } \\
\text { which providers performed various } \\
\text { actions }\end{array}$ & $\checkmark$ & $\mathrm{O}$ & 39 & $039 \times 1$ to $039 \times 77$ & $\begin{array}{l}\text { Present as a bar chart for the } 4 \text { actions listed. } \\
\text { Note that the unit of analysis is the IUD } \\
\text { insertion, not the provider or client. }\end{array}$ \\
\hline $\begin{array}{l}\text { 93. Percent of injections during which } \\
\text { providers performed various } \\
\text { actions }\end{array}$ & $\checkmark$ & 0 & 40 & $040 \times 1$ to $040 \times 77$ & $\begin{array}{l}\text { Present as a bar chart for the } 3 \text { actions listed. } \\
\text { Note that the unit of analysis is the injection, } \\
\text { not the provider or client. }\end{array}$ \\
\hline $\begin{array}{l}\text { 94. Percent of NORPLANT }{ }^{\circledR} \text { insertions } \\
\text { during which providers performed } \\
\text { various actions }\end{array}$ & $\checkmark$ & 0 & 41 & $041 \times 1$ to $041 \times 77$ & $\begin{array}{l}\text { Present as a bar chart for the } 4 \text { actions listed. } \\
\text { Note that the unit of analysis is the } \\
\text { NORPLANT }{ }^{\oplus} \text { insertion, not the provider or } \\
\text { client. }\end{array}$ \\
\hline $\begin{array}{l}\text { 95. Percent of procedures during } \\
\text { which providers used sterile } \\
\text { gloves }\end{array}$ & $\checkmark$ & 0 & 42 & 042 & $\begin{array}{l}\text { This is sometimes reported only for IUD and } \\
\text { NORPLANT }{ }^{\circledR} \text { insertions, since strict sterility is } \\
\text { not fully necessary for the other procedures. }\end{array}$ \\
\hline $\begin{array}{l}\text { 96. Percent of providers observed to } \\
\text { take action with FP clients who } \\
\text { present problems with method }\end{array}$ & $\checkmark$ & $\mathrm{O}$ & 8,9 & $\begin{array}{l}08 \\
09 \times 1 \text { to } 09 \times 77\end{array}$ & Present as a pie chart. Use $\mathrm{q} .8$ as a filter. \\
\hline
\end{tabular}

$I=$ Inventory $O=$ Observation guide $F=F P$ exit interview $S=$ Staff interview $M=M C H$ exit interview 


\begin{tabular}{|c|c|c|c|c|c|}
\hline $\begin{array}{l}\text { Quality indicator } \\
\checkmark=\text { frequently used indicator }\end{array}$ & & Instr. & $\begin{array}{l}\text { Question } \\
\text { numbers }\end{array}$ & Variables & Comments \\
\hline $\begin{array}{l}\text { 97. Percent of revisit FP clients with } \\
\text { problems who feel they received } \\
\text { proper attention from the provider }\end{array}$ & & $\mathrm{F}$ & 65 & F65 & Compare this to the previous indicator. \\
\hline $\begin{array}{l}\text { 98. Percent of providers who report } \\
\text { that they would properly treat a } \\
\text { pill client without her menses at } \\
\text { the time of the consultation }\end{array}$ & & $\mathrm{S}$ & 23 & $\mathrm{~S} 23 \times 1$ to $\mathrm{S} 23 \times 7$ & Present as a pie chart. \\
\hline $\begin{array}{l}\text { 99. Percent of FP clients assessed } \\
\text { properly for STDs }\end{array}$ & $\checkmark$ & 0 & 3,4 & $\begin{array}{l}03 \times 3 \text { to } 03 \times 6 \\
04 \times 8\end{array}$ & \\
\hline $\begin{array}{l}\text { 100. Percent of providers observed to } \\
\text { take action with clients } \\
\text { suspected of having an STD }\end{array}$ & $\checkmark$ & 0 & 18,19 & $\begin{array}{l}018 \\
019 \times 1 \text { to } 019 \times 77\end{array}$ & Present as a bar chart. Use $\mathrm{q} .18$ as a filter. \\
\hline $\begin{array}{l}\text { 101. Percent of providers reporting } \\
\text { that they would take action with } \\
\text { clients with STDs }\end{array}$ & & $S$ & 26 & $S 26 \times 1$ to $S 26 \times 9$ & $\begin{array}{l}\text { Present as a bar chart. Compare this to the } \\
\text { previous indicator. }\end{array}$ \\
\hline $\begin{array}{l}\text { 102. Percent of providers reporting } \\
\text { that they would take action with } \\
\text { clients with HIV/AIDS }\end{array}$ & & $S$ & 27 & $S 27 \times 1$ to $S 27 \times 8$ & Present as a bar chart. \\
\hline $\begin{array}{l}\text { 103. Percent of providers reporting } \\
\text { that they test antenatal clients } \\
\text { for syphilis }\end{array}$ & & $\mathrm{S}$ & 28 & $S 28$ & \\
\hline $\begin{array}{l}\text { 104. Percent of providers who report } \\
\text { that they would not recommend } \\
\text { methods to clients with STDs }\end{array}$ & & $S$ & $21,21 \mathrm{a}$ & $\begin{array}{l}\text { S21 } \\
\text { S21AX1 to } S 21 A \times 77\end{array}$ & Present as a bar chart by method. \\
\hline
\end{tabular}

$\mathrm{I}=$ Inventory $\mathrm{O}=$ Observation guide $\mathrm{F}=\mathrm{FP}$ exit interview $\mathrm{S}=$ Staff interview $\mathrm{M}=\mathrm{MCH}$ exit interview 


\begin{tabular}{|c|c|c|c|c|c|}
\hline $\begin{array}{l}\text { Quality indicator } \\
\checkmark=\text { frequently used indicator }\end{array}$ & & Instr. & $\begin{array}{l}\text { Question } \\
\text { numbers }\end{array}$ & Variables & Comments \\
\hline $\begin{array}{l}\text { 105. Percent of providers who report } \\
\text { various advice that they would } \\
\text { give to a pill client at high risk of } \\
\text { STDs }\end{array}$ & & $\mathrm{S}$ & 25 & $\mathrm{~S} 25 \times 1$ to $\mathrm{S} 25 \times 98$ & Present as a bar chart by method. \\
\hline $\begin{array}{l}\text { 106. Percent of FP clients recieving } \\
\text { other services }\end{array}$ & $\checkmark$ & $\mathrm{F}$ & 3,4 & $\begin{array}{l}F 3 \\
F 4 \times 1 \text { to } F 4 \times 16\end{array}$ & $\begin{array}{l}\text { Present as a bar chart. } \\
\text { These results can also be compared to } \mathrm{MCH} \\
\text { clients (MCH interview q.3). }\end{array}$ \\
\hline \multicolumn{6}{|l|}{ Mechanisms to encourage continuity } \\
\hline $\begin{array}{l}\text { 107. Percent of FP clients who were } \\
\text { observed to receive a written } \\
\text { follow-up date }\end{array}$ & & 0 & 33,34 & 033,034 & $\begin{array}{l}\text { Present as a pie chart with three slices: no } \\
\text { follow-up date, unwritten follow-up date, and } \\
\text { written follow-up date. }\end{array}$ \\
\hline $\begin{array}{l}\text { 108. Percent of FP clients reporting } \\
\text { that they were given a follow-up } \\
\text { date }\end{array}$ & $\checkmark$ & $\mathrm{F}$ & 22 & F22 & $\begin{array}{l}\text { To compare this to previous indicator, link the } \\
\text { FP exit interview with the observation. }{ }^{3}\end{array}$ \\
\hline $\begin{array}{l}\text { 109. Percent of FP clients who } \\
\text { received a supply of their } \\
\text { method today }\end{array}$ & $\checkmark$ & 0 & 28 & 028 & \\
\hline $\begin{array}{l}\text { 110. Mean cycles of pills supplied to } \\
\text { FP clients }\end{array}$ & & $\mathrm{O}$ & $\begin{array}{l}6,23,25 \\
32\end{array}$ & $06,023,025,032$ & $\begin{array}{l}\text { First, determine method used, from q. } 6,23, \\
\text { and } 25 \text {, depending on the type of client. } \\
\text { Then give amount supplied, from q. } 32 \text {. }\end{array}$ \\
\hline $\begin{array}{l}\text { 111. Percent of pill clients reporting } \\
\text { that they received a pill supply }\end{array}$ & & $\mathrm{F}$ & 78 & F78 & $\begin{array}{l}\text { In order to compare this to the observation, } \\
\text { link the observation and exit files. }\end{array}$ \\
\hline $\begin{array}{l}\text { 112. Mean cycles of pills that } \\
\text { providers report they would } \\
\text { provide to successful pill users } \\
\text { at each visit }\end{array}$ & & $\mathrm{S}$ & 24 & $S 24$ & $\begin{array}{l}\text { This measures the intention of staff to } \\
\text { resupply, not the actual availability of the } \\
\text { supplies. }\end{array}$ \\
\hline
\end{tabular}

$I=$ Inventory $O=$ Observation guide $F=F P$ exit interview $S=$ Staff interview $M=M C H$ exit interview 


\begin{tabular}{|c|c|c|c|c|c|}
\hline $\begin{array}{l}\text { Quality indicator } \\
\checkmark=\text { frequently used indicator }\end{array}$ & & Instr. & $\begin{array}{l}\text { Question } \\
\text { numbers }\end{array}$ & Variables & Comments \\
\hline $\begin{array}{l}\text { 113. Mean pieces of condoms/ } \\
\text { spermicide supplied to clients }\end{array}$ & & 0 & $\begin{array}{l}6,23,25 \\
32\end{array}$ & $06,023,025,032$ & $\begin{array}{l}\text { First, determine method used, from q. } 6,23 \text {, } \\
\text { and } 25 \text {, depending on the type of client. } \\
\text { Then give amount supplied, from q.32. }\end{array}$ \\
\hline $\begin{array}{l}\text { 114. Among FP clients who did not } \\
\text { receive a supply of their chosen } \\
\text { method, reason for lack of } \\
\text { supply }\end{array}$ & & 0 & 29 & 029 & Present as a bar chart. \\
\hline $\begin{array}{l}\text { 115. Among FP clients who did not } \\
\text { receive a supply of their chosen } \\
\text { method, percent who were given } \\
\text { a supply of an alternative } \\
\text { method }\end{array}$ & $\checkmark$ & 0 & 30,31 & 030,031 & Present as a bar chart by method. \\
\hline $\begin{array}{l}\text { 116. Percent of FP clients told where } \\
\text { to go for resupply }\end{array}$ & $\checkmark$ & O & 35,36 & $\begin{array}{l}035 \\
036 \times 1 \text { to } 036 \times 5\end{array}$ & Present as exploded pie. \\
\hline $\begin{array}{l}\text { 117. Among pill clients who did not } \\
\text { receive supply of pills today, } \\
\text { alternate source of supply }\end{array}$ & & $\mathrm{F}$ & 79 & F79 & Present as pie chart. \\
\hline $\begin{array}{l}\text { 118. Among condom/spermicide } \\
\text { clients who did not receive } \\
\text { supply of condoms/ spermicides } \\
\text { today, alternate source of supply }\end{array}$ & & $\mathrm{F}$ & 98,99 & F98,F99 & Present as pie chart. \\
\hline $\begin{array}{l}\text { 119. Among injectable clients who did } \\
\text { not receive injection today, } \\
\text { alternate source for injection }\end{array}$ & & $F$ & 89,90 & F89,F90 & Present as pie chart. Use $q .89$ as a filter. \\
\hline $\begin{array}{l}\text { 120. Percent of } \mathrm{MCH} \text { clients who go } \\
\text { elsewhere for FP services, and } \\
\text { reason }\end{array}$ & & M & 47,48 & $M 47, M 48$ & \\
\hline
\end{tabular}

$I=$ Inventory $O=$ Observation guide $F=F P$ exit interview $S=$ Staff interview $M=M C H$ exit interview 


\begin{tabular}{|c|c|c|c|c|c|}
\hline $\begin{array}{l}\text { Quality indicator } \\
\checkmark=\text { frequently used indicator }\end{array}$ & & Instr. & $\begin{array}{l}\text { Question } \\
\text { numbers }\end{array}$ & Variables & Comments \\
\hline \multicolumn{6}{|c|}{ Appropriateness and acceptability of services } \\
\hline $\begin{array}{l}\text { 121. Percent of FP clients generally } \\
\text { satisfied with their visit }\end{array}$ & & $\mathrm{F}$ & 1 & $\mathrm{~F} 1$ & $\begin{array}{l}\text { Often, this indicator has a very positive result } \\
\text { because clients want to be polite. This } \\
\text { "courtesy bias" reduces the indicator's } \\
\text { validity. } \\
\text { These results can also be compared to } \mathrm{MCH} \\
\text { clients (MCH interview q. } 2 \text { ). }\end{array}$ \\
\hline $\begin{array}{l}\text { 122. Percent of FP clients satisfied } \\
\text { with particular aspects of the } \\
\text { services }\end{array}$ & $\checkmark$ & $\mathrm{F}$ & $5,15,16$ & $\mathrm{~F} 5, \mathrm{~F} 15, \mathrm{~F} 16$ & $\begin{array}{l}\text { These include: the client received the } \\
\text { information she wanted, had enough privacy, } \\
\text { and understood the provider. } \\
\text { These results can also be compared to } \mathrm{MCH} \\
\text { clients (MCH interview q. } 4,14,15 \text { ). }\end{array}$ \\
\hline $\begin{array}{l}\text { 123. Percent of FP clients with other } \\
\text { SDPs nearer to their homes, and } \\
\text { reason for coming to this SDP } \\
\text { instead }\end{array}$ & & $\mathrm{F}$ & $\begin{array}{l}31,32, \\
33\end{array}$ & $\mathrm{~F} 31, \mathrm{~F} 32, \mathrm{~F} 33$ & $\begin{array}{l}\text { Present especially } q .33 \text { as pie chart. } \\
\text { These results can also be compared to } \mathrm{MCH} \\
\text { clients (MCH interview q. } 32,33,34 \text { ). }\end{array}$ \\
\hline $\begin{array}{l}\text { 124. Percent of FP clients who find } \\
\text { the clinic hours convenient }\end{array}$ & $\boldsymbol{V}$ & $\mathrm{F}$ & 23 & $\mathrm{~F} 23$ & $\begin{array}{l}\text { These results can also be compared to } \mathrm{MCH} \\
\text { clients (MCH interview q.27). }\end{array}$ \\
\hline $\begin{array}{l}\text { 125. Of those FP clients who find the } \\
\text { hours inconvenient, hours that } \\
\text { would be preferable }\end{array}$ & & $\mathrm{F}$ & 23,24 & $\mathrm{~F} 23, \mathrm{~F} 24$ & Present as a pie chart. Use q. 23 as a filter \\
\hline $\begin{array}{l}\text { 126. Percent of FP clients who have } \\
\text { ever been turned away from this } \\
\text { SDP during working hours }\end{array}$ & & $\mathrm{F}$ & 25 & $\mathrm{~F} 25$ & $\begin{array}{l}\text { These results can also be compared to } \mathrm{MCH} \\
\text { clients (MCH interview q.28). }\end{array}$ \\
\hline
\end{tabular}

$I=$ Inventory $O=$ Observation guide $F=F P$ exit interview $S=$ Staff interview $M=M C H$ exit interview 


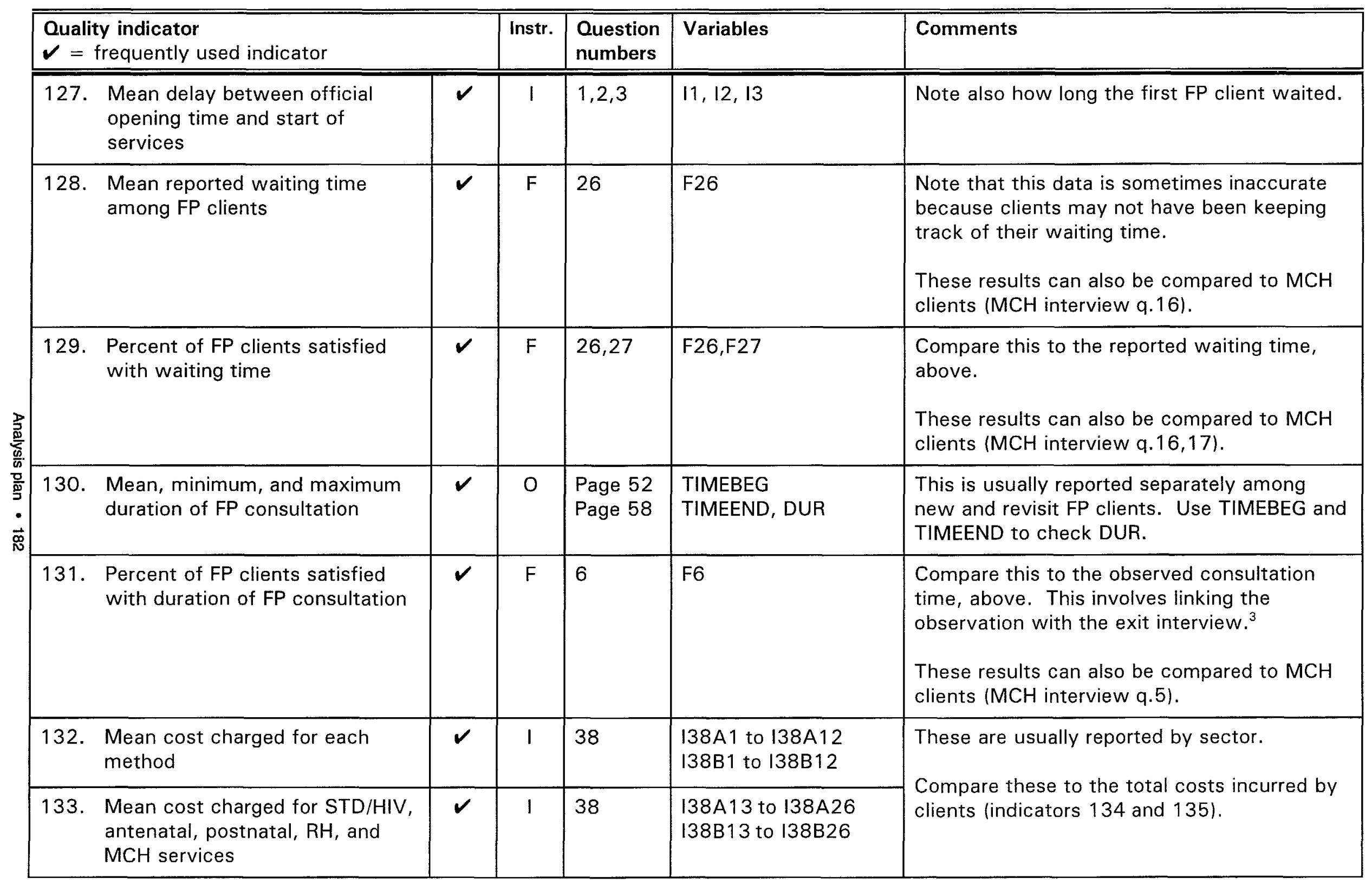

$I=$ Inventory $O=$ Observation guide $F=F P$ exit interview $S=$ Staff interview $M=M C H$ exit interview 


\begin{tabular}{|c|c|c|c|c|c|}
\hline \multicolumn{2}{|l|}{$\begin{array}{l}\text { Quality indicator } \\
\checkmark=\text { frequently used indicator }\end{array}$} & \multirow{2}{*}{\begin{tabular}{|l|} 
Instr. \\
$\mathrm{F}$
\end{tabular}} & \multirow{2}{*}{$\begin{array}{l}\begin{array}{l}\text { Question } \\
\text { numbers }\end{array} \\
\begin{array}{l}34,35 \\
36\end{array}\end{array}$} & \multirow{2}{*}{$\begin{array}{l}\text { Variables } \\
\text { F34,F35,F36 }\end{array}$} & \multirow{2}{*}{$\begin{array}{l}\text { Comments } \\
\text { Can report this combined with the next } \\
\text { indicator as total cost to clients. } \\
\text { These results can also be compared to } \mathrm{MCH} \\
\text { clients (MCH interview variables } \mathrm{M} 37 \times 1 \text { to } \\
\text { M37X3). }\end{array}$} \\
\hline $\begin{array}{l}\text { 134. Mean cost paid by clients for } \\
\text { consultation/ medicines / other } \\
\text { consumables }\end{array}$ & & & & & \\
\hline $\begin{array}{l}\text { 135. Average cost paid by clients for } \\
\text { registration, travel, other }\end{array}$ & & $\mathrm{F}$ & $\begin{array}{l}37,38 \\
39\end{array}$ & F37,F38,F39 & $\begin{array}{l}\text { Can report this combined with the previous } \\
\text { indicator as total cost to clients. } \\
\text { These results can also be compared to } \mathrm{MCH} \\
\text { clients (MCH interview variables } M 37 \times 4 \text { to } \\
\text { M37X6). }\end{array}$ \\
\hline $\begin{array}{l}\text { 136. Percent of FP clients satisfied } \\
\text { with the cost of services }\end{array}$ & & $\mathrm{F}$ & 40 & $\mathrm{~F} 40$ & $\begin{array}{l}\text { Compare this to the cost paid for services. } \\
\text { These results can also be compared to } \mathrm{MCH} \\
\text { clients (MCH interview q.38). }\end{array}$ \\
\hline $\begin{array}{l}\text { 137. Mean travel time required by FP } \\
\text { clients }\end{array}$ & $r$ & $\mathrm{~F}$ & 28 & F28 & $\begin{array}{l}\text { These results can also be compared to } \mathrm{MCH} \\
\text { clients ( } \mathrm{MCH} \text { interview q.29). }\end{array}$ \\
\hline $\begin{array}{l}\text { 138. Percent of FP clients taking } \\
\text { various means of travel to the } \\
\text { SDP }\end{array}$ & & $\mathrm{F}$ & 29 & $\mathrm{~F} 29$ & $\begin{array}{l}\text { Present as a pie chart. } \\
\text { These results can also be compared to } \mathrm{MCH} \\
\text { clients (MCH interview q.30). }\end{array}$ \\
\hline
\end{tabular}

$I=$ Inventory $\quad O=$ Observation guide $F=F P$ exit interview $S=$ Staff interview $M=M C H$ exit interview 


\section{Notes to analysis plan}

1. This analysis is usually performed as follows. First, calculate the FP client load among all SDPs, as required by indicator 13 . Then, sort the SDPs by client load, with the largest client loads first, progressing to the smallest client loads. With the SDPs in this order, divide them into four equal groups, or quartiles. If there are 200 SDPs in the study, this will result in four groups of 50 SDPs, the first group consisting of the 50 largest SDPs, and the fourth group consisting of the 50 smallest SDPs.

Each of these four groups serve a certain percentage of the overall client load. From the client load information, it is possible to sum to a total number of clients served by the entire FP system. This total can be used as the denominator to determine the percent of clients served by each quartile of SDPs.

For example, suppose the 200 SDPs mentioned above handle 12,000 client visits per year. This averages to 60 clients per SDP per year. But some SDPs are quite large, and others quite small. If the largest quartile of SDPs are grouped together, we may find that as a group, they serve 8,000 clients, or $75 \%$ of the total annual client load. The remaining three quartiles may serve $12 \%, 8 \%$, and $5 \%$ of the total client load, respectively. These very skewed findings are quite typical, and may point to differences in quality between the high load and low load SDPs.

2. The indicators on barriers to services are concerned with four barriers (age, marital status, parity, and spousal consent), and five methods (COC, condom, IUD, injectables, and sterilization). The idea of indicators 61 and 62 is to measure the propor- tion of providers who impose these barriers, as well as the extent of those barriers among those who impose them.

Indicator 61 requires a count of those providers who impose each barrier on each method. How many providers, for example, require a client to be married before they will prescribe an IUD? Each combination of barrier and method will result in a specific result, giving 20 pieces of information ( 4 barriers $\times 5$ methods). This information is usually presented as a table or bar chart by method.

The percent of providers who impose parity, marital status, and spousal consent barriers on each method can be easily calculated from questions 15,17 , and 18 of the staff interview. The percent of providers who impose age barriers is more complicated. In questions 11 and 12, staff are asked first whether there is a minimum age below which they will not prescribe methods, and if so, are asked to state what that age is. If a provider says that she has no minimum age requirement for pills, for example, then she clearly does not impose an age barrier. If a provider reports that she requires a client to be 21 before providing pills, then she clearly does impose an age barrier.

But some providers might say they require a client to be only 10 or 12 years old for the pill. By many program standards, this is effectively not an age barrier. Similarly, providers might say that their maximum age limit for condom distribution is 75 . Clearly this is an age barrier in name only, and does not pose a significant barrier for clients. In these cases, providers who say they have minimum or maximum age barriers but whose actual thresholds are extremely low or high, should not be considered to be im- 
posing age barriers. The analyst must agree with program managers on the minimum and maximum age that will be considered true barriers for each method. Then, providers whose age constraints fall outside these thresholds will not be considered to be imposing age barriers. The data from questions 11 through 14 must be very carefully analyzed with these issues in mind.

Indicator 62 concerns itself with the nature of the age and parity barriers that are imposed. In other words, among those providers who do impose a minimum age limit for pills, what is the mean age required? These means should be calculated only among those providers that do impose a true age barrier. Remember that providers whose age barriers are outside the thresholds established for indicator 61 should not be included in these means. As for parity, requiring even one child for any method (including IUD) is usually considered a barrier, so this mean should be calculated among all those providers who declare in question 15 that they impose any parity requirement whatsoever.

3. Linking data between modules requires patience, but it allows for a much richer and more informative analysis. In several indicators, links are required between the inventory and the observation; the inventory and the FP exit interview; and the observation and the FP exit interview. In other words, it is sometimes necessary to know not only at which SDP a particular observation took place, but also have access to inventory information about that SDP. Likewise, it is sometimes necessary to have information from the observation of a particular client to compare to her responses on the exit interview.
This is achieved through the identifying variables on the first page of each questionnaire. For example, indicator 76 is "Percent of FP clients with whom IEC materials were used (at SDPs with IEC materials available)." This requires a link between the inventoryto know if IEC materials were present-and the observation-to know if the materials were actually used during the consultation. Both the inventory and the observation have the variable HFCODE, which should identify the health facility across both modules. In the observation, the HFCODE variable is the link back to the inventory, which supplies the information on IEC availability. Similarly, both the observation and the exit interview share a variable CLIID, which should be the same for all clients. This variable should link the observation and exit interview directly.

These linking variables must identify cases uniquely. That is, the variable HFCODE must have a different value for each SDP - no two SDPs can share the same health facility code. Likewise, no two staff members at the same SDP should have the same STAFFID. In this way, the combination of HFCODE and STAFFID identifies providers uniquely. Also, no two clients who were observed with the same provider should have the same CLIID. The combination of HFCODE, STAFFID, and CLIID should identify each client uniquely. If these variables do not identify cases uniquely, you will not be able to link across modules. For this reason, check and clean these variables thoroughly before linking.

In Epi Info, a variable that is shared between two datasets can link two files with the command RELATE. In SPSS, the shared variables can link two datasets with the MATCH FILES command with a TABLES subcommand. 
See the relevant manuals for more information on how to use these commands.

4. Knowledge scores can be calculated in a variety of ways. In general, the objective is to produce a score for each client that is easily interpreted, and that gives an idea of the amount of knowledge she has about a particular topic. One method of calculation that has been used in SA studies is to simply calculate the percentage of questions that the client responds to appropriately.

For example, there are six pill knowledge questions in the exit interview (questions 72 through 77). In the simplest model, the client would be given a score of 0 to 6 , to indicate the number of questions she answered correctly. However, not all questions have such a clearly "correct" answer. Question 76, for example, requires that a client list the side effects of the pill that she is aware of. The table includes six side effects, but the client should certainly not be required to mention all six. The analyst must first decide what threshold to use-for example, the client might be required to mention any two or three side effects in order to be seen as "knowledgeable" on side effects. In this way, if she mentions enough side effects, she is considered to have answered the side effects question "correctly." Each question must be considered in this way and scored appropriately, given the program's objectives and expectations.

Once each question is scored in this way, each client will result with a score from 0 to 6. This is useful for pill clients, but it would be useful to be able to compare pill clients' knowledge with the knowledge of users of other methods. But if there are, for example, 4 questions on injectables, then the scales are different and the results are not comparable. For this reason, knowledge scores are usually normalized to a percentage. The pill client who answers 3 of 6 questions correctly is given a score of .50 . The injectable client who answers 3 of 4 questions correctly is given a score of .75 . These results are comparable.

Previous versions of the staff interview also included knowledge questions by method. This allowed for calculation of staff knowledge scores, which were a useful indicator of technical competence. Unfortunately, the extremely long series of questions led to protests from the interviewees, so these questions were discontinued. However, some knowledge questions still remain, such as the methods recommended for spacing and limiting births, which could also form the basis of knowledge scores. 


\section{Sample indicator lists}

As mentioned earlier, no SA report would include all 138 indicators listed in the analysis plan because that is simply too much information to process effectively. Similarly, many studies manipulate the data in different ways and devise their own indicators that are not listed above. The result is that each country's list of indicators is unique, a product of consensus among program managers and researchers.
For reference, two such lists are included in Tables 2 and 3, from Senegal and Botswana. These are the actual lists that were used for primary or secondary analysis of SA data, and are being used by program managers to evaluate their programs and design interventions. The Senegal list presents a fairly standard collection of indicators. In Botswana, many new indicators on reproductive health were added, and the Situation Analysis instruments were altered significantly to collect the relevant information. 
TABLE 2. Senegal indicators, 1994

Functional capacity indicators

Training

1. Percent of staff trained in clinical family planning

2. Percent of staff trained in family planning counseling

Services offered

3. Percent of SDPs that offer the minimum package of MCH/FP services on demand

Equipment and supplies

4. Percent of SDPs with all equipment necessary for family planning services

5. Percent of SDPs with $70 \%$ of the equipment necessary for family planning services

6. Percent of SDPs with $50 \%$ of equipment necessary for IUD insertion/removal

Commodities and logistics

7. Percent of SDPs with a written inventory of received stock

8. Percent of SDPs having a stock-out of any one method in the last six months

9. Percent of SDPs having a stock-out of COC in the last six months

10. Percent of SDPs having a stock-out of injectables in the last six months

Supervision and management

11. Percent of SDPs that received a supervisory visit in the three months prior to the study

12. Percent of family planning registers properly filled in

13. Percent of SDPs that have sent a report during the last month

Quality of care indicators

1. Percent of family planning clients able to furnish half the requested information about their method: total

2. ... among pill users

3. ... among IUD users

4. ... among injectable users

5. ... among NORPLANT® users

6. Percent of new clients who did not receive the method of their choice (for nonmedical reasons)

7. Percent of family planning clients with whom at least one other service was discussed

8. Percent of $\mathrm{MCH}$ clients who heard about family planning services from a provider

9. Percent of providers who follow the norms and protocols of MCH/FP service delivery: Understanding client needs

a. Provider asks clients about reproductive intentions

b. Provider asks clients if breastfeeding

c. Provider asks new clients if they have concerns about any method

d. Provider asks revisit clients if they want to stop or change methods

e. Provider asks revisit clients if they had problems with their method

f. Provider addresses problems expressed by revisit clients

g. Provider discusses STDs with clients

h. Average of understanding client needs

Choice of method

a. Provider mentions at least one method other than that accepted

b. Provider describes at least one method other than that accepted

c. Provider does not overtly encourage one method in particular

d. Provider imposes barriers on half or fewer of the methods offered at the SDP

e. Provider recommends the appropriate methods for spacing and limiting in most cases

f. Provider ascertains clients' method preference

g. Provider refers clients if method unavailable

h. Average of choice of method

continued on next page 
Quality indicator 9, continued:

Information given to clients

a. Provider informs new acceptors how to use method

b. Provider informs new acceptors of advantages of method

c. Provider informs new acceptors of disadvantages of method

d. Provider informs new acceptors of side effects of method

e. Provider informs new acceptors of the possibility of changing methods

f. Provider informs new clients that condoms prevent STDs/HIV

g. Provider uses IEC materials

h. Provider uses contraceptive sample

i. Average of information given to clients

Technical competence

a. Provider takes medical history

b. Provider asks clients for LMP

c. Provider asks clients about unusual bleeding

d. Provider asks clients about STD symptoms

e. Provider takes clients' BP

f. Provider weighs clients

g. Provider performs physical exam

h. Provider performs pelvic exam

i. Provider follows all protocols for pelvic exam

j. Provider follows all protocols for IUD insertion

k. Provider follows all protocols for injections

l. Provider follows all protocols for NORPLANT® insertion

m. Average of technical competence

Mechanisms for ensuring continuity

a. Provider tells clients when to return

b. Provider gives clients written or nonverbal reminder of return

c. Provider tells clients where to go for resupply

d. Provider informs new acceptors what to do if have problems

e. Average of mechanisms for ensuring continuity

Interpersonal relations
a. Provider greets clients in a friendly manner
b. Provider was easily understood by clients
c. Provider gives enough time for consultation
d. Provider answers clients' questions satisfactorily
e. Provider's clients feel waiting time was reasonable
f. Provider's clients feel consultation was sufficiently private
g. Average of interpersonal relations 
TABLE 3. Botswana indicators, 1995

Functional capacity indicators

Training

1. Percentage of staff trained in counselling, STD/HIV management, MCH/FP, and IEC, by type of training (pre-service, in-service, post-basic)

2. Mean years since each type of training

Integration

3. Percentage of health facilities that offer MCH/FP and STD/HIV services on a daily basis

4. Percentage of health providers carrying out STD risk assessment in MCH/FP clients

5. Percentage of health providers carrying out STD counselling in MCH/FP clients

6. Percentage of health providers promoting dual methods

7. Percentage of health providers who ask or counsel STD clients about FP use

8. Percentage of clients receiving services other than the one sought for

Orientation of new officers

9. Percentage of health facilities that have a current standard orientation package

10. Percentage of new officers that have been oriented and have the standard orientation package

Research and evaluation

11. Percentage of planned research projects in $\mathrm{RH}$ that have been carried out

12. Percentage of projects in RH that have been evaluated according to plan

13. Percentage of completed research studies that have been disseminated

Equipment and supplies

14. Percentage of facilities with functioning standardized basic equipment

15. Percentage of facilities with adequate ( 3 month buffer) supply of unexpired stock

Information, education, communication

16. Percentage of health facilities with poster/flip chart/pamphlet on MCH, STD/AIDS, or FP

17. Percentage of clients given any IEC material on RH Infrastructure

18. Percentage of facilities with working clients' toilets

19. Percentage of facilities with functioning water source on the compound

20. Percentage of facilities with sheltered waiting areas

21. Percentage of facilities with separate counselling/exam room

22. Percentage of facilities with working source of energy

Infection control

23. Percentage of facilities with equipment for keeping/holding/decontaminating used medical equipment/supplies (sharps container, dustbin)

24. Percentage of facilities with adequate medical waste disposal mechanisms (pits, burning, incineration)

Accessibility

25. Percentage of facilities that are observed to give RH services after $1: 45 \mathrm{pm}$

26. Percentage of clients indicating that waiting time is acceptable

27. Mean waiting time

28. Percentage of facilities with signs to facilitate client flow

Supervision

29. Percentage of planned visits that have been honored

30. Percentage of supervised health facilities that received feedback

Management

31. Percentage of DHTs with up-to-date guidelines, service standards, and reference manuals

32. Number of filled posts compared to established posts

33. Percentage of health facilities that have experienced a stock-out in last 3 months

34. Percentage of facilities with well-completed data collection tools (tally sheets, stock books, monthly summary forms, registers, FWE record books)

Transport and communication

35. Percentage of facilities/institutions with a vehicle in working condition

36. Percentage of facilities/institutions with a mode of communication

continued on next page 
Botswana indicators, 1995, continued

Quality of services

Policy

37. Percentage of facilities with current policy documents

Information given to clients

38. Percentage of new clients given information on all appropriate methods available

39. Percentage of new clients given information on accepted method

Choice of methods

40. Percentage of clients referred if method unavailable

41. Percentage of providers who report that they impose restrictions on methods due to age, parity, marital status, or spousal consent

Interpersonal relations

42. Percentage of clients who received a welcome by being greeted and offered a chair

43. Percentage of clients who feel they were provided with privacy

44. Percentage of clients allowed to ask questions

45. Percentage of clients satisfied with time spent with provider

Mechanisms to encourage continuity

46. Percentage of clients who were informed of when to return for resupply/checkup

47. Percentage of clients past due dates who have been contacted through follow-up

Technical competence

48. Percentage of new clients who underwent:

blood pressure

weight

physical exam

breast exam

pelvic exam

STD screening

urinalysis

medical history

49. Percentage of providers who can demonstrate skills in clinical procedures according to stipulated guidelines and service standards:

Taking weight

Physical exam

Breast exam

Urinalysis

History taking

IUD insertion

Pap smear collection

STD management using syndromic approach

STD risk assessment

Injection

50. Percentage of providers demonstrating skills in use of visual aids during counselling (e.g. models, Impact

flip charts, booklets, posters)

51. Percentage of clients knowledgeable on prevention of STD/HIV/AIDS

52. Percentage of clients knowledgeable on signs/symptoms of STD/HIV/AIDS

53. Percentage of clients using other methods of FP who accepted condom during that visit

54. Percentage of clients who were using dual methods and still continue using 


\section{Sample graphs}

Once the indicators have been selected and calculated, they should be presented in the final report as effectively as possible. Usually, the results are presented as bar or pie charts, as appropriate, and a typical report might contain as many as sixty such charts. This type of presentation is generally clear and more easily interpreted than tables with numbers.

The following twelve charts give examples of some of the most common SA findings and how they can be effectively presented in charts. The data are from a recent study conducted in Africa. 


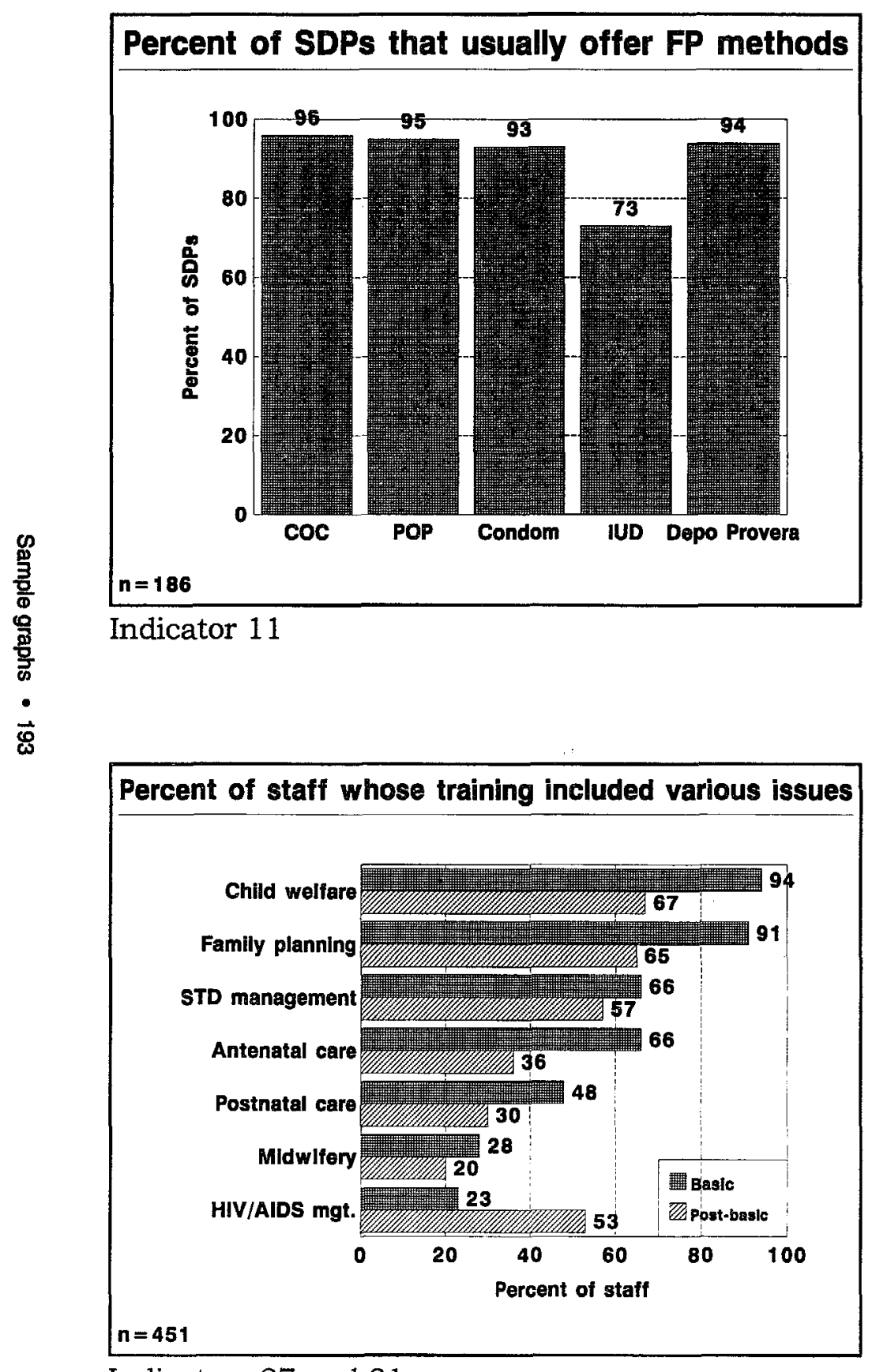

Indicators 27 and 31

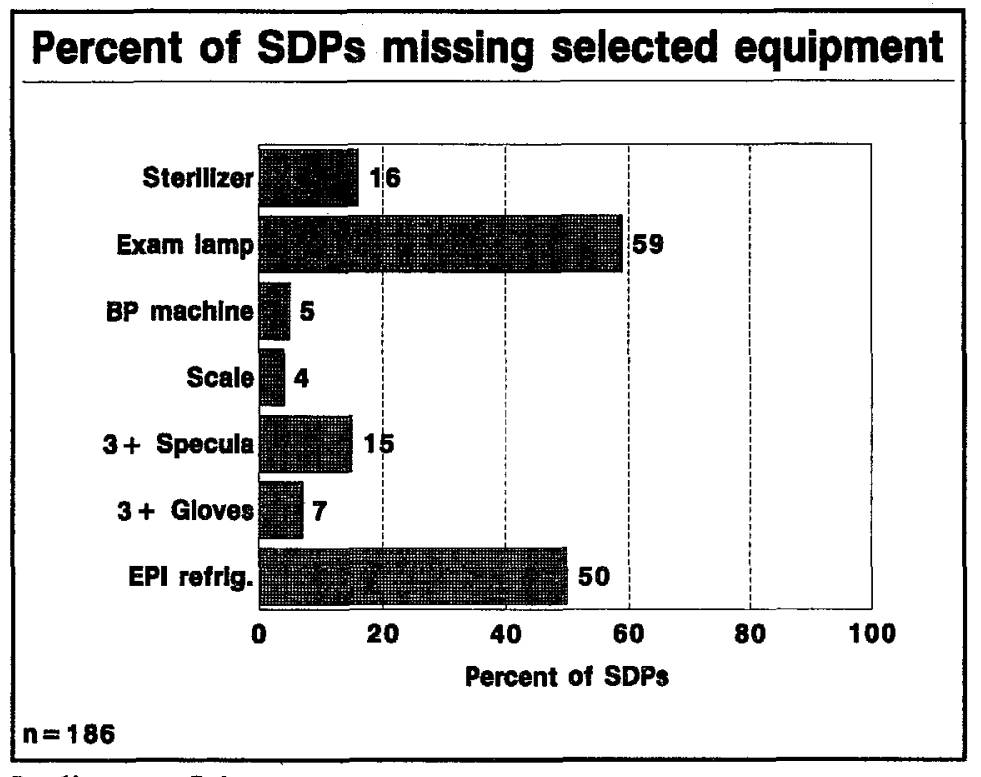

Indicator 24

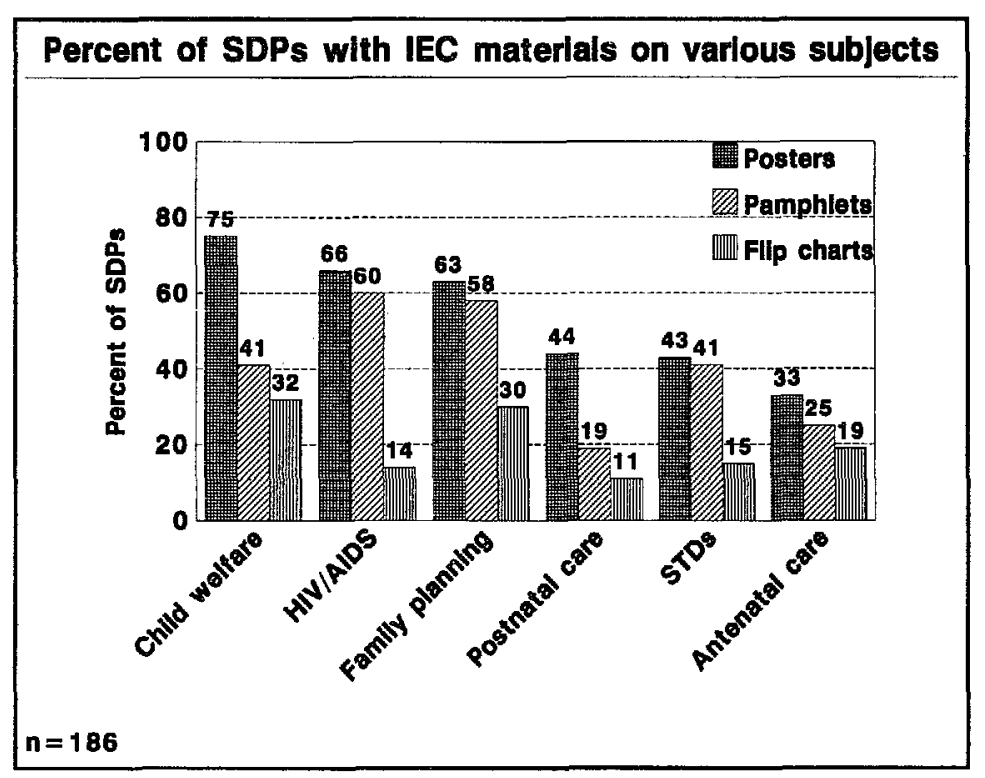

Indicator 36 


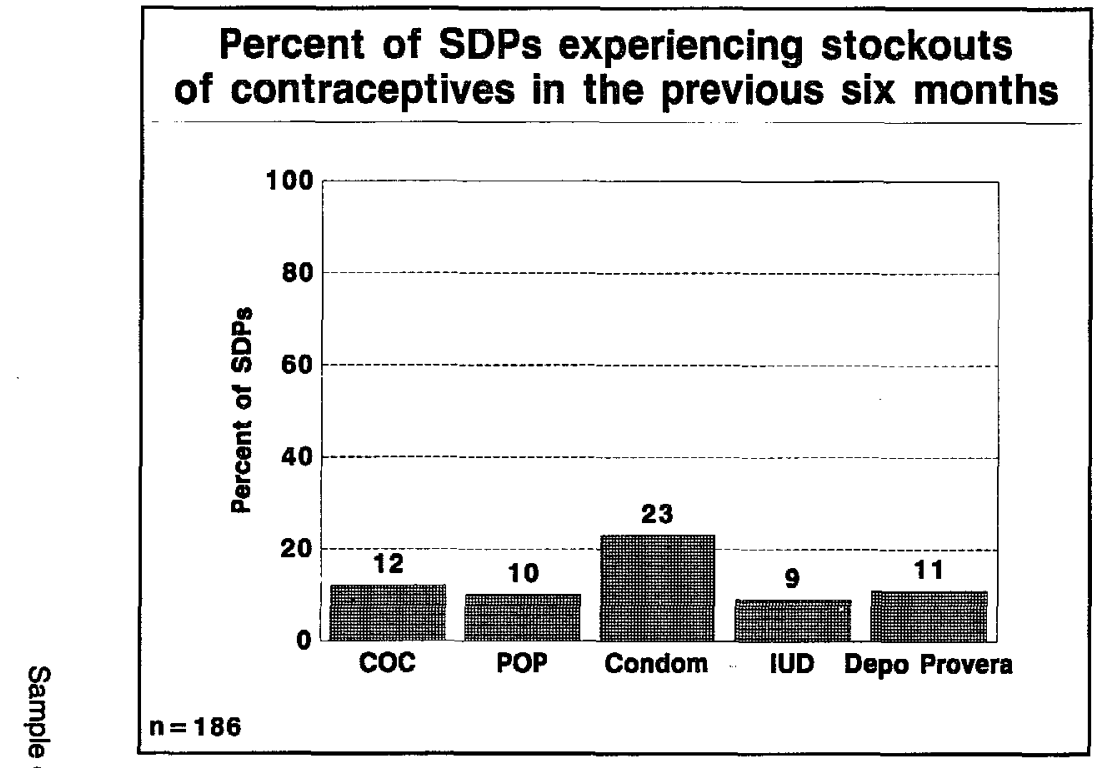

Indicator 39

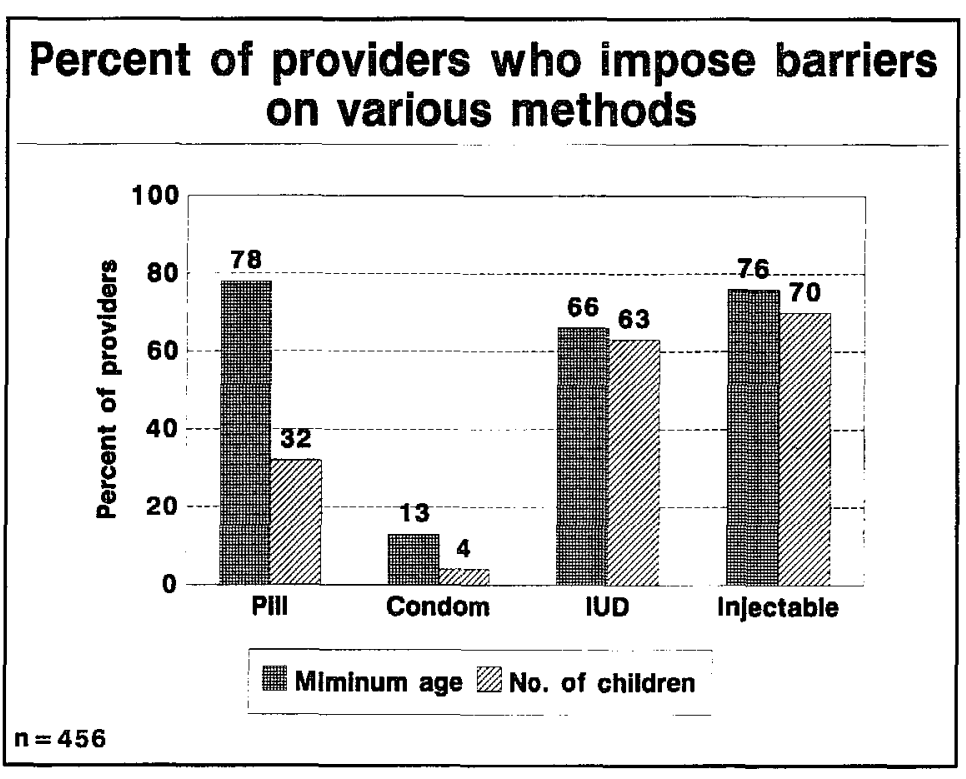

Indicator 61

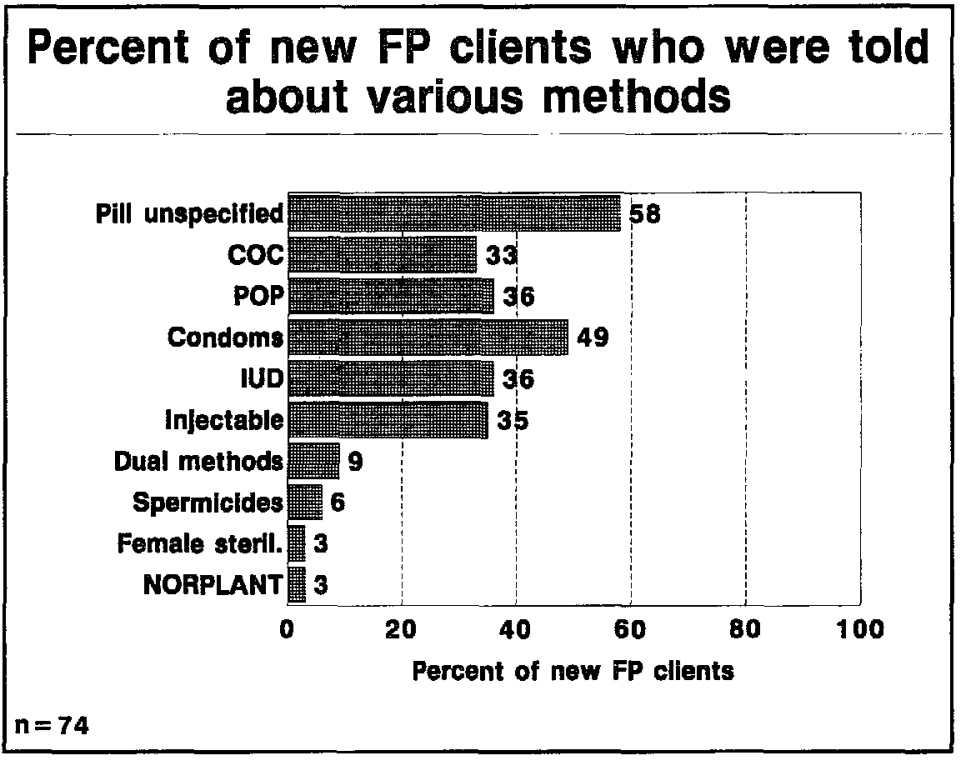

Indicator 56

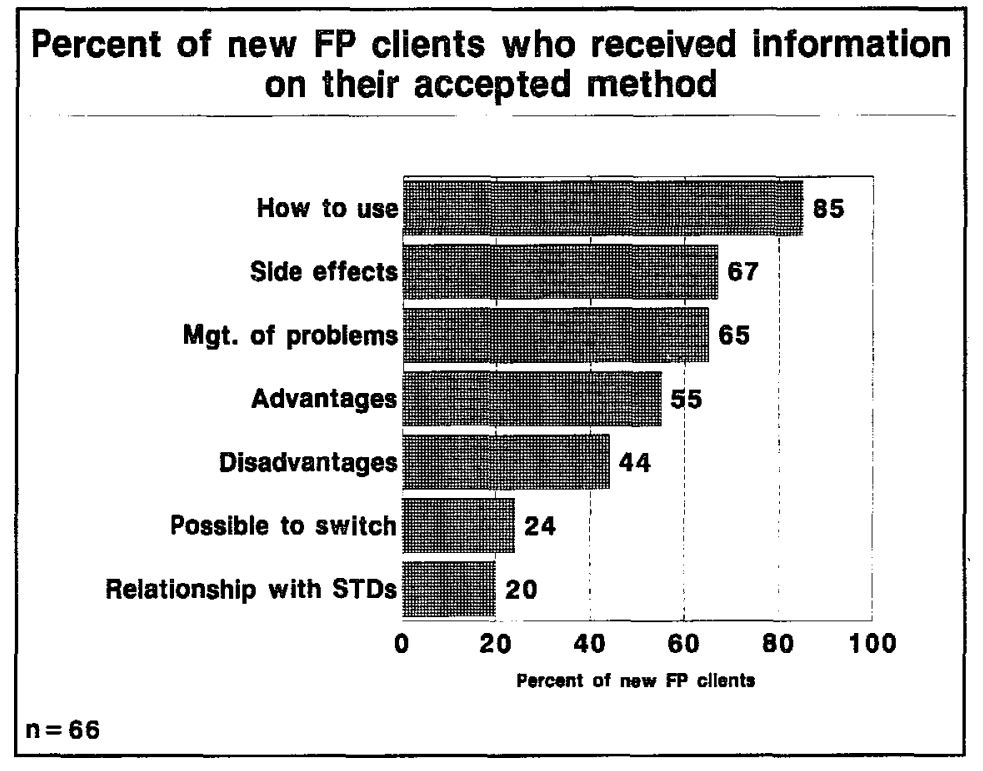

Indicator 73 

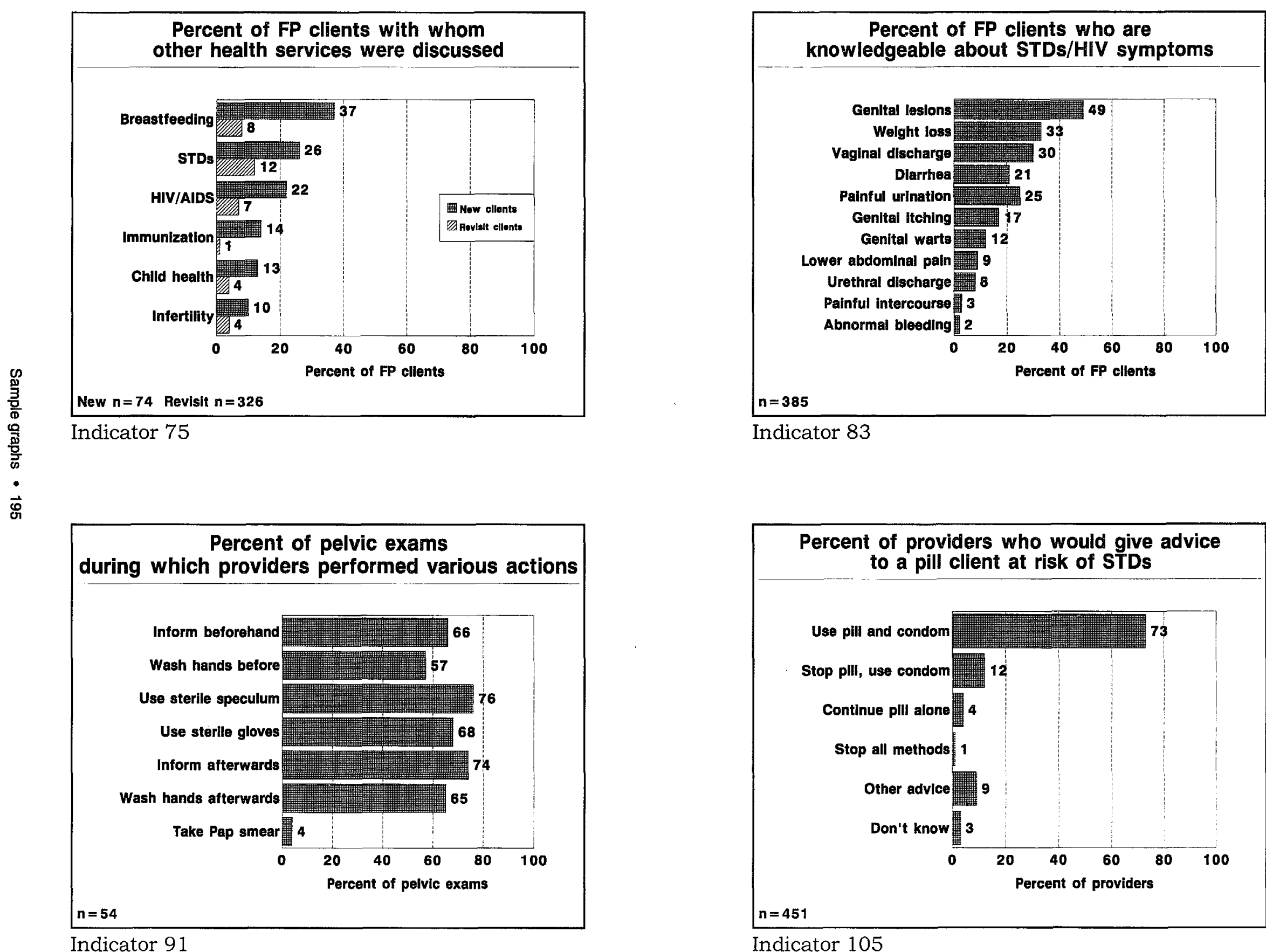

Indicator 83

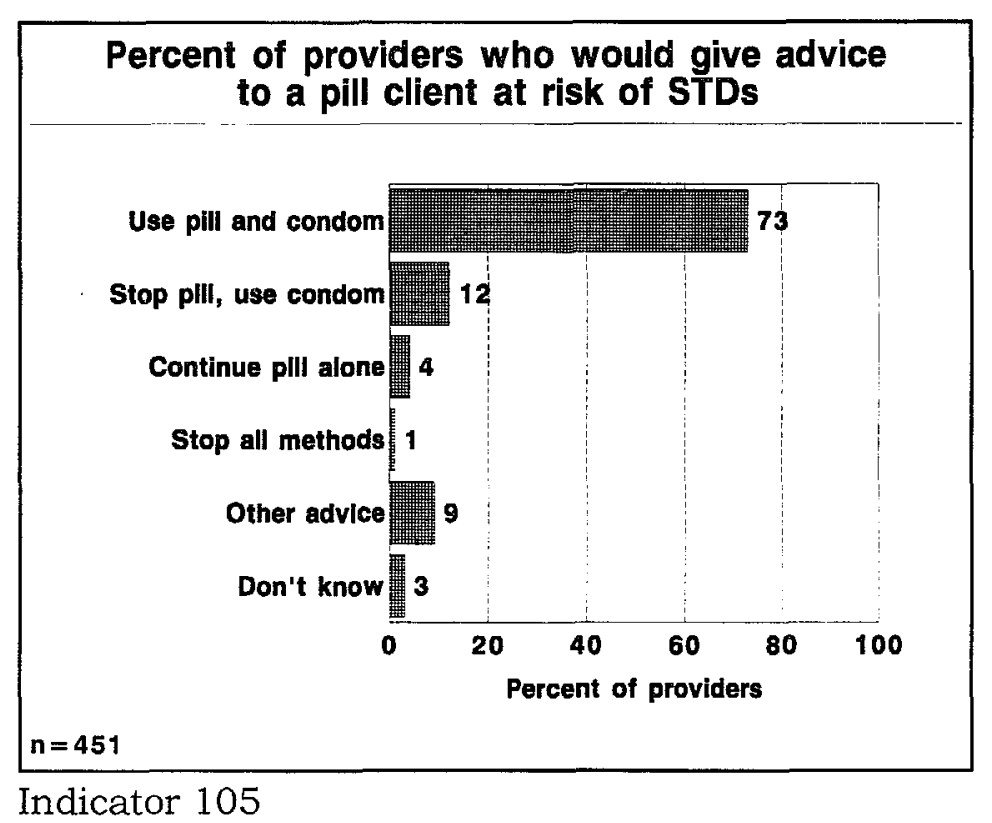

